\title{
Constitution and Reactivity of Palladium Ate Complexes in Cross-Coupling Reactions
}

\author{
Dissertation \\ for the award of the degree \\ "Doctor rerum naturalium" (Dr. rer. nat.) \\ of the Georg-August-University of Göttingen
}

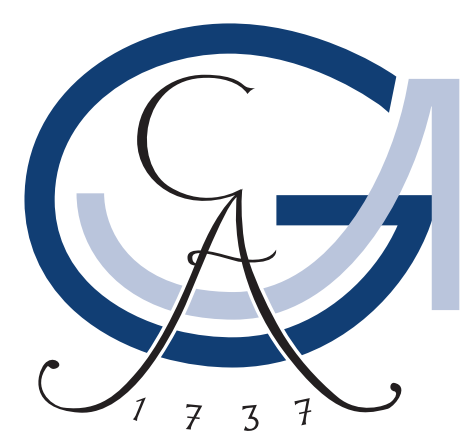

within the doctoral program

"Catalysis for Sustainable Synthesis" (CaSuS)

of the Georg-August-University School of Science (GAUSS)

submitted by

Marlene Kolter

from Marburg

Göttingen, 2019 



\section{Thesis Committee}

Prof. Dr. Konrad Koszinowski, Institute of Organic and Biomolecular Chemistry

Prof. Dr. Lutz Ackermann, Institute of Organic and Biomolecular Chemistry

Prof. Dr. Manuel Alcarazo, Institute of Organic and Biomolecular Chemistry

\section{Members of the Examination Board}

Reviewer: Prof. Dr. Konrad Koszinowski, Institute of Organic and Biomolecular Chemistry

Second Reviewer: Prof. Dr. Lutz Ackermann, Institute of Organic and Biomolecular Chemistry

\section{Further Members of the Examination Board}

Prof. Dr. Manuel Alcarazo, Institute of Organic and Biomolecular Chemistry

Dr. Holm Frauendorf, Institute of Organic and Biomolecular Chemistry

Dr. Michael John, Institute of Organic and Biomolecular Chemistry

Prof. Dr. Franc Meyer, Institute of Inorganic Chemistry

Date of the Oral Examination: 24.09.2019 



\section{Declaration}

Hereby I declare that I have written the present thesis under the supervision of Prof. Dr. Konrad Koszinowski independently and without illicit assistance from third parties. I confirm that I used none other than the mentioned source materials and aids. No part of the thesis has been submitted for the award of any other degree or diploma prior to this date.

Göttingen, 02.08.2019

Marlene Kolter 



\section{Danksagung}

Zuerst gebührt mein Dank Herrn Prof. Dr. Konrad Koszinowski für die Möglichkeit, unter seiner Anleitung die vorliegende Arbeit anzufertigen. Hervorgehoben seien an dieser Stelle sowohl seine engagierte fachliche Betreuung und die Bereitschaft, bei auftauchenden Fragen und Problemen jederzeit unterstützend zur Seite zu stehen, als auch seine freundliche und gelassene Art, die in der gesamten Gruppe für ein angenehmes und motivierendes Arbeitsklima gesorgt hat.

Herrn Prof. Dr. Lutz Ackermann sowie Herrn Prof. Dr. Manuel Alcarazo möchte ich für die Betreuung dieser Arbeit im Rahmen des CaSuS-Promotionsprogramms danken. Herrn Dr. Holm Frauendorf, Herrn Dr. Michael John und Herrn Prof. Dr. Franc Meyer danke ich für die Bereitschaft, sich als Mitglieder der Prüfungskommission zur Verfügung zu stellen.

Herrn Dr. Holm Frauendorf und Herrn Dr. Michael John gilt mein Dank überdies für die Hilfe bei der Planung und Durchführung der GC-MS-Experimente sowie der NMR-spektroskopischen Untersuchungen.

Meinen Mitstreitern in der Arbeitsgruppe, Andreas, Christoph, Finn, Friederike, Friedrich, Niklas, René, Sebastian, Stefan, Thomas und Tobias, sei an dieser Stelle ebenfalls herzlich gedankt für die Hilfsbereitschaft im Laboralltag, die vielen bereichernden fachlichen und außerfachlichen Diskussionen, die gute Arbeitsatmosphäre und viel Spaß bei den gemeinsamen Gruppenausflügen. Ich danke außerdem Marcel und Marius, die ich im Rahmen der Bachelorarbeit bzw. eines Forschungspraktikums betreuen durfte.

Des Weiteren möchte ich Christian, Niklas und Stefan für das gewissenhafte Korrekturlesen dieser Arbeit danken.

Mein besonderer Dank gilt schließlich meiner Familie und meinem Freund Christian, auf deren vorbehaltlose Unterstützung ich mich stets verlassen kann. 

Parts of the results presented in this thesis have been published in:

Stability and Unimolecular Reactivity of Palladate(II) Complexes $\left[L_{n} P d R_{3}\right]^{-}$( $L=$ Phosphine, $R=$ Organyl,$n=0$ and 1 )

M. Kolter, K. Koszinowski, Chem. Eur. J. 2016, 22, 15744-15750.

Anionic Palladium(0) and Palladium(II) Ate Complexes

M. Kolter, K. Böck, K. Karaghiosoff, K. Koszinowski, Angew. Chem. Int. Ed. 2017, 56, 13244-13248; Angew. Chem. 2017, 129, 13427-13431.

Formation of Transient Anionic Metal Clusters in Palladium/Diene-Catalyzed Cross-Coupling Reactions

M. Kolter, K. Koszinowski, Chem. Eur. J. 2019, 25, 13376-13384. 



\section{Contents}

1 Introduction 1

1.1 Palladium-Catalyzed Cross-Coupling Reactions . . . . . . . . . . . . . . . . . . 1

1.2 Palladate Complexes Bearing Halide or Acetate Ligands and Their Role in CrossCoupling Reactions . . . . . . . . . . . . . . . . . . . . 3

1.3 Organopalladate(II) Complexes as Intermediates in Precatalyst Activation . . . . 5

1.4 Organopalladate Complexes in Cross-Coupling Reactions Proceeding After a Transmetalation-First Mechanism . . . . . . . . . . . . . . . 7

1.5 Analysis of Anionic Palladium Complexes by Electrospray-Ionization Mass Spectrometry: Motivation and Preliminary Results . . . . . . . . . . . . . . . . 9

2 Theoretical Background: Electrospray-Ionization Mass Spectrometry 13

2.1 Setup of a Mass Spectrometer . . . . . . . . . . . . . . . . . . . 13

2.2 Electrospray Ionization . . . . . . . . . . . . . . . . . . . 14

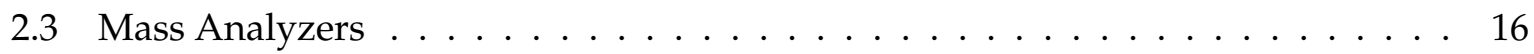

2.3 .1 Time-of-Flight Analyzer $\ldots \ldots \ldots \ldots$. . . . . . . . . . . . . . . . . . . . . . . . . . .

2.3 .2 Quadrupole Analyzers . . . . . . . . . . . . . . . . . . . . . . . . . 17

2.4 Investigating Reactivities of Ions in the Gas-Phase . . . . . . . . . . . . . . 18

$2.4 .1 \quad$ Unimolecular Reactions: Gas-Phase Fragmentation . . . . . . . . . . . . . 18

$2.4 .2 \quad$ Bimolecular Reactions: Ion-Molecule Reactions Inside the Ion Trap . . . . 19

2.5 ESI Mass Spectrometry of Organometallic Analytes: Advantages and Limitations 20

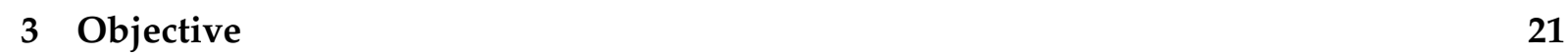

4 Results and Discussion 23

4.1 Organopalladate Complexes [(S-PHOS)PdR $]^{-}$as Intermediates in Precatalyst

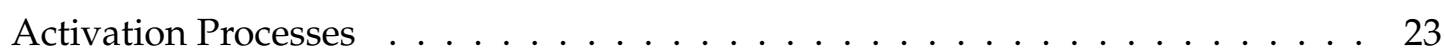

4.1.1 Transmetalation of the Palladium(II) Precursor: Influence of the Reaction Conditions on the Formation and Stability of $\left[(\mathrm{S}-\mathrm{PHOS}) \mathrm{PdR}_{3}\right]^{-} \quad \ldots \quad$. . . 23

4.1.2 Influence of the Phosphine Ligand on the Stability of Organopalladate

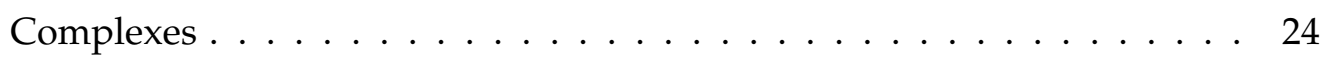

4.1.3 Influence of the Organic Substituent on the Formation of [(S-PHOS)PdR $\left.{ }_{3}\right]^{-}$ and the Reductive Elimination of $\mathrm{R}_{2} \ldots \ldots \ldots$. . . . . . . . . 26

4.1.4 The Role of Organopalladate(II) Complexes for the Activation of Palladium(II) Precatalysts . . . . . . . . . . . . . . . . . . . 29

4.2 Inorganic Palladates $\left[\mathrm{L}_{n} \mathrm{PdX}\right]^{-}$and Their Reactivities Towards Electrophiles . . . 31

4.2.1 Formation and Stability of Palladate Complexes $\left.\left[\mathrm{L}_{n} \mathrm{PdX}\right]^{-}\right] \ldots$. . . . . . . 31 
4.2.2 Influence of the Phosphine Ligand on the Stability of $\left[\mathrm{L}_{3} \mathrm{PdBr}\right]^{-}$. . . . . . 41

$4.2 .3 \quad$ Reactivity of Palladate Complexes $\left[\mathrm{L}_{n} \mathrm{PdX}\right]^{-}$Towards Organyl Electrophiles 44

$4.2 .4 \quad$ Role of Palladate Complexes $\left[\mathrm{L}_{n} \mathrm{PdX}\right]^{-}$in Cross-Coupling Reactions . . . 51

4.3 Organopalladate Intermediates in Cross-Coupling Reactions in the Presence of

1,3-Diene Ligands . . . . . . . . . . . . . . . . . . . . 52

4.3.1 Transmetalation of $\left[\mathrm{Pd}_{2}(\mathrm{dba})_{3}\right]$ with Grignard Reagents in the Presence of 1,3 -Diene Ligands . . . . . . . . . . . . . . . . . . . . 52

4.3.2 Time-Dependent Formation of Palladate Complexes in Different Aggregation States . . . . . . . . . . . . . . . . . . . 54

$4.3 .3 \quad$ Structure of the Observed Palladate Complexes: Binding Mode of the Diene Ligand $\ldots \ldots \ldots \ldots \ldots \ldots$

$4.3 .4 \quad$ Influence of the Transmetalating Agent . . . . . . . . . . . . . . . . . . 61

$4.3 .5 \quad$ Reactivity of Organopalladates Towards Organyl Electrophiles . . . . . . 62

4.3 .6 Formation of C-C Coupling Products: Reductive Elimination . . . . . . . 64

$4.3 .7 \quad$ Different Reactivities of Aryl and Alkyl Electrophiles . . . . . . . . . . . . 67

4.3 .8 Transmetalation of Palladium(II) Precursors $\ldots \ldots \ldots$. . . . . . . . . . . . . . . . 68

4.3 .9 Implications for the Catalytic Cycle $\ldots \ldots \ldots . \ldots . \ldots . \ldots 6$

4.4 Organopalladates Containing the Electron-Poor Phosphine Ligand $\operatorname{PAr}_{3} \ldots \ldots$

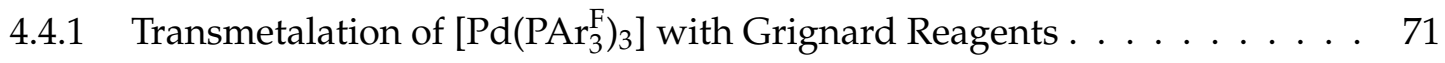

$4.4 .2 \quad$ Influences of the Transmetalating Agent and the Phosphine Ligand . . . . 74

4.4 .3 Electronic Properties of $\left[\mathrm{L}_{n} \mathrm{PdR}\right]^{-}$in Comparison to $\left[\mathrm{L}_{n} \mathrm{PdX}\right]^{-} \ldots \ldots$. . . . 76

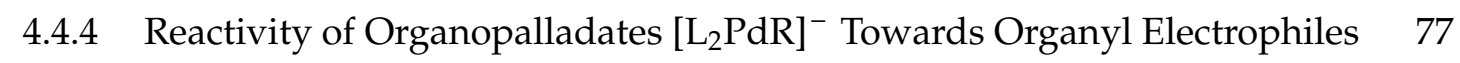

4.4.5 Formation of $\mathrm{C}-\mathrm{C}$ Coupling Products: Unimolecular Reactivity of Triply Substituted Heteroleptic Palladates . . . . . . . . . . . . . . . . 81

$4.4 .6 \quad$ Preliminary Experiments for Synthetic Applications . . . . . . . . . . . . . 82

4.4 .7 Suggested Catalytic Cycle of a Cross-Coupling Reaction with ElectronPoor Palladium-Phosphine Catalysts . . . . . . . . . . . . 83

$\begin{array}{lll}5 \text { Conclusion and Outlook } & 85\end{array}$

\begin{tabular}{lll}
\hline 6 & Experimental Section & 91
\end{tabular}

6.1 General $\ldots \ldots \ldots \ldots \ldots \ldots$. . . . . . . . . . . . . . . . . . . . . . . . . . . . .

6.2 Exact Concentrations of Organometallic Reagents . . . . . . . . . . . . . . . 91

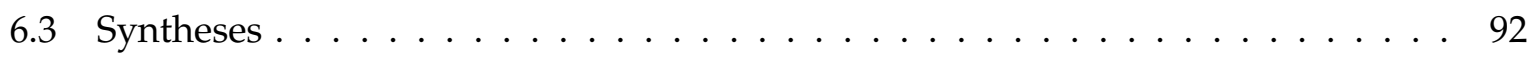

6.3 .1 Syntheses of Organometallic Reagents . . . . . . . . . . . . . . . . . . . . . . . . . . . . . . . . 92

6.3 .2 Ligand Syntheses . . . . . . . . . . . . . . . . . . . . . . . . . . . . . . . . . . . . . . . . . 93

6.4 Analytical Methods $\ldots \ldots \ldots \ldots$. . . . . . . . . . . . . . . . . 95

$6.4 .1 \quad$ ESI Mass Spectrometry $\ldots \ldots \ldots \ldots \ldots$. . . . . . . . . . . . . . . . . . . . . . . . . . . . . 95

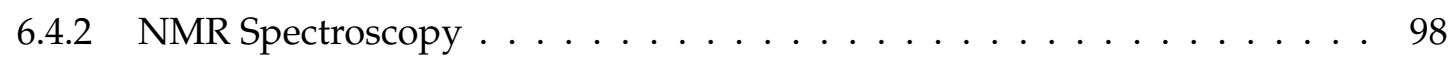

6.4 .3 Electrical Conductometry . . . . . . . . . . . . . . . . . . . . . . . . . . 98

$6.4 .4 \quad \mathrm{UV} / \mathrm{Vis}$ Spectroscopy $\ldots \ldots \ldots \ldots$. . . . . . . . . . . . . . . 99

\begin{tabular}{ll}
\hline References and Notes & 101
\end{tabular} 


\section{Introduction}

\subsection{Palladium-Catalyzed Cross-Coupling Reactions}

Transition-metal catalyzed cross-coupling reactions between organometallic reagents $\mathrm{R}-\mathrm{M}$ and organyl (pseudo)halides $R^{\prime}-X$ are an efficient and widely used method for the formation of new carbon-carbon bonds in modern organic synthesis (equation (1.1)). [1. [3]

$$
\mathrm{R}-\mathrm{M}+\mathrm{R}^{\prime}-\mathrm{X} \stackrel{\text { catalyst }}{\longrightarrow} \mathrm{R}-\mathrm{R}^{\prime}+\mathrm{M}-\mathrm{X}
$$

Palladium-based catalysts were found to be very well suitable for these reactions early on and have been of outstanding importance in this field ever since. ${ }^{[1+3]}$ One reason for their utility is of course the ability of palladium to mediate all elementary steps that are necessary to achieve a complete cross-coupling reaction (scheme 1.1). Furthermore, palladium-based catalysts display a couple of beneficial characteristics, such as a high functional group tolerance and a relatively low sensitivity of organyl palladium complexes against air and moisture.1]

Several types of palladium-catalyzed cross-coupling reactions are known to date, which are classified according to the organometallic reagent that is used for the transmetalation step (table 1.1).

Table 1.1: Different types of palladium-catalyzed cross-coupling reactions categorized with regard to the used transmetalating reagent $[\mathrm{M}]-\mathrm{R} \cdot\left[\frac{[24]}{2}\right.$

\begin{tabular}{|c|c|c|}
\hline Name Reaction & {$[\mathbf{M}]-\mathbf{R}$} & Additional Information \\
\hline Murahashi[5] & $\mathrm{Li}-\mathrm{R}$ & \\
\hline Kumada-Tamao[ & $\mathrm{XMg}-\mathrm{R}$ & nickel- or palladium-catalyzed \\
\hline Sonogashira-Hagihara ${ }^{|7|}$ & $\mathrm{Cu}-\mathrm{C} \equiv \mathrm{C}-\mathrm{R}$ & in situ from $\mathrm{HC} \equiv \mathrm{CR}+\mathrm{CuI}+$ base \\
\hline Negishi[8] & $\mathrm{RZn}-\mathrm{R} ; \mathrm{XZn}-\mathrm{R}$ & $\begin{array}{l}\text { analogous reactions with } \mathrm{AlR}_{3} \text { and } \\
{\left[\mathrm{ZrClRCp} \mathrm{p}_{2}\right]}\end{array}$ \\
\hline Suzuki-Miyaura & {$\left[(\mathrm{OH})_{2} \mathrm{XB}-\mathrm{R}\right]^{-}$} & $\begin{array}{l}\text { in situ from } \mathrm{BR}(\mathrm{OH})_{2}+\text { anionic base } \\
\mathrm{X}^{-}\end{array}$ \\
\hline Hiyama 10 & {$\left[\mathrm{~F}_{n+1} \mathrm{Me}_{3-n} \mathrm{Si}-\mathrm{R}\right]^{-}$} & in situ from $\mathrm{SiRMe}_{3-n} \mathrm{~F}_{n}+\mathrm{F}^{-}$ \\
\hline Stille 11 & $\mathrm{R}_{3}{ }_{3} \mathrm{Sn}-\mathrm{R}$ & $\mathrm{R}^{\prime \prime}=\mathrm{Alkyl}$ \\
\hline
\end{tabular}


The above-shown cross-coupling reactions differ significantly with regard to the substrate scope and the applicable reaction conditions, mainly due to the different reactivities and functional group tolerances of the involved organometallic reagents. In contrast, all of these cross-coupling reactions are generally acknowledged to follow the same basic catalytic cycle, comprising an oxidative addition, a transmetalation, and the reductive elimination of the cross-coupling product (scheme 1.1).

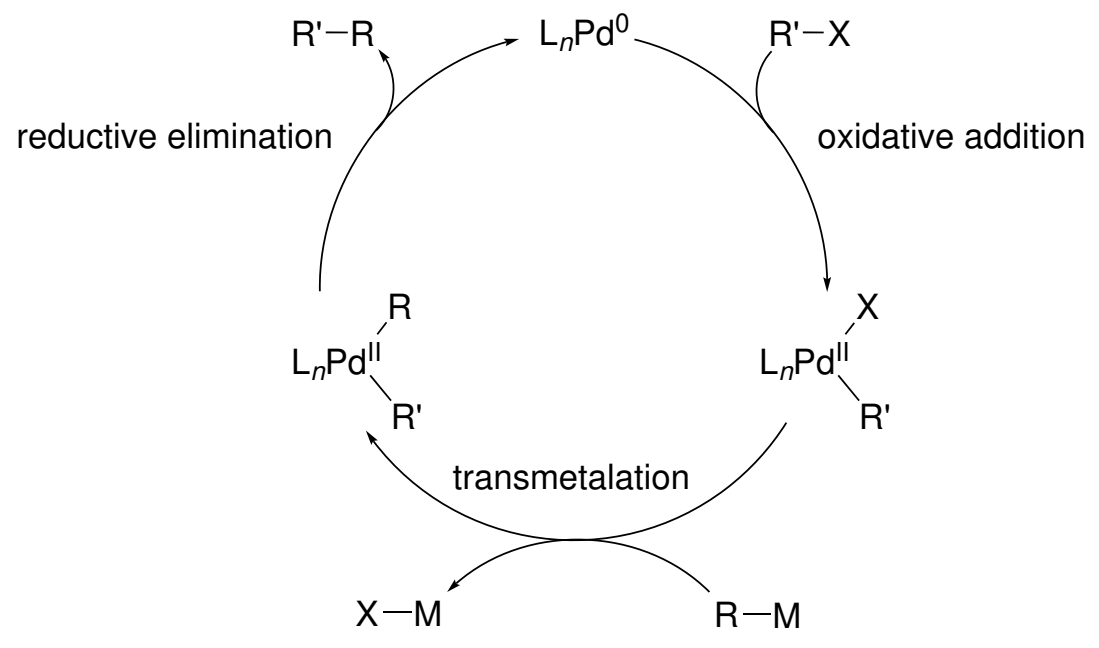

Scheme 1.1: Catalytic cycle of a palladium-catalyzed cross-coupling reaction between an organyl (pseudo)halide $\mathrm{R}^{\prime}-\mathrm{X}$ and an organometallic reagent $\mathrm{R}-\mathrm{M}(\mathrm{L}=$ ligand, for example a phosphine ligand).

Usually, the reaction starts with the oxidative addition of an organyl electrophile $R^{\prime}-X$ to a palladium(0) catalyst. In the second step, the organic substituent $\mathrm{R}$ is transferred from the transmetalation reagent $\mathrm{R}-\mathrm{M}$ onto the resulting organopalladium(II) species under elimination of $M-X$. The cross-coupling product $R-R^{\prime}$ is then formed in a reductive elimination reaction, which regenerates the palladium(0) catalyst. Of course, depending on the nature of the applied palladium precursors and the used ligands, additional reaction steps, such as catalyst activation, cis-trans-isomerization, or ligand association/dissociation processes, can be involved.

While the palladium intermediates included in this catalytic cycle are described as neutral species in most cases, it is easily imaginable that anionic derivatives of the shown complexes can be formed if additional anionic ligands $\mathrm{R}^{-}, \mathrm{R}^{\prime}$, or $\mathrm{X}^{-}$coordinate to the palladium center. Palladate complexes resulting from such reactions have been suggested as important reaction intermediates in various palladium-catalyzed transformations (see below). 


\subsection{Palladate Complexes Bearing Halide or Acetate Ligands and Their Role in Cross-Coupling Reactions}

For many transition-metal-catalyzed reactions in general and palladium-catalyzed $\mathrm{C}-\mathrm{C}$ coupling reactions in particular, the addition of halide salts to the reaction mixture was found to have a beneficial effect on the performance of the applied catalyst. ${ }^{[12]}$ A popular explanation as to why the presence of halides should enhance the reactivity of a palladium catalyst is the formation of anionic palladium complexes through the addition of a halide anion to the neutral palladium(0) species. Such a palladate complex can be expected to exhibit higher reactivites in oxidative addition reactions compared to its neutral analogon due to the increased electron density on the palladium center. As the oxidative addition step is the rate-determining step in many palladium-catalyzed cross-coupling reactions, a faster oxidative addition thus leads to an acceleration of the overall transformation.

First experimental evidence of an interaction between a palladium(0) catalyst with a lithium halide was provided by Negishi et al., who reported that the reduction of $\left[\left(\mathrm{PPh}_{3}\right)_{2} \mathrm{Pd}^{\mathrm{II}} \mathrm{X}_{2}\right]$, with $\mathrm{X}=\mathrm{Cl}, \mathrm{Br}$, or I, with an organolithium reagent resulted in the formation of $\left[\left(\mathrm{PPh}_{3}\right)_{2} \mathrm{Pd}^{0} \mathrm{XLi}\right]$, $\left[\left(\mathrm{PPh}_{3}\right)_{2} \mathrm{Pd}^{0} \mathrm{X}_{2} \mathrm{Li}_{2}\right]$, or analogous higher aggregates, according to ${ }^{31} \mathrm{P}-\mathrm{NMR}$ studies. ${ }^{[13]}$ The further investigation of anionic halide- and also acetate- or trifluoroacetate-containing palladium complexes and their role in cross-coupling reactions was pursued by Amatore and Jutand in the following years. These studies were mainly conducted by means of electrochemical methods, the analysis of reaction kinetics especially of the oxidative addition step, and ${ }^{31} \mathrm{P}-\mathrm{NMR}$ spectroscopy, [14] and were later complemented with quantum-chemical calculations. ${ }^{[15]}$ The authors chose an electrochemical method to generate the coordinatively unsaturated fragment $\left[\left(\mathrm{PPh}_{3}\right)_{2} \mathrm{Pd}^{0}\right]$ in situ from $\left[\left(\mathrm{PPh}_{3}\right)_{2} \mathrm{Pd}^{\mathrm{II}} \mathrm{X}_{2}\right]$, with $\mathrm{X}=\mathrm{Cl}, \mathrm{Br}$, or I (equation 1.2$)$ ). $14 \mathrm{~b}$ monitored the reaction kinetics of the oxidative addition of phenyl iodide (PhI) to the palladium(0) complex by cyclic voltammetry (equation (1.3)).

$$
\begin{gathered}
{\left[\left(\mathrm{PPh}_{3}\right)_{2} \mathrm{Pd}^{\mathrm{II}} \mathrm{X}_{2}\right]+2 \mathrm{e}^{-} \longrightarrow\left[\left(\mathrm{PPh}_{3}\right)_{2} \mathrm{Pd}^{0}\right]+2 \mathrm{X}^{-}} \\
{\left[\left(\mathrm{PPh}_{3}\right)_{2} \mathrm{Pd}^{0}\right]+\mathrm{PhI} \longrightarrow\left[\left(\mathrm{PPh}_{3}\right)_{2} \mathrm{Pd}^{\mathrm{II}} \mathrm{PhI}\right]}
\end{gathered}
$$

From the finding that the observed half-life of the reactant complex $\left[\left(\mathrm{PPh}_{3}\right)_{2} \mathrm{Pd}^{0}\right]$ in the reaction with phenyl iodide varied depending on the precursor that was used to generate the palladium(0) complex, they deduced that the free halide anions $\mathrm{X}^{-}$arising from the reduction were not inert, but interacted with the palladium species, hence influencing the reactivity of the palladium complex. Information from further kinetic studies led them to the conclusion that the $\left[\left(\mathrm{PPh}_{3}\right)_{2} \mathrm{Pd}^{0}\right]$ fragment generated from $\left[\left(\mathrm{PPh}_{3}\right)_{2} \mathrm{Pd}^{\mathrm{II}} \mathrm{Cl}_{2}\right]$ (equation (1.2)) was actually the palladate species $\left[\left(\mathrm{PPh}_{3}\right)_{2} \mathrm{PdCl}\right]^{-}$, in fast equilibrium with its dimer $\left[\left(\mathrm{PPh}_{3}\right)_{2} \mathrm{PdCl}\right]_{2}{ }^{2-}$ and its chloride adduct $\left[\left(\mathrm{PPh}_{3}\right)_{2} \mathrm{PdCl}_{2}\right]^{2-}$ (scheme 1.2). 


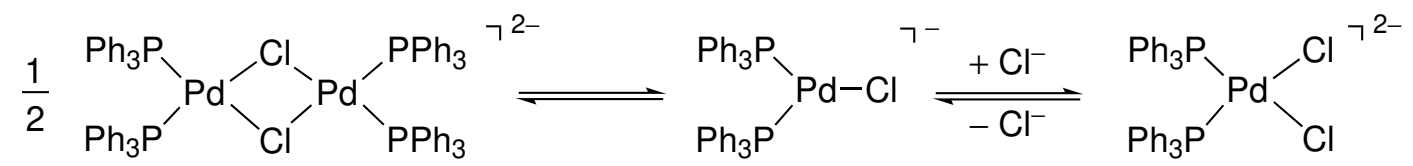

Scheme 1.2: Equilibrium between the anionic palladium complex $\left[\left(\mathrm{PPh}_{3}\right)_{2} \mathrm{PdCl}\right]^{-}$and its derivatives $\left[\left(\mathrm{PPh}_{3}\right)_{2} \mathrm{PdCl}_{2}{ }^{2-}\right.$ and $\left[\left(\mathrm{PPh}_{3}\right)_{2} \mathrm{PdCl}_{2}\right]^{2-} . \underline{14 \mathrm{~b}}$

Later reports found the formation of analogous complexes $\left[\left(\mathrm{PPh}_{3}\right)_{n} \mathrm{Pd}(\mathrm{OAc})\right]^{-}$, with $n=2$ and 3 , with acetate instead of halide anions when palladium acetate was used as a precursor. $[14 \mathrm{e}, 14 \mathrm{f}$ The acetate-containing complex, too, underwent oxidative addition reactions with $\mathrm{PhI}$.

Further studies on the oxidative addition of aryl halides (ArX) to electrochemically produced $\left[\left(\mathrm{PPh}_{3}\right)_{2} \mathrm{PdCl}\right]^{-}$with ${ }^{31} \mathrm{P}-\mathrm{NMR}$ spectroscopy, cyclic voltammetry, and halide titration experiments showed that one product of the considered reaction was the expected neutral tetracoordinate palladium complex trans-[( $\left.\left.\mathrm{PPh}_{3}\right)_{2} \mathrm{PdArX}\right]$, but that this product formed only after some time rather than directly during the oxidative addition step.14d] Instead, the authors found the formation of an an anionic intermediate, $\left[\left(\mathrm{PPh}_{3}\right)_{2} \mathrm{PdArClX}\right]^{-}$, with two equivalent phosphine ligands, which they assumed to exhibit a pentacoordinate structure. Later, an alternative square-planar structure for this species was suggested by Gooßen and Thiel based on quantum-chemical calculations, in which the aryl iodide linearly coordinates the palladium center over the iodine atom. [16] According to Amatore and Jutand, the reaction from the anionic intermediate to the tetracoordinate product then proceeded via an exchange of the chloride ion for a solvent molecule or, if available, a phosphine ligand, and a subsequent ligand dissociation. However, the authors pointed out that in the presence of a nucleophile, the transmetalation step would likely take place directly on the pentacoordinate intermediate, continuing the catalytic cycle and suppressing the presumably slower formation of trans$\left[\left(\mathrm{PPh}_{3}\right)_{2} \mathrm{PdArX}\right]$.

Based on the above results, they proposed an alternative catalytic cycle featuring anionic palladate intermediates, which allowed for a faster overall reaction than the previously suggested mechanism involving neutral species (scheme 1.3). $14 \mathrm{~d} \mid 14 \mathrm{~g}$ 


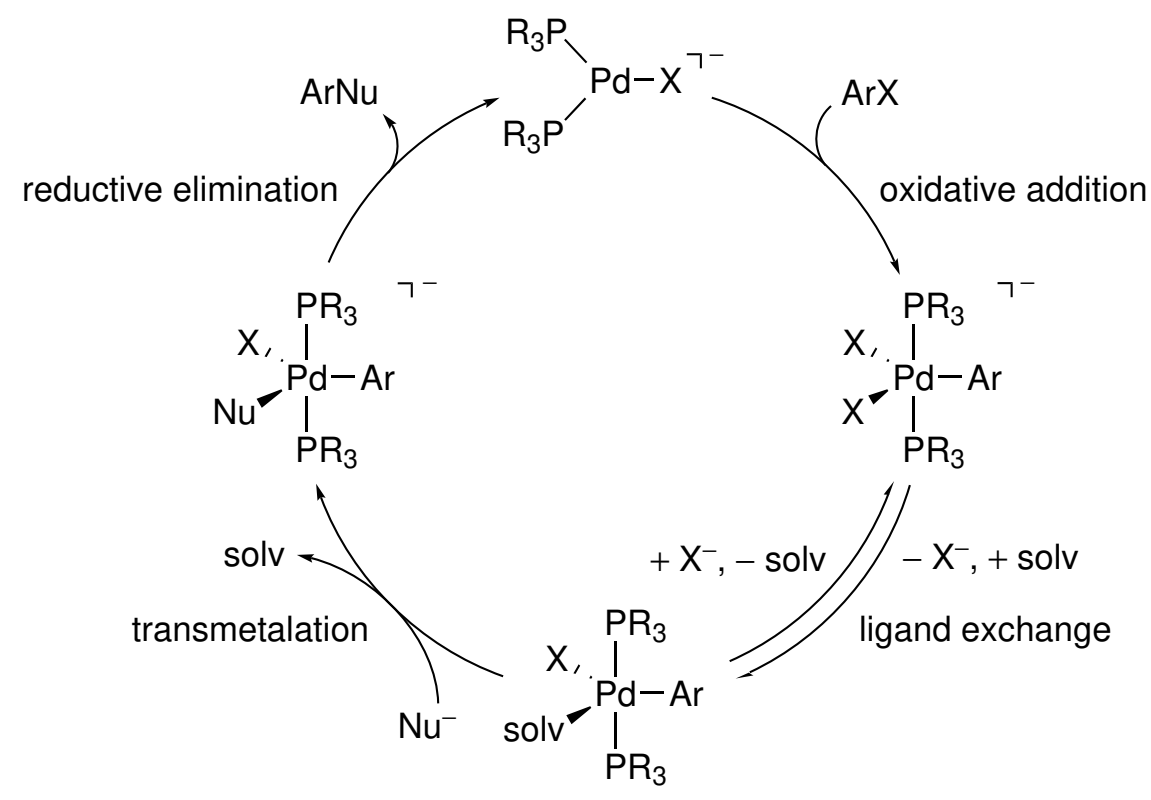

Scheme 1.3: Catalytic cycle of a palladium-catalyzed cross-coupling reaction between an aryl halide ArX and a nucleophile $\mathrm{Nu}^{-}$in the presence of halide anions $\mathrm{X}^{-}$involving palladate intermediates $($ solv $=$ solvent). $14 \mathrm{~d} \mid 14 \mathrm{~g}]$ For reasons of simplicity, all present halide ions are assumed to be identical.

Since then, anionic intermediates have been widely acknowledged to play an important role in many palladium-catalyzed cross-coupling and Heck-type reactions. Nevertheless, the knowledge about the molecular structure and reactivity of such complexes remains limited: Beyond the work of Amatore and coworkers, studies providing experimental evidence of palladium $(0)$ ate complexes by other analytical methods have been rather scarce. $17-21]$

\subsection{Organopalladate(II) Complexes as Intermediates in Precatalyst Activation}

Compared to zero-valent palladium, palladium(II) species have a higher tendency to form stable anionic complexes due to the lower electron density at the palladium center. In addition to the readily available inorganic palladate salts, such as $\mathrm{Na}_{2} \mathrm{PdCl}_{4}$, there have also been examples for palladate(II) species containing organyl ligands. Complexes of the type $\mathrm{M}^{+}\left[\mathrm{LPdR}_{3}\right]^{-}$and $\mathrm{M}_{2}^{+}\left[\mathrm{PdR}_{4}\right]^{2-}$, with $\mathrm{M}=\mathrm{Li}, \mathrm{MgCl}$, or $\mathrm{MgBr}$, and $\mathrm{R}=\mathrm{Me}, \mathrm{Et}$, $\mathrm{Ph}$, or $\mathrm{C}_{6} \mathrm{~F}_{5}$, were obtained upon transmetalation of palladium(II) precursors with organolithium or Grignard

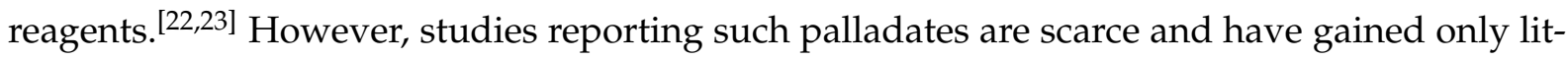
tle attention.

Complexes of the type $\left[\mathrm{L}_{2} \mathrm{PdR}_{2}\right],\left[\mathrm{LPdR}_{3}\right]^{-}$, or $\left[\mathrm{PdR}_{4}\right]^{2-}$, L being a triorganylphosphine ligand, might offer valuable insights in the context of palladium-catalyzed transformations, especially with regard to the activation of palladium(II) precatalysts. As discussed above, many palladium-catalyzed transformations involve palladium(0) complexes as catalytically active 
species. In cases where preformed palladium(0) complexes, such as $\mathrm{Pd}\left(\mathrm{PPh}_{3}\right)_{4}$, are not applicable, the active species is often formed in situ by the reduction of a palladium(II) precursor such as palladium acetate in the presence of the phosphine ligand of choice. As Amatore and coworkers showed, the reduction of the precursor can be brought about by the phosphine ligand, one equivalent of which is oxidized to the corresponding phosphine oxide in the process (equations (1.4) to (1.7).

$$
\begin{aligned}
& \mathrm{Pd}^{\mathrm{II}}(\mathrm{OAc})_{2}+2 \mathrm{PPh}_{3} \longrightarrow\left[\left(\mathrm{PPh}_{3}\right)_{2} \mathrm{Pd}^{\mathrm{II}}(\mathrm{OAc})_{2}\right] \\
& {\left[\left(\mathrm{PPh}_{3}\right)_{2} \mathrm{Pd}^{\mathrm{II}}(\mathrm{OAc})_{2}\right] \stackrel{\text { slow }}{\longrightarrow}\left[\left(\mathrm{PPh}_{3}\right) \mathrm{Pd}^{0}\right]+(\mathrm{OAc})^{-}+\mathrm{AcO}-\mathrm{PPh}_{3}{ }^{+}} \\
& \mathrm{AcO}-\mathrm{PPh}_{3}+\stackrel{(\mathrm{OAc})^{-}}{\longrightarrow} \mathrm{Ac}_{2} \mathrm{O}+\mathrm{O}=\mathrm{PPh}_{3} \\
& {\left[\left(\mathrm{PPh}_{3}\right) \mathrm{Pd}^{0}\right]+2 \mathrm{PPh}_{3} \stackrel{\text { fast }}{\longrightarrow}\left[\left(\mathrm{PPh}_{3}\right)_{3} \mathrm{Pd}\right]}
\end{aligned}
$$

Another possible activation pathway is the reduction of the palladium(II) species by an organometallic reagent $\mathrm{R}-\mathrm{M}$. For example, it has been shown that organolithium reagents are capable of reducing [ $\left.\left(\mathrm{PPh}_{3}\right)_{2} \mathrm{PdX}_{2}\right]$, with $\mathrm{X}=\mathrm{Cl}$, Br, or I, yielding palladium(0) species (section 1.2). Also, the addition of organometallic reagents to palladium(II) precursors in the absence of a stabilizing ligand often leads to the formation of palladium black, further confirming a reduction process. $\frac{[25] 26]}{2}$ While the exact mechanism of this reduction process is still insufficiently understood, it is likely that a transmetalation reaction yields organopalladium complexes $\mathrm{PdR}_{2}$ or similar species, which then undergo a reductive elimination to give the active palladium $(0)$ catalyst (equations (1.8) and (1.9)).

$$
\begin{aligned}
\mathrm{Pd}^{\mathrm{II}}(\mathrm{OAc})_{2}+2 \mathrm{R}-\mathrm{M} & \longrightarrow \mathrm{Pd}^{\mathrm{II}} \mathrm{R}_{2}+2 \mathrm{M}(\mathrm{OAc}) \\
\mathrm{Pd}^{\mathrm{II}} \mathrm{R}_{2} & \longrightarrow \mathrm{Pd}^{0}+\mathrm{R}_{2}
\end{aligned}
$$

As many palladium-catalyzed $\mathrm{C}-\mathrm{C}$-coupling reactions are conducted in the presence of phosphine ligands, and at the same time involve organometallic reagents in large excess relative to the palladium catalyst, it can be assumed that the two catalyst activation mechanisms can compete to a certain degree. It has been shown that the phosphine ligand does not necessarily reduce the palladium(II) precursor quantitatively. [26] Thus, the transmetalation of residual palladium(II) species by organometallic reagents might have a significant influence on the nature and also on the amount of catalytically active species in solution. It is yet unclear, though, if organopalladate complexes of the type $\left[\mathrm{LPdR}_{3}\right]^{-}, \mathrm{L}$ being a tertiary phosphine, play a role in such a reduction mechanism, or if neutral species dominate this process. 


\subsection{Organopalladate Complexes in Cross-Coupling Reactions Proceeding After a Transmetalation-First Mechanism}

In palladium-catalyzed cross-coupling reactions, unsaturated substrates such as alkenyl, alkynyl, or aryl compounds are used as starting materials in the majority of cases. The development of applicable cross-coupling reactions with unactivated alkyl (pseudo)halides as coupling partners represents a special challenge due to some characteristics of the involved reactions and intermediates: The oxidative addition of alkyl halides to transition metal centers tends to be slow, compared with that of unsaturated organyl halides. Furthermore, the alkylmetal complexes formed by such reactions can undergo $\beta$-hydride elimination easily, leading to the formation of unwanted side products. In many cases, the formation of homocoupling products instead of the cross-coupling product is also a problem. Nonetheless, several successful strategies for palladium-catalyzed cross-coupling reactions of unactivated alkyl (pseudo)halides have been found in the past decades. $27-[29]$ Possibilities to overcome the mentioned difficulties are the acceleration of the oxidative addition and the suppression of side reactions such as $\beta$-hydride eliminations, for example by the application of polar solvents or the choice of suitable electron-rich and/or sterically demanding ligands such as N-heterocyclic carbenes or electron-rich phosphines. $277-[29]$

Another approach was taken by Kambe and coworkers, who conducted a nickel-catalyzed Kumada-Corriu cross-coupling reaction between alkyl halides or tosylates and Grignard reagents in the presence of 1,3-diene ligands, which led to the selective formation of the crosscoupling products with excellent yields. $[30]$ A palladium-catalyzed variant of this reaction was reported shortly after (equation 1.10 with $\mathrm{R}=$ aryl, alkyl).

$$
\text { Alkyl-X }+\mathrm{RMgCl} \underset{1,3-\text { butadiene }}{\stackrel{\mathrm{Pd}(\mathrm{acac})_{2}}{\longrightarrow}} \text { Alkyl-R }
$$

The authors suggested the operation of an alternative catalytic cycle for the diene-containing catalysts, in which the order of the elementary steps was reversed compared to the usually assumed sequence of oxidative addition, transmetalation, and reductive elimination (scheme 1.4. 29.31 


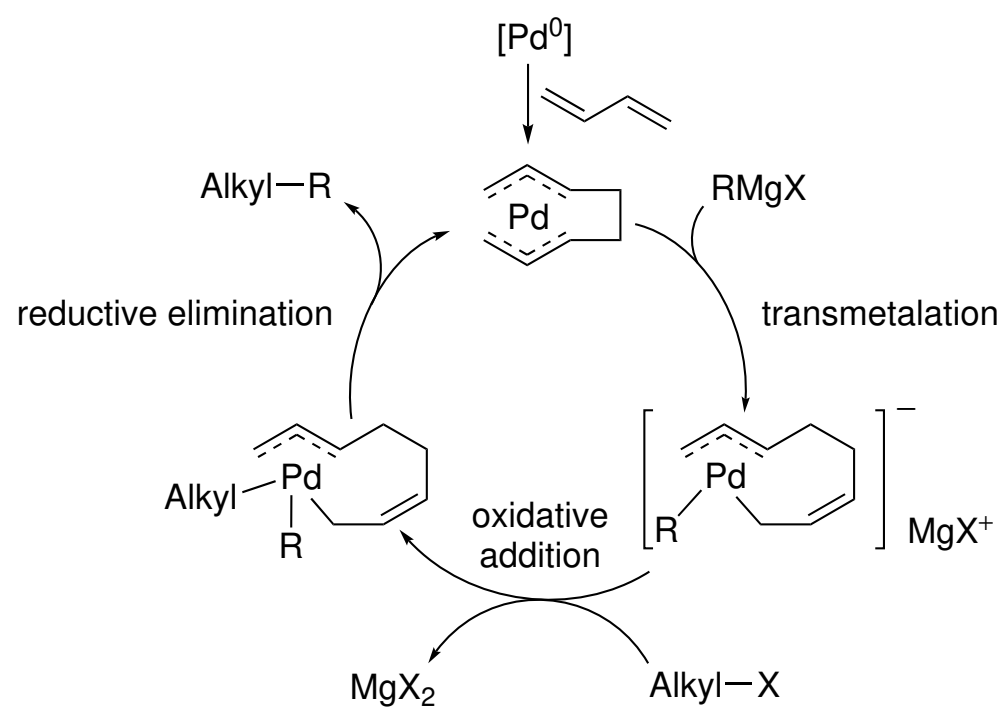

Scheme 1.4: Catalytic cycle of a palladium-catalyzed cross-coupling reaction between an alkyl halide Alkyl-X and a Grignard reagent $\mathrm{RMgCl}$ in the presence of 1,3-butadiene. [29]

First, the palladium(0) precursor reacts with two equivalents of the 1,3-diene ligand to form a bis- $\left(\eta^{3}\right.$-allyl)-palladium complex as the active catalyst. In the next step, the transmetalation by the Grignard reagent yields an anionic $\left(\eta^{1}, \eta^{3}\right.$-allyl)-palladium intermediate. The oxidative addition of the alkyl electrophile presumably follows an $S_{N}$ 2-like mechanism, possibly facilitated through an activation of the halide by the magnesium counterion, producing a neutral heteroleptic species. The reductive elimination of the cross-coupling product then regenerates the catalyst.

Experimental evidence for the proposed catalytic cycle in general and the anionic intermediate in particular was obtained for the nickel-catalyzed reaction through thorough mechanistic studies. 32 The authors were able to confirm the suggested order of reaction steps in kinetic studies and to identify the anionic nickel intermediate in ${ }^{1} \mathrm{H}-\mathrm{NMR}$-spectroscopic experiments. Furthermore, they could isolate the nickelate complex produced in the reaction of bis(cyclooctadiene)nickel(0) with 2,6-dimethylphenyllithium in the presence of 1,3-butadiene and confirm its presumed structure by X-ray crystallography after recrystallization in the presence of 12 -crown-4 ether.

In the case of palladium, the reaction mechanism and the structure of the involved intermediates were largely identified based on the assumed analogy to the nickel-catalyzed reaction at first, and were later confirmed by conducting cross-coupling reactions with preformed bis- $\left(\eta^{3}-\right.$ allyl)-palladium as catalyst. For these modified systems, containing two simple allyl ligands instead of dimerized 1,3-butadiene, the formation of a $\left(\eta^{1}, \eta^{3}\right.$-allyl)-palladium species was found in ${ }^{1} \mathrm{H}-\mathrm{NMR}$ studies, supporting the proposed mechanism for the reactions with palladium/1,3diene catalysts. 33 


\subsection{Analysis of Anionic Palladium Complexes by Electrospray-Ionization Mass Spectrometry: Motivation and Preliminary Results}

As mentioned above, anionic palladium complexes are discussed as important intermediates in a number of palladium-catalyzed transformations. However, these species are challenging in several ways when it comes to the choice of suitable analytical methods. In-situ formed palladate intermediates often have only limited lifetimes and/or display a high susceptibility against air and moisture, rendering the use of, for example, crystallographic techniques difficult. Furthermore, they are not present as isolated species, but as part of a complex mixture, which poses a drawback to many spectroscopic methods. As the palladate anions of interest bear a charge by definition, the use of mass spectrometry is a straightforward approach in this case. Electrospray-ionization (ESI) mass spectrometry allows for the generation and analysis of gas-phase ions from susceptible analytes under mild ionization conditions and has been successfully applied for the characterization of reactive organometallic species in general and for the observation of palladium-catalyzed transformations in particular. $26,34,38$

Leading up to the studies presented in this work, ESI mass spectrometry had been applied in preliminary experiments to analyze anionic palladium complexes $\left[\left(\mathrm{PAr}_{3}^{\mathrm{F}}\right)_{n} \mathrm{PdX}^{-}\left(\left(\mathrm{PAr}_{3}^{\mathrm{F}}\right)=\operatorname{tris}^{-}\right.\right.$ $\left.\left.\left[3,5 \text {-bis(trifluoromethyl)phenyl]phosphine) and [(S-PHOS) } \mathrm{PdR}_{3}\right]^{-}(\operatorname{chart} 11) \cdot 39\right] 40\right]$<smiles>FC(F)(F)c1cc(P(c2cc(C(F)(F)F)cc(C(F)(F)F)c2)c2cc(C(F)(F)F)cc(C(F)(F)F)c2)cc(C(F)(F)F)c1</smiles><smiles>COc1cccc(OC)c1-c1ccccc1PC1CCCC2CCCCC2C1</smiles>

S-PHOS

Chart 1: Phosphine ligands $\operatorname{PAr}_{3}^{\mathrm{F}}$ (left) and S-PHOS (right) used in preliminary ESI-mass spectrometric experiments.

\section{ESI mass spectrometry of palladate complexes $\left[\left(\operatorname{PAr}_{3}^{\mathrm{F}}\right)_{n} \mathrm{PdX}\right]^{-}$}

Anionic palladium(0) complexes can be assumed to have a very high electron density on the palladium center, which is expected to decrease their stability and thus reduce the chances for their detection by ESI mass spectrometry. Therefore, a catalyst bearing an electron-poor phosphine ligand was found suitable as a model system to allow for the formation of better stabilized palladate complexes. The chosen catalyst $\left[\mathrm{Pd}\left(\mathrm{PAr}_{3}^{\mathrm{F}}\right)_{3}\right]$ is known to be active in Heck and cross-coupling reactions. $\stackrel{41,42]}{ }$ As anticipated, $\left[\operatorname{Pd}\left(\mathrm{PAr}_{3}^{\mathrm{F}}\right)_{3}\right]$ showed the formation of palladate complexes $\left[\left(\mathrm{PAr}_{3}^{\mathrm{F}}\right)_{n} \mathrm{PdX}\right]^{-}$, with $n=2$ and 3 , in high signal intensities when combined 
with lithium halides LiX in preliminary ESI-mass spectrometric experiments. The formation of palladates was further confirmed by conductivity studies of $\left[\mathrm{Pd}\left(\mathrm{PAr}_{3}^{\mathrm{F}}\right)_{3}\right]$ with various added salts ( $\mathrm{LiF}, \mathrm{LiCl}, \mathrm{LiBr}, \mathrm{LiI}, \mathrm{LiClO}_{4}, \mathrm{NBu}_{4} \mathrm{Cl}$ ) in tetrahydrofuran (THF) as well as by ${ }^{31} \mathrm{P}-\mathrm{NMR}$ spectroscopic experiments. $\stackrel{[40]}{[}$ These results demonstrated that $\left[\operatorname{Pd}\left(\operatorname{PAr}_{3}^{\mathrm{F}}\right)_{3}\right]$ was a very wellsuited model catalyst for undertaking a more detailed analysis of the formation, stability, and reactivity of palladate( 0 ) complexes bearing (pseudo)halide ligands.

\section{ESI mass spectrometry of organopalladate complexes [(S-PHOS)PdR $]^{-}$}

Previous results from ESI-mass spectrometric studies on the possibility of a transmetalation/ reductive elimination sequence for the reduction of palladium(II) precatalysts (section 1.3) showed that the transmetalation of a mixture of $\mathrm{Pd}(\mathrm{OAc})_{2}$ and 2-dicyclohexylphosphino-2', $6^{\prime}-$ dimethoxybiphenyl (S-PHOS) with a Grignard reagent $\mathrm{RMgCl}$, with $\mathrm{R}=\mathrm{Ph}$ and $\mathrm{Bn}$, yielded triply substituted organopalladate complexes $\left[\mathrm{PdBn}_{3}\right]^{-}$and $\left[(\mathrm{S}-\mathrm{PHOS}) \mathrm{PdR}_{3}\right]^{-}$(figure 1.1 for the example of $\mathrm{R}=\mathrm{Ph}) .39]$ These complexes readily underwent reductive elimination in gasphase fragmentation reactions, yielding the corresponding palladium(0) anions $[(\mathrm{S}-\mathrm{PHOS}) \mathrm{PdR}]^{-}$and $[\mathrm{PdBn}]^{-}$(figure 1.2 for the example of $\left[(\mathrm{S}-\mathrm{PHOS}) \mathrm{PdPh}_{3}\right]^{-}$).

For both $\mathrm{R}=\mathrm{Ph}$ and $\mathrm{R}=\mathrm{Bn}$, a minor fragmentation pathway was the loss of $\mathrm{RH}$, which corresponded to a $\mathrm{C}-\mathrm{H}$ activation reaction. The product ions of these reactions, $\left[(\mathrm{S}-\mathrm{PHOS}) \mathrm{PdR}_{2}-\mathrm{H}\right]^{-}$, were present already in the mass spectra without any additional fragmentation, suggesting the loss of $\mathrm{RH}$ to be a relevant decomposition pathway also in solution. Furthermore, the collision-induced dissociation of $\left[(\mathrm{S}-\mathrm{PHOS}) \mathrm{PdPh}_{2}-\mathrm{H}\right]^{-}$produced $[(\mathrm{S}-\mathrm{PHOS}) \mathrm{Pd}-\mathrm{H}]^{-}$in a reductive elimination of $\mathrm{Ph}_{2}$, indicating that the hydrogen atom in the dissociation of RH may also stem from the S-PHOS ligand.

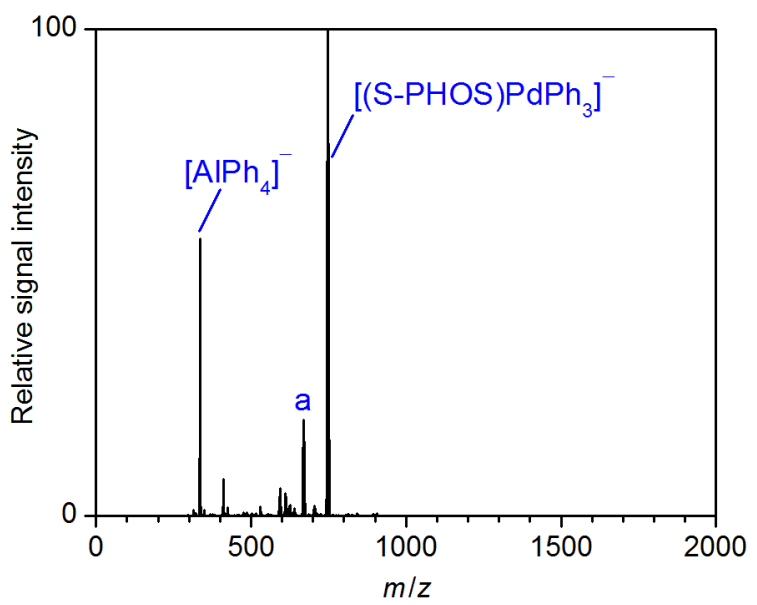

Figure 1.1: Negative-ion mode ESI mass spectrum of a solution of $\mathrm{Pd}(\mathrm{OAc})_{2}(3 \mathrm{mM})$, SPHOS $(6 \mathrm{mM})$, and $\mathrm{PhMgCl}(12 \mathrm{mM})$ in THF $\left(\mathrm{a}=\left[(\mathrm{S}-\mathrm{PHOS}) \mathrm{PdPh}_{2}-\mathrm{H}\right]^{-}\right) .43$

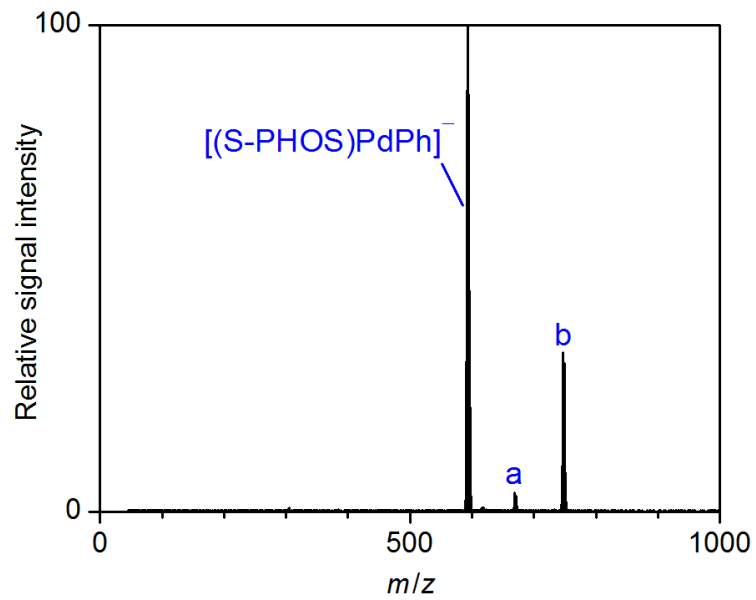

Figure 1.2: Mass spectrum of mass-selected $\left[(\mathrm{S}-\mathrm{PHOS}) \mathrm{PdPh}_{3}\right]^{-}$(b) and its fragment ions produced upon collision-induced dissociation (Acceleration energy $E_{\mathrm{LAB}}=8.0 \mathrm{eV}$, $\left.\mathrm{a}=\left[(\mathrm{S}-\mathrm{PHOS}) \mathrm{PdPh}_{2}-\mathrm{H}\right]^{-}\right)$. 
In all cases, the organopalladate complexes of interest were obtained in relatively low signal intensities, pointing to their correspondingly low concentration in the sample solutions. Conducting the same reaction with $n$ - $\mathrm{BuMgCl}$ did not lead to any detectable palladate complexes at first; the formation of $\left[(\mathrm{S}-\mathrm{PHOS}) \mathrm{PdBu}_{3}\right]^{-}$was only achieved when lithium chloride was added to the mixture to enhance the reactivity of the Grignard reagent. 4 The transmetalation with $n$-BuLi, surprisingly, did not yield any detectable palladate complexes, despite the fact that organyllithium reagents had been found before to react with palladium(II) species to form palladates. $\frac{[22[23]}{2}$ Yet, it is possible that the chosen reaction conditions gave rise to follow-up reactions, or that palladate complexes were actually formed, but could not be detected due to the formation of contact-ion pairs with the lithium counterion. Control experiments with the palladium(0) precursor $\mathrm{Pd}\left(\mathrm{PPh}_{3}\right)_{4}$ did not show any palladium-containing anions.

These first studies made clear that organopalladate(II) complexes are formed in transmetalation reactions and also show the reductive elimination under formation of palladium( $(0)$ species as suggested in section 1.3 , and that the considered anions can be probed by ESI-mass spectrometric methods. Still, the present results raised several interesting questions regarding, for example, the influences of the nature of the phosphine ligands and the organic substituents $R$ on the formation and reactivity of these palladate(II) complexes, which is why further investigations were required.

As the above-shown previous research and preliminary results demonstrate, ESI mass spectrometry is a promising method to identify and characterize ionic intermediates in palladiumcatalyzed reactions. Hence, it was applied as the primary analytical method in the studies presented in this work, and will therefore be explained in more detail in the following. 



\section{Theoretical Background: Electrospray-Ionization Mass Spectrometry}

\subsection{Setup of a Mass Spectrometer}

Mass spectrometry is an analytical method that allows the generation and analysis of ions in the gas phase. Generally, any mass spectrometer consists of the same basic components (figure 2.1. 4 . The analyte is transferred through the sample inlet into the ion source, where gasphase ions are generated. The ions are then separated according to their mass-to-charge $(\mathrm{m} / \mathrm{z})$ ratio by the mass analyzer before they are allowed to pass into the detector. Depending on the instrument type, high vacuum or ultra-high vacuum conditions are applied for the generation and analysis of gas-phase ions in most cases. Ion guides like ion funnels or multipoles ensure an efficient transfer of the ions between the different parts of the mass spectrometer. A computer with a suitable software is used to control the instrument and to process the aquired data. Mass spectra are prepared by plotting the obtained signal intensities against the respective $\mathrm{m} / \mathrm{z}$ ratio of the analyte ions.

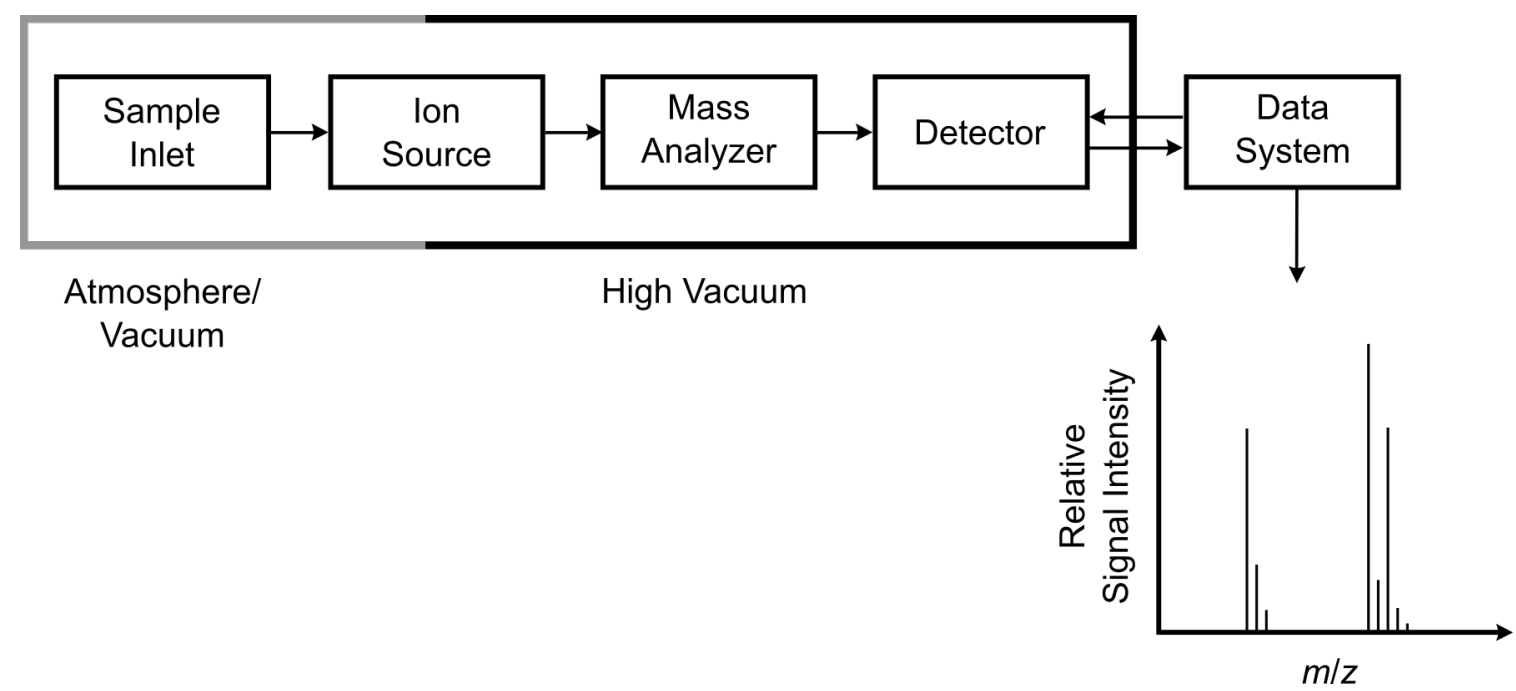

Figure 2.1: Schematic representation of the general setup of a mass spectrometer.45] 


\subsection{Electrospray Ionization}

Electrospray ionization is an ionization technique that was first introduced by Malcolm Dole in the late 1960s. [46] The further development into an efficient and practical ionization method was achieved by John B. Fenn in the 1980s, who was later awarded with the Nobel prize for his research in this field. 47 Compared to other methods, ESI is a mild ionization technique, which allows the transfer of ions into the gas-phase at ambient pressure with little or no fragmentation. [48] It allows the investigation of large, non-volatile molecules directly from the sample solution, which makes it an ideal method for the analysis of biomolecules such as oligonucleotides, oligosaccharides, and proteins. $[45[48$ Due to the mild ionization conditions, ESI is also very well suited to study sensitive organometallic complexes. The first studies utilizing ESI mass spectrometry to characterize organometallic analytes mainly focused on cations, $\underline{\text { [49] }}$ although anionic species were also observed in some cases. $[50]$ In 1996, Lipshutz and coworkers were the first to successfully employ this method for the analysis of organometallic ate complexes. ${ }^{[34]}$ Since then, ESI mass spectrometry has been applied to study a variety

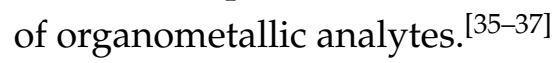

For the generation of gas-phase ions by ESI, the sample solution is slowly fed through a steel capillary, to which a high voltage is applied (figure 2.2). $48,51,52$ 


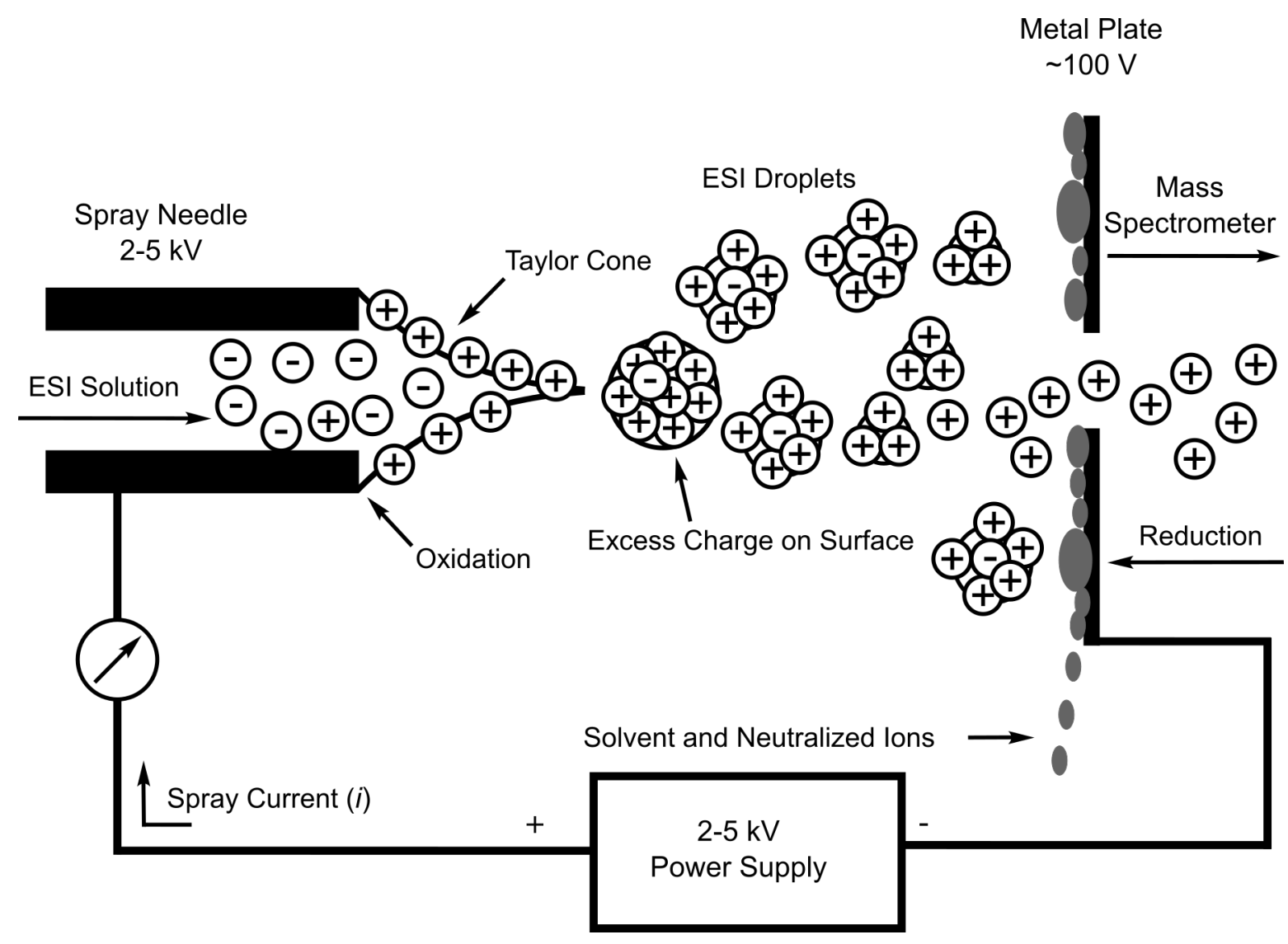

Figure 2.2: Schematic representation of the ESI process. Enrichment of positive analyte ions on the surface leads to the formation of the Taylor cone and to the emission of charged droplets. Evaporation of solvent and Coulomb explosions lead to smaller droplets from which gas phase ions are released. Adapted from reference [48].

The resulting electric field between the capillary and a counter electrode results in an accumulation of positive or negative ions on the surface of the sample solution depending on the polarity of the applied voltage, which leads to the formation of the so-called Taylor cone. Once the Rayleigh limit is reached, i. e. once the Coulomb repulsion between the accumulated ions equals the surface tension of the sample solution, small droplets with an excess charge are released. To minimize the dispersion of the resulting electrospray, a coaxial flow of inert gas is applied. The droplets are guided towards the entrance of the mass spectrometer by the applied electric field, passing through a heated dry gas flow on their way. This leads to further evaporation of solvent and thus to an increasing charge density of the droplets. As a result, smaller droplets are formed through Coulomb explosions as soon as the Coulomb repulsion exceeds the surface tension. The cycle of evaporation and droplet fission continues until droplets with a size of only a few nanometers are formed. From these droplets, gas-phase ions are generated by one of the following mechanisms (figure 2.3). 


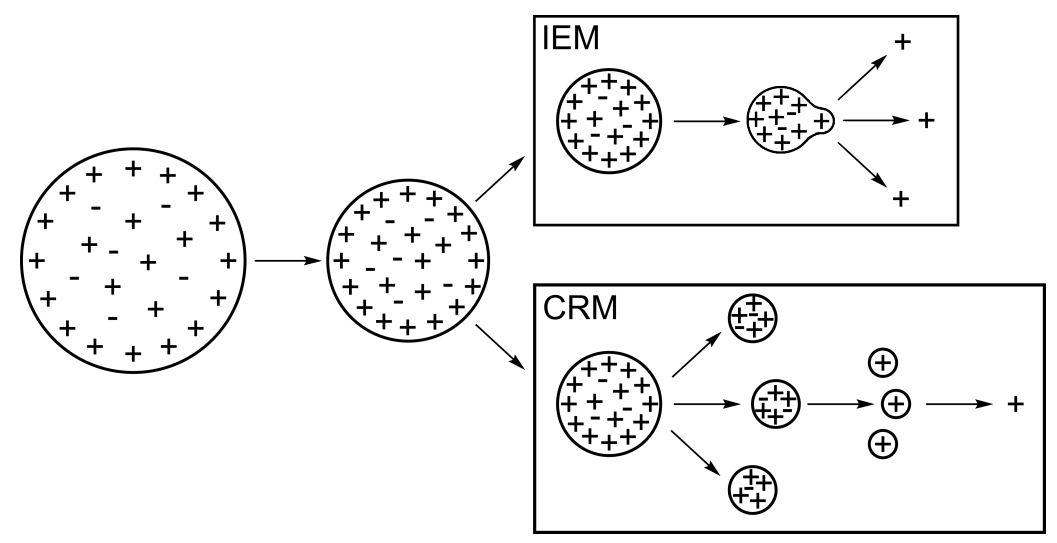

Figure 2.3: Schematic representation of the formation of gas-phase ions from charged droplets: ion evaporation model (top) and charge residue model (bottom). Adapted from reference [53].

The charge residue model (CRM) describes the generation of free ions in the gas phase as a sequence of Coulomb explosion processes, resulting in the formation of smaller and smaller charged droplets. $[46 a \mid 54]$ At the end of this cascade, droplets containing only one analyte ion remain, which ultimately evaporate to dryness. This model is mainly used to describe the transfer of large globular analytes, e.g. charged proteins, into the gas phase. For smaller analyte ions, the ion evaporation model (IEM) is applied. [55[56] Here, the desorption of single solvated ions takes place as soon as the Coulomb repulsion overcomes the surface tension of the droplet. Subsequent collisions with the heated background gas free the analyte ion of residual solvent molecules. A third mechanism, the chain ejection model (CEM), is discussed for non-globular macromolecules such as unfolded proteins. ${ }^{[56]}$ In this case, the largely hydrophobic properties of the chains lead to their migration to the droplet surface, where one chain terminus is then released into the gas phase. The desorption of the remaining protein proceeds stepwise until the whole analyte ion is ejected.

\subsection{Mass Analyzers}

\subsubsection{Time-of-Flight Analyzer}

In a time-of-flight (TOF) analyzer, ions of the charge $q$ are accelerated in an electric field with the acceleration voltage $U$ and subsequently allowed to pass a field-free drift region. ${ }^{[57-[59]}$ The electrical energy $E_{\mathrm{el}}=q \cdot U$ (with $q=e \cdot z$ ) transferred to a specific ion corresponds to its kinetic energy $E_{\mathrm{kin}}=\frac{1}{2} m v^{2}$. The velocity $v$ of the ion stays constant during its passage through the field-free region and is given by the length of the drift region $L$ divided by the flight time $t$. Thus, the $m / z$ ratio of a specific ion can be deduced from the time it requires to pass the length 
of the drift region (equations (2.1) and (2.2)).

$$
\begin{array}{r}
e \cdot z \cdot U=\frac{1}{2} m \cdot\left(\frac{L}{t}\right)^{2} \\
\frac{m}{z}=\frac{2 U e t^{2}}{L^{2}}
\end{array}
$$

As not all ions of a certain $m / z$ ratio enter the acceleration stage with exactly the same velocity and at the same position, it follows that the resulting kinetic energies after acceleration differ slightly. This leads to deviations in the recorded time of flight and, as a consequence, to a worsened mass resolution. To minimize errors arising from these slight differences, a reflector can be applied to focus the incoming ions in time. A simple reflector consists mainly of a retarding electric field, in which incoming ions are decelerated and ultimately reflected to pass through the drift region a second time before they reach the detector. As faster ions pass deeper into the reflector field before being reflected, deviations in the original velocity are equalized, which results in a significantly enhanced mass resolution (figure 2.4).

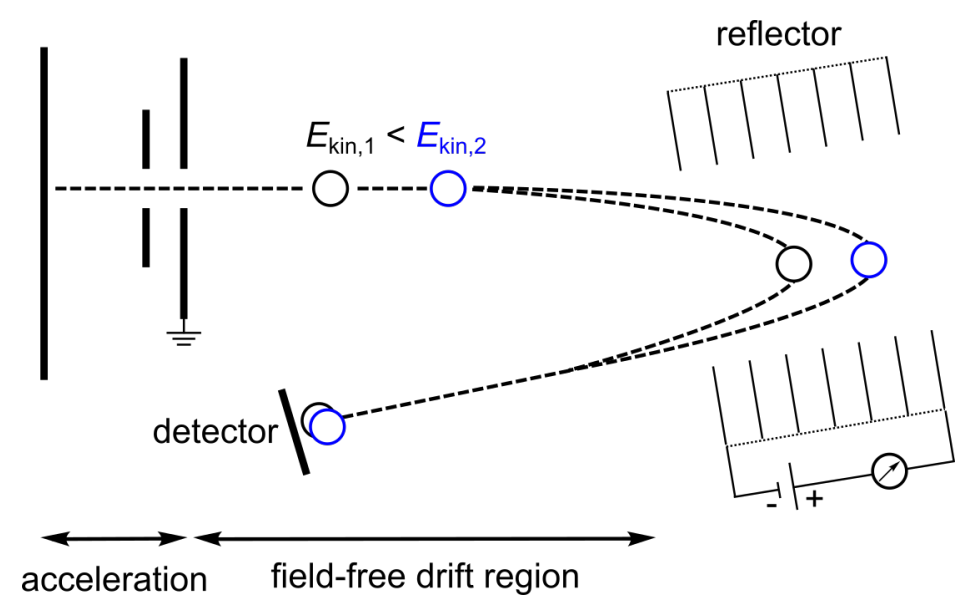

Figure 2.4: Schematic representation of a reflector-TOF analyzer. 4 [459]

\subsubsection{Quadrupole Analyzers}

\section{Linear Quadrupole Analyzer}

The principle of a linear quadrupole analyzer was first introduced by Paul and coworkers in 1953. [60] In a linear quadrupole analyzer, four cylindrically or hyperbolically shaped rods are positioned in a square arrangement. $[45]$ Potentials, consisting of a radio frequency (RF) and a direct current (DC) component, are applied to the rods in such a way that the oppositely placed rods are held at the same potential. This exerts attractive or repulsive forces, respectively, on ions entering the quadrupole parallel to the rods (along the $\mathrm{z}$ axis), causing an oscillatory motion of the ions in the xy plane. The resulting trajectories of the ions can be unstable or stable, depending on wether the ions hit the rods during their oscillation or not. A stable 
trajectory is given when the oscillation of the considered ion is held within a limited amplitude (smaller than the distance between the rods) in the xy plane, which depends on the $m / z$ ratio of a given ion as well as on the applied voltages. Conditions that ensure stable ion trajectories can be deduced from the Mathieu equations. 61] When the DC voltage is set to zero, all ions are allowed to pass through the quadrupole, which in this case works as an ion guide. Setting both $\mathrm{RF}$ and DC voltages to fixed values turns the analyzer into a mass filter, which can be passed only by ions of a certain $m / z$ ratio. In contrast, a scan over a range of values for the $m / z$ ratio is possible when the applied voltages are varied continuously.

\section{Three-Dimensional Quadrupole Ion Trap}

The three-dimensional ion trap was, as the linear quadrupole analyzer, developed by Wolfgang Paul, who was awarded with the Nobel prize for his achievements in 1989. [62] Its working principle resembles closely that of a linear quadrupole mass analyzer, except that ions can be stored within the ion trap for a certain amount of time rather than merely passing through the device. In a three-dimensional quadrupole ion trap, a symmetrical, three-dimensional RF quadrupole field is generated between two hyperbolic end cap electrodes and a ring electrode by applying an RF voltage to the ring electrode while the end caps are grounded (figure 2.5. . $\frac{.65] 63}{4}$ As a result, entering ions oscillate along the $\mathrm{z}$ axis as well as in the $\mathrm{xy}$ plane, which allows for stable trajectories inside the confines of the ion trap. The frequency of these oscillations depends on the amplitude and the frequency of the RF voltage on the ring electrode as well as on the $\mathrm{m} / \mathrm{z}$ ratio of the considered ions. Again, conditions for stable trajectories can be derived from the Mathieu equations. ${ }^{[61]}$ To trap the ions in the potential well produced by the quadrupole field, their kinetic energy upon entering the ion trap needs to be reduced. To this end, ions are allowed to collide with a background gas such as helium, thus losing a part of their kinetic energy, which facilitates a more efficient ion capture. To use the ion trap as a mass analyzer, all ions inside a chosen range of $m / z$ ratios are stored within the ion trap and then released successively by resonant ejection. For this purpose, a supplementary RF voltage is applied to the endcap electrodes, which matches the frequency of the axial oscillation of ions of a certain $\mathrm{m} / \mathrm{z}$ ratio. These oscillations are thus excited, and the ions are eventually expelled from the ion trap towards the detector. By continually varying the auxiliary voltage, a full scan over the whole $m / z$ range is realized. Alternatively, all ions can be ejected except for those of a defined $m / z$ ratio, which can then be subjected to gas-phase experiments.

\subsection{Investigating Reactivities of Ions in the Gas-Phase}

\subsubsection{Unimolecular Reactions: Gas-Phase Fragmentation}

In addition to single-stage mass-spectrometric methods $\left(\mathrm{MS}^{1}\right)$, individual ions can be isolated and further characterized using $\mathrm{MS}^{2}$ experiments. For this purpose, ions of interest are massselected and subsequently exposed to an excitation voltage $V_{\text {Exc }}$ inside the collision cell of a 


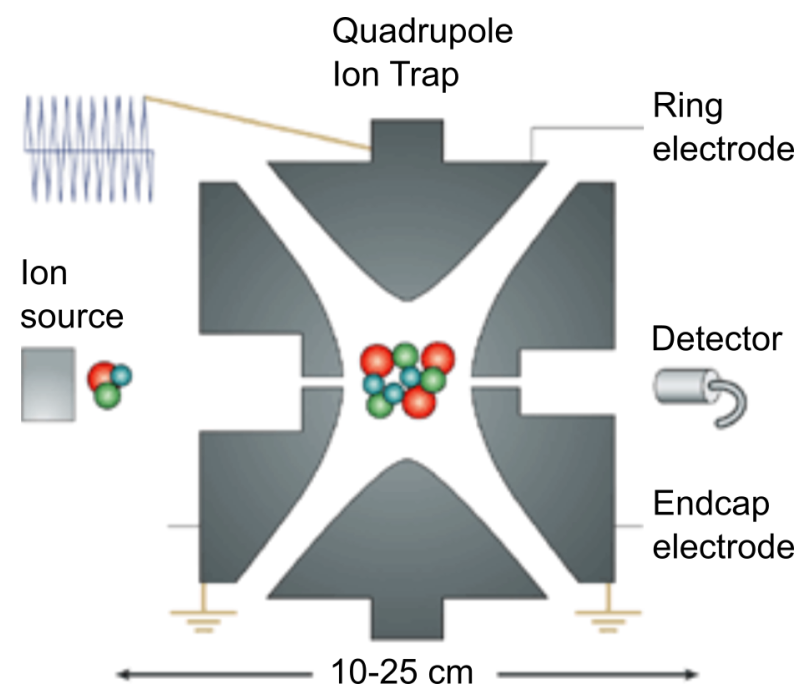

Figure 2.5: Schematic representation of a three-dimensional quadrupole ion trap. Adapted from reference [64].

mass spectrometer. $[\sqrt[45]]{ }$ In consequence of the excitation, the ions gain kinetic energy and experience collisions with the background gas present in the collision cell, usually helium or nitrogen, resulting in their fragmentation. This process is referred to as collision-induced dissociation (CID). Depending on the instrument, resulting fragment ions can again be mass-selected and subjected to further fragmentation in $\mathrm{MS}^{n}$ experiments. Fragmentation patterns derived from such studies can provide valuable information on the structure of unknown ions. Furthermore, reactivities of selected individual species in the gas-phase can be investigated without the influence of counterions or solvent molecules. It is also possible to derive estimates for thermodynamic data from energy-dependent CID experiments. $35 \mathrm{a}[45] 65,66]$

\subsubsection{Bimolecular Reactions: Ion-Molecule Reactions Inside the Ion Trap}

Gaining insight into bimolecular reactions of well-defined reaction partners in the gas phase can be of great value in mechanistic studies of, for example, metal-catalyzed transformations involving ionic intermediates. $\frac{[6768]}{6}$ Ion trap mass spectrometers are well-suited for this kind of experiments, as they are capable of storing ions without significant loss of signal intensity over a relatively long time and can tolerate comparatively high concentrations of neutral reactant gas within the reaction chamber. Exposing mass-selected ions to a neutral substrate gas inside a quadrupole ion trap can be realized by directly introducing the reactant gas into the reaction chamber using a leak valve. ${ }^{68]}$ However, this can sometimes lead to complications regarding the reliable determination of the partial pressure of the substrate gas. An alternative method which avoids these difficulties is the preparation of a well-defined mixture of the substrate gas with helium, which is then added to the reaction chamber at a constant flow rate. ${ }^{[69]}$ Massselected ions of interest can then be kept inside the reaction chamber for defined storage times and their reaction with the substrate gas can be monitored based on the relative signal intensites of precursor and product ions. 


\subsection{ESI Mass Spectrometry of Organometallic Analytes: Advantages and Limitations}

The ESI process offers the possibility for ionic (or easily ionized) species to be transferred directly from the sample solution into the gas phase and analyzed with regard to their mass-tocharge ratio. The elemental constitution of single components of sometimes complex mixtures can thus be identified unambiguously from their exact mass-to-charge ratio and isotopic pattern. This way, short-lived intermediates or species that display only low concentrations in the sample solution can be detected as well. Furthermore, the composition of sample solutions can be followed in real-time if, for example, the course of a chemical reaction is to be examined. Monitoring the relative signal intensities over time can provide qualitative information on the reaction kinetics.

If the employed instrument is equipped with a collision cell, ESI mass specrometry offers the possibility to analyze ions of choice with regard to their unimolecular and bimolecular reactivity (section 2.4). Especially if, for example, the identity of the catalytically active intermediate(s) in a reaction mixture is to be clarified, the possibility to test the reactivities of individual species independently and without competing reactions or solvent effects can be of great value.

One major drawback of ESI mass spectrometry is that only analytes are accessible that are already ionic or can be ionized easily. Yet, in many cases this problem can be circumvented by

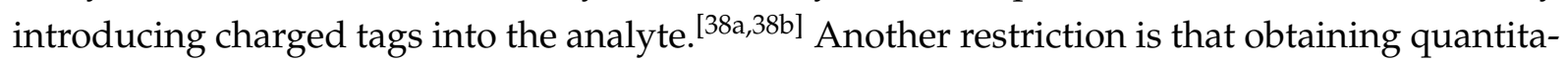
tive information from ESI-mass spectrometric experiments is only possible to a limited degree. The relative signal intensity of the analyte ions does not correspond linearly to their relative concentrations in solution, as the efficiency of their transfer into the gas phase is dependent on their surface activity among other factors. Also, mass discrimination effects during the transfer of the gas-phase ions inside the mass spectrometer can distort their relative amounts even further. Finally, the concentration increase during the ESI process can give rise to aggregation processes and eventually the formation of adduct ions that were not part of the original sample solution. However, it is possible to gain semi-quantitative information, for example if the signal intensities of certain ions increase or decrease over time. When analyzing sensitive organometallics, oxidation or hydrolysis can pose another problem. The use of gas-tight syringes for the transfer of sample solutions into the ESI source and an increased sample concentration can help to reduce these influences. 


\section{Objective}

Though anionic palladium species are widely assumed to act as reactive intermediates in a number of palladium-catalyzed cross-coupling reactions, their characterization is far from complete. As these reactions are of outstanding importance in organic synthesis, a more detailed understanding of the formation and reactivity of potentially involved anionic palladium complexes is desirable. In the present work, ESI mass spectrometry shall be used among other techniques to characterize anionic palladium species and to gather information regarding their stability and reactivity in order to better understand their role in $\mathrm{C}-\mathrm{C}$ coupling reactions.

Organopalladium complexes are formed during the activation of palladium(II) precursors by transmetalating agents in a reaction sequence of transmetalation and reductive elimination, which competes with the alternative reduction of the precursor by a phosphine ligand (if present). To determine the role of palladate ions in this context, the analysis of the influence of reaction conditions, ligands, and transmetalation reagents shall shed light on the factors contributing to the formation of $\left[\mathrm{L}_{n} \mathrm{PdR}_{3}\right]^{-}$anions. Additionally, the subsequent reductive elimination step shall be further investigated by means of CID experiments.

The formation of $\left[\mathrm{L}_{n} \mathrm{PdX}\right]^{-}$anions is one popular explanation for the beneficial effects of halide salts as additives in cross-coupling reactions. The electron-poor catalyst $\left[\operatorname{Pd}\left(\operatorname{PAr}_{3}^{\mathrm{F}}\right)_{3}\right]$ poses a suitable model system to study such anions. In the present work, the formation, stability, and unimolecular reactivity of various anions of the type $\left[\mathrm{L}_{n} \mathrm{PdX}\right]^{-}$will be investigated by ESI mass spectrometry and CID experiments. Furthermore, the formation equilibrium of $\left[\mathrm{L}_{n} \mathrm{PdBr}\right]^{-}$is to be analyzed quantitatively by electrical conductometry as well as concentration-dependent NMR experiments. Finally, the oxidative addition of organyl halides to these complexes will be examined systematically, using ESI-mass spectrometric experiments from solution as well as time-dependent studies of bimolecular gas-phase reactions.

In the presence of 1,3-diene ligands, anionic organopalladium species have been proposed as essential intermediates in alkyl-alkyl cross-coupling reactions, following a transmetalation-first catalytic cycle. It is therefore another goal of the present work to validate the presence of such anions, to gain information on their structure and stability, and to test their reactivity against organyl electrophiles. As the electron-poor catalyst $\left[\mathrm{Pd}\left(\mathrm{PAr}_{3}^{\mathrm{F}}\right)_{3}\right]$ has been found to form stable anionic palladium(0) complexes with halide ligands, it might also be possible to generate stable organopalladate(0) complexes with this ligand and, potentially, to realize alkyl-alkyl cross-coupling reactions. The formation of such palladates and their reactions with alkyl electrophiles shall be explored with the help of ESI-mass spectrometric experiments and gas-phase studies. 



\section{Results and Discussion}

\subsection{Organopalladate Complexes [(S-PHOS) $\left.\mathrm{PdR}_{3}\right]^{-}$as Intermediates in Precatalyst Activation Processes}

The formation of palladate complexes of the type $\left[(\mathrm{S}-\mathrm{PHOS}) \mathrm{PdR}_{3}\right]^{-}$, with $\mathrm{R}=n-\mathrm{Bu}, \mathrm{Ph}, \mathrm{Bn}$, and $4-\mathrm{Me}-\mathrm{C}_{6} \mathrm{H}_{4}-\mathrm{CH}_{2}$, from palladium acetate and Grignard reagents, in the presence of the corresponding phosphine ligand and, for $\mathrm{R}=n-\mathrm{Bu}$, lithium chloride, was observed in previous ESI-mass spectrometric studies. The use of $n$ - $\mathrm{BuLi}$ as a transmetalating reagent, in contrast, did not lead to the complexes of interest (section 1.3). Applying $n-\mathrm{BuZnCl} \cdot \mathrm{LiCl}$ as a third alternative also did not lead to detectable palladate complexes, probably reflecting the lower reactivity of the organozinc reagent compared to the Grignard reagent. The studies presented herein were undertaken to gain a more detailed understanding of the stability and unimolecular reactivity of palladate complexes depending on the nature of the ligands, the organic substituents, and the reaction conditions.

\subsubsection{Transmetalation of the Palladium(II) Precursor: Influence of the Reaction Conditions on the Formation and Stability of [(S-PHOS)PdR $]_{3}^{-}$}

As the reduction of palladium(II) precatalysts to catalytically active palladium(0) species over a transmetalation/reductive elimination pathway competes with a reduction of the palladium precursor by the added phosphine ligand, [24a] the first interesting question was how the reaction time of the palladium(II) precursor with the phosphine ligand before the addition of the transmetalation agent influences the formation of $\left[(\mathrm{S}-\mathrm{PHOS}) \mathrm{PdR}_{3}\right]^{-}$. To answer this, a solution of $\mathrm{Pd}(\mathrm{OAc})_{2}$ with two equivalents of S-PHOS was stirred for $1 \mathrm{~h}$ and then treated with $\mathrm{PhMgCl}$ at room temperature. The overall signal intensity and especially the signal intensity of [(S-PHOS)PdPh $]^{-}$was decreased compared to the experiments with only 5-10 min reaction time of the precatalyst with the ligand. The decrease of $\left[(\mathrm{S}-\mathrm{PHOS}) \mathrm{PdR}_{3}\right]^{-}$is in line with the expectations, as a longer reaction time with the phosphine ligand should lead to a further decrease of palladium(II) species in the sample solution that are able to form the said organopalladate complexes. Still, the presence of $\left[(\mathrm{S}-\mathrm{PHOS}) \mathrm{PdR}_{3}\right]^{-}$demonstrated that the phosphine ligand did not suffice to achieve a quantitative reduction of the palladium acetate to palladium( 0 ) even after $1 \mathrm{~h}$ of reaction time, although the electron-rich nature of the S-PHOS ligand should allow for a relatively fast reduction compared to other popular phosphine ligands. It follows that the role of the transmetalation/reductive elimination pathway for the reduction 
of the palladium precatalyst becomes less important if the stirring times of the palladium(II) precursor with the phosphine ligand are long.

Another factor that may have an effect on the formation of $\left[(\mathrm{S}-\mathrm{PHOS}) \mathrm{PdR}_{3}\right]^{-}$complexes is the reaction temperature. It was shown for different turbo Grignard reagents $\mathrm{RMgCl} \cdot \mathrm{LiCl}$, $\mathrm{R}=\mathrm{Me}, \mathrm{Et}, n-\mathrm{Bu}$, and $t-\mathrm{Bu}$, that decreasing the temperature to $273 \mathrm{~K}$ suppressed the formation of $\left[(\mathrm{S}-\mathrm{PHOS}) \mathrm{PdR}_{3}\right]^{-}$completely. $\frac{[70]}{[7}$ The formation of neutral organopalladium species with two organyl ligands can of course not be fully excluded by mass spectrometric analysis; yet, the absence of singly transmetalated species $\left[(\mathrm{S}-\mathrm{PHOS})_{n} \mathrm{PdR}\right]^{+}$in the ESI mass spectra in the cationic mode indicated that the transmetalation reaction did not take place at all at lower temperatures.

\subsubsection{Influence of the Phosphine Ligand on the Stability of Organopalladate Complexes}

To compare palladate complexes containing different phosphine ligands with varying electronic and sterical properties, the S-PHOS ligand was exchanged for $\mathrm{PPh}_{3}$ and its trifluoromethylated derivative $\mathrm{PAr}_{3}^{\mathrm{F}}$, respectively (chart2).

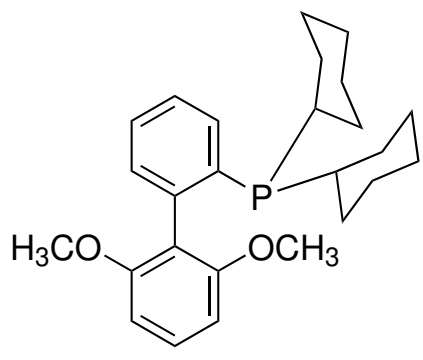

S-PHOS<smiles>c1ccc(P(c2ccccc2)c2ccccc2)cc1</smiles>

$\mathrm{PPh}_{3}$<smiles>FC(F)(F)c1cc(P(c2cc(C(F)(F)F)cc(C(F)(F)F)c2)c2cc(C(F)(F)F)cc(C(F)(F)F)c2)cc(C(F)(F)F)c1</smiles>

$\operatorname{PAr}_{3}$

Chart 2: Phosphine ligands applied for the generation of palladate(II) complexes.

While the S-PHOS-containing complex $\left[(\mathrm{S}-\mathrm{PHOS}) \mathrm{PdPh}_{3}\right]^{-}$displayed satisfactory signal intensities and was relatively stable over time, the analogous palladate $\left[\left(\mathrm{PPh}_{3}\right) \mathrm{PdPh}_{3}\right]^{-}$showed lower signal intensities in the ESI mass spectra and was only stable for approximately $30 \mathrm{~min}$. With the electron-poor $\operatorname{PAr}_{3}^{\mathrm{F}}$, no mononuclear palladate(II) species could be observed at all. The mass spectra were rather dominated by oligonuclear species with palladium centers in mixed oxidation states, such as $\left[\left(\mathrm{PAr}_{3}^{\mathrm{F}}\right)_{2} \mathrm{Pd}_{3}\left(\mathrm{PAr}_{2}^{\mathrm{F}}\right)_{3}\right]^{-}$or $\left[\left(\mathrm{PAr}_{3}^{\mathrm{F}}\right)_{4} \mathrm{Pd}_{4} \mathrm{Cl}_{2}\left(\mathrm{PAr}_{2}^{\mathrm{F}}\right)\right]^{-}$. The $\operatorname{PAr}_{2}^{\mathrm{F}}$ fragments incorporated in these palladate complexes resulted from decomposition reactions of the phosphine ligand, which were presumably brought about by the Grignard reagent. When palladium acetate was treated with $\mathrm{PhMgCl}$ without any added phosphine ligand in a control experiment, no stable palladate complexes were formed and a fast precipitation of palladium black was observed. When the precipitate was analyzed by matrix-assisted laser desorption ionization (MALDI) mass spectrometry, only mononuclear palladium species were detected. 
Next, the palladate complexes $\left[(\mathrm{S}-\mathrm{PHOS}) \mathrm{PdPh}_{3}\right]^{-}$and $\left[\left(\mathrm{PPh}_{3}\right) \mathrm{PdPh}_{3}\right]^{-}$were compared with regard to their gas-phase fragmentation behavior. It was found that the latter tended to lose its phosphine ligand easily at relatively low acceleration energies $E_{\mathrm{LAB}}$ (equation 4.1 , figure 4.1). The reductive elimination of $\mathrm{Ph}_{2}$ could also be observed as a minor fragmentation pathway (equation (4.2)). A second loss of $\mathrm{Ph}_{2}$ also yielded [ $\left.\mathrm{Pd}\left(\mathrm{PPh}_{2}\right)\right]^{-}$(equation (4.3)), while $\left[\mathrm{PdPh}_{2}-\mathrm{H}\right]^{-}$presumably originated from a combination of a ligand dissociation reaction and the loss of one benzene molecule (equation (4.4)).

$$
\begin{aligned}
& {\left[\left(\mathrm{PPh}_{3}\right) \mathrm{PdPh}_{3}\right]^{-} \longrightarrow\left[\mathrm{PdPh}_{3}\right]^{-}+\mathrm{PPh}_{3}} \\
& {\left[\left(\mathrm{PPh}_{3}\right) \mathrm{PdPh}_{3}\right]^{-} \longrightarrow\left[\left(\mathrm{PPh}_{3}\right) \mathrm{PdPh}\right]^{-}+\mathrm{Ph}_{2}} \\
& {\left[\left(\mathrm{PPh}_{3}\right) \mathrm{PdPh}_{3}\right]^{-} \longrightarrow\left[\mathrm{Pd}\left(\mathrm{PPh}_{2}\right)\right]^{-}+2 \mathrm{Ph}_{2}} \\
& {\left[\left(\mathrm{PPh}_{3}\right) \mathrm{PdPh}_{3}\right]^{-} \longrightarrow\left[\mathrm{PdPh}_{2}-\mathrm{H}\right]^{-}+\mathrm{PPh}_{3}+\mathrm{PhH}}
\end{aligned}
$$

In contrast, previous results for the S-PHOS-containing complex had already shown the reductive elimination of $\mathrm{Ph}_{2}$ as the main fragmentation channel, with the loss of one benzene molecule being the only other fragmentation pathway (equations 4.5 , and (4.6).

$$
\begin{aligned}
& {\left[(\mathrm{S}-\mathrm{PHOS}) \mathrm{PdPh}_{3}\right]^{-} \longrightarrow[(\mathrm{S}-\mathrm{PHOS}) \mathrm{PdPh}]^{-}+\mathrm{Ph}_{2}} \\
& {\left[(\mathrm{~S}-\mathrm{PHOS}) \mathrm{PdPh}_{3}\right]^{-} \longrightarrow\left[(\mathrm{S}-\mathrm{PHOS}) \mathrm{PdPh}_{2}-\mathrm{H}\right]^{-}+\mathrm{PhH}}
\end{aligned}
$$

Repeating the collision-induced dissociation experiments at a higher acceleration energy resulted in only one additional fragmentation channel that yielded $\left[\mathrm{Pd}\left(\mathrm{PCy}_{2}\right)\right]^{-}(\mathrm{Cy}=$ cyclohexyl $)$ through a ligand decomposition reaction (figure 4.2, see also figure 1.2). A dissociation of the S-PHOS ligand was not achieved.

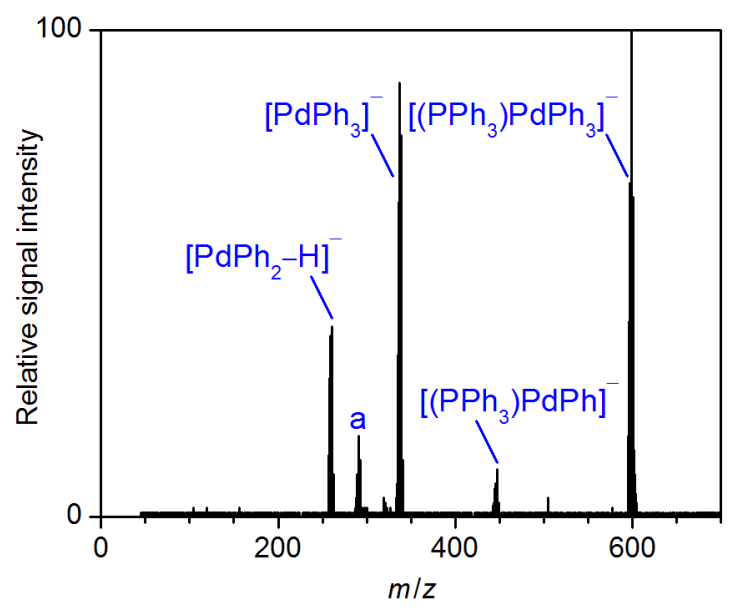

Figure 4.1: Mass spectrum of mass-selected $\left[\left(\mathrm{PPh}_{3}\right) \mathrm{PdPh}_{3}\right]^{-}$and its fragment ions produced upon collision-induced dissociation $\left(E_{\mathrm{LAB}}=5.0 \mathrm{eV}, \mathrm{a}=\left[\mathrm{Pd}\left(\mathrm{PPh}_{2}\right)\right]^{-}\right)$.

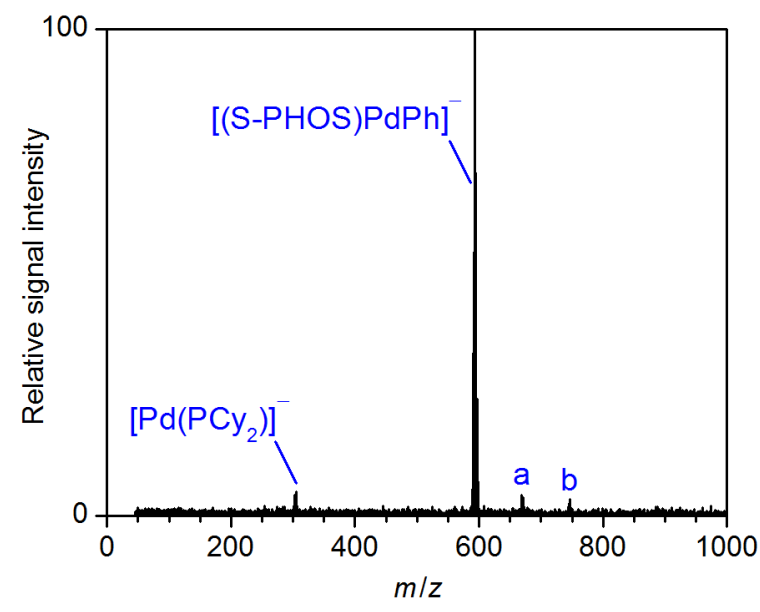

Figure 4.2: Mass spectrum of mass-selected $\left[(\mathrm{S}-\mathrm{PHOS}) \mathrm{PdPh}_{3}\right]^{-}$(b) and its fragment ions produced upon collision-induced dissociation $\left(E_{\mathrm{LAB}}=14.0 \mathrm{eV}, \mathrm{a}=\left[(\mathrm{S}-\mathrm{PHOS}) \mathrm{PdPh}_{2}-\mathrm{H}\right]^{-}\right)$. 
These results demonstrate that the S-PHOS ligand binds more strongly to the palladium(II) center than the $\mathrm{PPh}_{3}$ ligand in the analogous complex. Thus, the lower stability of the latter can be explained by the higher probability for ligand dissociation reactions in solution, resulting in coordinatively unsaturated complexes, which then undergo further decomposition reactions. In addition to the stronger palladium-ligand bond in case of the S-PHOS-containing species, the sterically demanding S-PHOS ligand may also shield the complex and thereby contribute a kinetic stabilization.

\subsubsection{Influence of the Organic Substituent on the Formation of [(S-PHOS)PdR $]^{-}$ and the Reductive Elimination of $\mathbf{R}_{2}$}

To study the tendencies of different organic ligands $\mathrm{R}$ to be incorporated in palladate(II) complexes, equimolar amounts of two different Grignard reagents $\mathrm{RMgCl}$, with $\mathrm{R}=n-\mathrm{Bu}, \mathrm{Ph}$, and $\mathrm{Bn}$, were applied as transmetalation reagents. When $\mathrm{PhMgCl}$ and $\mathrm{BnMgCl}$ were present in the sample solutions, the preferably formed organopalladate was [(S-PHOS)PdBnPh 2$]^{-}$, while $\left[(\mathrm{S}-\mathrm{PHOS}) \mathrm{PdBn}_{2} \mathrm{Ph}\right]^{-}$and $\left[(\mathrm{S}-\mathrm{PHOS}) \mathrm{PdPh}_{3}\right]^{-}$were present with lower signal intensities (figure 4.3). With mixtures of $\mathrm{PhMgCl}$ and $n-\mathrm{BuMgCl}$, [(S-PHOS) $\left.\mathrm{PdPh}_{2}-\mathrm{H}\right]^{-}$was the base peak, whereas the organopalladate complexes bearing three organyl ligands displayed only small signal intensities. The most abundant of these species was [(S-PHOS)PdBuPh$]^{-}$, followed by $\left[(\mathrm{S}-\mathrm{PHOS}) \mathrm{PdBu}_{2} \mathrm{Ph}\right]^{-}$and $\left[(\mathrm{S}-\mathrm{PHOS}) \mathrm{PdPh}_{3}\right]^{-}$. Competition experiments with $\mathrm{BnMgCl}$ and $n-\mathrm{BuMgCl}$ did not show a clear preference for one of the organyl residues to be incorporated into palladate complexes. In this case, the mixed complexes [(S-PHOS)PdBn $\left.{ }_{2} \mathrm{Bu}\right]^{-}$ and $\left[(\mathrm{S}-\mathrm{PHOS}) \mathrm{PdBnBu}_{2}\right]^{-}$were present with comparable signal intensities. The overall signal intensities were especially low and unstable in experiments where $n-\mathrm{BuMgCl}$ was involved, reflecting the low tendency of the butyl ligand to form stable palladate complexes (section 1.5).

Gas-phase fragmentation of $\left[(\mathrm{S}-\mathrm{PHOS}) \mathrm{PdBnPh}_{2}\right]^{-}$and $\left[(\mathrm{S}-\mathrm{PHOS}) \mathrm{PdBuPh}_{2}\right]^{-}$yielded the product ions of the reductive elimination of $\mathrm{Ph}_{2},[(\mathrm{~S}-\mathrm{PHOS}) \mathrm{PdBn}]^{-}$and $[(\mathrm{S}-\mathrm{PHOS}) \mathrm{PdBu}]^{-}$, respectively, as main products (equation (4.7), figure 4.4 for the example of [(S-PHOS) $\left.\mathrm{PdBnPh}_{2}\right]^{-}$). Other fragmentation channels included the reductive elimination of $\mathrm{BnPh}$, the formation of $[(\mathrm{S}-\mathrm{PHOS}) \mathrm{Pd}-\mathrm{H}]$ presumably by a reductive elimination of $\mathrm{Ph}_{2}$ combined with the loss of a toluene molecule, the formation of $\left[\mathrm{Pd}\left(\mathrm{PCy}_{2}\right)\right]^{-}$in a ligand decomposition reaction, and the dissociation of a free benzyl anion (equations 4.8 to 4.10$)$ ).

$$
\begin{aligned}
& {\left[(\mathrm{S}-\mathrm{PHOS}) \mathrm{PdBnPh}_{2}\right]^{-} \longrightarrow[(\mathrm{S}-\mathrm{PHOS}) \mathrm{PdBn}]^{-}+\mathrm{Ph}_{2}} \\
& {\left[(\mathrm{~S}-\mathrm{PHOS}) \mathrm{PdBnPh}_{2}\right]^{-} \longrightarrow[(\mathrm{S}-\mathrm{PHOS}) \mathrm{PdPh}]^{-}+\mathrm{BnPh}} \\
& {\left[(\mathrm{S}-\mathrm{PHOS}) \mathrm{PdBnPh}_{2}\right]^{-} \longrightarrow[(\mathrm{S}-\mathrm{PHOS}) \mathrm{Pd}-\mathrm{H}]^{-}+\mathrm{Ph}_{2}+\mathrm{BnH}} \\
& {\left[(\mathrm{S}-\mathrm{PHOS}) \mathrm{PdBnPh}_{2}\right]^{-} \longrightarrow\left[(\mathrm{S}-\mathrm{PHOS}) \mathrm{PdPh}_{2}\right]+\mathrm{Bn}^{-}}
\end{aligned}
$$




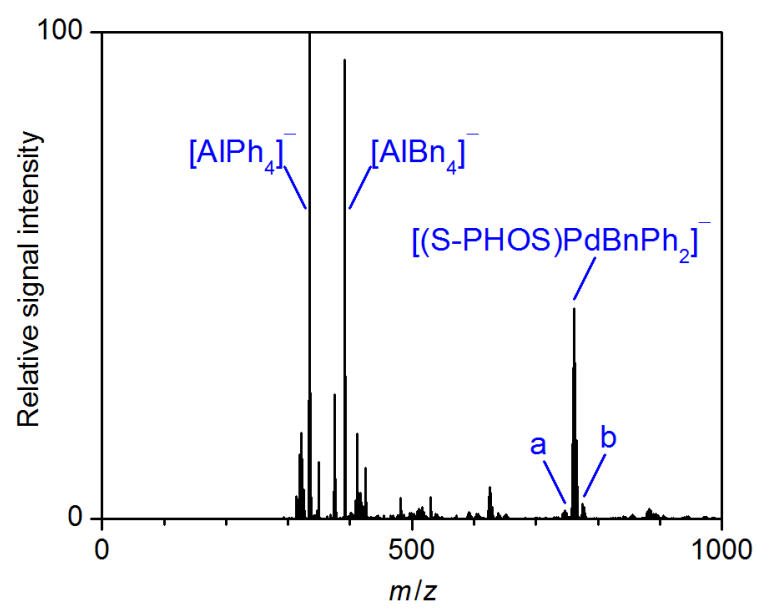

Figure 4.3: Negative-ion mode ESI mass spectrum of a solution of $\mathrm{Pd}(\mathrm{OAc})_{2}(3 \mathrm{mM})$, SPHOS $(6 \mathrm{~mm}), \mathrm{PhMgCl}(7.5 \mathrm{mM})$, and $\mathrm{Bn}-$ $\mathrm{MgCl}(7.5 \mathrm{mM})$ in THF $\left(\mathrm{a}=\left[(\mathrm{S}-\mathrm{PHOS}) \mathrm{PdPh}_{3}\right]^{-}\right.$, $\left.\mathrm{b}=\left[(\mathrm{S}-\mathrm{PHOS}) \mathrm{PdBn}_{2} \mathrm{Ph}\right]^{-}\right)$. 43

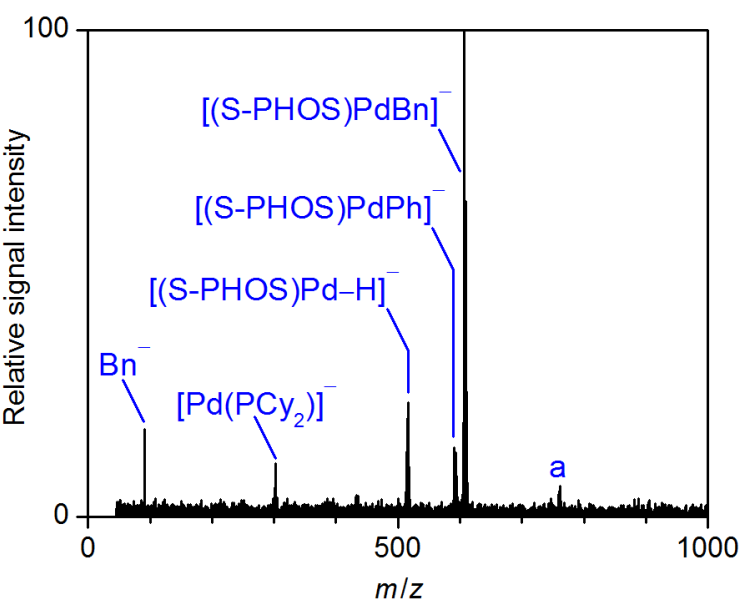

Figure 4.4: Mass spectrum of mass-selected $\left[(\mathrm{S}-\mathrm{PHOS}) \mathrm{PdBnPh}_{2}\right]^{-}$(a) and its fragment ions produced upon collision-induced dissociation $\left(E_{\mathrm{LAB}}=18.0 \mathrm{eV}\right)$.

The reductive elimination of $\mathrm{Ph}_{2}$ from the mixed palladate $\left[(\mathrm{S}-\mathrm{PHOS}) \mathrm{PdBnPh}_{2}\right]^{-}$set in at considerably lower acceleration energies $E_{\mathrm{LAB}}$ than the elimination of the alternative mixed coupling product $\mathrm{BnPh}$, as was seen in energy-dependent gas-phase fragmentation experiments (figure 4.5). For $\left[(\mathrm{S}-\mathrm{PHOS}) \mathrm{PdBuPh}_{2}\right]^{-}$, no reductive elimination of $\mathrm{BuPh}$ or other alternative fragmentation channels could be observed at all before further increase of the acceleration energy led to a breakdown of the overall signal intensity (figure 4.6). The acceleration energies needed for the reductive elimination of $\mathrm{Ph}_{2}$ were quite similar for [(S- $\left.\left.\mathrm{PHOS}\right) \mathrm{PdBnPh}_{2}\right]^{-}$, $\left[(\mathrm{S}-\mathrm{PHOS}) \mathrm{PdBuPh}_{2}\right]^{-}$, and $\left[(\mathrm{S}-\mathrm{PHOS}) \mathrm{PdPh}_{3}\right]^{-}$.

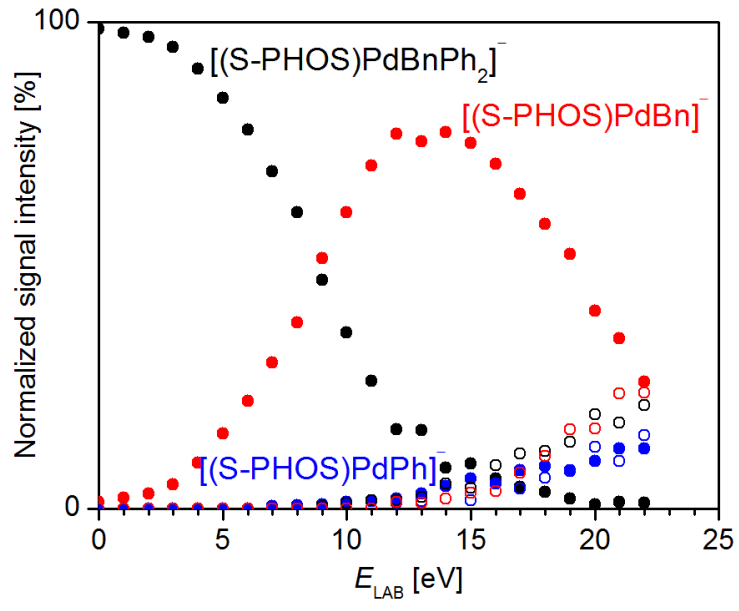

Figure 4.5: Normalized signal intensities of mass-selected $\left[(\mathrm{S}-\mathrm{PHOS}) \mathrm{PdBnPh}_{2}\right]^{-}$(black) and its fragment ions [(S-PHOS)PdBn] ${ }^{-}$(red), [(S-PHOS)PdPh $]^{-}$(blue), [(S-PHOS)Pd-H $]^{-}$ (black, open symbols), $\mathrm{Bn}^{-}$(red, open symbols), and $\left[\mathrm{Pd}\left(\mathrm{PCy}_{2}\right)\right]^{-}$(blue, open symbols) produced upon collision-induced dissociation, plotted against the applied collision energy $E_{\mathrm{LAB}}$.

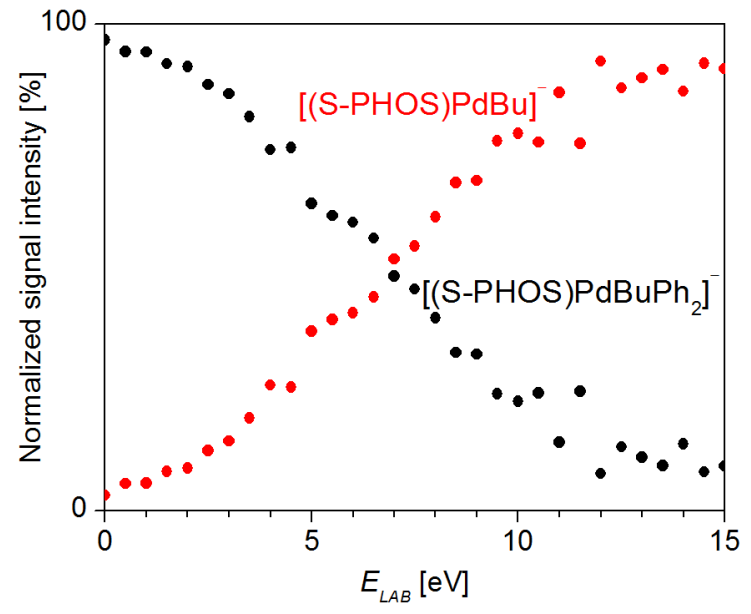

Figure 4.6: Normalized signal intensities of massselected $\left[(\mathrm{S}-\mathrm{PHOS}) \mathrm{PdBuPh}_{2}\right]^{-}$(black) and its fragment ion $[(\mathrm{S}-\mathrm{PHOS}) \mathrm{PdBu}]^{-}$(red) produced upon collision-induced dissociation, plotted against the applied collision energy $E_{\mathrm{LAB}}$. 
In contrast to the reactivities found for the phenyl-containing complexes, no reductive elimination reactions could be observed at all when [(S-PHOS) $\left.\mathrm{PdBn}_{2} \mathrm{Bu}\right]^{-}$or [(S-PHOS)PdBnBu $]^{-}$ were subjected to collision-induced dissociation. Instead, [(S-PHOS) $\left.\mathrm{PdBn}_{2} \mathrm{Bu}\right]^{-}$displayed a loss of a free benzyl anion as the only fragmentation channel (equation (4.11)), and $\left[(\mathrm{S}-\mathrm{PHOS}) \mathrm{PdBnBu}_{2}\right]^{-}$showed no fragmentation at all.

$$
\left[(\mathrm{S}-\mathrm{PHOS}) \mathrm{PdBn}_{2} \mathrm{Bu}\right]^{-} \longrightarrow[(\mathrm{S}-\mathrm{PHOS}) \mathrm{PdBnBu}]+\mathrm{Bn}^{-}
$$

The situation for $\left[(\mathrm{S}-\mathrm{PHOS}) \mathrm{PdBu}_{3}\right]^{-}$was similar to its benzyl-substituted counterparts in such a way that no reductive elimination product $[(\mathrm{S}-\mathrm{PHOS}) \mathrm{PdBu}]^{-}$could be detected on collisioninduced dissociation (figure 4.7).

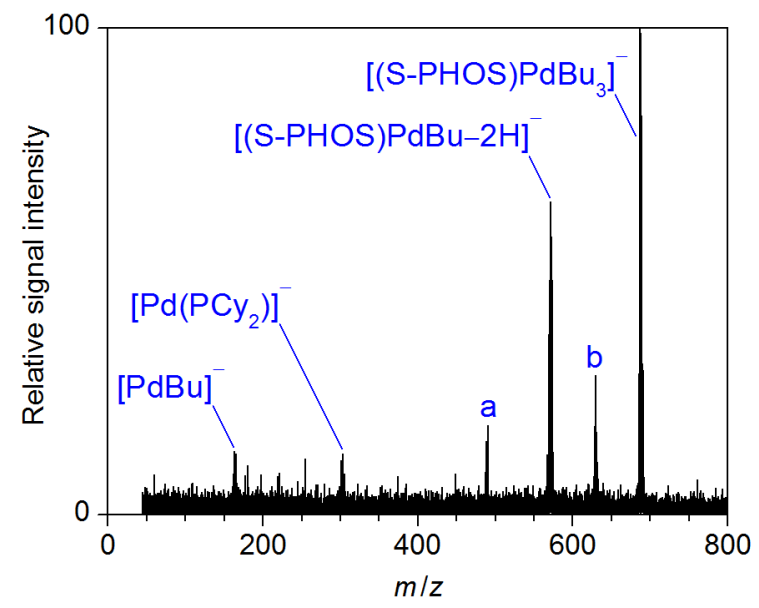

Figure 4.7: Mass spectrum of mass-selected $\left[(\mathrm{S}-\mathrm{PHOS}) \mathrm{PdBu}_{3}\right]^{-}$and its fragment ions produced upon collision-induced dissociation $\left(E_{\mathrm{LAB}}=15.0 \mathrm{eV}, \mathrm{a}=\left[\mathrm{Pd}, \mathrm{P}, \mathrm{C}_{14} \mathrm{H}_{13} \mathrm{O}_{2}, \mathrm{Cy}, \mathrm{Bu}-\mathrm{H}\right]^{-}\right.$, $\left.\mathrm{b}=\left[(\mathrm{S}-\mathrm{PHOS}) \mathrm{PdBu}_{2}-\mathrm{H}\right]^{-}\right)$.

The dominating fragmentation pathway was the loss of one and two butane molecules, respectively (equations (4.12) and (4.13)), followed by a ligand decomposition reaction leading to $\left[\mathrm{Pd}\left(\mathrm{PCy}_{2}\right)\right]^{-}$.

$$
\begin{aligned}
{\left[(\mathrm{S}-\mathrm{PHOS}) \mathrm{PdBu}_{3}\right]^{-} } & \longrightarrow\left[(\mathrm{S}-\mathrm{PHOS}) \mathrm{PdBu}_{2}-\mathrm{H}\right]^{-}+\mathrm{BuH} \\
{\left[(\mathrm{S}-\mathrm{PHOS}) \mathrm{PdBu}_{2}-\mathrm{H}\right]^{-} } & \longrightarrow[(\mathrm{S}-\mathrm{PHOS}) \mathrm{PdBu}-2 \mathrm{H}]^{-}+\mathrm{BuH}
\end{aligned}
$$

In small signal intensities, $[\mathrm{PdBu}]^{-}$was obtained, which might be the product of a combined ligand loss and $\mathrm{Bu}_{2}$ elimination. However, the absence of any products of these two individual fragmentation reactions, the lacking tendency of the butyl ligand to be incorporated in reductive elimination products of the mixed palladate $\left[(\mathrm{S}-\mathrm{PHOS}) \mathrm{PdBuPh}_{2}\right]^{-}$, and the general reluctance of the analyzed palladate complexes to dissociate the S-PHOS ligand (section 4.1.2) caution against this interpretation. 
In summary, it can be said that the formation of stable organopalladate(II) complexes $\left[(\mathrm{S}-\mathrm{PHOS}) \mathrm{PdR}_{3}\right]^{-}$is strongly favored when $\mathrm{PhMgCl}$ is used as a transmetalating agent. This preference might be explained by the stabilization of the negative charge of the anionic complex over the $\pi$-system of the phenyl ligand. The reductive elimination to form palladium(II) species is also preferred for $\mathrm{R}=\mathrm{Ph}$, which is in line with quantum-chemical calculations for related neutral palladium(II) species suggesting the energy barrier for the reductive elimination to be

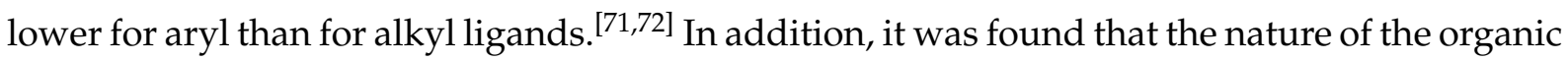
substituent not participating in the elimination does not have a large influence on the tendency of $\left[(\mathrm{S}-\mathrm{PHOS}) \mathrm{PdR}_{3}\right]^{-}$to undergo reductive elimination reactions.

\subsubsection{The Role of Organopalladate(II) Complexes for the Activation of Palladium(II) Precatalysts}

The above results confirmed the formation of organopalladate(II) complexes as products of the transmetalation of palladium acetate by Grignard reagents as well as the generation of potentially catalytically active palladium(0) species by reductive elimination of these palladate anions in the gas phase. Furthermore, the formation of palladate(II) anions could still be observed after long reaction times of the palladium(II) precursor with the phosphine ligand, demonstrating that even an electron-rich phosphine ligand such as S-PHOS does not reduce the palladium precursor quantitatively. Thus, it is likely that a transmetalation/reductive elimination mechanism plays a role for the activation of palladium(II) precursors in palladium-catalyzed reactions whenever $\mathrm{RMgCl}$ is involved as a transmetalating agent, even if a reduction by the phosphine ligand takes place simultaneously. Presumably, the importance of the transmetalationreductive elimination mechanism increases if the reaction rate of the phosphine-induced reduction is low and the reaction time of the palladium precursor with the phosphine ligand is short.

The observed transmetalation reaction might also lead to a catalyst deactivation if stable organopalladium(II) species are formed by transmetalation that do not react in a subsequent reductive elimination in solution. Indeed, the analyzed anionic palladium(II) complexes were not found to undergo reductive elimination reactions spontaneously. Instead, they only showed the discussed reactivity if suitable organic ligands were involved and the complexes were subjected to considerable acceleration energies during collision-induced dissociation experiments. The reductive elimination was found to occur most easily if the coupling products contained phenyl substituents. This mirrors the behavior expected for related neutral palladium complexes.

While the above-shown findings indicate that the discussed catalyst activation mechanism is unlikely to proceed through anionic complexes on a significant scale in solution, the relatively low overall signal intensities in the ESI mass spectra suggested that most palladium species present in the sample solutions were actually neutral and therefore not accessible to mass spectrometric analysis. It can be assumed that these neutral organopalladium complexes, due to the lower electron density at the palladium center, undergo reductive elimination more 
easily than their negatively charged counterparts, thus facilitating the discussed catalyst activation pathway. In conclusion, even though the investigated catalyst activation mechanism is more likely to proceed over neutral species, the analysis of the formation and reactivity of the corresponding organopalladates $\left[(\mathrm{S}-\mathrm{PHOS}) \mathrm{PdR}_{3}\right]^{-}$offered a detailed insight into the influences of the individual constituents of the reaction mixture on the occurring reaction steps. 


\subsection{Inorganic Palladates $\left[\mathrm{L}_{n} \mathrm{PdX}\right]^{-}$and Their Reactivities Towards Electrophiles}

\subsubsection{Formation and Stability of Palladate Complexes $\left[\mathrm{L}_{n} \mathrm{PdX}\right]^{-}$}

\section{Characterization of $\left[\mathrm{L}_{n} \mathrm{PdX}\right]^{-}$by ESI Mass Spectrometry}

Preliminary results showed that the electron-poor phosphine $\operatorname{PAr}_{3}^{\mathrm{F}}(\mathrm{L})$ is capable of stabilizing palladate complexes $\left[\mathrm{L}_{n} \mathrm{PdX}\right]^{-}$sufficiently to allow their detection by ESI mass spectrometry (section 1.5).

Systematic studies of solutions of $\left[\mathrm{L}_{3} \mathrm{Pd}\right]$ and five equivalents of a lithium halide $\mathrm{LiX}$, with $\mathrm{X}=\mathrm{Cl}, \mathrm{Br}$, and $\mathrm{I}$, in THF by ESI mass spectrometry confirmed the formation of $\left[\mathrm{L}_{3} \mathrm{PdX}\right]^{-}$as the main species for each applied halide (figure 4.8 for the example of $\mathrm{LiBr}$ ). The dominance of these anions in the mass spectra clearly suggested that the the generation of mononuclear palladates is strongly favored under the present conditions, and that their general tendency to undergo aggregation reactions is rather low. For bromides and especially for iodides, the formation of oxidized species, such as $\left[\mathrm{L}_{2} \mathrm{PdI}_{3}\right]^{-}$or the dinuclear $\left[\mathrm{L}_{3} \mathrm{Pd}_{2} \mathrm{Br}_{3}\right]^{-}$anion, was observed as well. The aggregation into dimeric species was also seen for non-oxidized palladates, namely in the generation of $\left[\mathrm{L}_{4} \mathrm{Pd}_{2} \mathrm{X}\right]^{-}$with small signal intensities. It was unclear whether these dimers were already formed in solution or were generated from the mononuclear anions during the ESI process. To address this question, the amount of added lithium bromide was reduced to 0.5 equivalents relative to the palladium catalyst (figure 4.9 ).

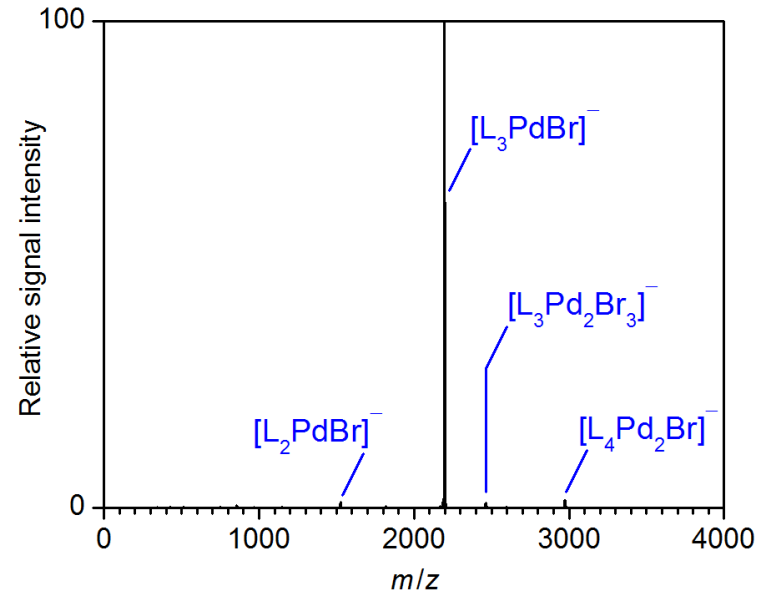

Figure 4.8: Negative-ion mode ESI mass spectrum of a solution of $\left[\mathrm{Pd}\left(\mathrm{PAr}_{3}^{\mathrm{F}}\right)_{3}\right]\left(\left[\mathrm{L}_{3} \mathrm{Pd}\right], 3 \mathrm{mM}\right)$, and $\mathrm{LiBr}(15 \mathrm{mM})$ in THF.

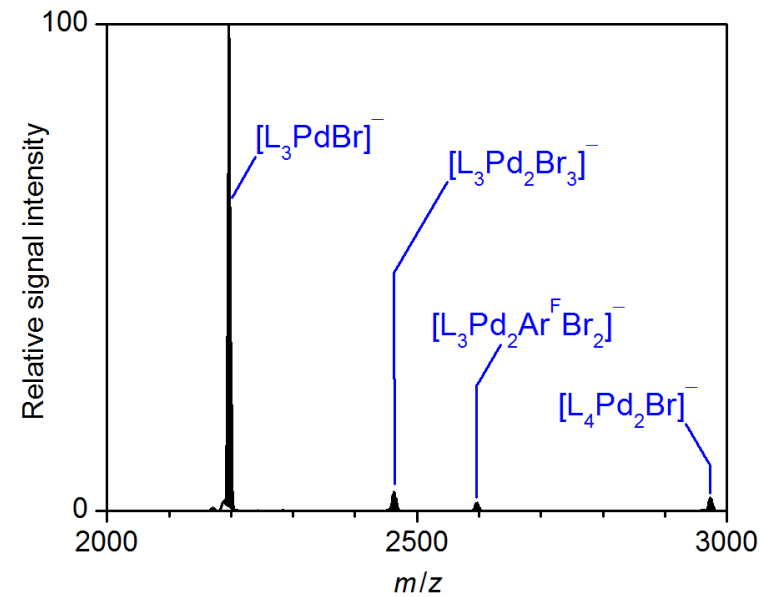

Figure 4.9: Negative-ion mode ESI mass spectrum (excerpt) of a solution of $\left[\mathrm{Pd}\left(\mathrm{PAr}_{3}^{\mathrm{F}}\right)_{3}\right]\left(\left[\mathrm{L}_{3} \mathrm{Pd}\right]\right.$, $3 \mathrm{mM})$, and $\mathrm{LiBr}(1.5 \mathrm{mM})$ in THF.

This led to a very slight increase of the relative signal intensity of the dimeric species. The fact that the amount of $\mathrm{LiBr}$ added to the sample solution had any influence at all onto the signal intensity of the dimeric anions suggests that some complexes of the sort are already formed in solution, yet additional aggregation processes during the transfer of the ions into the gas phase 
cannot be ruled out completely. In addition, a slightly higher relative amount of complexes containing palladium in higher oxidation states resulted from the reduced $\mathrm{LiBr}$ concentration. The said complexes $\left[\mathrm{L}_{3} \mathrm{Pd}_{2} \mathrm{Br}_{3}\right]^{-}$and $\left[\mathrm{L}_{3} \mathrm{Pd}_{2} \mathrm{Ar}^{\mathrm{F}} \mathrm{Br}_{2}\right]^{-}$contain palladium centers that can be described as displaying either the oxidation states 0 and $+\mathrm{II}$ or the oxidation state $+\mathrm{I}$. Which description is more suitable in this case could not be established with certainty. Gas-phase fragmentation of $\left[\mathrm{L}_{3} \mathrm{Pd}_{2} \mathrm{Br}_{3}\right]^{-}$did not yield any mononuclear palladium anions as fragments that could have allowed conclusions regarding the involved oxidation states, but instead led to sequential ligand dissociation, suggesting a high stablity of the dimeric core. The origin of the oxidized species probably lies in reactions of the electron-rich palladate complexes with traces of oxygen in the sample solutions and/or inside the mass spectrometer. In the case of lithium iodide, traces of molecular iodine that could not be removed entirely through heating presumably contributed to the oxidation. The incorporation of the aryl substituent $\mathrm{Ar}^{\mathrm{F}}$ into palladate complexes like $\left[\mathrm{L}_{3} \mathrm{Pd}_{2} \mathrm{Ar}^{\mathrm{F}} \mathrm{Br}_{2}\right]^{-}$was sometimes observed, especially in mass spectra that were recorded some time after the preparation of the sample, as a consequence of ligand decomposition reactions taking place in the sample solutions and possibly also during the ESI process.

As the incorporation of acetate anions in palladate complexes $\left[\left(\mathrm{PPh}_{3}\right)_{n} \mathrm{Pd}(\mathrm{OAc})\right]^{-}, n=2$ and 3 , was previously suggested for catalysts prepared from palladium acetate and triphenylphosphine, $14 \mathrm{e}$ the preparation of a palladate complex $\left[\mathrm{L}_{n} \mathrm{Pd}(\mathrm{OAc})\right]^{-}\left(\mathrm{L}=\mathrm{PAr}_{3}^{\mathrm{F}}\right)$ was attempted in analogy to the above-shown halide complexes from $\left[\mathrm{Pd}\left(\mathrm{PAr}_{3}^{\mathrm{F}}\right)_{3}\right]$ and lithium acetate $(\mathrm{Li}(\mathrm{OAc}))$. The low solubility of $\mathrm{Li}(\mathrm{OAc})$ in THF necessitated a change of solvent, but the palladate complex $\left[\mathrm{L}_{3} \mathrm{Pd}(\mathrm{OAc})\right]^{-}$could eventually be detected by ESI mass spectrometry with satisfactory signal intensity along with a variety of palladium-free anions, which were largely assigned to lithium acetate aggregates (figure 4.10).

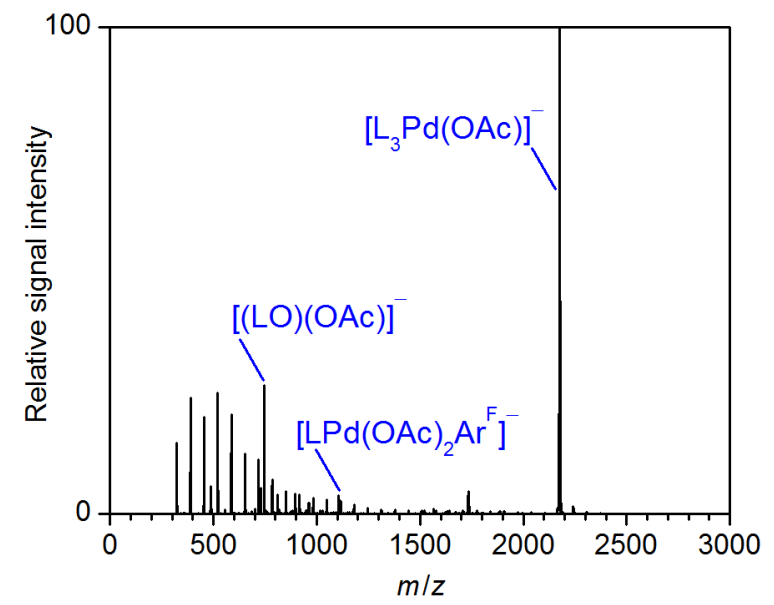

Figure 4.10: Negative-ion mode ESI mass spectrum of a solution of $\left[\operatorname{Pd}\left(\operatorname{PAr}_{3}^{\mathrm{F}}\right)_{3}\right]\left(\left[\mathrm{L}_{3} \mathrm{Pd}\right], 3 \mathrm{mM}\right)$, and LiOAc (15 mM) in a 1:1-mixture of THF and $\mathrm{MeOH}$. 
Next, the stability of the above-shown mononuclear palladates $\left[\mathrm{L}_{3} \mathrm{PdX}\right]^{-}$, with $\mathrm{X}=\mathrm{Cl}, \mathrm{Br}, \mathrm{I}$, and $(\mathrm{OAc})$, was tested in gas-phase fragmentation experiments. In all cases, ligand dissociation reactions yielding $\left[\mathrm{L}_{2} \mathrm{PdX}\right]^{-}$and $[\mathrm{LPdX}]^{-}$were the only observable fragmentation reactions (equations (4.14) and (4.15), figures 4.11 and 4.12 for the examples of $\left[\mathrm{L}_{3} \mathrm{PdBr}\right]^{-}$and $\left.\left[\mathrm{L}_{3} \mathrm{Pd}(\mathrm{OAc})\right]^{-}\right)$.

$$
\begin{aligned}
& {\left[\mathrm{L}_{3} \mathrm{PdX}\right]^{-} \longrightarrow\left[\mathrm{L}_{2} \mathrm{PdX}\right]^{-}+\mathrm{L}} \\
& {\left[\mathrm{L}_{2} \mathrm{PdX}\right]^{-} \longrightarrow[\mathrm{LPdX}]^{-}+\mathrm{L}}
\end{aligned}
$$

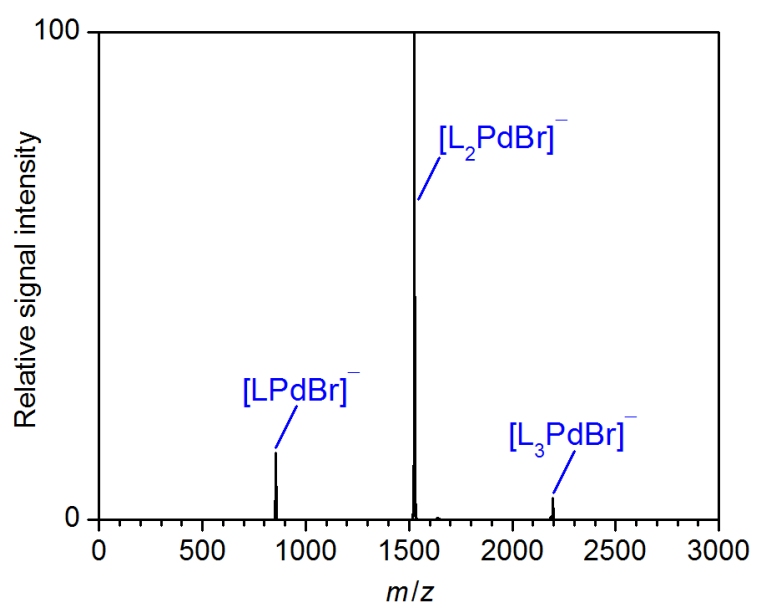

Figure 4.11: Mass spectrum of mass-selected $\left[\mathrm{L}_{3} \mathrm{PdBr}\right]^{-}$and its fragment ions produced upon collision-induced dissociation $\left(E_{\mathrm{LAB}}=15.0 \mathrm{eV}\right)$.

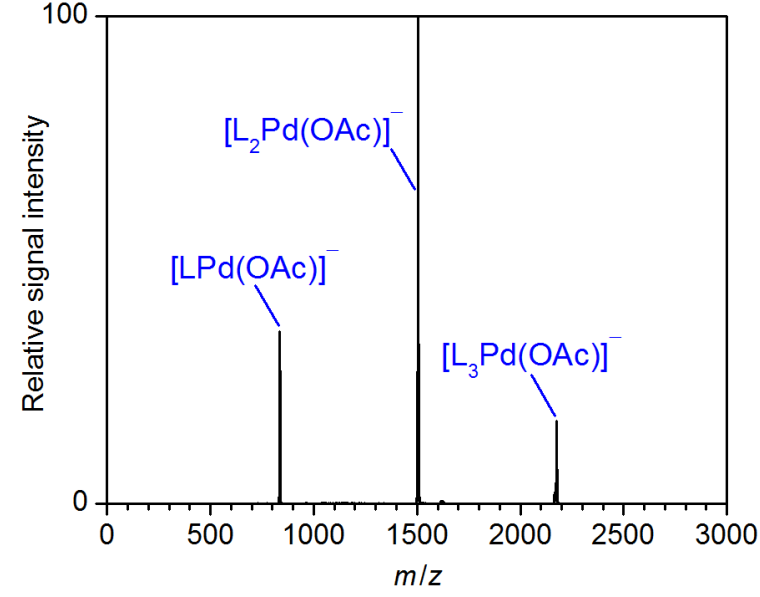

Figure 4.12: Mass spectrum of mass-selected $\left[\mathrm{L}_{3} \mathrm{Pd}(\mathrm{OAc})\right]^{-}$and its fragment ions produced upon collision-induced dissociation $\left(E_{\mathrm{LAB}}=15.0 \mathrm{eV}\right)$.

The exclusive occurrence of the ligand dissociation in combination with the constantly high signal intensities can be interpreted as an indication for the stability of the $\mathrm{Pd}-\mathrm{X}$ bond, as the cleavage of this bond during collision-induced dissociation would have resulted in the detection of free halide or acetate ions or at least in a breakdown of the overall signal intensity. The relative signal intensities of $\left[\mathrm{L}_{2} \mathrm{PdX}\right]^{-}$and $[\mathrm{LPdX}]^{-}$depended, as one might expect, on the applied acceleration energies: The signal intensity of the fragment ion bearing only one phosphine ligand increased when higher acceleration energies were applied.

Not only the acceleration energies had an influence on the relative signal intensities of the detected precursor and fragment ions; the tendency of $\left[\mathrm{L}_{3} \mathrm{PdX}\right]^{-}$to undergo ligand dissociation reactions varied also depending on the nature of the $X$ ligand, as was analyzed in gas-phase fragmentation experiments at constant acceleration energies $E_{\mathrm{LAB}}$ (table 4.1). As the masses of the ions of interest differed only slightly, the assumption was made that constant acceleration energies $E_{\mathrm{LAB}}$ led to sufficiently similar collision energies in this case. 
Table 4.1: Relative signal intensities of the precursor ions $\left[\mathrm{L}_{3} \mathrm{PdX}\right]^{-}(\mathrm{X}=\mathrm{Cl}, \mathrm{Br}, \mathrm{I},(\mathrm{OAc}))$ and their fragment ions $\left[\mathrm{L}_{2} \mathrm{PdX}\right]^{-}$and $[\mathrm{LPdX}]^{-}$at an acceleration energy of $E_{\mathrm{LAB}}=15 \mathrm{eV}$ in $\%$, normalized to the sum of all considered species.

\begin{tabular}{llll}
\hline & ${\left[\mathbf{L}_{3} \mathbf{P d X}\right]^{-}}^{-}$ & ${\left[\mathbf{L}_{2} \mathbf{P d X}\right]^{-}}^{-}$ & {$\left[_{\mathbf{L P d X}]^{-}}\right.$} \\
\hline $\mathbf{X}=\mathbf{C l}$ & 5.6 & 85.0 & 9.4 \\
$\mathbf{X}=\mathbf{B r}$ & 3.8 & 84.5 & 11.7 \\
$\mathbf{X}=\mathbf{I}$ & 0.9 & 91.7 & 7.4 \\
$\mathbf{X}=\mathbf{( O A c )}$ & 11.2 & 65.5 & 23.3 \\
\hline
\end{tabular}

The comparison of the fragmentation reactions of the halide-containing complexes $\left[\mathrm{L}_{3} \mathrm{PdCl}\right]^{-}$, $\left[\mathrm{L}_{3} \mathrm{PdBr}\right]^{-}$, and $\left[\mathrm{L}_{3} \mathrm{PdI}\right]^{-}$revealed that the relative signal intensity of the precursor ion was highest for $\left[\mathrm{L}_{3} \mathrm{PdCl}\right]^{-}$, whereas $\left[\mathrm{L}_{3} \mathrm{PdI}\right]^{-}$fragmented almost quantitavely at the chosen acceleration energy, indicating that the first ligand dissociation reaction is slightly favored in the case of $\left[\mathrm{L}_{3} \mathrm{PdI}\right]^{-}$compared to $\left[\mathrm{L}_{3} \mathrm{PdCl}\right]^{-}$and also, with limitations, to $\left[\mathrm{L}_{3} \mathrm{PdBr}\right]^{-}$. This trend, however, was not very strong and could not be confirmed for the second ligand dissociation reaction.

An interesting difference compared to the halide-containing palladates could be observed in the fragmentation behavior of $\left[\mathrm{L}_{3} \mathrm{Pd}(\mathrm{OAc})\right]^{-}$, which tended to lose one ligand rather reluctantly, but on the other hand showed a larger ratio of the fragment ion resulting from the dissociation of two phosphine ligands, $[\mathrm{LPd}(\mathrm{OAc})]^{-}$. This reactivity, which seems counterintuitive at the first glance, might possibly be explained by a change in the coordination of the acetate substituent to the palladium center from a monodentate to a bidentate binding mode upon the loss of the first phosphine ligand, stabilizing the palladate anion so that the second ligand dissociation is facilitated.

\section{Analysis of the Association and Ligand Dissociation Equilibria in Solution}

While ESI-mass spectrometric experiments provide qualitative insight into the formation of $\left[\mathrm{L}_{3} \mathrm{PdX}\right]^{-}$and its reactivity in the gas phase, no reliable quantitative information can be gained from these studies, as discussed above (section 2.5). Therefore, other analytical techniques were applied to quantify the association equilibrium between the starting materials, $\left[\mathrm{L}_{3} \mathrm{Pd}\right]$ and $\mathrm{LiBr}$, and the palladate complex, $\left[\mathrm{L}_{3} \mathrm{PdBr}\right]^{-}$(equation 4.16)).

$$
\left[\mathrm{L}_{3} \mathrm{Pd}\right]+\mathrm{LiBr} \stackrel{K_{\text {ass }}}{\rightleftharpoons}\left[\mathrm{L}_{n} \mathrm{PdBr}\right]^{-} \mathrm{Li}^{+}+(3-n) \mathrm{L}
$$

First, concentration-dependent electrical conductivity measurements of solutions of $\left[\mathrm{L}_{3} \mathrm{Pd}\right]$ with varying amounts of $\mathrm{LiBr}$ were conducted (figure 4.13). 


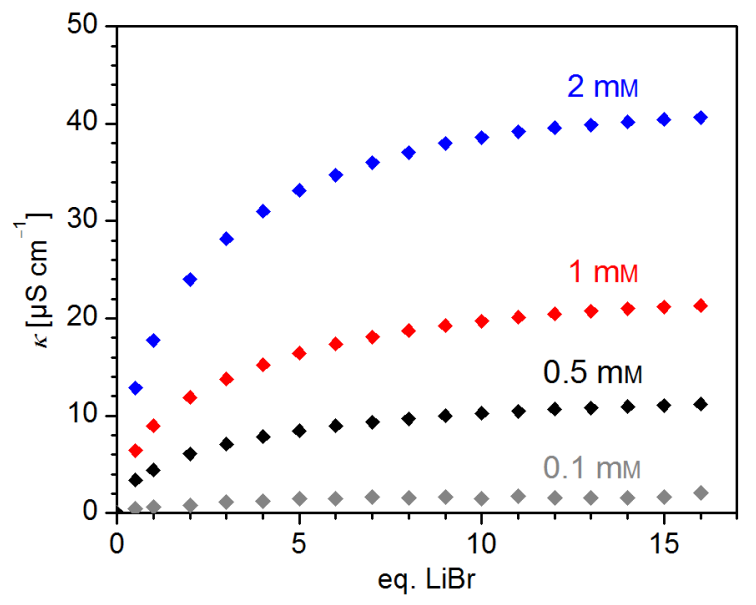

Figure 4.13: Specific electrical conductivities of solutions of $\left[\mathrm{L}_{3} \mathrm{Pd}\right]$ in $\mathrm{THF}$ at concentrations of $0.1 \mathrm{mM}$ (grey), $0.5 \mathrm{mM}$ (black), $1.0 \mathrm{mM}$ (red), and $2.0 \mathrm{~mm}$ (blue) with varying amounts of $\mathrm{LiBr}$ at $298 \mathrm{~K}$.

Pure lithium bromide does not exhibit significant electrical conductivity in THF. Thus, it can be assumed that the observed increase in conductivity upon the addition of LiBr to the neutral palladium catalyst is caused by palladate complexes. The measured specific conductivites increased steeply upon the addition of the first five equivalents of $\mathrm{LiBr}$, then the increase flattened somewhat until the conductivity reached a plateau at about 10-15 equivalents of LiBr. The next question regarded the tendency of the palladate complexes formed by the addition of $\mathrm{LiBr}$ to solutions of $\left[\mathrm{L}_{3} \mathrm{Pd}\right]$ to form contact-ion pairs and aggregates in solution. If aggregation and the generation of contact-ion pairs played an important role in solution under the present conditions, the molar conductivity would be expected to change considerably with increasing concentration. High concentrations should facilitate the aggregation of mononuclear palladate complexes into larger clusters as well as the coordination of lithium cations to the palladate anions to form ion pairs. This would, in consequence, lower the concentration of free ions able to transport charges through the solution relative to the starting concentration of [ $\left.\mathrm{L}_{3} \mathrm{Pd}\right]$. Furthermore, the resulting larger cluster ions would be expected to be less mobile. The electrical conductivity depends on the concentration of charged species in the sample solution as well as

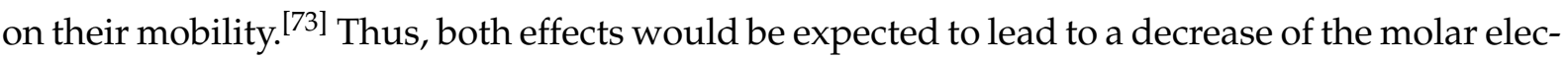
trical conductivity with increasing concentrations. However, it was found that the dependence of the specific conductivity on the palladium concentration was approximately linear when the ratio between $\left[\mathrm{L}_{3} \mathrm{Pd}\right]$ and $\mathrm{LiBr}$ was kept constant, which corresponds to a constant molar conductivity in the considered concentration range. A slight saturation effect could only be observed in solutions that contained large amounts of $\mathrm{LiBr}$ (figure 4.14). 


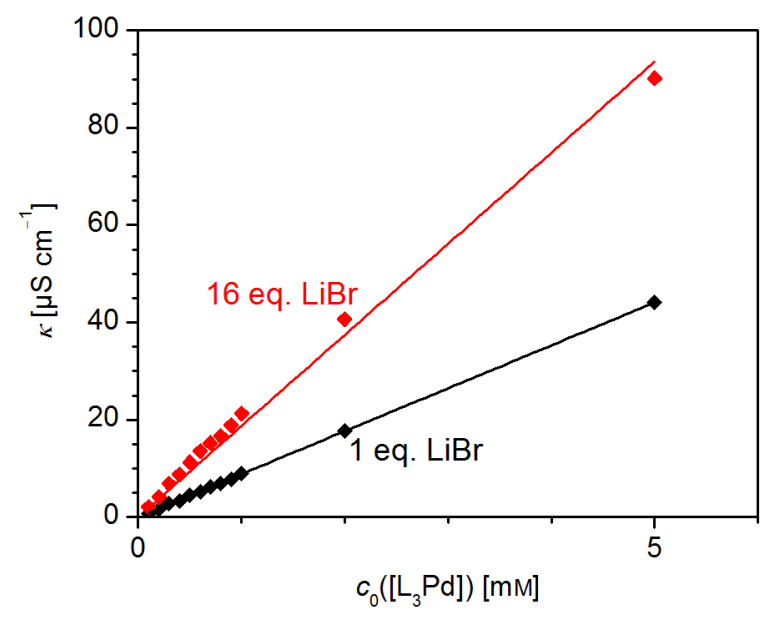

Figure 4.14: Specific electrical conductivities of solutions of $\left[\mathrm{L}_{3} \mathrm{Pd}\right]$ in THF with 1 eq. (black) and 16 eq. (red) of $\mathrm{LiBr}$ at varying concentrations with linear functions fitted to the data points (solid lines).

The above results suggest that palladate complexes $\left[\mathrm{L}_{n} \mathrm{PdBr}\right]^{-}$have a low tendency to form larger aggregates or contact-ion pairs in solution, being present largely as free anions even at relatively high concentrations. However, a further quantitative analysis of the formation equilibrium based only on the obtained conductivity values proved impractical.

Another promising method to gain qualitative as well as quantitative information on the reaction between $\left[\mathrm{L}_{3} \mathrm{Pd}\right]$ and $\mathrm{LiBr}$ was ${ }^{31} \mathrm{P}-\mathrm{NMR}$ spectroscopy. Previous ${ }^{31} \mathrm{P}-\mathrm{NMR}$-spectroscopic experiments had already shown the formation of $\left[\mathrm{L}_{n} \mathrm{PdBr}\right]^{-}$from $\left[\mathrm{L}_{3} \mathrm{Pd}\right]$ and $\mathrm{NBu}_{4} \mathrm{Br}^{.74]} \mathrm{In}$ a first series of experiments, a solution of $\left[\mathrm{L}_{3} \mathrm{Pd}\right]$ in $\mathrm{THF}-\mathrm{D}_{8}$ was repeatedly treated with solutions of $\mathrm{LiBr}$ in $\mathrm{THF}^{-\mathrm{D}_{8}}$ and the resulting solutions, containing 0 to 8 equivalents of $\mathrm{LiBr}$, were analyzed by ${ }^{31} \mathrm{P}-\mathrm{NMR}$ spectroscopy at $223 \mathrm{~K}$ (figure 4.15 .

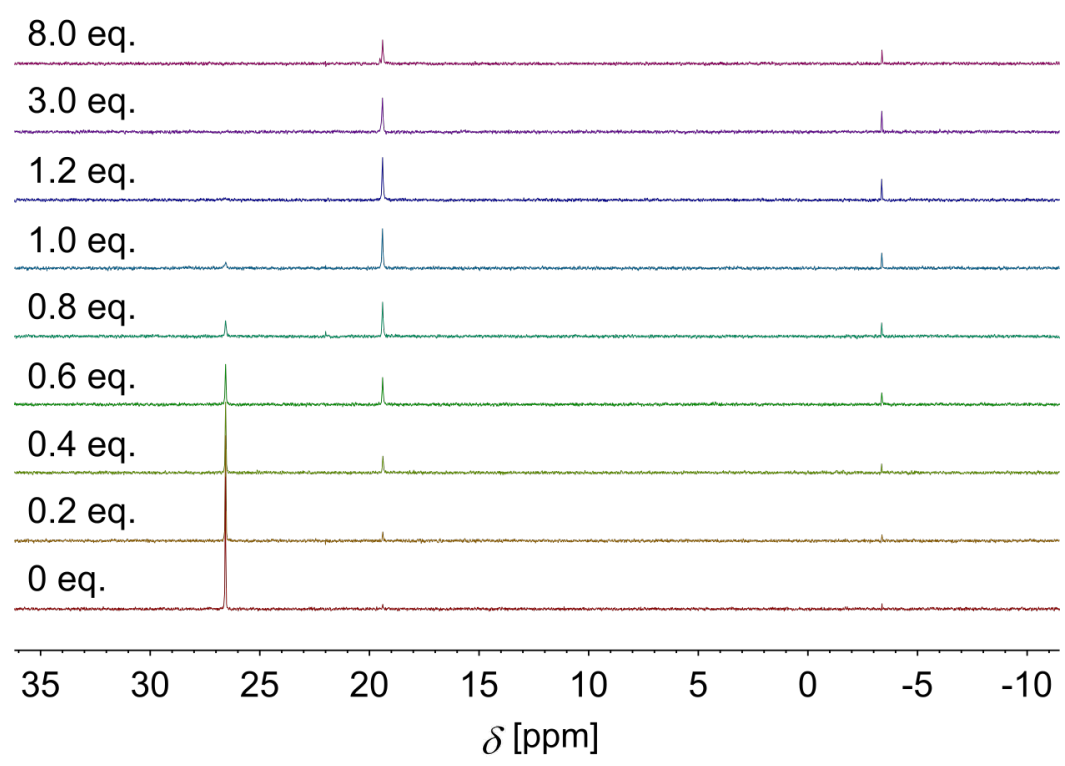

Figure 4.15: ${ }^{31} \mathrm{P}-\mathrm{NMR}$ spectra of solutions of $\left[\mathrm{L}_{3} \mathrm{Pd}\right]$ in $\mathrm{THF}^{-\mathrm{D}_{8}}(c=1 \mathrm{mM})$ containing varying amounts of $\mathrm{LiBr}(0-8$ eq.). 
The NMR spectra showed the disappearance of the signal of the neutral catalyst at $\delta=26.6 \mathrm{ppm}$ and the appearance of a new signal, which was assigned to a palladate complex $\left[\mathrm{L}_{n} \mathrm{PdBr}\right]^{-}$, at $\delta=19.4 \mathrm{ppm}$. The signal intensity of the neutral palladium complex was already close to zero after the addition of one equivalent of $\mathrm{LiBr}$, which is in line with the results previously obtained for the reaction with $\mathrm{NBu}_{4} \mathrm{Br} . \stackrel{40]}{.}$ Furthermore, the signal of the free phosphine ligand could be found at $\delta=-3.4 \mathrm{ppm}$. The appearance of the free ligand signal upon addition of lithium bromide was particularly interesting as it showed the formation of a coordinatively unsaturated and thus more reactive palladium species in the presence of halide anions. It has indeed been suggested that the coordination of halide ions has a stabilizing effect on such species, preventing decomposition and aggregation processes and thus exerting a beneficial effect on the overall performance of palladium catalysts. ${ }^{[14 \mathrm{~b} \mid}\left[\mathrm{L}_{3} \mathrm{PdBr}\right]^{-}$and its derivative $\left[\mathrm{L}_{2} \mathrm{PdBr}\right]^{-}$formed by ligand dissociation could not be distinguished by ${ }^{31} \mathrm{P}-\mathrm{NMR}$ spectroscopy. The phosphine oxide derived from $\mathrm{L}$ was also represented in the spectrum by a signal arising at $\delta=19.5 \mathrm{ppm}$ after the addition of several equivalents of $\mathrm{LiBr}$.

While these results demonstrated that quantitative analysis of the equilibrium in question was possible using NMR spectroscopy, they also pointed out several problems with the chosen experimental approach. First, the signal of the palladate complex appeared to be significantly broadened at the present temperature, decreasing the overall signal intensity. Second, the reproduction of the obtained results revealed large deviations in the signal intensities of the species in question, which had their origin in the difficulty of handling very small volumes of added $\mathrm{LiBr}$ solution with adequate accuracy. Finally, the oxidation of the phosphine ligand L was presumed to influence the equilibrium.

Therefore, the experimental method was changed in order to minimize inaccuracies and oxidation reactions. To this end, a sample solution containing $\left[\mathrm{L}_{3} \mathrm{Pd}\right]$ and $\mathrm{LiBr}$ in a 1:1 ratio was prepared and diluted to different concentrations ranging from $5 \mathrm{mM}$ to $0.5 \mathrm{mM}$ under argon atmosphere. The sample solutions were analyzed at $198 \mathrm{~K}$, which significantly reduced the signal broadening (figure 4.16).

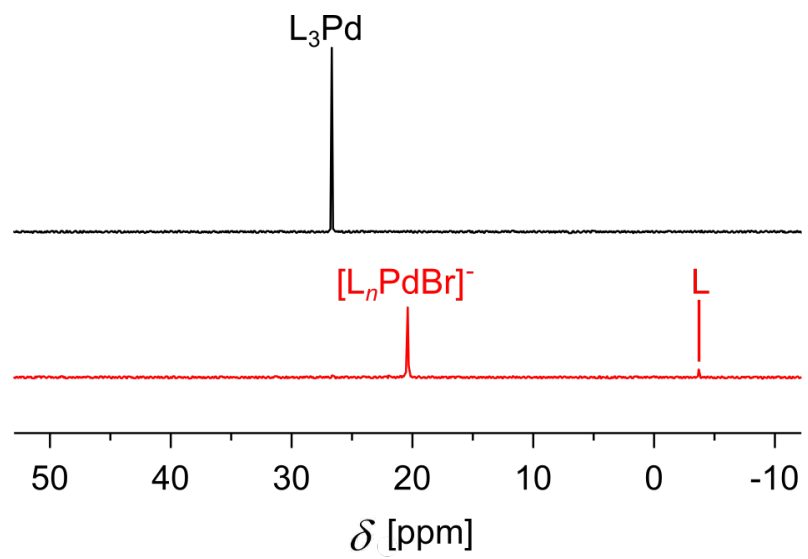

Figure 4.16: ${ }^{31} \mathrm{P}-\mathrm{NMR}$ spectra of solutions of $\left[\mathrm{L}_{3} \mathrm{Pd}\right]$ in THF- $\mathrm{D}_{8}(c=2 \mathrm{mM})$ with (red) and without (black) 1 eq. of $\mathrm{LiBr}$. 
As a beneficial side effect, the slight temperature-dependent shift of the signals led to a better separability of the palladate-representing signal, now at $\delta=20.4 \mathrm{ppm}$, and the signal of the phosphine oxide at $\delta=19.4 \mathrm{ppm}$. To determine the concentrations of the considered species in solution, and ultimately to estimate the equilibrium constant, the signal integrals were determined and normalized to the sum of all considered species (table 4.2).

Table 4.2: Relative signal integrals (normalized to the sum of all considered species) of [ $\mathrm{L}_{3} \mathrm{Pd}$, $\left[\mathrm{L}_{n} \mathrm{PdBr}\right]^{-}$, and $\mathrm{L}$ in the ${ }^{31} \mathrm{P}-\mathrm{NMR}$ spectra at different starting concentrations $c_{0}$. Only measurements where the relative integral of the phosphine oxide LO, which is not included here, was smaller than $3 \%$ were taken into account.

\begin{tabular}{llll}
\hline $\boldsymbol{c}_{\mathbf{0}}[\mathrm{mM}]$ & $\boldsymbol{I}\left(\left[\mathbf{L}_{3} \mathbf{P d}\right]\right)$ & $\boldsymbol{I}\left(\left[\mathrm{L}_{n} \mathbf{P d B r}\right]^{-} \mathbf{L i}^{+}\right)$ & $\boldsymbol{I}(\mathbf{L})$ \\
\hline $\mathbf{5 . 0}$ & 0.041 & 0.930 & 0.021 \\
& 0.032 & 0.941 & 0.020 \\
$\mathbf{2 . 0}$ & 0.019 & 0.954 & 0.019 \\
& 0.018 & 0.908 & 0.054 \\
$\mathbf{1 . 0}$ & 0.015 & 0.960 & 0.026 \\
& 0.021 & 0.946 & 0.047 \\
$\mathbf{0 . 7 5}$ & 0.021 & 0.936 & 0.041 \\
& 0.040 & 0.826 & 0.107 \\
& 0.008 & 0.953 & 0.041 \\
$\mathbf{0 . 5}$ & 0.028 & 0.924 & 0.037 \\
& 0.038 & 0.873 & 0.078 \\
& 0.014 & 0.939 & 0.046 \\
& 0.045 & 0.876 & 0.057 \\
\hline
\end{tabular}

As the signal of the free ligand $\mathrm{L}$ could only be detected after the addition of $\mathrm{LiBr}$, it can be assumed that the ligand dissociation occurs only from the palladate complex. Thus, the combined signals of $\left[\mathrm{L}_{n} \mathrm{PdBr}\right]^{-}$and the free ligand represent the palladate complex $\left[\mathrm{L}_{3} \mathrm{PdBr}\right]^{-} \mathrm{Li}^{+}$ along with its potential derivatives formed in ligand dissociation reactions. This simplification results in a modified reaction equilibrium with the association constant $K_{\text {ass }}$ (equations 4.17) and (4.18)).

$$
\begin{array}{r}
{\left[\mathrm{L}_{3} \mathrm{Pd}\right]+\mathrm{LiBr} \stackrel{K_{\text {ass }}}{\rightleftharpoons}\left[\mathrm{L}_{3} \mathrm{PdBr}\right]^{-} \mathrm{Li}^{+}} \\
K_{\text {ass }}=\frac{c\left(\left[\mathrm{~L}_{3} \mathrm{PdBr}\right]^{-} \mathrm{Li}^{+}\right)}{c^{2}\left(\left[\mathrm{~L}_{3} \mathrm{Pd}\right]\right)}
\end{array}
$$

The concentration of $\left[\mathrm{L}_{3} \mathrm{Pd}\right]$ equals the concentration of LiBr. Furthermore, $\left[\mathrm{L}_{3} \mathrm{Pd}\right]$ can be described as the difference between the starting concentration $c_{0}$ of $\left[\mathrm{L}_{3} \mathrm{Pd}\right]$ and the concentration of the palladate complex $\left[\mathrm{L}_{3} \mathrm{PdBr}\right]^{-} \mathrm{Li}^{+}$, which will be referred to as $c_{\text {ate }}$ for reasons of clarity (equation (4.19)). Thus, the association constant can be expressed depending only on $c_{0}$ and $c_{\text {ate }}$ (equation (4.20). Solving this equation for $c_{\text {ate }}$ offers the possibility to simulate concentrations $c_{\text {ate }}$ for different association constants $K_{\text {ass }}$ (equation (4.21).. .75] From these theoretical concentrations $c_{\text {ate, }}$, molar fractions $\chi$ of $\left[\mathrm{L}_{3} \mathrm{PdBr}\right]^{-} \mathrm{Li}^{+}$and $\left[\mathrm{L}_{3} \mathrm{Pd}\right]$ can be calculated (equations 4.19 , 
(4.22) and (4.23).

$$
\begin{aligned}
{\left[\mathrm{L}_{3} \mathrm{Pd}\right] } & =c_{0}-c_{\text {ate }} \\
K_{\mathrm{ass}} & =\frac{c_{\mathrm{ate}}}{\left(c_{0}-c_{\mathrm{ate}}\right)^{2}} \\
c_{\mathrm{ate}} & =\frac{2 c_{0} \cdot K_{\mathrm{ass}}+1-\sqrt{4 c_{0} \cdot K_{\mathrm{ass}}+1}+1}{2 \cdot K_{\mathrm{ass}}} \\
\chi_{\text {ate }} & =\frac{c_{\text {ate }}}{c_{0}} \\
\chi\left(\left[\mathrm{L}_{3} \mathrm{Pd}\right]\right) & =\frac{c\left(\left[\mathrm{~L}_{3} \mathrm{Pd}\right]\right)}{c_{0}}
\end{aligned}
$$

When plotting the experimentally determined fractions $\chi\left(\left[\mathrm{L}_{3} \mathrm{Pd}\right]\right)$ and $\chi_{\text {ate, }}$ which correspond directly to the normalized signal integrals as given in table 4.2 , as a function of the starting concentration $c_{0}$, it could be observed that the ratio of the regarded species did not change significantly at lower concentrations, as would be expected for high association constants $K_{\text {ass }}$ (figure 4.17). By comparison of the experimental results with theoretical values for $\chi_{\text {ate }}$ and $\chi\left(\left[\mathrm{L}_{3} \mathrm{Pd}\right]\right)$, the association constant $K_{\mathrm{ass}}$ was estimated to lie between 1 and $10 \mu \mathrm{M}^{-1}$.

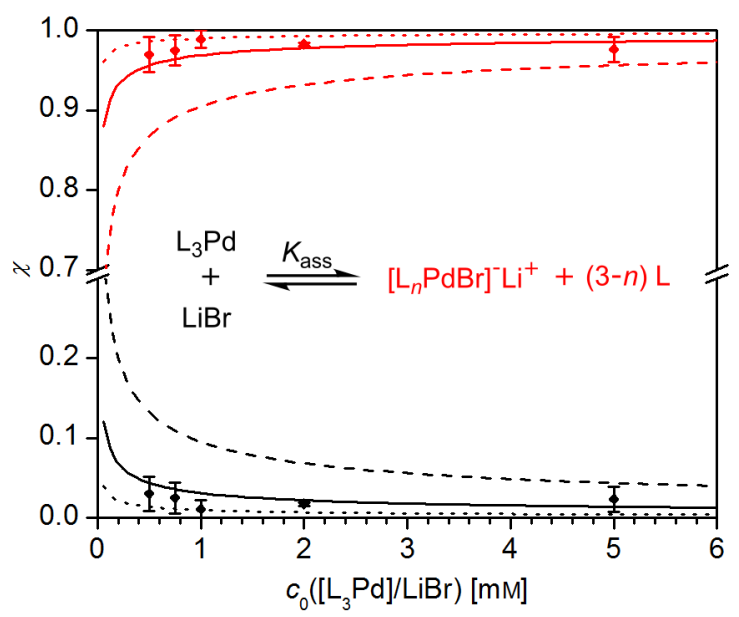

Figure 4.17: Normalized fractions of the ate complexes $\left[\mathrm{L}_{n} \mathrm{PdBr}\right]^{-} \mathrm{Li}^{+}+(3-n) \mathrm{L}(n=2$ and 3; red symbols) and [ $\left.\mathrm{L}_{3} \mathrm{Pd}\right]$ (black symbols) together with simulations for $K_{\mathrm{ass}}=0.1 \mu \mathrm{M}^{-1}$ (dashed lines), $K_{\text {ass }}=1 \mu \mathrm{M}^{-1}$ (solid lines), and $K_{\mathrm{ass}}=10 \mu \mathrm{M}^{-1}$ (dotted lines). Error bars correspond to one standard deviation.

The NMR experiments also gave insight into the ligand dissociation equilibrium (equation (4.24).

$$
\left[\mathrm{L}_{3} \mathrm{PdBr}\right]^{-} \stackrel{K_{\text {diss }}}{\rightleftharpoons}\left[\mathrm{L}_{2} \mathrm{PdBr}\right]^{-}+\mathrm{L}
$$

The signal integrals of the palladate complexes $\left[\mathrm{L}_{n} \mathrm{PdBr}\right]^{-}$, with $n=2$ and 3 , and the free ligand $\mathrm{L}$ are proportional to the absolute concentrations of the regarded species in solution multiplied by the number of contained phosphine atoms (equations (4.25) and (4.26). According to the stoichiometry of the ligand dissociation equilibrium, the concentration of the free ligand must 
correspond to the concentration of $\left[\mathrm{L}_{2} \mathrm{PdBr}\right]^{-}$(equation (4.27)). It follows that the concentration of $\left[\mathrm{L}_{3} \mathrm{PdBr}\right]^{-}$equals the overall concentration of palladate complexes in solution minus the concentration of the free ligand L (equation (4.28)).

$$
\begin{aligned}
I(\text { palladate }) & \propto 3 \cdot c\left(\left[\mathrm{~L}_{3} \mathrm{PdBr}\right]^{-}\right)+2 \cdot c\left(\left[\mathrm{~L}_{2} \mathrm{PdBr}\right]^{-}\right) \\
I(\mathrm{~L}) & \propto c(L) \\
c(\mathrm{~L}) & =c\left(\left[\mathrm{~L}_{2} \mathrm{PdBr}\right]^{-}\right) \\
c\left(\left[\mathrm{~L}_{3} \mathrm{PdBr}\right]^{-}\right) & =c(\text { palladate })-c(\mathrm{~L})
\end{aligned}
$$

From these assumptions, the ratio between the signal integrals $I$ (palladate) and $I(\mathrm{~L})$, which will be further referred to as $x$, can be formulated in dependence of the ligand concentration and the palladate concentration (equations (4.29) and (4.30). The solution of this equation for $c(\mathrm{~L})$ provides an expression for the ligand concentration which depends on the palladate concentration and the integral ratio $x$ (equation (4.31)).

$$
\begin{aligned}
\frac{I(\text { palladate })}{I(\mathrm{~L})} & =x=\frac{3 \cdot c\left(\left[\mathrm{~L}_{3} \mathrm{PdBr}\right]^{-}\right)+2 \cdot c\left(\left[\mathrm{~L}_{2} \mathrm{PdBr}\right]^{-}\right)}{c(\mathrm{~L})} \\
x & =\frac{3 \cdot(c(\text { palladate })-c(\mathrm{~L}))+2 \cdot c(\mathrm{~L})}{c(\mathrm{~L})} \\
c(\mathrm{~L}) & =\frac{3 \cdot c(\text { palladate })}{x+1}
\end{aligned}
$$

The dissociation constant $K_{\text {diss }}$ is given through the law of mass action (equation (4.32)). Substituting $c\left(\left[\mathrm{~L}_{2} \mathrm{PdBr}\right]^{-}\right)$and $c\left(\left[\mathrm{~L}_{3} \mathrm{PdBr}\right]^{-}\right)$according to equations (4.27) and (4.28) and $c(\mathrm{~L})$ according to equation (4.31) gives an expression for $K_{\text {diss }}$ which only depends on $c$ (palladate) and $x$ (equation (4.33). This formula can also be transposed into an expression for $x$ (equation 4.34$).$

$$
\begin{aligned}
K_{\text {diss }} & =\frac{c\left(\left[\mathrm{~L}_{2} \mathrm{PdBr}\right]^{-}\right) \cdot c(\mathrm{~L})}{c\left(\left[\mathrm{~L}_{3} \mathrm{PdBr}\right]^{-}\right)} \\
K_{\text {diss }} & =\frac{9 \cdot c(\text { palladate })}{x^{2}-x-2} \\
x & =\frac{1}{2}+\sqrt{2.25+\frac{9 \cdot c(\text { palladate })}{K_{\text {diss }}}}
\end{aligned}
$$

Values for $c$ (palladate) were determined for each experiment from the starting concentration $c_{0}$ and the combined normalized signal integrals of the palladate complexes and the free ligand (table 4.2). Plotting the integral fraction $x$ against $c$ (palladate) and comparing the experimental values with simulated curves for different values of $K_{\text {diss }}$ showed a dissociation constant between 10 and $100 \mu \mathrm{M}$ (figure 4.18). 


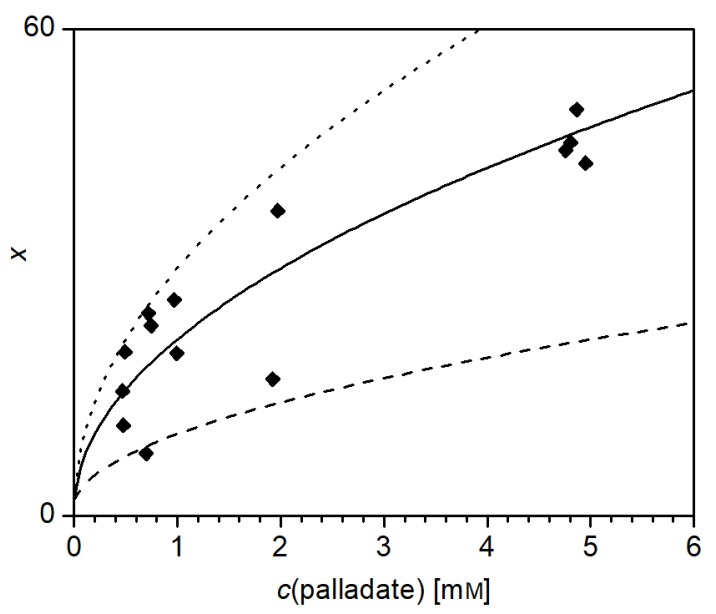

Figure 4.18: Integral fractions $x$ at different overall palladate concentrations $c$ (palladate), together with simulated curves calculated for $K_{\text {diss }}=10 \mu \mathrm{M}$ (dotted line), $K_{\text {diss }}=20 \mu \mathrm{M}$ (solid line), and $K_{\text {diss }}=100 \mu \mathrm{M}$ (dashed line).

\subsubsection{Influence of the Phosphine Ligand on the Stability of $\left[\mathrm{L}_{3} \mathrm{PdBr}\right]^{-}$}

Knowing that the strongly electron-withdrawing ligand $\mathrm{L}$ allowed the formation of stable palladate complexes, the generation of analogous complexes from $\left[\mathrm{Pd}\left(\mathrm{PPh}_{3}\right)_{4}\right]$ as a precursor was attempted. It could be seen in the ${ }^{31} \mathrm{P}-\mathrm{NMR}$ spectra of $\left[\mathrm{Pd}\left(\mathrm{PPh}_{3}\right)_{4}\right]$ in THF- $\mathrm{D}_{8}$ that the signal representing the neutral palladium complex was shifted upon the addition of one equivalent of $\mathrm{LiBr}$, suggesting that some kind of interaction takes place in this case as well, which is in line

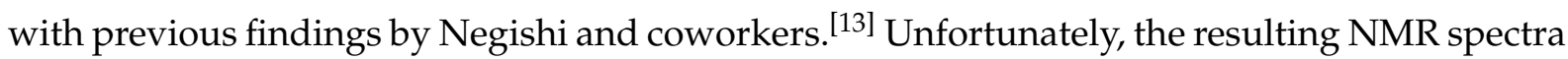
had a very low overall signal intensity and the observed signal was broadened in such a way as to make a quantitative analysis impossible. ESI-mass spectrometric analysis of a mixture of $\left[\mathrm{Pd}\left(\mathrm{PPh}_{3}\right)_{4}\right]$ and five equivalents of $\mathrm{LiBr}$ showed no palladium-containing complexes. This indicates that the triphenylphosphine ligand does not withdraw enough electron density from the palladium center to allow the formation of stable, free $\left[\left(\mathrm{PPh}_{3}\right)_{3} \mathrm{PdBr}\right]^{-}$ions in the gas phase. Any palladate complexes that are potentially formed are likely to form contact-ion pairs with $\mathrm{Li}^{+}$cations and therefore cannot be probed by ESI mass spectrometry.

To determine the minimum electron-withdrawing capacity of an applied phosphine ligand which is necessary to form stable, detectable palladate complexes $\left[\left(\mathrm{PR}_{3}\right)_{3} \mathrm{PdBr}\right]^{-}(\mathrm{R}=$ aryl substituent), ligands bearing phenyl groups as well as electron-withdrawing $\mathrm{Ar}^{\mathrm{F}}$ groups, $\mathrm{L}^{\mathrm{Ph} 1}$ and $\mathrm{L}^{\mathrm{Ph} 2}$, were synthesized (chart 3, section 6.3). 
<smiles>FC(F)(F)c1cc(P(c2cc(C(F)(F)F)cc(C(F)(F)F)c2)c2cc(C(F)(F)F)cc(C(F)(F)F)c2)cc(C(F)(F)F)c1</smiles>

Chart 3: Ligands used for the determination of the influence of the electronic properties of the used phosphine onto the formation and stability of palladate complexes.

First, $\mathrm{L}^{\mathrm{Ph} 1}$ and $\mathrm{L}^{\mathrm{Ph} 2}$ were combined with $\mathrm{Pd}(\mathrm{OAc})_{2}$ and lithium bromide to yield the corresponding palladate complexes, yet the ESI mass spectra of the mixtures only showed palladium(II)-containing species. The addition of hydrazine as reductant led to the formation of $\left[\mathrm{L}_{3}^{\mathrm{Ph} 1} \mathrm{PdBr}\right]^{-}$and, in small amounts, also $\left[\mathrm{L}_{3}^{\mathrm{Ph} 2} \mathrm{PdBr}\right]^{-}$, although the signal intensities were quite low and the mass spectra still displayed a lot of palladium(II)-based anions. Collisioninduced dissociation experiments of $\left[\mathrm{L}_{3}^{\mathrm{Ph} 1} \mathrm{PdBr}\right]^{-}$and $\left[\mathrm{L}_{3}^{\mathrm{Ph} 2} \mathrm{PdBr}\right]^{-}$showed that the loss of the less electron-withdrawing phosphine ligands occured at significantly lower acceleration energies $E_{\mathrm{LAB}}$, indicating a weaker palladium-ligand bond in these cases (figures 4.19 and 4.20 , see also figure 4.11 for $\left[\mathrm{L}_{3} \mathrm{PdBr}\right]^{-}$).

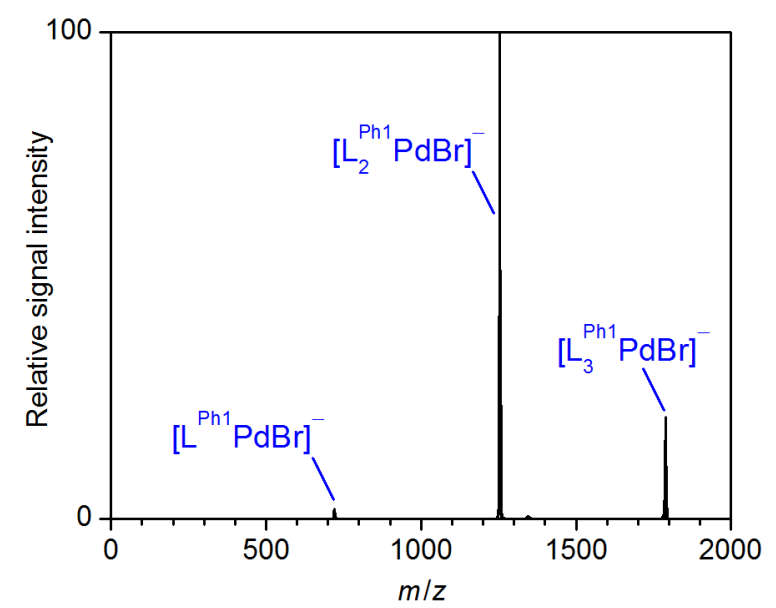

Figure 4.19: Mass spectrum of mass-selected $\left[\mathrm{L}_{3}^{\mathrm{Ph} 1} \mathrm{PdBr}\right]^{-}$and its fragment ions produced upon collision-induced dissociation $\left(E_{\mathrm{LAB}}=10.0 \mathrm{eV}\right)$.

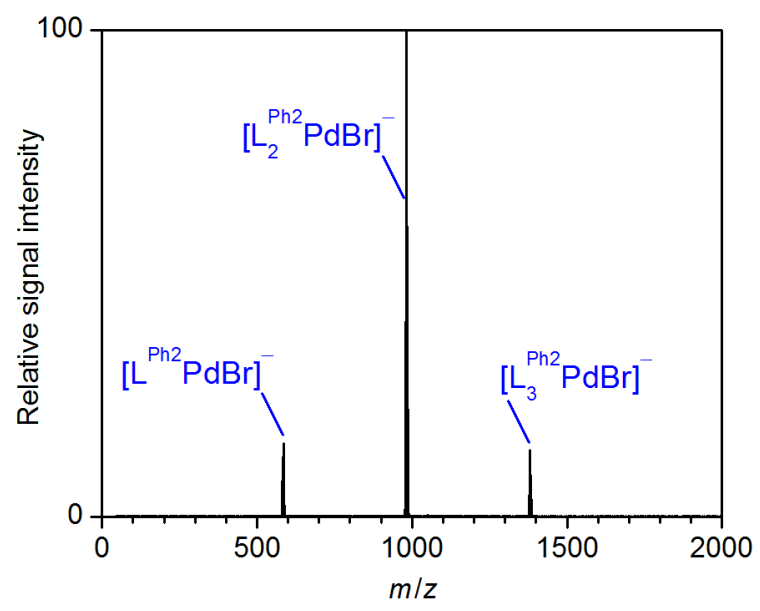

Figure 4.20: Mass spectrum of mass-selected $\left[\mathrm{L}_{3}^{\mathrm{Ph} 2} \mathrm{PdBr}\right]^{-}$and its fragment ions produced upon collision-induced dissociation $\left(E_{\mathrm{LAB}}=5.0 \mathrm{eV}\right)$.

To compare the tendencies of the different phosphine ligands to be incorporated in palladate complexes directly, competition experiments with $\mathrm{L}$ and $\mathrm{L}^{\mathrm{Ph} 1}$ or $\mathrm{L}^{\mathrm{Ph} 2}$, respectively, were conducted. To this end, solutions of $\left[\mathrm{L}_{3} \mathrm{Pd}\right]$ in THF were treated with three equivalents of $\mathrm{L}^{\mathrm{Ph} 1}$ or $\mathrm{L}^{\mathrm{Ph} 2}$ and $\mathrm{LiBr}$ and stirred for $10 \mathrm{~min}$. As could be expected due to the electronic properties of the applied ligands, the mass spectra recorded from these solutions demonstrated a strong 
preference for the coordination of the more electron-withdrawing phosphine ligand $\mathrm{L}$ to the palladium center of the anionic complexes, compared to the less electron-withdrawing $\mathrm{L}^{\mathrm{Ph} 1}$. The above-shown $\left[\mathrm{L}_{3} \mathrm{PdBr}\right]^{-}$dominated the spectrum, while mixed complexes $\left[\mathrm{L}^{\mathrm{Ph} 1} \mathrm{~L}_{2} \mathrm{PdBr}\right]^{-}$ and $\left[\mathrm{L}_{2}^{\mathrm{Ph} 1} \mathrm{LPdBr}\right]^{-}$were present at lower intensities. $\left[\mathrm{L}_{3}^{\mathrm{Ph} 1} \mathrm{PdBr}\right]^{-}$could only be detected with a very low signal intensity. The relative signal intensities of this complex and of the other $\mathrm{L}^{\mathrm{Ph} 1}$-containing species increased, as one would expect, when larger amounts of $\mathrm{L}^{\mathrm{Ph} 1}$ were added. The favored incorporation of $\mathrm{L}$ into the considered palladate species was even more pronounced when $\mathrm{L}^{\mathrm{Ph} 2}$ was added as second ligand. In this case, the only detectable $\mathrm{L}^{\mathrm{Ph} 2}$ containing palladate complex was $\left[\mathrm{L}^{\mathrm{Ph} 2} \mathrm{~L}_{2} \mathrm{PdBr}\right]^{-}$, even when the amount of added $\mathrm{L}^{\mathrm{Ph} 2}$ was increased to 20 equivalents relative to $\left[\mathrm{L}_{3} \mathrm{Pd}\right]$.

Gas-phase fragmentation experiments with the mixed complexes $\left[\mathrm{L}^{\mathrm{Ph} 2} \mathrm{~L}_{2} \mathrm{PdBr}\right]^{-}$, $\left[\mathrm{L}^{\mathrm{Ph} 1} \mathrm{~L}_{2} \mathrm{PdBr}\right]^{-}$, and $\left[\mathrm{L}_{2}^{\mathrm{Ph} 1} \mathrm{LPdBr}\right]^{-}$confirmed the stronger bond between the electron-poor phosphine $\mathrm{L}$ and the palladium center: The phenyl-substituted ligands $\mathrm{L}^{\mathrm{Ph} 1}$ and, especially, $\mathrm{L}^{\mathrm{Ph} 2}$ were dissociated preferably upon collision-induced dissociation, as energy-dependent CID experiments showed (equations 4.35) to 4.37), figures 4.21 and 4.22).

$$
\begin{aligned}
{\left[\mathrm{L}^{\mathrm{Ph} 2} \mathrm{~L}_{2} \mathrm{PdBr}\right]^{-} } & \longrightarrow\left[\mathrm{L}_{2} \mathrm{PdBr}\right]^{-}+\mathrm{L}^{\mathrm{Ph} 2} \\
{\left[\mathrm{~L}^{\mathrm{Ph} 1} \mathrm{~L}_{2} \mathrm{PdBr}\right]^{-} } & \longrightarrow\left[\mathrm{L}_{2} \mathrm{PdBr}\right]^{-}+\mathrm{L}^{\mathrm{Ph} 1} \\
{\left[\mathrm{~L}_{2}^{\mathrm{Ph} 1} \mathrm{LPdBr}\right]^{-} } & \longrightarrow\left[\mathrm{L}^{\mathrm{Ph} 1} \mathrm{LPdBr}\right]^{-}+\mathrm{L}^{\mathrm{Ph} 1}
\end{aligned}
$$

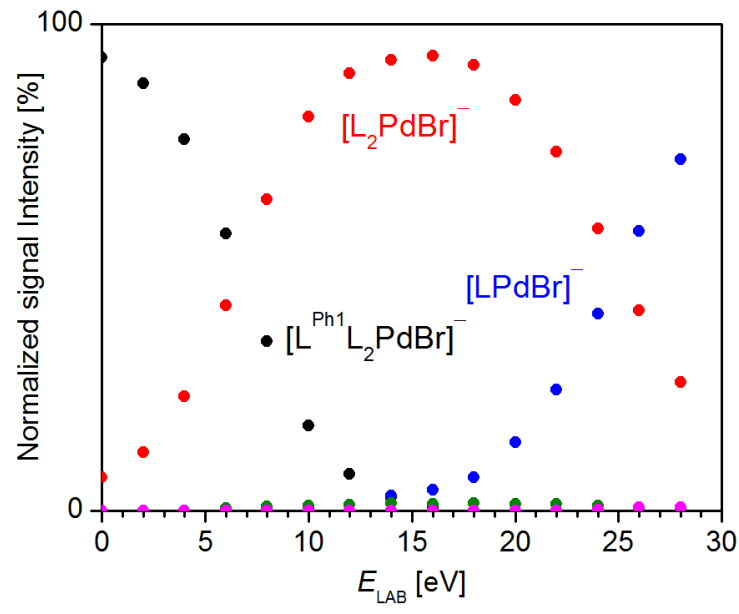

Figure 4.21: Normalized signal intensities of massselected $\left[\mathrm{L}^{\mathrm{Ph} 1} \mathrm{~L}_{2} \mathrm{PdBr}\right]^{-}$(black) and its fragment ions $\left[\mathrm{L}_{2} \mathrm{PdBr}\right]^{-}$(red), $[\mathrm{LPdBr}]^{-}$(blue), $\left[\mathrm{L}^{\mathrm{Ph} 1} \mathrm{LPdBr}\right]^{-}$(green), and $\left[\mathrm{L}^{\mathrm{Ph} 1} \mathrm{PdBr}\right]^{-}$(magenta) produced upon collision-induced dissociation at varying acceleration energies $E_{\mathrm{LAB}}$.

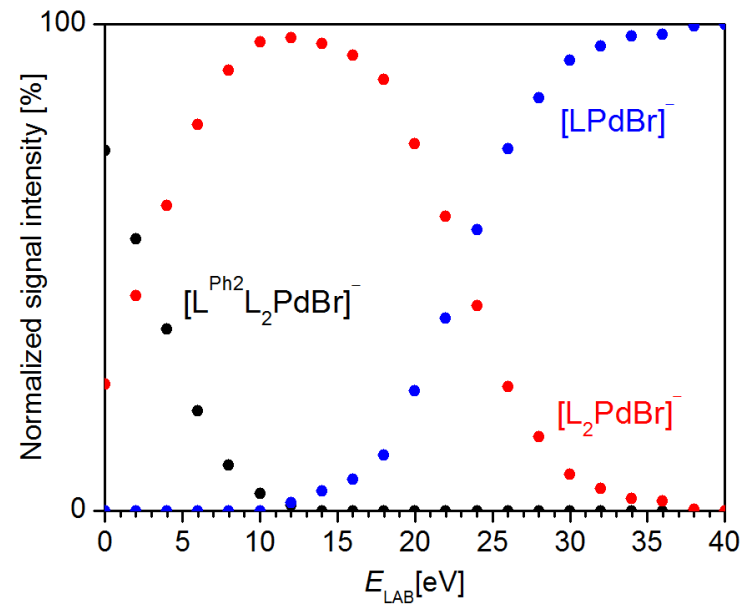

Figure 4.22: Normalized signal intensities of massselected $\left[\mathrm{L}^{\mathrm{Ph} 1} \mathrm{~L}_{2} \mathrm{PdBr}\right]^{-}$and its fragment ions $\left[\mathrm{L}_{2} \mathrm{PdBr}\right]^{-}$(red) and [LPdBr$^{-}$(blue) produced upon collision-induced dissociation at varying acceleration energies $E_{\mathrm{LAB}}$. 
The alternative dissociation of $\mathrm{L}$ was only observed in the case of $\left[\mathrm{L}^{\mathrm{Ph} 1} \mathrm{~L}_{2} \mathrm{PdBr}\right]^{-}$, where $\left[\mathrm{L}^{\mathrm{Ph} 1} \mathrm{LPdBr}\right]^{-}$was formed in very small amounts (equation $(4.38)$ ). When higher acceleration energies were applied, the dissociation of a second phosphine ligand could be induced in all cases (equations 4.39) and 4.40).

$$
\begin{aligned}
{\left[\mathrm{L}^{\mathrm{Ph} 1} \mathrm{~L}_{2} \mathrm{PdBr}\right]^{-} } & \longrightarrow\left[\mathrm{L}^{\mathrm{Ph} 1} \mathrm{LPdBr}\right]^{-}+\mathrm{L} \\
{\left[\mathrm{L}^{\mathrm{Ph} 1} \mathrm{LPdBr}\right]^{-} } & \longrightarrow[\mathrm{LPdBr}]^{-}+\mathrm{L}^{\mathrm{Ph} 1} \\
{\left[\mathrm{~L}_{2} \mathrm{PdBr}\right]^{-} } & \longrightarrow[\mathrm{LPdBr}]^{-}+\mathrm{L}
\end{aligned}
$$

In the competition experiments, the acceleration energies needed to bring about the dissociation of $\mathrm{L}$ were generally higher than those needed for the dissociation of $\mathrm{L}^{\mathrm{Ph} 1}$ and $\mathrm{L}^{\mathrm{Ph} 2}$, as was already seen for $\left[\mathrm{L}_{3}^{\mathrm{Ph} 1} \mathrm{PdBr}\right]^{-}$and $\left[\mathrm{L}_{3}^{\mathrm{Ph} 2} \mathrm{PdBr}\right]^{-}$. This finding, together with the preferred incorporation of the more electron-withdrawing complexes into the regarded palladate complexes, confirms the assumption that the bond between the palladium center and the phosphine ligand is stronger when the electron density at the aryl substituents of the phosphine ligand is reduced. This effect can be attributed to the $\pi$-backbonding interaction of the palladium center with the ligand, which can be expected to account for a substantial proportion of the bonding interaction between a very electron-rich metal center, such as a low-valent palladium center in an anionic complex, and a relatively electron-poor phosphine ligand. The more electron-withdrawing substituents are present in the phosphine ligands, the stronger the $\pi$-back-bonding becomes, resulting in a more stable palladium-ligand bond.

\subsubsection{Reactivity of Palladate Complexes $\left[\mathrm{L}_{n} \mathrm{PdX}\right]^{-}$Towards Organyl Electrophiles}

\section{Reactivity of Palladate Complexes $\left[\mathrm{L}_{n} \mathrm{PdX}\right]^{-}$Towards Aryl Halides in Solution}

The addition of ethyl 4-iodobenzoate (ArI) to solutions of $\left[\mathrm{L}_{3} \mathrm{Pd}\right]$ and $\mathrm{LiX}$, with $\mathrm{X}=\mathrm{Br}$ and I, resulted in the formation of palladate(II) complexes [ $\left.\mathrm{L}_{2} \mathrm{PdArIX}\right]^{-}$among other species, whereas the addition of $\mathrm{ArBr}$ did not lead to any aryl-containing palladates (figure 4.23 for ArI and $X=I)$. Time-dependent measurements showed that the signal intensity of the product ion $\left[\mathrm{L}_{2} \mathrm{PdArX}\right]^{-}$increased at the expense of the reactant ion $\left[\mathrm{L}_{3} \mathrm{PdX}\right]^{-}$(figure 4.24 for $\mathrm{X}=\mathrm{I}$ ). 


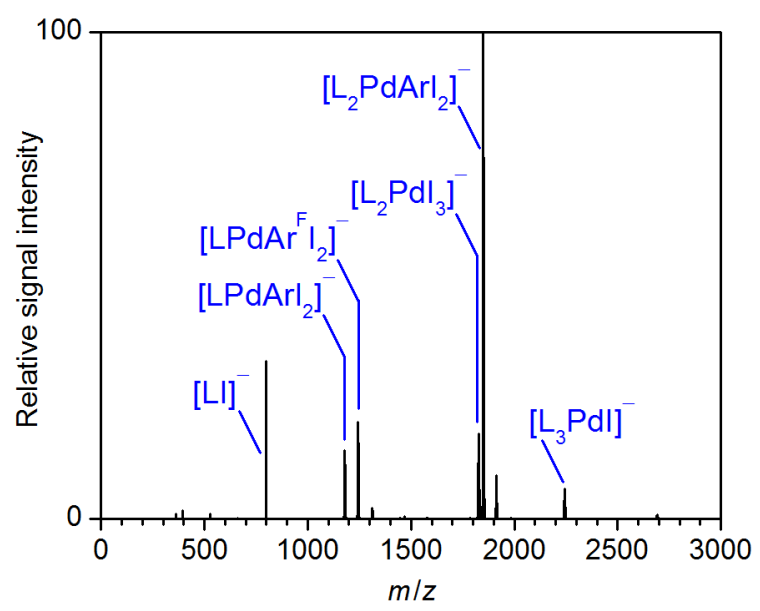

Figure 4.23: Negative-ion mode ESI mass spectrum of a solution of $\left[\mathrm{Pd}\left(\mathrm{PAr}_{3}^{\mathrm{F}}\right)_{3}\right]\left(\left[\mathrm{L}_{3} \mathrm{Pd}\right], 3 \mathrm{mM}\right)$, LiI (15 mM), and ethyl 4-iodobenzoate (ArI, $15 \mathrm{mM}$ ) in THF after $45 \mathrm{~min}$ reaction time at room temperature.

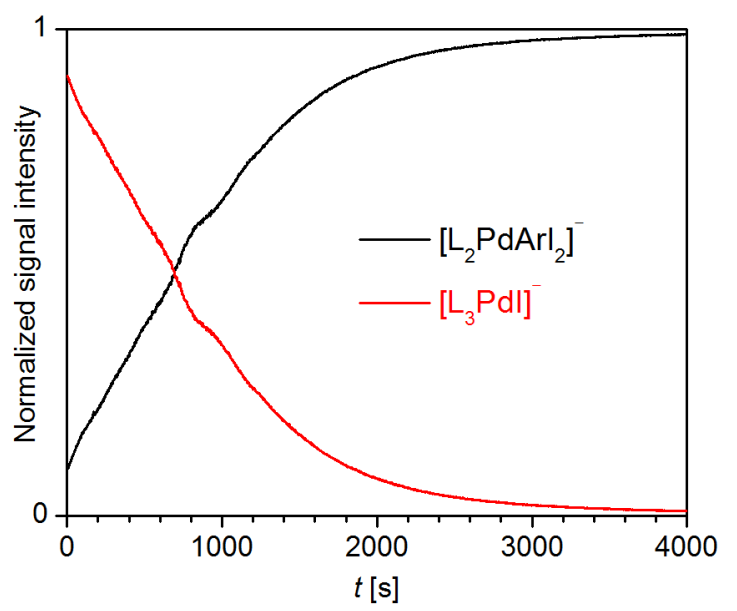

Figure 4.24: Time profiles of the normalized ESI signal intensities of $\left[\mathrm{L}_{3} \mathrm{PdI}\right]^{-}$(red) and $\left[\mathrm{L}_{2} \mathrm{PdArI}_{2}\right]^{-}$(black) observed after the addition of ethyl 4-iodobenzoate (ArI, $15 \mathrm{mM}$ ) to a solution of $\left[\mathrm{L}_{3} \mathrm{Pd}\right](3 \mathrm{mM})$ and $\mathrm{LiI}(15 \mathrm{mM})$ in THF. The measurement was started approx. 2 min after the addition of ArI.

For the product ion $\left.\left[\mathrm{L}_{2} \mathrm{PdArX}\right]_{2}\right]^{-}$, in the shown case $\left[\mathrm{L}_{2} \mathrm{PdArI}_{2}\right]^{-}$, two possible structures have been proposed (figure 4.25 .

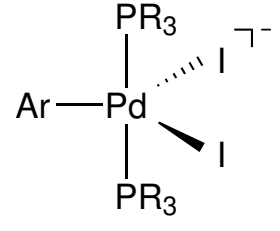

trigonal bipyramidal or<smiles>[3H][IH][Pb]([18OH])([18OH])I</smiles>

square-planar

Figure 4.25: Possible structures of the $\left[\mathrm{L}_{2} \mathrm{PdArI}_{2}\right]^{-}$intermediate as suggested by Amatore and coworkers $[14 \mathrm{~d}]$ and Gooßen and coworkers $[16]$.

The first possibility is a pentacoordinate structure resulting from a transfer of the aryl substituent to the palladium center. $\left[\frac{[4 \mathrm{~d}]}{1}\right.$ The other possibility is a tetracoordinate complex in which the aryl iodide binds to the palladium center over the iodine atom. [16] Gas-phase fragmentation of the ion in question led to the subsequent dissociation of the phosphine ligands as only fragmentation pathway. This behavior suggests a pentacoordinate structure, as in the other case a loss of ArI would be expected upon collision-induced dissociation. Preliminary studies of the said ion by ion mobility spectrometry were undertaken, but did not yield any conclusive results.

From the development of the signal intensities of only the two ions of interest, $\left[\mathrm{L}_{3} \mathrm{PdI}\right]^{-}$and $\left[\mathrm{L}_{2} \mathrm{PdArI}_{2}\right]^{-}$, an approximate reaction half life of $15 \mathrm{~min}$ was determined. However, it was obvious from the ESI mass spectra that several side reactions and follow-up reactions were taking place in the solution, such as ligand dissociation and ligand decomposition reactions and, in 
case of $\mathrm{X}=\mathrm{Br}$, halogen exchange reactions. In addition, as was mentioned above (section 2.5), the signal intensities cannot be assumed to correspond to the concentration of the regarded species in solution. Thus, the deduction of exact reaction rates from the signal intensities offers no promise of success.

Later, ESI-mass spectrometric studies of solutions of $\left[\mathrm{L}_{3} \mathrm{Pd}\right]$, various lithium salts $(\mathrm{LiCl}, \mathrm{LiBr}$, $\mathrm{LiI}$, and $\mathrm{Li}(\mathrm{OAc})$ ), and ArI demonstrated that the halide-containing sample solutions all showed analogous reactivity, with the reaction rate of the oxidative addition reaction slightly increasing in the order $\mathrm{I}<\mathrm{Br}<\mathrm{Cl} . \stackrel{[7]}{ }$ In these later experiments, the reaction was found to be generally faster than in the above-shown experiments. As different batches of the palladium catalyst and the aryl iodide were used in both series of experiments, the origin of these differences in reactivity is assumed to be lying in quality differences or storage-depending decay of the used chemicals. When lithium acetate was used instead of lithium halides, the fast formation of the oxidative addition product $\left[\mathrm{L}_{2} \mathrm{PdArI}(\mathrm{OAc})\right]^{-}$was observed, although the mass spectrum was dominated by the palladium-free $[\mathrm{L}(\mathrm{OAc})]^{-}$anion.

As the above-discussed results show, the analysis of the oxidative addition reaction of an aryl electrophile to a palladate complex $\left[\mathrm{L}_{n} \mathrm{PdX}\right]^{-}$in solution with the applied method poses several problems. In addition to the general difficulty to deduce reliable quantitative information on species in solution from signal intensities of ions in the gas phase, another problem is the complexity of the reaction mixture. Even if the assumed reactant ion and the assumed product ion are both represented in the mass spectrum, this does not necessarily mean that the latter is exclusively formed from the former in an oxidative addition reaction. For example, neutral complexes unaccessible to mass spectrometric analysis could also react in an oxidative addition reaction, then forming the product ion $\left[\mathrm{L}_{2} \mathrm{PdArIX}\right]^{-}$from $\left[\mathrm{L}_{2} \mathrm{PdArI}\right]$ by coordination of $\mathrm{X}^{-}$. Especially this last problem can be avoided by testing the reactivity of selected anions against electrophiles in the gas phase.

\section{Reactivity of Palladate Complexes $\left[\mathrm{L}_{n} \mathrm{PdX}\right]^{-}$Towards Organyl Electrophiles in the Gas Phase}

To test the bimolecular reactivity of selected palladates against organyl electrophiles in the gas phase, the species of interest were mass-selected and stored inside a quadrupole-ion trap, which contained the electrophile of choice as part of the background gas. The ions were exposed to the substrate gas for a defined reaction time before they were released from the ion trap and subsequently detected. As these experiments were conducted on a HCT quadrupole ion trap instrument, which was not able to probe heavier species such as $\left[\mathrm{L}_{3} \mathrm{PdX}\right]^{-}$, only the complexes bearing one and two phosphine ligands, respectively, could be analyzed. However, $\left[\mathrm{L}_{3} \mathrm{PdX}\right]^{-}$would have been unlikely to undergo any reactions with the electrophile without a preceding ligand loss in any case due to its lack of free coordination sites and its 18 valence electrons. In line with this assumption, no oxidative addition products bearing three phosphine ligands were observed in the experiments discussed above. 
The first gas-phase experiments were conducted with allyl bromide (AllBr) as electrophile, as a fast reaction with this substrate was expected. Indeed, when a sample solution of [ $\left.\mathrm{L}_{3} \mathrm{Pd}\right]$ and $\mathrm{LiBr}$ was analyzed by ESI mass spectrometry with AllBr as part of the background gas of the ion trap, small quantities of [ $\left.\mathrm{LPdAllBr}_{2}\right]^{-}$could already be observed in the $\mathrm{MS}^{1}$ spectrum (figure 4.26). Exposure of mass-selected [ $\mathrm{LPdBr}]^{-}$to $\mathrm{AllBr}$ in the gas phase also led to the expected product of the oxidative addition, $\left[\mathrm{LPdAllBr}_{2}\right]^{-}$, after short reaction times (equation (4.41), figure 4.27).

$$
[\mathrm{LPdBr}]^{-}+\mathrm{AllBr} \longrightarrow\left[\mathrm{LPdAllBr}_{2}\right]^{-}
$$

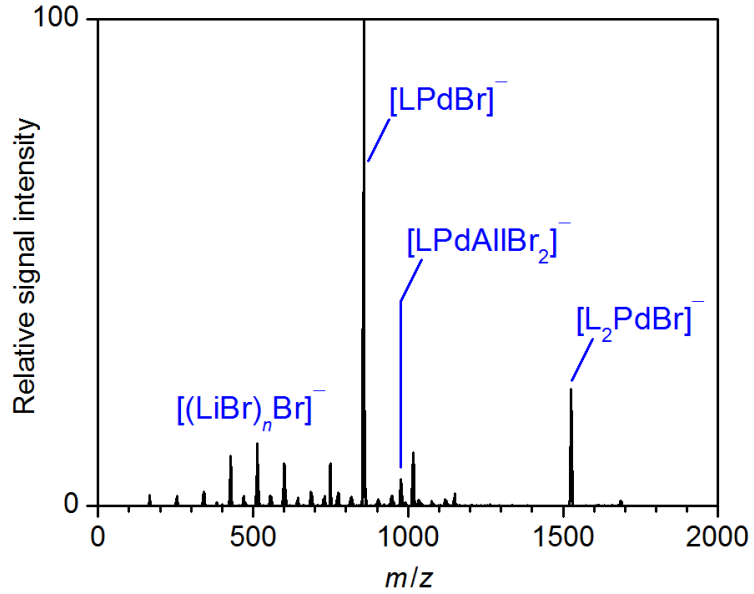

Figure 4.26: Negative-ion mode ESI mass spectrum of a solution of $\left[\mathrm{Pd}\left(\mathrm{PAr}_{3}^{\mathrm{F}}\right)_{3}\right]\left(\left[\mathrm{L}_{3} \mathrm{Pd}\right], 3 \mathrm{mM}\right)$ and $\mathrm{LiBr}(15 \mathrm{mM})$ in THF exposed to AllBr in the gas phase.

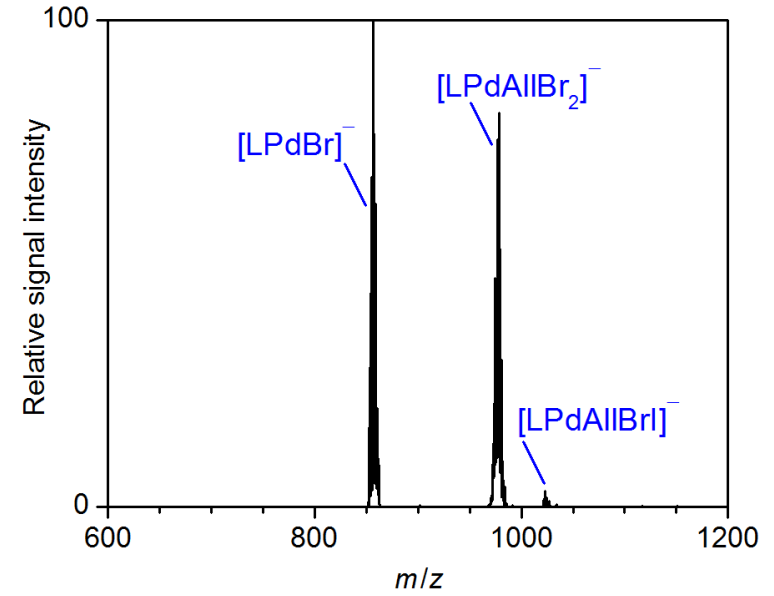

Figure 4.27: Mass spectrum of mass-selected $[\mathrm{LPdBr}]^{-}$and its product ions formed after the reaction with $\mathrm{AllBr}$ in the gas phase after a reaction time of $300 \mathrm{~ms}$.

In addition to the expected ions, [LPdAllBrI ${ }^{-}$was also detected in small signal intensities, which presumably stems from a contamination of the gas-mixing apparatus with allyl iodide. Plotting the relative signal intensities of the species of interest as a function of the reaction time showed an exponential decay of the reactant ion and a corresponding increase of the product ion. This is in line with the expectations, as the excess of substrate gas in the ion trap allows the assumption of pseudo-first order conditions for the considered reaction.

Next, taking into account that $\mathrm{sp}^{2}$-hybridized electrophiles are frequently used in cross-coupling reactions with the present palladium catalyst, vinyl iodide (VinI) was chosen as a model substrate. Mass-selected [LPdBr] ${ }^{-}$reacted with VinI in the gas phase to give the expected product ion [LPdVinBrI] ${ }^{-}$selectively (equation 4.42), figure 4.28).

$$
[\mathrm{LPdBr}]^{-}+\mathrm{VinI} \longrightarrow[\mathrm{LPdVinBrI}]^{-}
$$


In contrast, the reaction of $\left[\mathrm{L}_{2} \mathrm{PdBr}\right]^{-}$with VinI did not form the expected product ion $\left[\mathrm{L}_{2} \mathrm{PdVinBrI}\right]^{-}$. Instead, the product ion bearing only one phosphine ligand, [LPdVinBrI $]^{-}$, was observed in low signal intensities along with $[\mathrm{LPdBr}]^{-}$(figure 4.29). This observation suggests a dissociative mechanism taking place, in which the $\left[\mathrm{L}_{2} \mathrm{PdBr}\right]^{-}$ion first loses a phosphine ligand and reacts with VinI in the second step (equation (4.43)). The other imaginable mechanism for the formation of [LPdVinBrI ${ }^{-}$, starting with the oxidative addition of VinI followed by a ligand dissociation, seems unlikely as it does not account for the formation of $[\mathrm{LPdBr}]^{-}$. Also, the detection of $\left[\mathrm{L}_{2} \mathrm{PdVinBrI}\right]^{-}$at least in small amounts would be expected in this case.

$$
\left[\mathrm{L}_{2} \mathrm{PdBr}\right]^{-} \underset{-\mathrm{L}}{\longrightarrow}[\mathrm{LPdBr}]^{-} \stackrel{+\mathrm{VinI}}{\longrightarrow}[\mathrm{LPdVinBrI}]^{-}
$$

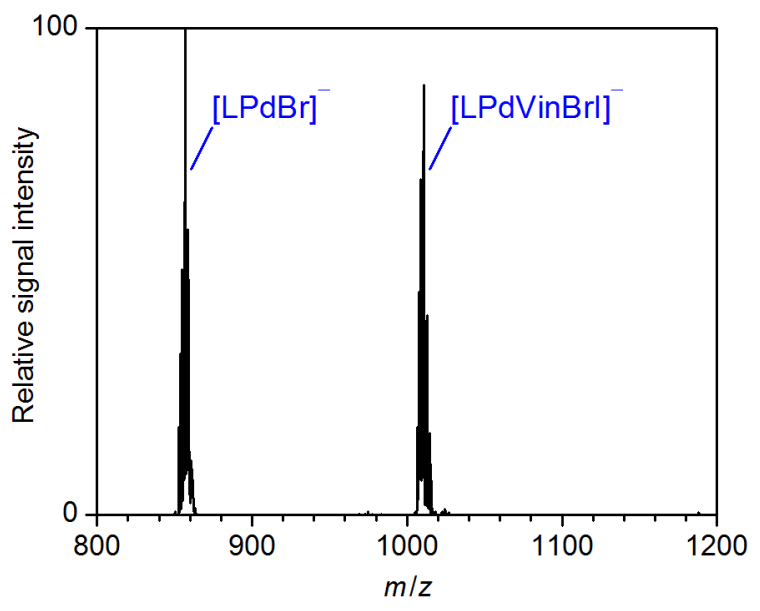

Figure 4.28: Mass spectrum of mass-selected $\left.{ }^{\mathrm{LPdBr}}\right]^{-}$and its product ions formed after the reaction with VinI in the gas phase after a reaction time of $1.6 \mathrm{~s}$.

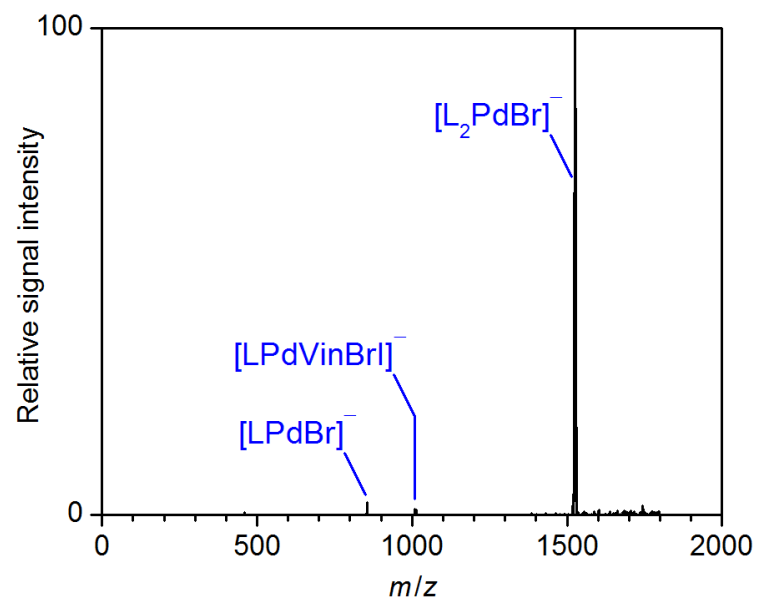

Figure 4.29: Mass spectrum of mass-selected $\left[\mathrm{L}_{2} \mathrm{PdBr}\right]^{-}$and its product ions formed after the reaction with VinI in the gas phase after a reaction time of $2.0 \mathrm{~s}$.

When the relative signal intensities of $[\mathrm{LPdBr}]^{-}$and $[\mathrm{LPdVinBrI}]^{-}$were plotted as a function of the reaction time and the resulting curve was fitted with an exponential function, the pseudofirst order reaction rate $k_{1}$ was directly accessible from the exponent of the fit function (figure 4.30). 


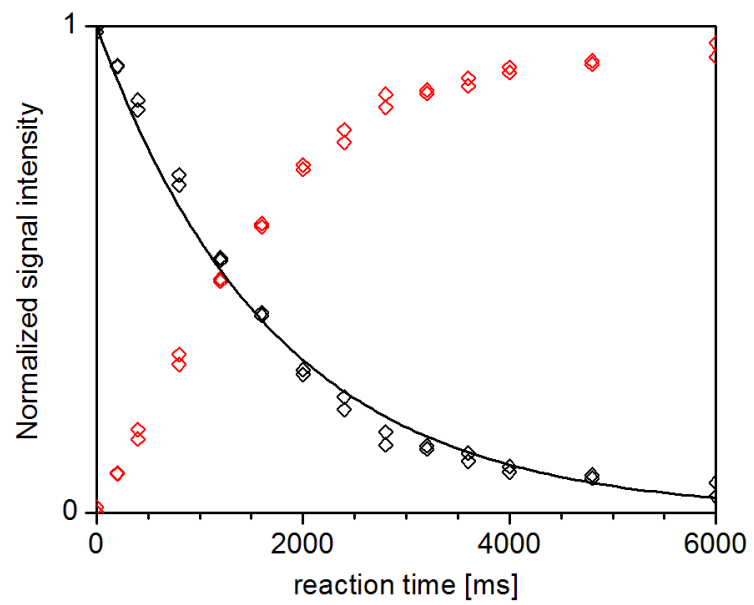

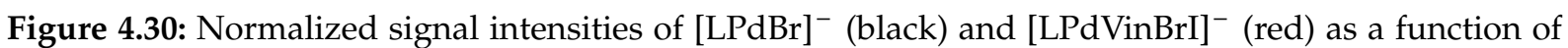
the reaction time, together with an exponential function fitted to the data points showing the decay of $[\mathrm{LPdBr}]^{-}$(black line).

Absolute bimolecular rate constants $k_{2}$ can be calculated from $k_{1}$ by dividing it by the number density of the substrate $N_{S}$ inside the ion trap (equation (4.44). .69$]$ The number density $N_{S}$ is derived from the absolute helium pressure inside the ion trap $p_{\mathrm{He}}$ and the amounts of helium and substrate gas in the ion trap, $n_{\mathrm{He}}$ and $n_{\mathrm{S}}$. Both amounts are accessible by the amounts of substrate gas and helium introduced into the gas mixing chamber, $n_{\mathrm{He}, \mathrm{GMC}}$ and $n_{\mathrm{S}, \mathrm{GMC}}$ (equations (4.45) and (4.46) with $M_{\mathrm{He}}$ and $M_{\mathrm{S}}$ representing the molar mass of helium and the substrate gas). The correction factor $\frac{\sqrt{M_{S}}}{\sqrt{M_{\mathrm{He}}}}$ is introduced in order to compensate for the slower diffusion of the reactant gas compared to helium. $n_{\mathrm{He}, \mathrm{GMC}}$ was determined to be 0.601 mol over the ideal gas law (equation 4.47) with $V_{\mathrm{GMC}}=2.5 \mathrm{~L}, p_{\mathrm{He}, \mathrm{GMC}}=6.0 \mathrm{bar}, R=8.314 \mathrm{~J} \cdot \mathrm{mol}^{-1} \cdot \mathrm{K}$, and $\left.T_{\mathrm{GMC}}=300 \mathrm{~K}\right) \cdot n_{\mathrm{S}, \mathrm{GMC}}$ was calculated from the volume $V_{\mathrm{S}}$ of the liquid substrate introduced into the gas mixing chamber, its density at room temperature $\rho_{\mathrm{S}}$, and its molar mass $M_{\mathrm{S}}$ according to equation (4.48).

$$
\begin{aligned}
k_{2} & =\frac{k_{1}}{N_{\mathrm{S}}} \\
N_{\mathrm{S}} & =\frac{p_{\mathrm{He}} \cdot \frac{n_{\mathrm{S}}}{n_{\mathrm{He}}} \cdot N_{\mathrm{A}}}{R \cdot T} \\
\frac{n_{\mathrm{S}}}{n_{\mathrm{He}}} & =\frac{n_{\mathrm{S}, \mathrm{GMC}}}{n_{\mathrm{He}, \mathrm{GMC}}} \cdot \frac{\sqrt{M_{\mathrm{S}}}}{\sqrt{M_{\mathrm{He}}}} \\
n_{\mathrm{He}, \mathrm{GMC}} & =\frac{V_{\mathrm{GMC}} \cdot p_{\mathrm{He}, \mathrm{GMC}}}{R \cdot T_{\mathrm{GMC}}} \\
n_{\mathrm{S}, \mathrm{GMC}} & =\frac{V_{\mathrm{S}} \cdot \rho_{\mathrm{S}}}{M_{\mathrm{S}}}
\end{aligned}
$$

For the reaction of $[\mathrm{LPdCl}]^{-}, \mathrm{LPdBr}^{-}$, and $[\mathrm{LPdI}]^{-}$with VinI, absolute bimolecular rate constants $k_{2}$ between $1.87 \cdot 10^{-11}$ and $5.95 \cdot 10^{-11} \mathrm{~cm}^{3} \cdot \mathrm{s}^{-1}$ were obtained (table 4.3 ). The deviations between the values obtained for different experiments are below $30 \%$, which is the expected error of rate constants determined with the present method. 69779 
Table 4.3: Absolute rate constants $k_{2}$ for the reaction between $[\mathrm{LPdCl}]^{-}$, $[\mathrm{LPdBr}]^{-}$, or $[\mathrm{LPdI}]^{-}$and vinyl iodide.

\begin{tabular}{llll}
\hline & [LPdCl] $^{-}$ & [LPdBr] $^{-}$ & [LPdI $^{-}$ \\
\hline $\boldsymbol{k}_{\mathbf{2}}(\mathbf{1})\left[\mathrm{cm}^{3} \cdot \mathrm{s}^{-1}\right]$ & $1.87 \cdot 10^{-11}$ & $2.51 \cdot 10^{-11}$ & $5.08 \cdot 10^{-11}$ \\
$\boldsymbol{k}_{\mathbf{2}}(\mathbf{2})\left[\mathrm{cm}^{3} \cdot \mathrm{s}^{-1}\right]$ & $1.90 \cdot 10^{-11}$ & $2.90 \cdot 10^{-11}$ & $5.95 \cdot 10^{-11}$ \\
$\boldsymbol{k}_{\mathbf{2}}(\mathbf{3})\left[\mathrm{cm}^{3} \cdot \mathrm{s}^{-1}\right]$ & & & $5.95 \cdot 10^{-11}$ \\
\hline
\end{tabular}

Comparing the gas-phase reaction rates of $[\mathrm{LPdCl}]^{-},[\mathrm{LPdBr}]^{-}$, and $[\mathrm{LPdI}]^{-}$in the reaction with vinyl iodide, a slight increase in reactivity in the order $\mathrm{Cl}<\mathrm{Br}<\mathrm{I}$ could be observed. While the difference between $[\mathrm{LPdCl}]^{-}$and $[\mathrm{LPdBr}]^{-}$was rather small, $k_{2}$ for the reaction of [LPdI] ${ }^{-}$ with VinI exceeded that for $[\mathrm{LPdBr}]^{-}$by a factor of two. This behavior might be explained by the electronic properties of the considered halides. The stronger $\sigma$-donating ability of the iodide ligand leads to an increased electron density at the palladium center, thus increasing its tendency to undergo oxidative addition reactions. In general, though, the differences in the reactivites of the halide-containing palladates towards the vinyl electrophile were rather small. In contrast, no reaction at all could be observed for the acetate-coordinated palladate [LPd(OAc) $]^{-}$ with VinI in the gas phase. A possible reason for this could be a bidentate coordination of the acetate ligand to the palladium center, which would block an additional coordination site. A reaction of tricoordinated palladium, at least in the gas phase, does not seem favorable in this case. This assumption is backed up by the gas-phase experiments with $\left[\mathrm{L}_{2} \mathrm{PdBr}\right]^{-}$(see above), which also showed no oxidative addition of VinI.

It has to be noted that the above results stand in contrast to the reactivities of palladate complexes $\left[\mathrm{L}_{2} \mathrm{PdX}\right]^{-}$towards ethyl 4-iodobenzoate in solution, where a fast reaction of the acetatecontaining complex $\left[\mathrm{L}_{2} \mathrm{Pd}(\mathrm{OAc})\right]^{-}$was observed and the reactivity of the halide-containing species increased in the order $(\mathrm{X}=\mathrm{I}<\mathrm{Br}<\mathrm{Cl})$. A similar trend was found by Amatore and Jutand for the reaction of $\left[\left(\mathrm{PPh}_{3}\right)_{2} \mathrm{PdX}\right]^{-}$, with $\mathrm{X}=\mathrm{Br}, \mathrm{Cl}$, with phenyl iodide $(\mathrm{X}=\mathrm{Br}<\mathrm{Cl}), \underline{14 \mathrm{~b}}$ which was attributed to the $\pi$-donor abilities of the halide ligands. $.12 f[80]$ One explanation for this discrepancy might lie in the different number and nature of phosphine ligands present in the precursor ions as well as in the different organyl electrophile. However, it also suggests that while gas-phase experiments reveal the intrinsic reactivity of the palladate complexes of interest, the investigation of their reactivity in solution can lead to different results due to additional factors such as counterion and solvent effects.

The aryl electrophile used for the oxidative addition in solution, ethyl 4-iodobenzoate, could not be transferred into the gas phase. Therefore, phenyl iodide (PhI) was chosen as an alternative with higher vapor pressure. However, the reaction of $[\mathrm{LPdBr}]^{-}$with $\mathrm{PhI}$ in the gas phase was too slow to be kinetically analyzed by the chosen method. Even exposure to larger amounts of $\mathrm{PhI}$ in the gas phase $\left(N_{\mathrm{PhI}}=7.9 \cdot 10^{10} \mathrm{~cm}^{-3}\right.$ compared to $\left.N_{\text {VinI }}=2.1 \cdot 10^{10} \mathrm{~cm}^{-3}\right)$ at reaction times of $8 \mathrm{~s}$ showed only minimal amounts of the expected product ion. Reaction 
times longer than this impaired the overall signal intensities significantly, which made phenyl iodide an unsuitable substrate for kinetic analysis in this case.

\subsubsection{Role of Palladate Complexes $\left[\mathrm{L}_{n} \mathrm{PdX}\right]^{-}$in Cross-Coupling Reactions}

The results discussed above demonstrate that palladate complexes as suggested by Amatore and Jutand (section 1.2) are indeed formed from palladium(0) catalysts with phosphine ligands in the presence of lithium salts. With the electron-withdrawing ligand L, palladate complexes $\left[\mathrm{L}_{n} \mathrm{PdX}\right]^{-}$were the dominating species in solution, which is in line with the findings of Negishi $[\underline{[13]}$ and Amatore and Jutand $[\stackrel{[14 \mathrm{~b}]}{=}$ for complexes bearing triphenylphosphine ligands. Furthermore, in synthetic practice, the amounts of salt additives often significantly exceed the quantities chosen for the above-discussed studies, presumably shifting the association equilibrium even further to the side of the palladate complexes. ${ }^{[12]}$ Thus, a predominance of anionic species can be assumed for related catalytic systems also under synthetic conditions.

Additionally, the observation of oxidative addition reactions of palladate complexes $\left[\mathrm{L}_{n} \mathrm{PdX}\right]^{-}$ with organyl electrophiles in solution $(n=2)$ and in the gas phase $(n=1,2)$ confirmed the direct participation of anionic species as reactive intermediates in the catalytic cycle. These findings corroborate the operation of a catalytic cycle involving palladate anions rather than neutral palladium complexes in the presence of halide or acetate salts (scheme 4.1).

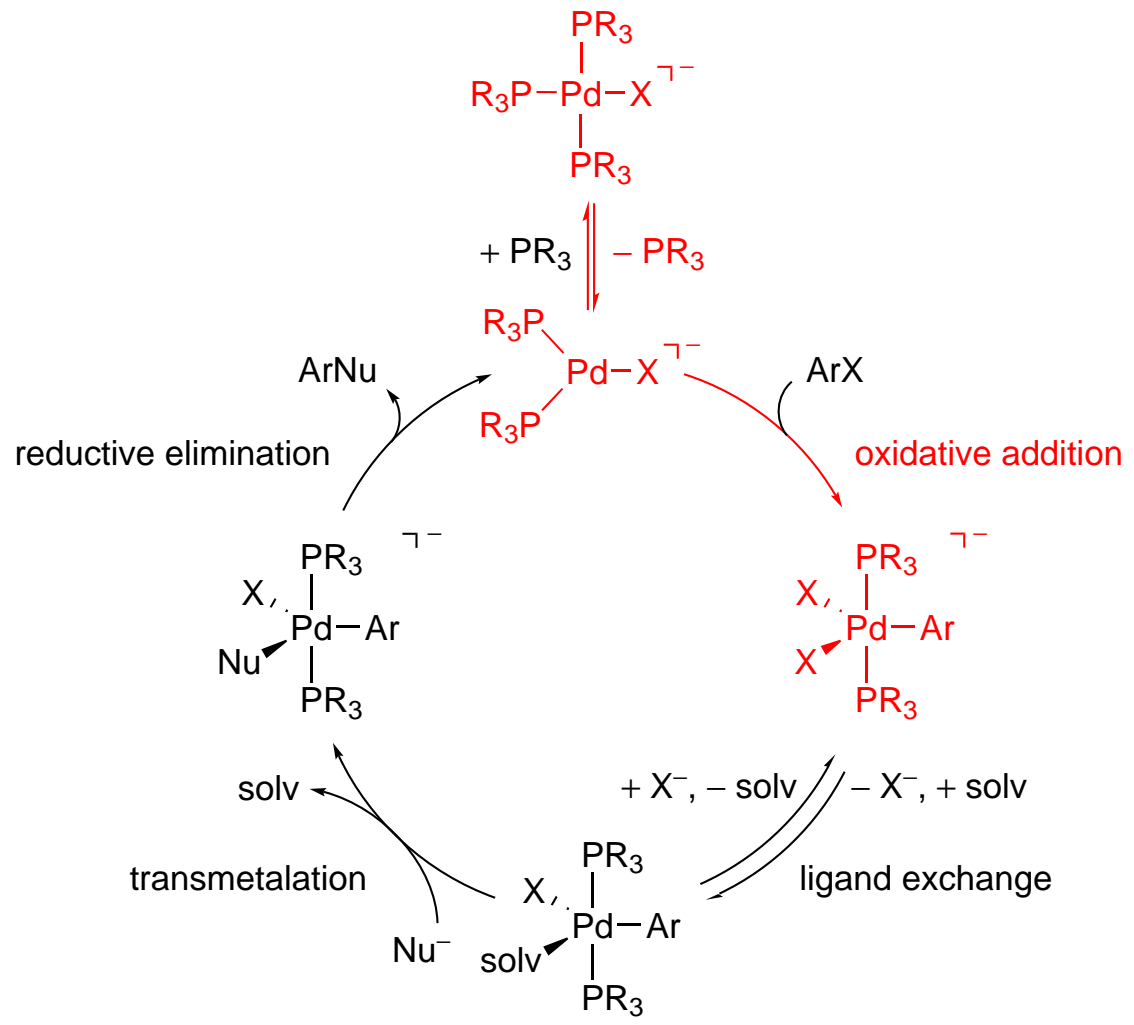

Scheme 4.1: Catalytic cycle of a palladium-catalyzed cross-coupling reaction between an aryl halide ArX and a nucleophile $\mathrm{Nu}^{-}$involving palladate intermediates. $|14 \mathrm{~d}| 14 \mathrm{~g} \mid$ Complexes and reactions marked in red were directly observed by ESI mass spectrometry or gas-phase experiments. 


\subsection{Organopalladate Intermediates in Cross-Coupling Reactions in the Presence of 1,3-Diene Ligands}

To monitor reactive intermediates that are formed during palladium-catalyzed cross-coupling in the presence of 1,3-diene ligands, palladium precursors were combined with 1,3-butadiene or isoprene and organometallic reagents.

\subsubsection{Transmetalation of $\left[\mathrm{Pd}_{2}(\mathrm{dba})_{3}\right]$ with Grignard Reagents in the Presence of 1,3-Diene Ligands}

As shown in the catalytic cycle proposed by Kambe and coworkers (section 1.4, scheme 1.4, the transmetalation step takes place on a bis-allylic palladium complex that is formed by the reaction of a palladium(0) precursor with 1,3-diene ligands (DE). Therefore, in a first series of experiments, the zero-valent catalyst precursor tris(dibenzylideneacetone)dipalladium( 0 ) $\left(\left[\mathrm{Pd}_{2}(\mathrm{dba})_{3}\right]\right)$ was treated with various transmetalating reagents in the presence of 1,3 -butadiene or isoprene. Control experiments without any diene ligand showed the rapid formation of palladium black, and no satisfactory signal intensities could be achieved in ESI-mass spectrometric experiments. Generally, signal intensities were higher and more stable over time when isoprene was used as a ligand. In contrast to this, the use of 1,3-butadiene led to lower signal intensities of the palladate ions of interest and a faster decay of the sample solutions.

ESI mass spectrometry of mixtures of $\left[\mathrm{Pd}_{2}(\mathrm{dba})_{3}\right]$, isoprene $\left(\mathrm{DE}^{\mathrm{I}}\right)$, and $n$ - $\mathrm{BuMgCl}$ showed the formation of $\left[\mathrm{Pd}_{2} \mathrm{Bu}\left(\mathrm{DE}^{\mathrm{I}}\right)_{2}\right]^{-}$and $\left[\mathrm{Pd}_{4} \mathrm{Bu}\left(\mathrm{DE}^{\mathrm{I}}\right)_{4}\right]$ as main species (figure 4.31). Similar results were obtained when using 1,3-butadiene as a ligand, although here, $\left[\mathrm{Pd}_{2} \mathrm{Bu}\left(\mathrm{DE}^{\mathrm{B}}\right)_{3}\right]^{-}$and the short-lived trinuclear palladates $\left[\mathrm{Pd}_{3} \mathrm{Bu}\left(\mathrm{DE}^{\mathrm{B}}\right)_{3}\right]^{-}$and $\left[\mathrm{Pd}_{3} \mathrm{Bu}\left(\mathrm{DE}^{\mathrm{B}}\right)_{4}\right]^{-}$could be observed as well (figure 4.32).

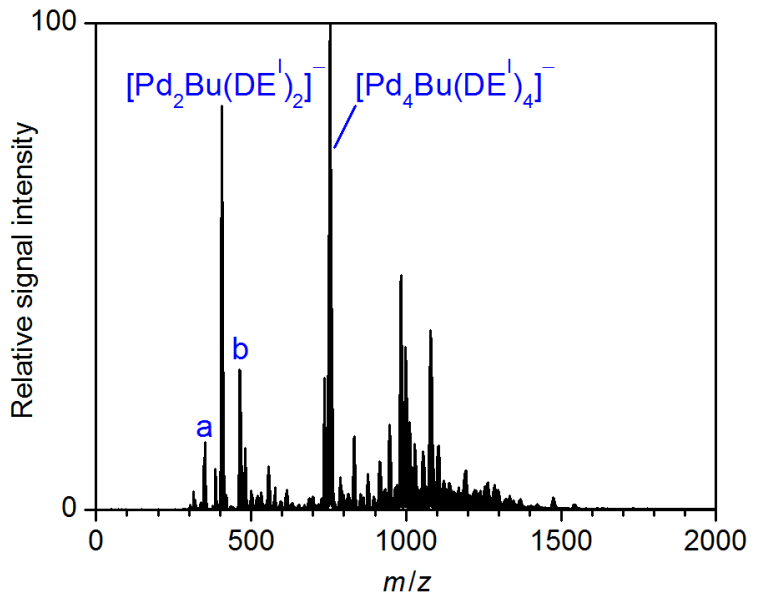

Figure 4.31: Negative-ion mode ESI mass spectrum (excerpt) of a solution of $\left[\mathrm{Pd}_{2}(\mathrm{dba})_{3}\right]$ $(1.5 \mathrm{mM})$, isoprene $\left(\mathrm{DE}^{\mathrm{I}}, 24 \mathrm{mM}\right)$, and $n$ $\mathrm{BuMgCl}(12 \mathrm{mM})$ in THF $\left(\mathrm{a}=\left[\mathrm{Pd}_{2} \mathrm{H}\left(\mathrm{DE}^{\mathrm{I}}\right)_{2}\right]^{-}\right.$, $\left.\mathrm{b}=\left[\mathrm{Pd}_{2} \mathrm{Bu}_{2} \mathrm{H}\left(\mathrm{DE}^{\mathrm{I}}\right)_{2}\right]^{-}\right)$.

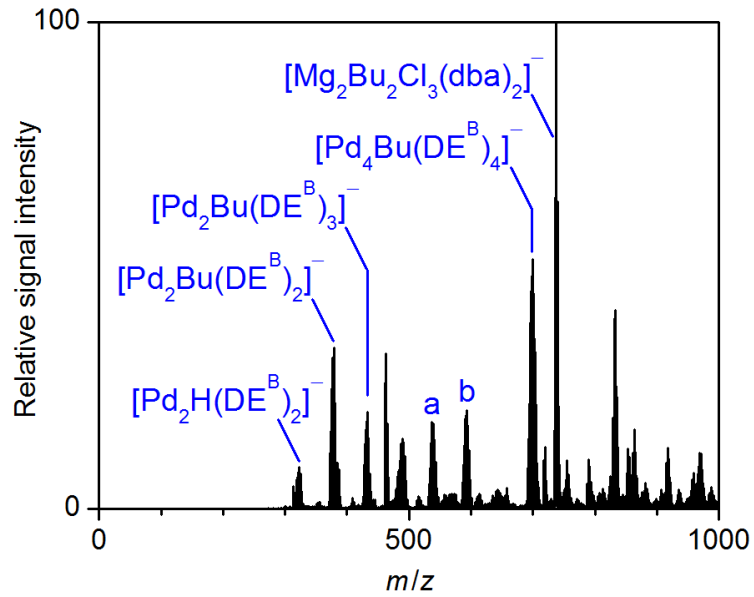

Figure 4.32: Negative-ion mode ESI mass spectrum (excerpt) of a solution of $\left[\mathrm{Pd}_{2}(\mathrm{dba})_{3}\right]$ $(1.5 \mathrm{mM}), 1,3$-butadiene $\left(\mathrm{DE}^{\mathrm{B}}, 24 \mathrm{mM}\right)$, and $n$ $\mathrm{BuMgCl}(12 \mathrm{mM})$ in THF $\left(\mathrm{a}=\left[\mathrm{Pd}_{3} \mathrm{H}\left(\mathrm{DE}^{\mathrm{B}}\right)_{4}\right]^{-}+\right.$ $\left.\left[\mathrm{Pd}_{3} \mathrm{Bu}\left(\mathrm{DE}^{\mathrm{B}}\right)_{3}\right]^{-}, \mathrm{b}=\left[\mathrm{Pd}_{3} \mathrm{Bu}\left(\mathrm{DE}^{\mathrm{B}}\right)_{4}\right]^{-}\right)$. 
In both cases, products of $\beta$-hydride elimination reactions such as $\left[\mathrm{Pd}_{2} \mathrm{H}(\mathrm{DE})_{2}\right]^{-}$were present. Whether these species were genuine components of the sample solution or were formed during the ESI process could not be established with certainty.

Substituting $n$ - $\mathrm{BuMgCl}$ with $\mathrm{PhMgCl}$ led to the analogous dinuclear species $\left[\mathrm{Pd}_{2} \mathrm{Ph}(\mathrm{DE})_{2}\right]^{-}$for both diene ligands and also to $\left[\mathrm{Pd}_{4} \mathrm{Ph}\left(\mathrm{DE}^{\mathrm{I}}\right)_{4}\right]^{-}$in the presence of isoprene (figure 4.33). However, trisubstituted species such as $\left[\mathrm{PdPh}_{3}(\mathrm{DE})\right]^{-}$and $\left[\mathrm{Pd}_{2} \mathrm{Ph}_{3}(\mathrm{DE})_{2}\right]^{-}$were much more abundant in these systems, especially with 1,3-butadiene as a ligand. A similar behavior could be observed with $\mathrm{BnMgCl}$ as a transmetalating agent, although the signal intensities of the triply substituted palladates were not quite as high as in the case of $\mathrm{PhMgCl}$ (figure 4.34).

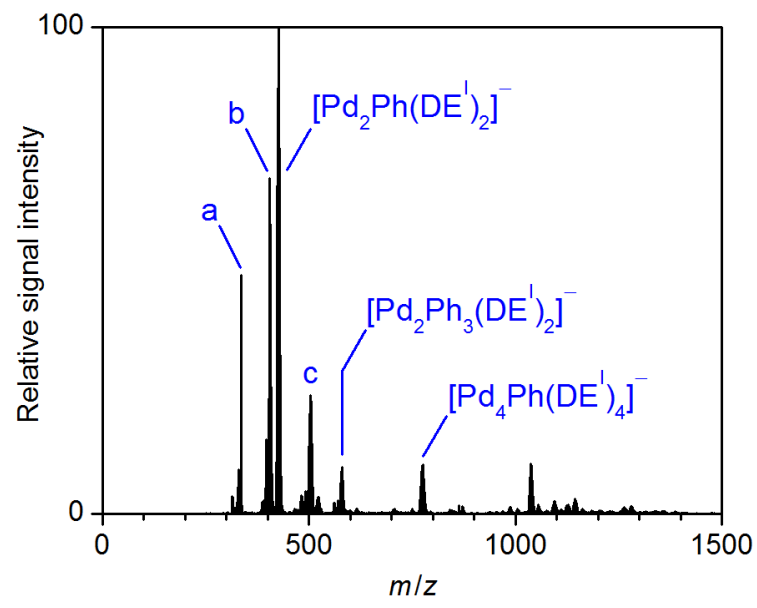

Figure 4.33: Negative-ion mode ESI mass spectrum of a solution of $\left[\mathrm{Pd}_{2}(\mathrm{dba})_{3}\right](1.5 \mathrm{mM})$, isoprene $\left(\mathrm{DE}^{\mathrm{I}}, 24 \mathrm{mM}\right)$, and $\mathrm{PhMgCl}(12 \mathrm{mM})$ in THF $\left(\mathrm{a}=\left[\mathrm{AlPh}_{4}\right]^{-}, 43 \mathrm{~b}=\left[\mathrm{PdPh}_{3}\left(\mathrm{DE}^{\mathrm{I}}\right)\right]^{-}\right.$, $\left.\mathrm{c}=\left[\mathrm{Pd}_{2} \mathrm{Ph}_{2}\left(\mathrm{DE}^{\mathrm{I}}\right)_{2}-\mathrm{H}\right]^{-}+\left[\mathrm{Pd}_{2} \mathrm{Ph}_{2} \mathrm{H}\left(\mathrm{DE}^{\mathrm{I}}\right)_{2}\right]^{-}\right)$.

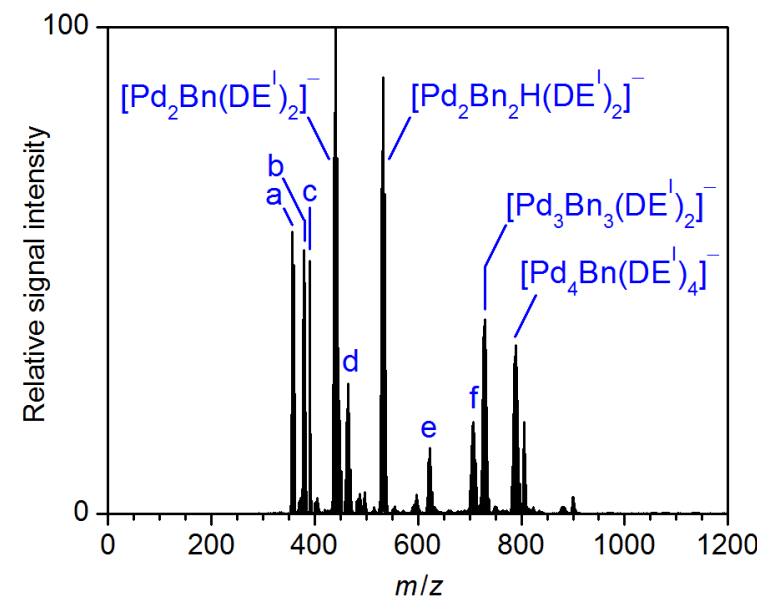

Figure 4.34: Negative-ion mode ESI mass spectrum (excerpt) of a solution of $\left[\mathrm{Pd}_{2}(\mathrm{dba})_{3}\right](1.5 \mathrm{mM})$, isoprene $\left(\mathrm{DE}^{\mathrm{I}}, 24 \mathrm{mM}\right)$, and $\mathrm{BnMgCl}(12 \mathrm{mM})$ in $\mathrm{THF} \quad\left(\mathrm{a}=\left[\mathrm{PdBn}_{2} \mathrm{H}\left(\mathrm{DE}^{\mathrm{I}}\right)\right]^{-}, \quad \mathrm{b}=\left[\mathrm{PdBn}_{3}\right]^{-}\right.$, $\left.\mathrm{c}=\left[\mathrm{AlBn}_{4}\right]^{-}, \mathrm{d3}\right] \mathrm{d}=\left[\mathrm{Pd}_{2} \mathrm{Bn}_{2} \mathrm{H}\left(\mathrm{DE}^{\mathrm{I}}\right)\right]^{-}$, $\left.\mathrm{e}=\left[\mathrm{Pd}_{2} \mathrm{Bn}_{3}\left(\mathrm{DE}^{\mathrm{I}}\right)_{2}\right]^{-}, \mathrm{f}=\left[\mathrm{Pd}_{3} \mathrm{Bn}_{2} \mathrm{H}\left(\mathrm{DE}^{\mathrm{I}}\right)_{3}\right]^{-}\right)$.

These complexes displayed higher oxidation states than the monosubstituted palladates $\left[\mathrm{Pd}_{2} \mathrm{R}(\mathrm{DE})_{2}\right]^{-}$, which indicates an oxidation process. A possible explanation for the presence of these species could be the reaction of the low-valent palladate complexes with traces of oxygen in the sample solutions or in the ESI source or with traces of organyl halides $\mathrm{RCl}$ from the used Grignard reagents followed by transmetalation.

Furthermore, hydride-containing species $\left[\mathrm{Pd}_{2} \mathrm{R}_{2} \mathrm{H}(\mathrm{DE})_{2}\right]^{-}$were present, which could also be observed for $\mathrm{R}=n$-Bu to a smaller extent. Whereas the formation of $\left[\mathrm{Pd}_{2} \mathrm{Bu}_{2} \mathrm{H}(\mathrm{DE})_{2}\right]^{-}$possibly involved a $\beta$-hydride elimination step to yield the hydride complex, for $\mathrm{R}=\mathrm{Ph}$ and $\mathrm{R}=\mathrm{Bn}$, the formation of such species has to be explained otherwise. A possible mechanism has recently

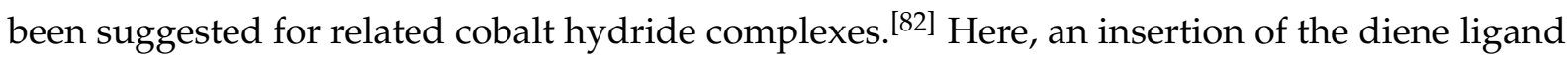
into the $\mathrm{Co}-\mathrm{C}$ bond takes place. Afterwards, a hydride elimination leads to the dissociation of a $[(\mathrm{DE}), \mathrm{R}-\mathrm{H}]$ moiety, leaving an ion with a $\mathrm{Co}-\mathrm{H}$ bond behind, which is then potentially coordinated by another diene ligand. An analogous mechanism could also be working in case of the palladium hydride complexes (scheme 4.2). 


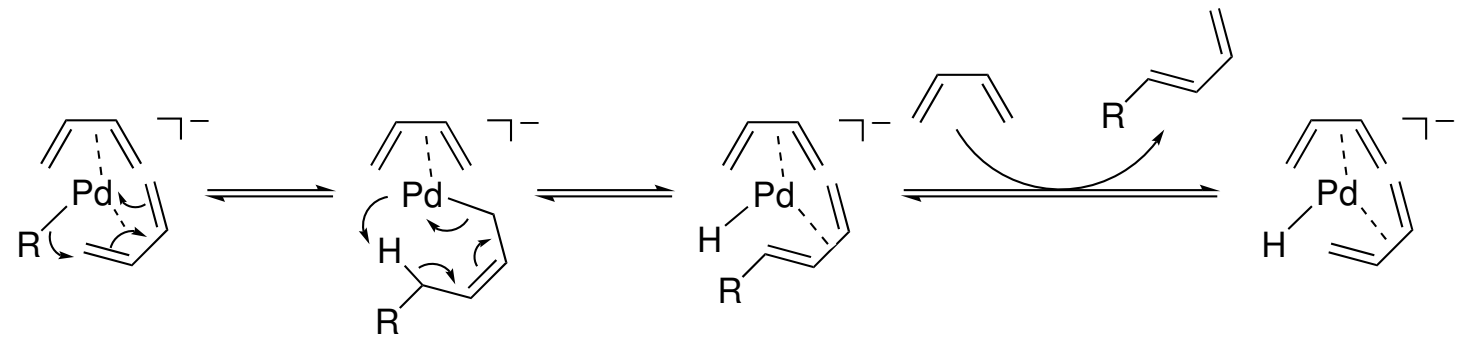

Scheme 4.2: Possible formation pathway of hydride-containing palladate complexes via diene insertion, hydride elimination, and ligand exchange. Note that the exact position of the hydride elimination is unclear. Additional organic substituents are omitted for clarity.

The ESI mass spectra of all sample solutions in the cationic mode were dominated by magnesium-based species such as $\left[\mathrm{Mg}_{3} \mathrm{Cl}_{3}(\mathrm{OMe})_{2}(\mathrm{THF})_{n}\right]^{+}, n=3$ and 4 , and $\left[\mathrm{Mg}_{3} \mathrm{Cl}_{5}(\mathrm{THF})_{5}\right]^{+}$ and did not show any palladium-containing cations. The methoxy groups present in some of the cations originated from traces of methanol, which remained in the source inlet of the mass spectrometer after purging. $37 \mathrm{e}$

\subsubsection{Time-Dependent Formation of Palladate Complexes in Different Aggregation States}

During each measurement, the relative signal intensities of the observed species changed significantly over time. Immediately after the addition of the Grignard reagent to the sample, short-lived monomeric complexes of the type $\left[\mathrm{PdR}\left(\mathrm{DE}^{\mathrm{I}}\right)_{n}\right]^{-}$with $\mathrm{R}=n-\mathrm{Bu}$ and $\mathrm{Ph}$ and $n=1$ and 2, were detected, the latter of which corresponded to the anionic intermediate proposed by Kambe and coworkers (section 1.4. [31a] Over the course of the measurement, the mononuclear and, where present, the trinuclear anions vanished completely after a few minutes. Furthermore, a shift towards higher masses was observed: over time, the relative signal intensity of the dinuclear $\left[\mathrm{Pd}_{2} \mathrm{R}(\mathrm{DE})_{2}\right]^{-}$decreased, while the tetranuclear and, in some cases, even hexanuclear aggregates became more abundant (as shown by the example of $\left[\mathrm{Pd}_{2}(\mathrm{dba})_{3}\right]$ and $\mathrm{PhMgCl}$ in the presence of isoprene, figure 4.35).

In general, oligonuclear species found in the mass spectrum are not necessarily present in the sample solution, as the increasing concentration of the analytes during the ESI process might shift aggregation equilibria towards heavier aggregates. This is, however, highly unlikely in this case, because of the increasing relative signal intensities of the considered species over time. Thus, the growth of small palladium nanoclusters in the sample solutions over time could be directly monitored by ESI mass spectrometry. Furthermore, the overall signal intensities tended to decrease over time, along with the clearly visible precipitation of palladium black. It can therefore be assumed that the observed palladium oligomers form even larger aggregates, which cannot be probed by ESI mass spectrometry under the chosen conditions. Presumably, this aggregation process eventually leads to the formation of solid palladium particles. 


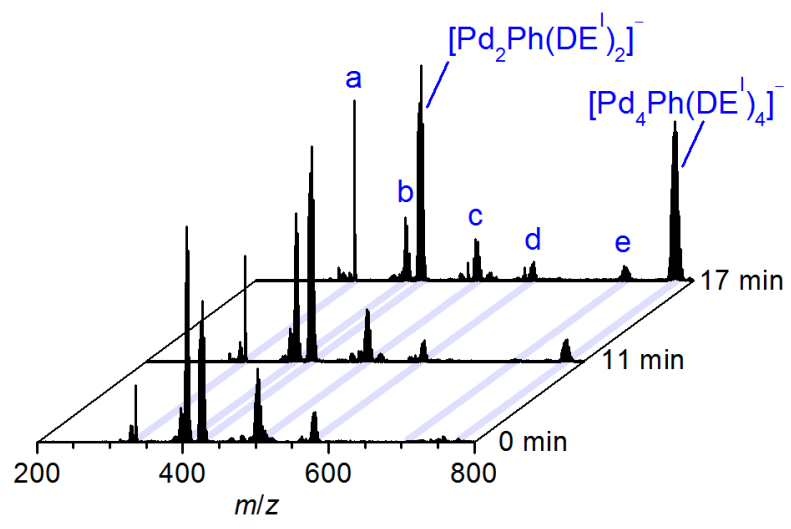

Figure 4.35: Negative-ion mode ESI mass spectra of a solution of $\left[\mathrm{Pd}_{2}(\mathrm{dba})_{3}\right](1.5 \mathrm{mM})$, isoprene $\left(\mathrm{DE}^{\mathrm{I}}, 24 \mathrm{mM}\right)$, and $\mathrm{PhMgCl}(12 \mathrm{mM})$ in THF 0,11 , and 17 minutes after the removal of the cooling bath $\left(198 \mathrm{~K}, \mathrm{a}=\left[\mathrm{AlPh}_{4}\right]^{-}, \underline{43]} \mathrm{b}=\left[\mathrm{PdPh}_{3}\left(\mathrm{DE}^{\mathrm{I}}\right)\right]^{-}, \mathrm{c}=\left[\mathrm{Pd}_{2} \mathrm{Ph}_{2}\left(\mathrm{DE}^{\mathrm{I}}\right)_{2}-\mathrm{H}\right]^{-}, \mathrm{d}=\left[\mathrm{Pd}_{2} \mathrm{Ph}_{3}\left(\mathrm{DE}^{\mathrm{I}}\right)_{2}\right]^{-}\right.$, $\left.\mathrm{e}=\left[\mathrm{Pd}_{4} \mathrm{Ph}\left(\mathrm{DE}^{\mathrm{I}}\right)_{3}\right]^{-}\right)$.

To confirm this assumption, a sample solution containing $\left[\mathrm{Pd}_{2}(\mathrm{dba})_{3}\right]$, isoprene, and $n$ - $\mathrm{BuMgCl}$ was examined by time-dependent UV/Vis spectroscopy. The obtained spectra showed the disappearance of the $\left[\mathrm{Pd}_{2}(\mathrm{dba})_{3}\right] \mathrm{d}-\mathrm{d}$ band at $\lambda=520 \mathrm{~nm}$ upon addition of the Grignard reagent as well as the formation of a new band at $\lambda=450 \mathrm{~nm}$ along with a broad absorption in the region between 500 and $700 \mathrm{~nm}$ (figure 4.36.

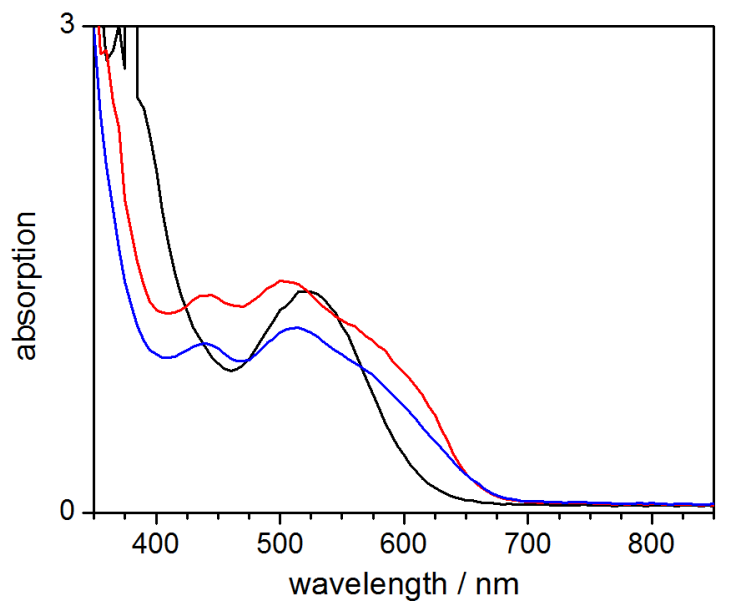

Figure 4.36: $\mathrm{UV} /$ Vis spectra of a solution of $\left[\mathrm{Pd}_{2}(\mathrm{dba})_{3}\right](1 \mathrm{mM})$ and isoprene $(16 \mathrm{mM})$, stirred at $278 \mathrm{~K}$ for $50 \mathrm{~min}$, before (black) and after the addition of 8 eq. of $n-\mathrm{BuMgCl}$ after $1 \mathrm{~min}$ (red) and $120 \mathrm{~min}$ (blue) reaction time at $278 \mathrm{~K}$.

Such broad absorptions at higher wavelengths can be an indication for the generation of palladium nanoclusters. $\frac{83.85]}{8}$ Furthermore, the precipitation of solid particles from the solution was reflected in the decrease of the overall absorption over time. 


\subsubsection{Structure of the Observed Palladate Complexes: Binding Mode of the Diene Ligand}

To gain more information on the structure of the palladate complexes of interest, gas-phase fragmentation experiments were applied. As Kambe and coworkers proposed a structure for the mononuclear palladates including two diene ligands in a dimerized form, leading to an oxidation state of the palladium center of $+\mathrm{II}$, a special interest lay in determining the binding mode of the incorporated diene ligands.

\section{Comparison of the Binding Strengths of 1,3-Butadiene and Isoprene}

1,3-butadiene and isoprene were added in equimolar amounts to $\left[\mathrm{Pd}_{2}(\mathrm{dba})_{3}\right]$ and $n$ - $\mathrm{BuMgCl}$ in a competition experiment to compare their tendencies to be incorporated into palladate complexes. ESI-mass spectrometric analysis of the sample solution containing both dienes yielded the highest signal intensities for palladate complexes with only 1,3-butadiene ligands, in particular the tetranuclear complex $\left[\mathrm{Pd}_{4} \mathrm{Bu}\left(\mathrm{DE}^{\mathrm{B}}\right)_{4}\right]^{-}$. The mixed species $\left[\mathrm{Pd}_{4} \mathrm{Bu}\left(\mathrm{DE}^{\mathrm{B}}\right)_{3}\left(\mathrm{DE}^{\mathrm{I}}\right)\right]^{-}$and $\left[\mathrm{Pd}_{4} \mathrm{Bu}\left(\mathrm{DE}^{\mathrm{B}}\right)_{2}\left(\mathrm{DE}^{\mathrm{I}}\right)_{2}\right]^{-}$were also present with relatively high and moderate relative signal intensities, respectively, whereas tetranuclear complexes containing three or more isoprene ligands were not detected at all. The dinuclear palladate complexes displayed a similar behavior: the most prominent of these anions was $\left[\mathrm{Pd}_{2} \mathrm{Bu}\left(\mathrm{DE}^{\mathrm{B}}\right)_{2}\right]^{-}$, followed by the heteroleptic $\left[\mathrm{Pd}_{2} \mathrm{Bu}\left(\mathrm{DE}^{\mathrm{B}}\right)\left(\mathrm{DE}^{\mathrm{I}}\right)\right]^{-}$and, with very small signal intensities, $\left[\mathrm{Pd}_{2} \mathrm{Bu}\left(\mathrm{DE}^{\mathrm{I}}\right)_{2}\right]^{-}$.

The higher affinity of the 1,3-butadiene ligand to the palladium center was confirmed by gasphase fragmentation of the heteroleptic palladate complexes. Upon collision induced dissociation, $\left[\mathrm{Pd}_{4} \mathrm{Bu}\left(\mathrm{DE}^{\mathrm{B}}\right)_{2}\left(\mathrm{DE}^{\mathrm{I}}\right)_{2}\right]^{-}$produced both $\left[\mathrm{Pd}_{4} \mathrm{H}\left(\mathrm{DE}^{\mathrm{B}}\right)_{2}\left(\mathrm{DE}^{\mathrm{I}}\right)\right]^{-}$and $\left[\mathrm{Pd}_{4} \mathrm{H}\left(\mathrm{DE}^{\mathrm{B}}\right)\left(\mathrm{DE}^{\mathrm{I}}\right)_{2}\right]^{-}$as fragment ions, which presumably resulted from a $\beta$-hydride elimination in combination with the dissociation of an isoprene ligand or a 1,3-butadiene ligand, respectively (equations (4.49) to 4.51$)$ ). The relative signal intensity of $\left[\mathrm{Pd}_{4} \mathrm{H}\left(\mathrm{DE}^{\mathrm{B}}\right)_{2}\left(\mathrm{DE}^{\mathrm{I}}\right)\right]^{-}$was approximately twice as high as the relative signal intensity of $\left[\mathrm{Pd}_{4} \mathrm{H}\left(\mathrm{DE}^{\mathrm{B}}\right)\left(\mathrm{DE}^{\mathrm{I}}\right)_{2}\right]^{-}$, reflecting the preferred dissociation of the isoprene ligand compared to that of the 1,3-butadiene ligand.

$$
\begin{gathered}
{\left[\mathrm{Pd}_{4} \mathrm{Bu}\left(\mathrm{DE}^{\mathrm{B}}\right)_{2}\left(\mathrm{DE}^{\mathrm{I}}\right)_{2}\right]^{-} \longrightarrow\left[\mathrm{Pd}_{4} \mathrm{H}\left(\mathrm{DE}^{\mathrm{B}}\right)_{2}\left(\mathrm{DE}^{\mathrm{I}}\right)_{2}\right]^{-}+\mathrm{C}_{4} \mathrm{H}_{8}} \\
{\left[\mathrm{Pd}_{4} \mathrm{H}\left(\mathrm{DE}^{\mathrm{B}}\right)_{2}\left(\mathrm{DE}^{\mathrm{I}}\right)_{2}\right]^{-} \longrightarrow\left[\mathrm{Pd}_{4} \mathrm{H}\left(\mathrm{DE}^{\mathrm{B}}\right)_{2}\left(\mathrm{DE}^{\mathrm{I}}\right)\right]^{-}+\left(\mathrm{DE}^{\mathrm{I}}\right)} \\
{\left[\mathrm{Pd}_{4} \mathrm{H}\left(\mathrm{DE}^{\mathrm{B}}\right)_{2}\left(\mathrm{DE}^{\mathrm{I}}\right)_{2}\right]^{-} \longrightarrow\left[\mathrm{Pd}_{4} \mathrm{H}\left(\mathrm{DE}^{\mathrm{B}}\right)\left(\mathrm{DE}^{\mathrm{I}}\right)_{2}\right]^{-}+\left(\mathrm{DE}^{\mathrm{B}}\right)}
\end{gathered}
$$

The competition experiments clearly demonstrated that 1,3-butadiene binds more strongly to the considered palladate complexes than isoprene. One possible explanation for this difference can be found in the electronic properties of the two 1,3-dienes: The methyl group present in the isoprene ligand exerts a positive inductive effect, potentially reducing the ability of the isoprene ligand to stabilize the negative charge of the palladate complex by backbonding interactions. Results by Kambe and coworkers show that catalyst systems containing 1,3-butadiene as a ligand allow for significantly better yields in cross-coupling reactions than those with 


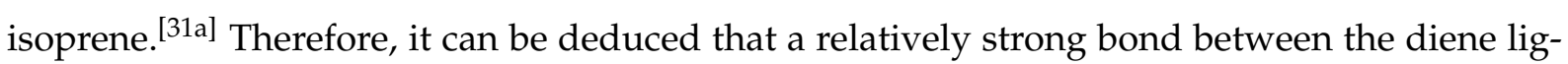
and and the palladium center in the palladate complex has a beneficial effect on the catalytic activity.

\section{Gas-phase Fragmentation of Mononuclear Palladate Complexes}

The fact that not only $\left[\mathrm{PdR}\left(\mathrm{DE}^{\mathrm{I}}\right)_{2}\right]^{-}$, but also $\left[\mathrm{PdR}\left(\mathrm{DE}^{\mathrm{I}}\right)\right]^{-}$, with $\mathrm{R}=n$-Bu and $\mathrm{Ph}$, were detectable by ESI mass spectrometry suggested that the dimerization of the isoprene ligand was not necessary for the formation of stable palladate complexes (figure 4.37 for $\mathrm{R}=n-\mathrm{Bu}$ ). Gasphase fragmentation of $\left[\mathrm{PdPh}\left(\mathrm{DE}^{\mathrm{I}}\right)_{2}\right]^{-}$and $\left[\mathrm{PdBu}\left(\mathrm{DE}^{\mathrm{I}}\right)_{2}\right]^{-}$led to the loss of a single isoprene ligand as the only fragmentation channel (equation 4.52 , figure 4.38 for $\mathrm{R}=n-\mathrm{Bu}$ ). For $\mathrm{R}=n-\mathrm{Bu}$, cryospray ionization was applied in order to achieve sufficient signal intensities of the shortlived mononuclear palladates to subject them to gas-phase fragmentation experiments.

$$
\left[\mathrm{PdR}(\mathrm{DE})_{2}\right]^{-} \longrightarrow[\mathrm{PdR}(\mathrm{DE})]^{-}+(\mathrm{DE})
$$

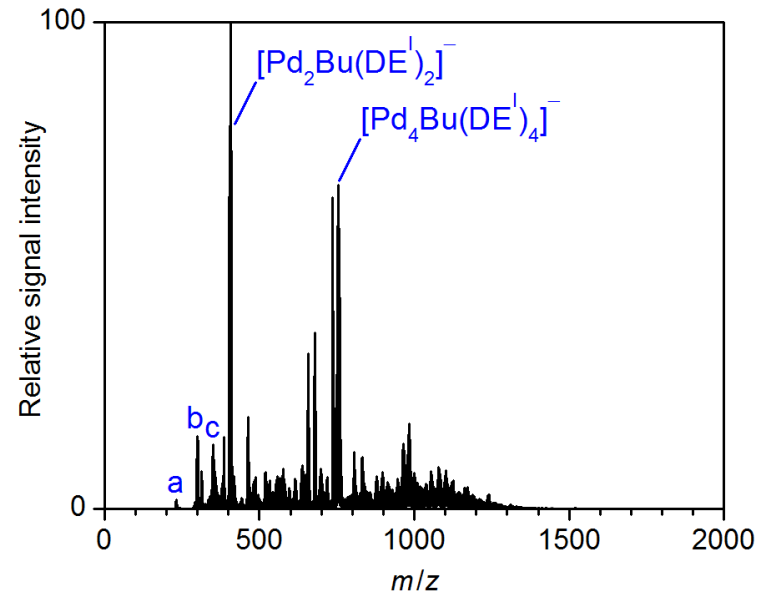

Figure 4.37: Negative-ion mode cryosprayionization mass spectrum of a solution of $\left[\mathrm{Pd}_{2}(\mathrm{dba})_{3}\right](1.5 \mathrm{mM})$, isoprene $\left(\mathrm{DE}^{\mathrm{I}}\right.$, $24 \mathrm{mM})$, and $n$-BuMgCl $(12 \mathrm{mM})$ in $\mathrm{THF}$, recorded immediately after sample preparation $\left(\mathrm{a}=\left[\mathrm{PdBu}\left(\mathrm{DE}^{\mathrm{I}}\right)\right]^{-}, \quad \mathrm{b}=\left[\mathrm{PdBu}\left(\mathrm{DE}^{\mathrm{I}}\right)_{2}\right]^{-}\right.$, $\left.\mathrm{c}=\left[\mathrm{Pd}_{2} \mathrm{H}\left(\mathrm{DE}^{\mathrm{I}}\right)_{2}\right]^{-}\right)$.

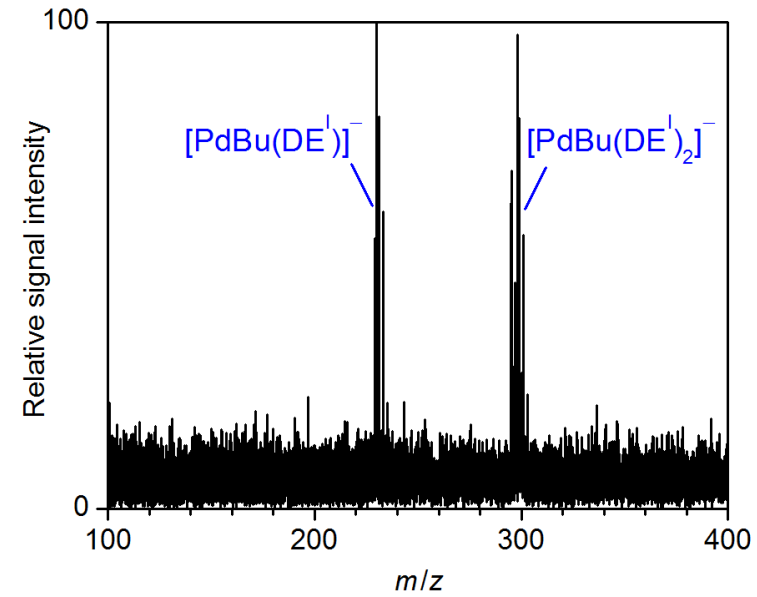

Figure 4.38: Mass spectrum of mass-selected $\left[\mathrm{PdBu}\left(\mathrm{DE}^{\mathrm{I}}\right)_{2}\right]^{-}$and its fragment ions produced upon collision-induced dissociation $\left(E_{\mathrm{LAB}}=5.0 \mathrm{eV}\right)$.

Especially in the case of the butyl-containing palladate complex, where, for example, a $\beta$-hydride elimination of butene would have been imaginable, the preference for the ligand dissociation reaction leads to the conclusion that the dimerization of the isoprene ligands does not take place or is at least easiliy reversible. 


\section{UV/Vis and NMR Spectroscopy}

Further evidence for this assumption was gained from UV/Vis- and ${ }^{1} \mathrm{H}-\mathrm{NMR}$-spectroscopic experiments. The UV/Vis spectrum of $\left[\mathrm{Pd}_{2}(\mathrm{dba})_{3}\right]$ did not change upon the addition of isoprene even after $50 \mathrm{~min}$ reaction time. ${ }^{1} \mathrm{H}$-NMR-spectroscopic analysis showed that the signals of isoprene did not shift upon the addition of four equivalents of isoprene to $\left[\mathrm{Pd}_{2}(\mathrm{dba})_{3}\right]$ and displayed only a slight broadening after $45 \mathrm{~min}$ reaction time. There was no indication of the formation of a bis-allylic complex. The addition of $\mathrm{PhMgBr}$ to the mixture led to a significant broadening of the isoprene signals in the ${ }^{1} \mathrm{H}$ - as well as in the ${ }^{13} \mathrm{C}-\mathrm{NMR}$ spectra. This suggests a fast equilibrium between free and palladium-bound isoprene, but does not clearly point towards an allylic binding mode (figure 4.39 ).

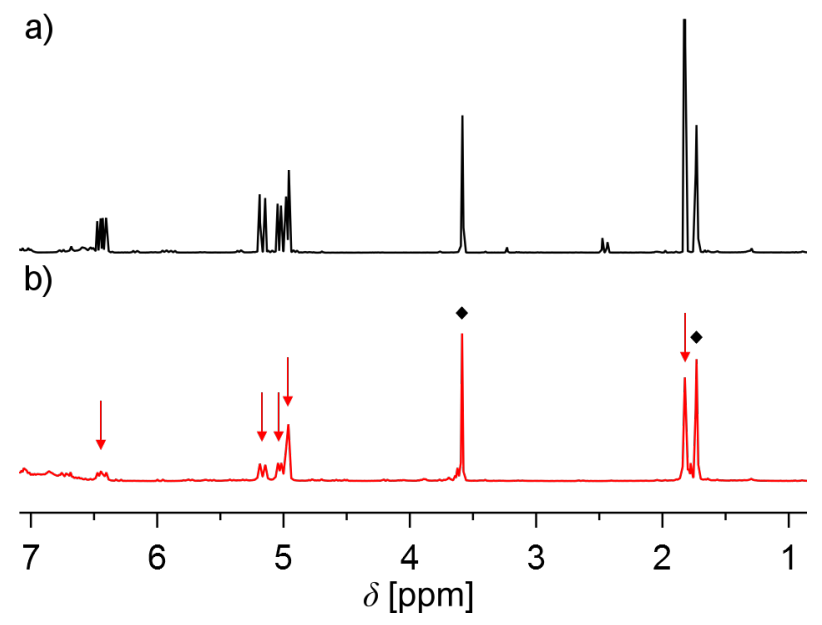

Figure 4.39: ${ }^{1} \mathrm{H}-\mathrm{NMR}$ spectra $\left(400 \mathrm{MHz}, \mathrm{THF}-\mathrm{D}_{8}\right)$ of a mixture of $\left[\mathrm{Pd}_{2}(\mathrm{dba})_{3}\right](25 \mathrm{mM})$ and isoprene $(100 \mathrm{mM}),(\mathrm{a})$ before and (b) after addition of $\mathrm{PhMgBr}$ at $298 \mathrm{~K}$. The signals marked with arrows correspond to isoprene, the signals marked with black diamonds represent THF.

\section{ESI Mass Spectrometry Using a Charge-Tagged Ligand}

To overcome the disadvantage inherent to mass-spectrometric techniques that potentially formed neutral species cannot be detected, the charge-tagged diene ligand (E)-buta-1,3-dien-1yltriphenylphosphonium bromide, $\left(\mathrm{DE}^{\mathrm{P}}\right) \mathrm{Br}^{-}$, was applied. $\left..38 \mathrm{a}\right] 38 \mathrm{~b}$ Sample solutions containing $\left[\mathrm{Pd}_{2}(\mathrm{dba})_{3}\right],\left(\mathrm{DE}^{\mathrm{P}}\right) \mathrm{Br}^{-}$, and $n$-BuMgCl were analyzed by positive-ion mode ESI mass spectrometry. In addition to a variety of palladium-free species, the quasi-anionic $\left[\mathrm{PdBu}\left(\mathrm{DE}^{\mathrm{P}}\right)_{2}\right]^{-}$was deteced, which can be interpreted as the cationized analogon of the above-described mononuclear palladate complexes $\left[\mathrm{PdBu}\left(\mathrm{DE}^{\mathrm{I}}\right)_{2}\right]^{-}$. The fact that complexes of this type were detected in the cationic as well as in the anionic mode emphasizes the strong tendency of such species to form under the chosen conditions. Furthermore, the quasi-neutral $\left[\mathrm{PdBuH}\left(\mathrm{DE}^{\mathrm{P}}\right)\left(\mathrm{PPh}_{3}\right)\right]$ was observed, which contained a free $\mathrm{PPh}_{3}$ group originating from the disintegration of the phosphonium-tagged diene ligand. It is noteworthy that no dinuclear or oligonuclear palladium complexes were detected when $\mathrm{DE}^{\mathrm{P}}$ was used as ligand, in contrast to the isoprene- and 1,3-butadiene-containing samples. This is not surprising, however, given 
the steric demand of the triphenylphosphonium tag and its positive charge, which leads to electrostatic repulsion between the ligands.

Regarding the question of the possible dimerization of the diene ligand, another interesting species present in the sample containing the tagged $\mathrm{DE}^{\mathrm{P}}$ ligand was the palladium-free ion $\mathrm{C}_{48} \mathrm{H}_{49} \mathrm{P}_{2}{ }^{+}$, which corresponds to a quasi-anion consisting of two $\mathrm{DE}^{\mathrm{P}}$ moieties and a butyl anion, $\left[\mathrm{Bu}\left(\mathrm{DE}^{\mathrm{P}}\right)_{2}\right]^{-}$. This ion could potentially be formed by the coupling of a butyl group with a diene dimer in a reductive elimination reaction from $\left[\mathrm{PdBu}\left(\mathrm{DE}^{\mathrm{P}}\right)_{2}\right]^{-}$(scheme 4.3, left). Another possibility that would not involve a prior dimerization of the diene ligand would be a direct attack of a butyl anion onto a diene molecule and a subsequent reaction of the resulting anion with another diene moiety (scheme 4.3 , right).

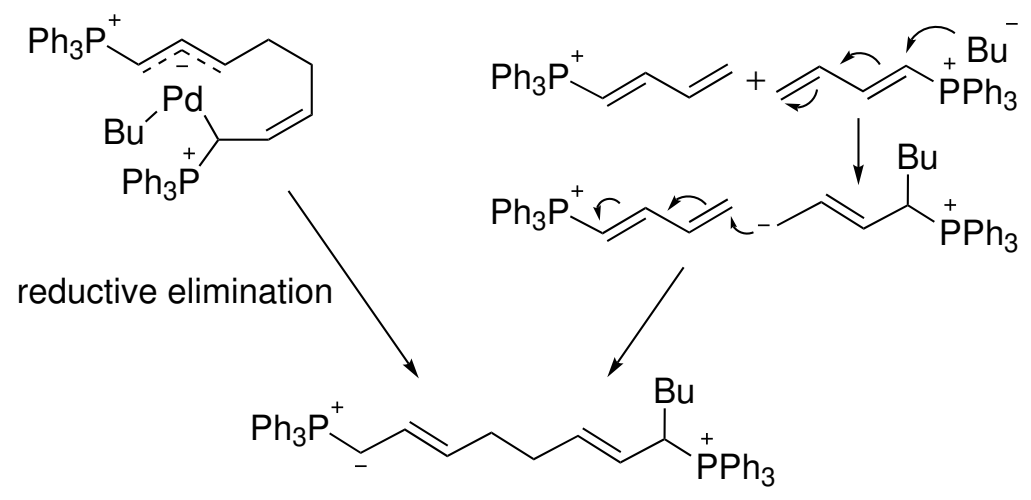

Scheme 4.3: Possible formation pathways of $\left[\mathrm{Bu}\left(\mathrm{DE}^{\mathrm{P}}\right)_{2}\right]^{-}$from $\left[\mathrm{PdBu}\left(\mathrm{DE}^{\mathrm{P}}\right)_{2}\right]^{-}$(left) or by a nucleophilic attack of a $\mathrm{Bu}^{-}$anion to a $\mathrm{DE}^{\mathrm{P}}$ cation with subsequent attack onto a second $\mathrm{DE}^{\mathrm{P}}$ cation (right).

To distinguish between these two possible formation pathways, the potential precursor ion $\left[\mathrm{PdBu}\left(\mathrm{DE}^{\mathrm{P}}\right)_{2}\right]^{-}$was subjected to gas-phase fragmentation. The main fragmentation channel was found to be a $\beta$-hydride elimination of butene to yield $\left[\mathrm{PdH}\left(\mathrm{DE}^{\mathrm{P}}\right)_{2}\right]^{-}$(equation 4.53 ).

$$
\left[\operatorname{PdBu}\left(\mathrm{DE}^{\mathrm{P}}\right)_{2}\right]^{-} \longrightarrow\left[\mathrm{PdH}\left(\mathrm{DE}^{\mathrm{P}}\right)_{2}\right]^{-}+\mathrm{C}_{4} \mathrm{H}_{8}
$$

Other fragmentation channels included decomposition reactions of the charge-tagged diene, for example the loss of $\mathrm{PPh}_{3}$ or $\mathrm{PPh}_{4}{ }^{+}$. A reductive elimination of $\left[\mathrm{Bu}\left(\mathrm{DE}^{\mathrm{P}}\right)_{2}\right]^{-}$was not observed. This finding suggests that the $\left[\mathrm{Bu}\left(\mathrm{DE}^{\mathrm{P}}\right)_{2}\right]^{-}$ion is not formed via reductive elimination from a palladium complex containing two dimerized diene ligands. In conclusion, there was no evidence gained from the gas-phase fragmentation of $\left[\mathrm{PdBu}\left(\mathrm{DE}^{\mathrm{P}}\right)_{2}\right]^{-}$that indicated a dimerization of the diene ligands on the palladium center.

Gas-phase fragmentation of $\left[\mathrm{PdBuH}\left(\mathrm{DE}^{\mathrm{P}}\right)\left(\mathrm{PPh}_{3}\right)\right]$ and other $\mathrm{DE}^{\mathrm{P}}$-containing palladium complexes, such as $\left[\mathrm{PdBu}\left(\mathrm{DE}^{\mathrm{P}}\right)_{2}\left(\mathrm{PPh}_{3}\right)\right]^{-}$and $\left[\mathrm{Pd}\left(\mathrm{DE}^{\mathrm{P}}\right)\left(\mathrm{PPh}_{3}\right)_{2}\right]$, also showed the elimination of butene, where possible, along with ligand dissociation and ligand decomposition reactions. 


\section{Gas-phase Reactivity of Dinuclear and Oligonuclear Palladate Complexes}

A deeper insight into the structure of the dinuclear, tetranuclear, and hexanuclear palladate complexes $\left[\mathrm{Pd}_{n} \mathrm{R}(\mathrm{DE})_{n}\right]^{-}$, with $n=2,4$, and 6 , and $\mathrm{R}=n-\mathrm{Bu}, \mathrm{Ph}$, and $\mathrm{Bn}$, was obtained by collision-induced dissociation experiments. When $\left[\mathrm{Pd}_{2} \mathrm{R}(\mathrm{DE})_{2}\right]^{-}$, with $\mathrm{R}=n$-Bu, was subjected to gas-phase fragmentation, the main fragmentation channel was the $\beta$-hydride elimination of butene (equation (4.54)). With isoprene as a ligand, a single ligand loss was observed as well (equation (4.55). For both dienes, a combination of the former fragmentation reactions took place as a minor pathway. Notably, no dissociation of single palladium moieties was observed, indicating the relative stability of the $\mathrm{Pd}_{2}$ core. Furthermore, compared with the fragmentation of the mononuclear palladates $\left[\mathrm{PdBu}(\mathrm{DE})_{2}\right]^{-}$, the $\beta$-hydride elimination was now favored over the single ligand dissociation, indicating a more stable palladium-ligand bond in the dinuclear complexes. For $\mathrm{R}=\mathrm{Ph}$ and $\mathrm{Bn}$, the loss of a single diene ligand was the only fragmentation channel (equation (4.55). Additionally, ion-molecule reactions with traces of dioxygen inside the collision cell gave rise to oxygen-containing species $\left[\mathrm{Pd}_{2}, \mathrm{R},(\mathrm{DE}), \mathrm{O}_{2}\right]^{-}$(equation $(4.56)$ ). The formation of such ions reflects the high tendency of palladate complexes $\left[\mathrm{Pd}_{2} \mathrm{R}(\mathrm{DE})\right]^{-}$to undergo oxidation reactions and, consequently, the low-valent nature of the palladium center.

$$
\begin{aligned}
{\left[\mathrm{Pd}_{2} \mathrm{Bu}(\mathrm{DE})_{2}\right]^{-} } & \longrightarrow\left[\mathrm{Pd}_{2} \mathrm{H}(\mathrm{DE})_{2}\right]^{-}+\mathrm{C}_{4} \mathrm{H}_{8} \\
{\left[\mathrm{Pd}_{2} \mathrm{Bu}\left(\mathrm{DE}^{\mathrm{I}}\right)_{2}\right]^{-} } & \longrightarrow\left[\mathrm{Pd}_{2} \mathrm{Bu}\left(\mathrm{DE}^{\mathrm{I}}\right)\right]^{-}+\left(\mathrm{DE}^{\mathrm{I}}\right) \\
{\left[\mathrm{Pd}_{2} \mathrm{R}\left(\mathrm{DE}^{\mathrm{I}}\right)\right]^{-}+\mathrm{O}_{2} } & \longrightarrow\left[\mathrm{Pd}_{2}, \mathrm{R},\left(\mathrm{DE}^{\mathrm{I}}\right), \mathrm{O}_{2}\right]^{-}
\end{aligned}
$$

The tetranuclear and hexanuclear nanoclusters mainly lost dinuclear $\left[\mathrm{Pd}_{2}(\mathrm{DE})_{2}\right]$ units upon collision-induced dissociation (equation (4.57) with $n=4$ and 6, figure 4.40).

$$
\left[\mathrm{Pd}_{n} \mathrm{R}(\mathrm{DE})_{n}\right]^{-} \longrightarrow\left[\mathrm{Pd}_{n-2} \mathrm{R}(\mathrm{DE})_{n-2}\right]^{-}+\left[\mathrm{Pd}_{2}(\mathrm{DE})_{2}\right]
$$

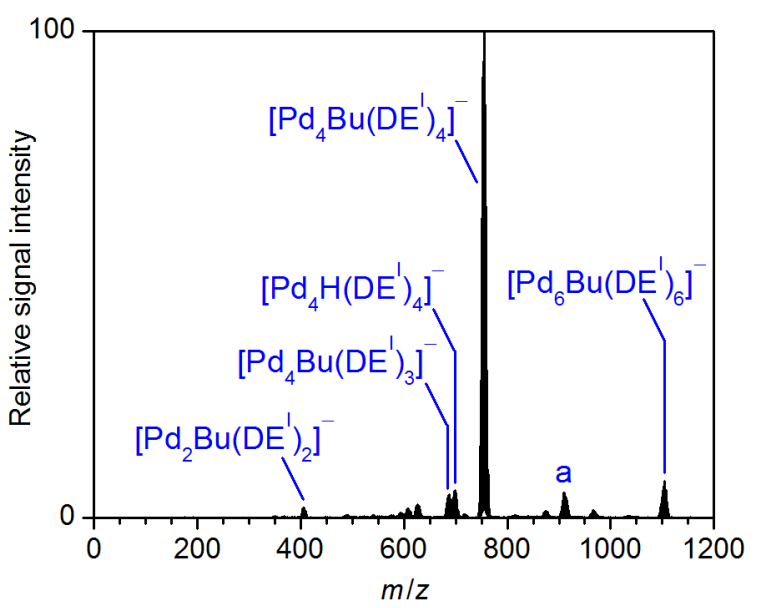

Figure 4.40: Mass spectrum of mass-selected $\left[\mathrm{Pd}_{6} \mathrm{Bu}\left(\mathrm{DE}^{\mathrm{I}}\right)_{6}\right]^{-}$and its fragment ions produced upon collision-induced dissociation $\left(E_{\mathrm{LAB}}=10.0 \mathrm{eV}, \mathrm{a}=\left[\mathrm{Pd}_{6} \mathrm{H}\left(\mathrm{DE}^{\mathrm{I}}\right)_{4}\right]^{-}\right)$. 
It is therefore likely that these nanoclusters are aggregates formed from dinuclear subunits. This finding again underlines the relative stability of such dimeric complexes. Furthermore, they also showed the already discussed $\beta$-hydride elimination and ligand dissociation reactions (equations (4.54) and (4.55), and combinations thereof, to a smaller extent.

\subsubsection{Influence of the Transmetalating Agent}

In addition to the experiments with Grignard reagents, $n$ - $\mathrm{BuLi}$ and $n$ - $\mathrm{BuZnCl} \cdot \mathrm{LiCl}$ were applied as transmetalating agents as well. The reaction with $n$-BuLi gave, among others, the above-shown organopalladate complexes $\left[\mathrm{Pd}_{n} \mathrm{Bu}\left(\mathrm{DE}^{\mathrm{I}}\right)_{n}\right]^{-}$, with $n=2,4$, and 6 , in high signal intensities, along with the mononuclear palladates $\left[\mathrm{PdBu}\left(\mathrm{DE}^{\mathrm{I}}\right)_{n}\right]^{-}$with $n=1,2$, and 3 (figure 4.41. Furthermore, several heterobimetallic complexes, such as $\left[\mathrm{LiPd}_{2} \mathrm{Bu}_{2}\left(\mathrm{DE}^{\mathrm{I}}\right)_{4}\right]^{-}$and $\left[\mathrm{LiPd}_{3} \mathrm{Bu}_{2}\left(\mathrm{DE}^{\mathrm{I}}\right)_{4}\right]^{-}$, were detected. As in the experiments with Grignard reagents, a timedependent increase of the heavier aggregates at the expense of the mono- and dinuclear complexes was observed (figure 4.42).

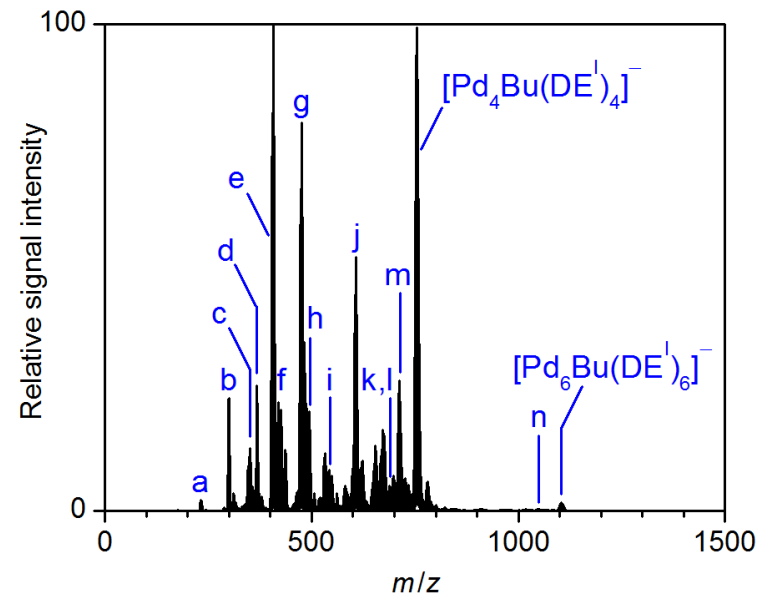

Figure 4.41: Negative-ion mode ESI mass spectrum of a solution of $\left[\mathrm{Pd}_{2}(\mathrm{dba})_{3}\right](1.5 \mathrm{mM})$, isoprene $\left(\mathrm{DE}^{\mathrm{I}}, 24 \mathrm{mM}\right)$, and $n$-BuLi $(12 \mathrm{mM})$ in THF, recorded immediately after sample preparation $\quad\left(\mathrm{a}=\left[\mathrm{PdBu}\left(\mathrm{DE}^{\mathrm{I}}\right)\right]^{-}, \quad \mathrm{b}=\left[\mathrm{PdBu}\left(\mathrm{DE}^{\mathrm{I}}\right)_{2}\right]^{-}\right.$, $\mathrm{c}=\left[\mathrm{Pd}_{2} \mathrm{H}\left(\mathrm{DE}^{\mathrm{I}}\right)_{2}\right]^{-}$, $\mathrm{e}=\left[\mathrm{Pd}_{2} \mathrm{Bu}\left(\mathrm{DE}^{\mathrm{I}}\right)_{2}\right]^{-}$, $\mathrm{g}=\left[\mathrm{Pd}_{2} \mathrm{Bu}\left(\mathrm{DE}^{\mathrm{I}}\right)_{3}\right]^{-}$, $\mathrm{i}=\left[\mathrm{Pd}_{2} \mathrm{Bu}\left(\mathrm{DE}^{\mathrm{I}}\right)_{4}\right]^{-}$, $\mathrm{k}=\left[\mathrm{Pd}_{4} \mathrm{Bu}\left(\mathrm{DE}^{\mathrm{I}}\right)_{3}\right]^{-}$, $\left.\mathrm{m}=\left[\mathrm{LiPd}_{3} \mathrm{Bu}_{2}\left(\mathrm{DE}^{\mathrm{I}}\right)_{4}\right]^{-}, \mathrm{n}=\left[\mathrm{Pd}_{6} \mathrm{H}\left(\mathrm{DE}^{\mathrm{I}}\right)_{6}\right]^{-}\right)$.

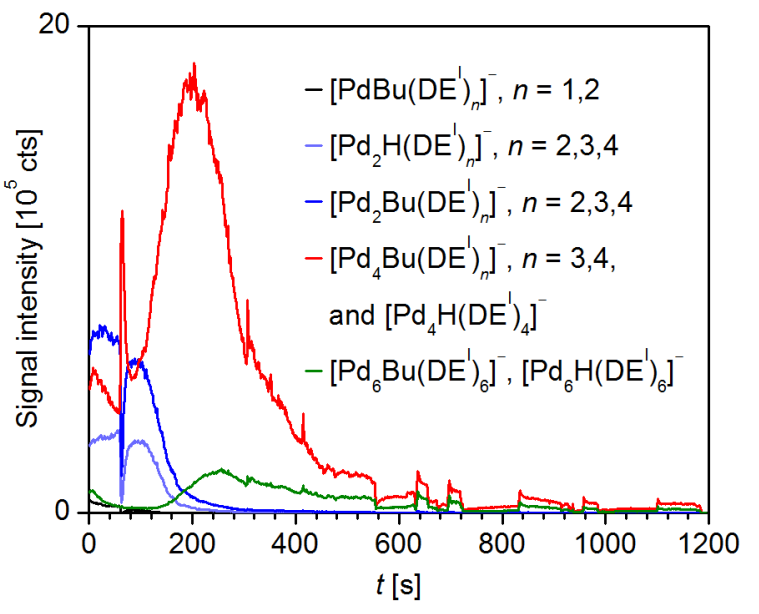

Figure 4.42: Absolute signal intensities of selected palladate complexes in the negative-ion mode ESI mass spectra of a solution of $\left[\mathrm{Pd}_{2}(\mathrm{dba})_{3}\right]$ $(1.5 \mathrm{mM})$, isoprene $\left(\mathrm{DE}^{\mathrm{I}}, 24 \mathrm{mM}\right)$, and $n$-BuLi $(12 \mathrm{mM})$ in THF plotted against the time after removal of the cooling bath (198 K).

In contrast, when $n$ - $\mathrm{BuZnCl} \cdot \mathrm{LiCl}$ was used, no transmetalation products could be found in the ESI mass spectra, which were dominated by zincate species such as $\left[\mathrm{Zn}_{2} \mathrm{BuCl}_{4}\right]^{-}$and $\left[\mathrm{Zn}_{3} \mathrm{Bu}_{3} \mathrm{Cl}_{4}\right]^{-}$. Organozinc reagents are known to exhibit lower reactivities than Grignard reagents. [1] Yet, they are also known to readily undergo transmetalation reactions in the course of Negishi-type cross-coupling reactions. However, in these reactions, the reaction partner is a more Lewis-acidic palladium(II) center. The lack of any transmetalation reactions achieved by 
the organozinc compound can thus be interpreted as an indication towards a higher electron density at the palladium atom. This would be consistent with an oxidation state of zero, which points towards a neutral binding mode of the diene ligands rather than a diene dimerization and formation of an $\left(\eta^{1}, \eta^{3}\right.$-allyl)-palladium complex.

\subsubsection{Reactivity of Organopalladates Towards Organyl Electrophiles}

In the next step, following the catalytic cycle proposed by Kambe and coworkers, the discussed palladate complexes were exposed to organyl halides. An especially interesting feature of the considered catalytic system is the possibility to conduct cross-coupling reactions with alkyl halides. Consequently, propyl bromide was chosen as a model electrophile. First, the reactivity of propyl bromide against $\left[\mathrm{Pd}_{2}(\mathrm{dba})_{3}\right]$ in the presence of isoprene was tested without the addition of a transmetalating reagent. As expected, no reaction could be observed, confirming the formation of the anionic organopalladium intermediate by transmetalation as the first step of the catalytic cycle.

\section{Reactivity of Phenyl- and Benzyl-Substituted Palladate Complexes Towards Propyl Bromide}

The addition of propyl bromide to a solution of $\left[\mathrm{Pd}_{2}(\mathrm{dba})_{3}\right]$ and $\mathrm{PhMgCl}$ in the presence of isoprene led to the formation of the dinuclear complex $\left[\mathrm{PdPh}_{2} \operatorname{Pr}\left(\mathrm{DE}^{\mathrm{I}}\right)_{2}\right]^{-}$as the main species (figure 4.43). This ion can be regarded as an anionized derivative of the neutral intermediate [PdRAlkyl(DE $)_{2}$ ] proposed by Kambe and coworkers, which is formed from the latter by an additional transmetalation step (equation (4.58).

$$
\left[\mathrm{PdRAlkyl}(\mathrm{DE})_{2}\right]+\mathrm{RMgCl} \longrightarrow\left[\mathrm{PdR}_{2} \mathrm{Alkyl}(\mathrm{DE})_{2}\right]^{-} \mathrm{MgCl}^{+}
$$

Also present were the $\left[\mathrm{PdPh}_{2} \mathrm{H}\left(\mathrm{DE}^{\mathrm{I}}\right)_{2}\right]^{-}$anion, which was presumably derived from $\left[\mathrm{PdPh}_{2} \operatorname{Pr}\left(\mathrm{DE}^{\mathrm{I}}\right)_{2}\right]^{-}$by $\beta$-hydride elimination, and the already-known singly substituted ions $\left[\mathrm{PdPh}\left(\mathrm{DE}^{\mathrm{I}}\right)\right]^{-}, \quad\left[\mathrm{PdPh}\left(\mathrm{DE}^{\mathrm{I}}\right)_{2}\right]^{-}$, and $\left[\mathrm{Pd}_{2} \mathrm{Ph}\left(\mathrm{DE}^{\mathrm{I}}\right)_{2}\right]^{-}$along with the triply substituted $\left[\mathrm{PdPh}_{3}\left(\mathrm{DE}^{\mathrm{I}}\right)\right]^{-}$(see section 4.3.1. Especially noteworthy was the presence of $\left[\mathrm{PdPh}_{2} \operatorname{Pr}_{2}\left(\mathrm{DE}^{\mathrm{I}}\right)\right]^{-}$, which was probably formed by the reaction of $\left[\mathrm{PdPh}\left(\mathrm{DE}^{\mathrm{I}}\right)\right]^{-}$with propyl bromide and subsequent transmetalation. It is also imaginable that this anion is formed from $\left.\left[\mathrm{PdPh}_{2} \operatorname{Pr}_{(\mathrm{DE}}\right)_{2}\right)^{-}$ in a ligand dissociation reaction. Collision-induced dissociation of $\left[\mathrm{PdPh}_{2} \operatorname{Pr}\left(\mathrm{DE}^{\mathrm{I}}\right)_{2}\right]^{-}$, however, did not yield $\left[\mathrm{PdPh}_{2} \operatorname{Pr}\left(\mathrm{DE}^{\mathrm{I}}\right)\right]^{-}$as a fragment ion, so that this formation pathway could be excluded. Thus, the presence of this species bearing one isoprene ligand again indicates that the dimerization of the diene during transmetalation does not occur completely, if at all. More importantly, the present finding shows that two dimerized diene ligands are not a necessary condition for the reaction of the palladate complex with an alkyl electrophile. When the sample solution was left to stir for $40 \mathrm{~min}$, the heteroleptic complexes disappeared again and were replaced by the above-described nanoclusters $\left[\mathrm{Pd}_{n} \mathrm{Ph}(\mathrm{DE})_{n}\right]^{-}$with $n=2,4$, and 6 (figure 4.44). 


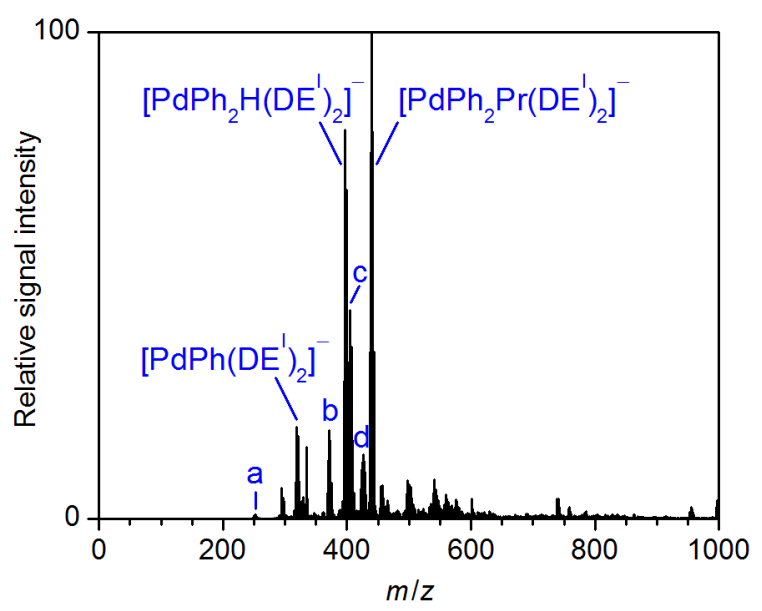

Figure 4.43: Negative-ion mode ESI mass spectrum of a solution of $\left[\mathrm{Pd}_{2}(\mathrm{dba})_{3}\right](1.5 \mathrm{mM})$, isoprene (DE $\left.{ }^{\mathrm{I}}, 24 \mathrm{mM}\right), \mathrm{PhMgCl}(12 \mathrm{mM})$, and $\operatorname{PrBr}(12 \mathrm{mM})$ in THF $\left(\mathrm{a}=\left[\mathrm{PdPh}\left(\mathrm{DE}^{\mathrm{I}}\right)\right]^{-}\right.$, $\mathrm{b}=\left[\mathrm{PdPh}_{2} \operatorname{Pr}\left(\mathrm{DE}^{\mathrm{I}}\right)\right]^{-}, \quad \mathrm{c}=\left[\mathrm{PdPh}_{3}\left(\mathrm{DE}^{\mathrm{I}}\right)\right]^{-}$, $\left.\mathrm{d}=\left[\mathrm{Pd}_{2} \mathrm{Ph}\left(\mathrm{DE}^{\mathrm{I}}\right)_{2}\right]^{-}\right)$.

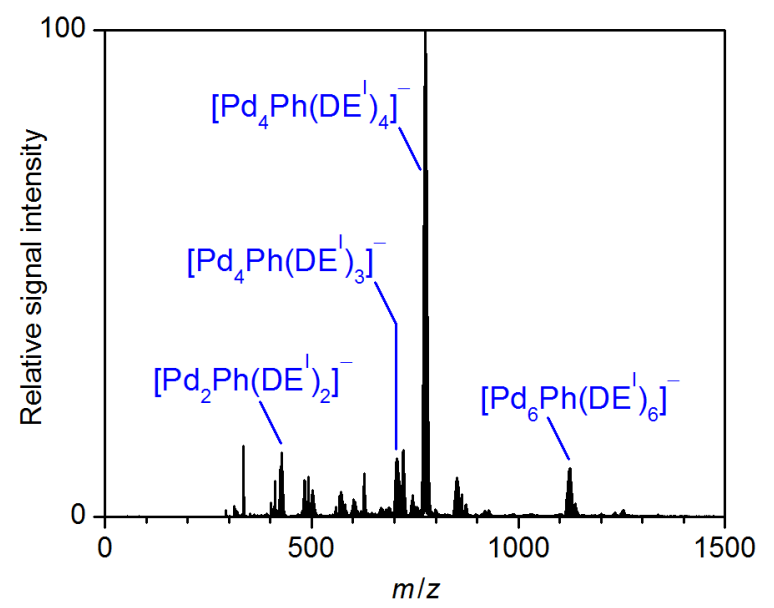

Figure 4.44: Negative-ion mode ESI mass spectrum of a solution of $\left[\mathrm{Pd}_{2}(\mathrm{dba})_{3}\right](1.5 \mathrm{mM})$, isoprene (DE $\left.{ }^{\mathrm{I}}, 24 \mathrm{mM}\right), \mathrm{PhMgCl}(12 \mathrm{mM})$, and $\mathrm{PrBr}$ $(12 \mathrm{mM})$ in THF after $40 \mathrm{~min}$ reaction time.

Surprisingly, no dinuclear or oligonuclear complexes were found that had incorporated a propyl substituent. Apparently, the mononuclear palladates are indeed the only catalytically active species in this case, whereas the higher aggregates serve as a catalyst reservoir but do not react with the alkyl electrophile.

Changing the applied Grignard reagent to $\mathrm{BnMgCl}$ gave ions analogous to those observed in the experiments with $\mathrm{PhMgCl}$. The propyl-containing anions $\left[\mathrm{PdBn}_{2} \operatorname{Pr}\left(\mathrm{DE}^{\mathrm{I}}\right)\right]^{-}$and $\left[\mathrm{PdBn}_{2} \operatorname{Pr}\left(\mathrm{DE}^{\mathrm{I}}\right)_{2}\right]^{-}$were both present, along with their $\beta$-hydride elimination products $\left[\mathrm{PdBn}_{2} \mathrm{H}\left(\mathrm{DE}^{\mathrm{I}}\right)\right]^{-}$and $\left[\mathrm{PdBn}_{2} \mathrm{H}\left(\mathrm{DE}^{\mathrm{I}}\right)_{2}\right]^{-}$. The main species in the ESI mass spectrum, however, was $\left[\mathrm{PdBn}_{3}\right]^{-}$, an ion presumably formed by oxidation processes and subsequent transmetalation, which was already observed in the experiments without any added electrophile (section 4.3.1). A noticeable difference between the experiments with $\mathrm{PhMgCl}$ and $\mathrm{BnMgCl}$ was the presence of dinuclear heteroleptic complexes $\left[\mathrm{Pd}_{2} \mathrm{Bn}_{2} \operatorname{Pr}\left(\mathrm{DE}^{\mathrm{I}}\right)_{2}\right]^{-}$in the latter case, though only in very small signal intensities. This indicates that, depending on the organic substituent, also dinuclear palladate complexes $\left[\mathrm{Pd}_{2} \mathrm{R}\left(\mathrm{DE}^{\mathrm{I}}\right)_{2}\right]^{-}$are capable of reacting directly with an alkyl halide.

\section{Reactivity of Butyl-Substituted Palladate Complexes Towards Propyl Bromide}

This result was confirmed by the ESI-mass spectrometric experiments with $n$ - $\mathrm{BuMgCl}$ as transmetalating agent. Here, no mononuclear $\left[\mathrm{PdBu}_{2} \operatorname{Pr}\left(\mathrm{DE}^{\mathrm{I}}\right)_{2}\right]^{-}$complexes or derivatives were detected. Instead, the dinuclear palladates $\left[\mathrm{Pd}_{2} \mathrm{Bu}_{2} \operatorname{Pr}\left(\mathrm{DE}^{\mathrm{I}}\right)_{2}\right]^{-}$and $\left[\mathrm{Pd}_{2} \mathrm{BuHPr}\left(\mathrm{DE}^{\mathrm{I}}\right)_{2}\right]^{-}$could be observed (figure 4.45). The propyl-containing species proved to be very short-lived, however, and the above-shown butyl complexes $\left[\mathrm{Pd}_{2} \mathrm{Bu}\left(\mathrm{DE}^{\mathrm{I}}\right)_{2}\right]^{-}$and $\left[\mathrm{Pd}_{4} \mathrm{Bu}\left(\mathrm{DE}^{\mathrm{I}}\right)_{4}\right]^{-}$remained the dominating species in the ESI mass spectra (figure 4.46). 


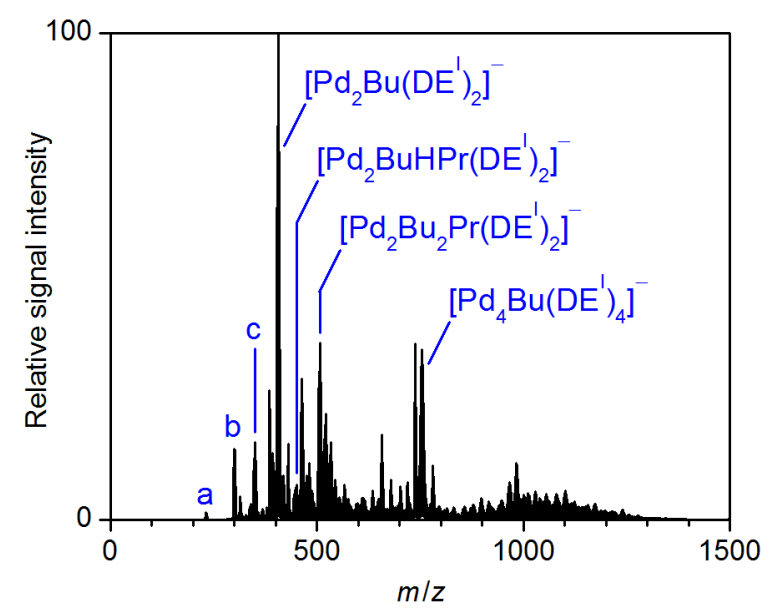

Figure 4.45: Negative-ion mode ESI mass spectrum of a solution of $\left[\mathrm{Pd}_{2}(\mathrm{dba})_{3}\right](1.5 \mathrm{mM})$, isoprene $\left(\mathrm{DE}^{\mathrm{I}}, 24 \mathrm{mM}\right), n$ - $\mathrm{BuMgCl}(12 \mathrm{mM})$, and $\operatorname{PrBr}(12 \mathrm{mM})$ in THF $\left(\mathrm{a}=\left[\mathrm{PdBu}\left(\mathrm{DE}^{\mathrm{I}}\right)\right]^{-}\right.$, $\mathrm{b}=\left[\mathrm{PdBu}\left(\mathrm{DE}^{\mathrm{I}}\right)_{2}\right]^{-}, \mathrm{c}=\left[\mathrm{Pd}_{2} \mathrm{H}\left(\mathrm{DE}^{\mathrm{I}}\right)_{2}\right]^{-}$.

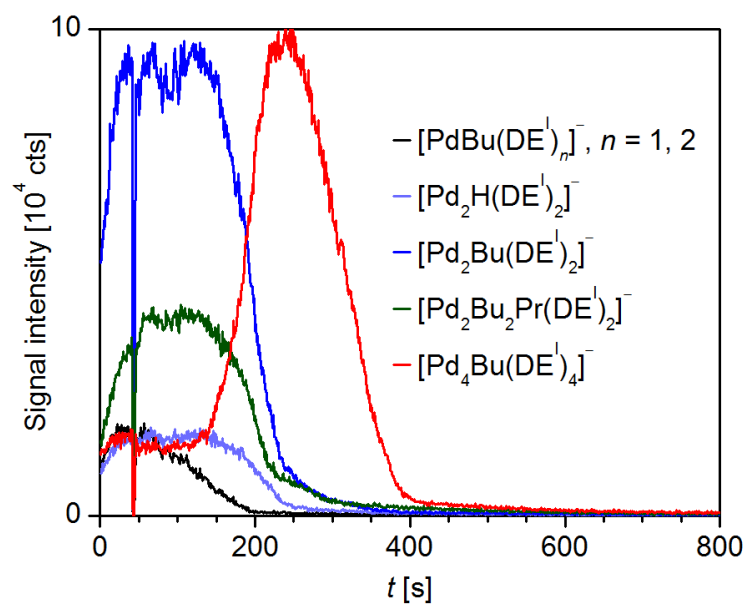

Figure 4.46: Absolute signal intensities of selected palladate complexes in the negative-ion mode ESI mass spectra of a solution of $\left[\mathrm{Pd}_{2}(\mathrm{dba})_{3}\right]$ $(1.5 \mathrm{mM})$, isoprene $\left(\mathrm{DE}^{\mathrm{I}}, 24 \mathrm{mM}\right), n-\mathrm{BuMgCl}$ $(12 \mathrm{mM})$, and $\mathrm{PrBr}(12 \mathrm{mM})$ in THF plotted against the time after removal of the cooling bath (198 K).

\section{Reactivity of Butyl-Substituted Palladate Complexes Towards Other Alkyl Halides}

Changing the added alkyl electrophile to propyl iodide led to a dominance of magnesate species and inorganic palladate complexes in the ESI mass spectrum, while none of the aboveshown homoleptic or heteroleptic organopalladates could be observed. Assuming this to be the consequence of fast decomposition reactions of the palladates of interest, the sample injection method was altered in order to be able to record mass spectra immediately after the addition of the electrophile and directly from the cooled sample solution. To achieve this, a pressurized sample infusion (PSI) approach was chosen (see the experimental section for details). 86 Under these conditions, the overall signal intensities were still rather low and the mass spectra were dominated by magnesate species. Yet, the dinuclear $\left[\mathrm{Pd}_{2} \mathrm{Bu}_{2} \operatorname{Pr}\left(\mathrm{DE}^{\mathrm{I}}\right)_{2}\right]^{-}$was detectable as well.

In contrast to that, the reaction with propyl chloride did not lead to any propyl-containing palladates. Likewise, isopropyl bromide as an example for a secondary alkyl electrophile did not show any reaction.

\subsubsection{Formation of C-C Coupling Products: Reductive Elimination}

\section{Unimolecular Reactivity of Triply Substituted Heteroleptic Palladates}

Following the transmetalation and the oxidative addition, which are discussed above, a reductive elimination of the coupling product would close the catalytic cycle of the palladiumcatalyzed cross-coupling reaction. To take a closer look at this reaction step, the propyl- 
containing palladates $\left[\mathrm{PdR}_{2} \operatorname{Pr}\left(\mathrm{DE}^{\mathrm{I}}\right)_{n}\right]^{-}$, with $n=1$ and 2 and $\mathrm{R}=\mathrm{Ph}$ and $\mathrm{Bn}$, and $\left[\mathrm{Pd}_{2} \mathrm{R}_{2} \operatorname{Pr}\left(\mathrm{DE}^{\mathrm{I}}\right)_{2}\right]^{-}$, with $\mathrm{R}=\mathrm{Bn}$ and $n-\mathrm{Bu}$, were subjected to gas-phase fragmentation.

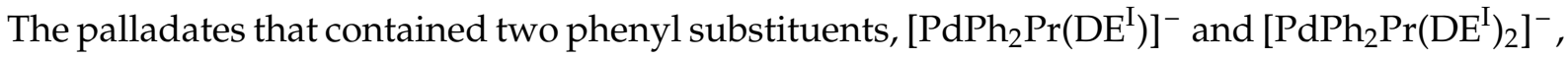
did not react in a reductive elimination to produce the cross-coupling product, although both ions eliminated the homo-coupling product $\mathrm{Ph}_{2}$, in the case of $\left[\mathrm{PdPh}_{2} \operatorname{Pr}\left(\mathrm{DE}^{\mathrm{I}}\right)_{2}\right]^{-}$even as the main fragmentation pathway (equation 4.59 ). In contrast, $\left[\mathrm{PdPh}_{2} \operatorname{Pr}\left(\mathrm{DE}^{\mathrm{I}}\right)\right]^{-}$showed a combined loss of propane and a single isoprene ligand as the most preferable fragmentation channel (equation (4.61)). Another prominent fragmentation channel of these precursor ions was the dissociation of benzene (equation (4.60)). The analogous reaction took place for $\left[\mathrm{PdBn}_{2} \operatorname{Pr}\left(\mathrm{DE}^{\mathrm{I}}\right)_{2}\right]^{-}$, which lost one or two toluene molecules, respectively, upon collisioninduced dissociation (equations (4.62) and (4.63)). Furthermore, the dissociation of single free benzyl anions (equation (4.64) ) as well as the formation of [PdBn] ${ }^{-}$was observed.

$$
\begin{aligned}
& {\left[\mathrm{PdPh}_{2} \operatorname{Pr}\left(\mathrm{DE}^{\mathrm{I}}\right)_{2}\right]^{-} \longrightarrow\left[\mathrm{PdPr}\left(\mathrm{DE}^{\mathrm{I}}\right)_{2}\right]^{-}+\mathrm{PrPh}} \\
& \left.\left[\mathrm{PdPh}_{2} \operatorname{Pr}\left(\mathrm{DE}^{\mathrm{I}}\right)_{2}\right]^{-} \longrightarrow\left[\mathrm{PdPhPr}^{\mathrm{D}} \mathrm{DE}^{\mathrm{I}}\right)_{2}-\mathrm{H}\right]^{-}+\mathrm{PhH} \\
& {\left[\mathrm{PdPh}_{2} \operatorname{Pr}\left(\mathrm{DE}^{\mathrm{I}}\right)^{-} \longrightarrow\left[\mathrm{PdPh}_{2}-\mathrm{H}\right]^{-}+\left[\mathrm{PrH},\left(\mathrm{DE}^{\mathrm{I}}\right)\right]\right.} \\
& {\left[\mathrm{PdBn}_{2} \operatorname{Pr}\left(\mathrm{DE}^{\mathrm{I}}\right)_{2}\right]^{-} \longrightarrow\left[\mathrm{PdBnPr}\left(\mathrm{DE}^{\mathrm{I}}\right)_{2}-\mathrm{H}\right]^{-}+\mathrm{BnH}} \\
& {\left[\mathrm{PdBn}_{2} \operatorname{Pr}\left(\mathrm{DE}^{\mathrm{I}}\right)_{2}\right]^{-} \longrightarrow\left[\mathrm{PdPr}\left(\mathrm{DE}^{\mathrm{I}}\right)_{2}-2 \mathrm{H}\right]^{-}+2 \mathrm{BnH}} \\
& {\left[\mathrm{PdBn}_{2} \operatorname{Pr}\left(\mathrm{DE}^{\mathrm{I}}\right)_{2}\right]^{-} \longrightarrow\left[\mathrm{PdBnPr}^{\mathrm{I}}\left(\mathrm{DE}^{\mathrm{I}}\right)_{2}\right]+\mathrm{Bn}^{-}}
\end{aligned}
$$

A different situation was found for the butyl-substituted dinuclear palladate complex $\left[\mathrm{Pd}_{2} \mathrm{Bu}_{2} \operatorname{Pr}\left(\mathrm{DE}^{\mathrm{I}}\right)_{2}\right]^{-}$. Here, the cross-coupling product PrBu, along with the homo-coupling product $\mathrm{Bu}_{2}$, was formed readily at relatively low acceleration energies (figure 4.47, equations (4.65) and (4.66)).

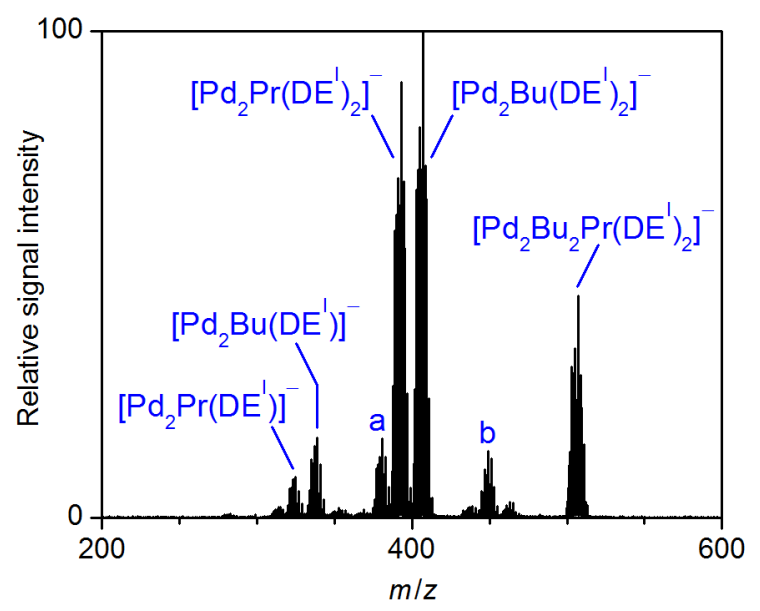

Figure 4.47: Mass spectrum of mass-selected $\left[\mathrm{Pd}_{2} \mathrm{Bu}_{2} \operatorname{Pr}\left(\mathrm{DE}^{\mathrm{I}}\right)_{2}\right]^{-}$and its fragment ions produced upon collision-induced dissociation $\left(E_{\mathrm{LAB}}=5.0 \mathrm{eV}, \mathrm{a}=\left[\mathrm{Pd}_{2} \mathrm{BuPr}\left(\mathrm{DE}^{\mathrm{I}}\right)-\mathrm{H}\right]^{-}, \mathrm{b}=\left[\mathrm{Pd}_{2} \mathrm{BuPr}(\mathrm{DE})_{2}^{\mathrm{I}}-\mathrm{H}\right]^{-}\right)$. 


$$
\begin{aligned}
& {\left[\mathrm{Pd}_{2} \mathrm{Bu}_{2} \operatorname{Pr}\left(\mathrm{DE}^{\mathrm{I}}\right)_{2}\right]^{-} \longrightarrow\left[\mathrm{PdBu}\left(\mathrm{DE}^{\mathrm{I}}\right)_{2}\right]^{-}+\mathrm{PrBu}} \\
& {\left[\mathrm{Pd}_{2} \mathrm{Bu}_{2} \operatorname{Pr}\left(\mathrm{DE}^{\mathrm{I}}\right)_{2}\right]^{-} \longrightarrow\left[\operatorname{PdPr}\left(\mathrm{DE}^{\mathrm{I}}\right)_{2}\right]^{-}+\mathrm{Bu}_{2}}
\end{aligned}
$$

Further fragmentation reactions of this precursor ion included the above-shown elimination reactions combined with the loss of a single diene ligand, leading to $\left[\mathrm{Pd}_{2} \mathrm{Bu}\left(\mathrm{DE}^{\mathrm{I}}\right)\right]^{-}$and $\left[\operatorname{Pd}_{2} \operatorname{Pr}\left(\mathrm{DE}^{\mathrm{I}}\right)\right]^{-}$, as well as the elimination of butane with and without the additional dissociation of an isoprene ligand, resulting in the formation of $\left[\operatorname{Pd}_{2} \mathrm{BuPr}\left(\mathrm{DE} \mathrm{E}^{\mathrm{I}}\right)-\mathrm{H}\right]^{-}$and $\left[\mathrm{Pd}_{2} \mathrm{BuPr}\left(\mathrm{DE}^{\mathrm{I}}\right)_{2}-\mathrm{H}\right]^{-}$, respectively.

\section{Formation of the Cross-Coupling Product in Solution: Application of a Charge-Tagged Electrophile}

While the reductive elimination from $\left[\mathrm{Pd}_{2} \mathrm{Bu}_{2} \operatorname{Pr}\left(\mathrm{DE}^{\mathrm{I}}\right)_{2}\right]^{-}$could be monitored in the gas-phase at moderate excitation energies, it was desirable to see the formation of the cross-coupling product taking place in solution. To this end, and also to detect other potentially formed neutral intermediates, the phosphonium-tagged alkyl electrophile (6-bromohexyl)triphenylphosphonium bromide $\left((\mathrm{RBr}) \mathrm{Br}^{-}\right)$was used. When this substrate was added to solutions of $\left[\mathrm{Pd}_{2}(\mathrm{dba})_{3}\right]$ and $n-\mathrm{BuMgCl}$ in the presence of isoprene, the positive-ion mode ESI mass spectrum was dominated by the signal of the quasi-neutral substrate $\mathrm{RBr}$, along with small quantities of the quasi-anionic bromide-containing dimer $(\mathrm{RBr})_{2} \mathrm{Br}^{-}$, the $\mathrm{HBr}$ elimination product $[\mathrm{R}-\mathrm{H}]$, and the cross-coupling product $\mathrm{RBu}$. Tripling the amount of the Grignard reagent relative to $(\mathrm{RBr}) \mathrm{Br}^{-}$resulted in the disappearance of the dimer and a significant increase of the signal intensities of $[\mathrm{R}-\mathrm{H}]$ and $\mathrm{RBu}$ (figure 4.48).

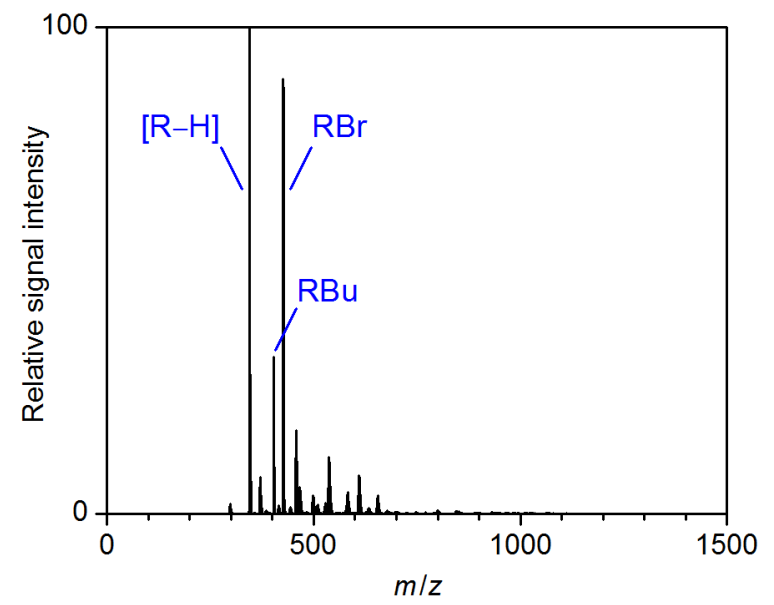

Figure 4.48: Positive-ion mode ESI mass spectrum of a solution of $\left[\mathrm{Pd}_{2}\left(\mathrm{dba}_{3}\right](1.5 \mathrm{mM})\right.$, isoprene ( $\mathrm{DE}^{\mathrm{I}}$, $24 \mathrm{mM}), n-\mathrm{BuMgCl}(36 \mathrm{mM})$, and $(\mathrm{RBr}) \mathrm{Br}^{-}(12 \mathrm{mM})$ in THF.

The ESI mass spectra in the cationic mode did not show any palladium-containing ions. In the anionic mode, the quasi-dianionic species $\left[\mathrm{PdBr}_{3} \mathrm{R}\right]^{2-}$ was formed. When the concentration of 
the Grignard reagent was increased, the quasi-dianions $\left[\mathrm{Pd}, \mathrm{Bu}_{2}, \mathrm{Ph}, \mathrm{R}\right]^{2-}$ and $[\mathrm{Pd}, \mathrm{Br}, \mathrm{Bu}, \mathrm{Ph}, \mathrm{R}]^{2-}$ appeared. The phenyl substituent incorporated in these ions presumably originated from the decomposition of the triphenylphosphonium tag. The formation of the said palladate complexes demonstrates that a transfer of the organic substituent of the electrophile to the palladium center takes place, although the actual intermediate from which the product is formed could not be identified. A possible explanation for this is the high reactivity of the catalytically active species, which might undergo further reactions as soon as it is formed, thus preventing a detection by ESI mass spectrometry. The detection of the cross-coupling product but not the corresponding palladium intermediate has also been experienced in other studies, in which charge-tagged electrophiles were utilized to monitor palladium-catalyzed cross-coupling reactions. $[38 \mathrm{~b}$

\subsubsection{Different Reactivities of Aryl and Alkyl Electrophiles}

To compare the reactivity of an aryl electrophile to the above-described alkyl electrophiles, such as propyl bromide, a solution of $\left[\mathrm{Pd}_{2}(\mathrm{dba})_{3}\right]$, isoprene, and $n-\mathrm{BuMgCl}$ was treated with ethyl 4-iodobenzoate (ArI). The oxidative addition of the electrophile proceeds in an $\mathrm{S}_{\mathrm{N}} 2$-type fashion according to Kambe and coworkers (see section 1.4). Thus, this reaction should be strongly disfavored when an aromatic substrate is involved. Indeed, the ESI mass spectra of the solutions containing ArI did not show any palladate complexes incorporating both butyl and aryl substituents. Instead, the dominating species were the products to be expected from classical oxidative addition reactions of the aryl iodide to the neutral palladium(0) catalyst, anionized by an additional iodide substituent, such as $\left[\mathrm{PdArI}_{2}\right]^{-}$and $\left[\mathrm{PdArI}_{2}\left(\mathrm{DE}^{\mathrm{I}}\right)\right]^{-}$, along with $\left[\mathrm{Pd}_{2} \mathrm{I}_{3}\left(\mathrm{DE}^{\mathrm{I}}\right)\right]^{-}$.

Palladate complexes bearing butyl as well as aryl substituents could only be prepared by decreasing the concentration of the aryl iodide to 0.4 equivalents relative to the Grignard reagent. That way, the mixed palladates $\left[\mathrm{PdAr}_{2} \mathrm{Bu}\left(\mathrm{DE}^{\mathrm{I}}\right)\right]^{-}$and $\left[\mathrm{PdArBu}_{2}\left(\mathrm{DE}^{\mathrm{I}}\right)\right]^{-}$as well as the $\beta$-hydride elimination product of the latter, $\left[\operatorname{PdArBuH}\left(\mathrm{DE}^{\mathrm{I}}\right)\right]^{-}$, could be generated. $\left[\mathrm{PdArBuH}\left(\mathrm{DE}^{\mathrm{I}}\right)_{2}\right]^{-}$, which was presumably formed in a $\beta$-hydride elimination from $\left[\mathrm{PdArBu}_{2}\left(\mathrm{DE}^{\mathrm{I}}\right)_{2}\right]^{-}$, was also present, along with several singly substituted complexes such as $\left[\operatorname{PdAr}\left(\mathrm{DE}^{\mathrm{I}}\right)\right]^{-},\left[\operatorname{PdAr}\left(\mathrm{DE}^{\mathrm{I}}\right)_{2}\right]^{-}$, $\left[\mathrm{Pd}_{2} \mathrm{Bu}\left(\mathrm{DE}^{\mathrm{I}}\right)_{2}\right]^{-}$, and $\left[\mathrm{Pd}_{2} \mathrm{Ar}\left(\mathrm{DE}^{\mathrm{I}}\right)_{2}\right]^{-}$.

While $\left[\mathrm{PdArBu}_{2}\left(\mathrm{DE}^{\mathrm{I}}\right)\right]^{-}$was too short-lived to be probed in gas-phase experiments, $\left[\operatorname{PdArBuH}\left(\mathrm{DE}^{\mathrm{I}}\right)_{2}\right]^{-}$showed the elimination of both $\mathrm{ArH}$ and BuAr upon collision-induced dissociation. Interestingly, gas-phase fragmentation of $\left[\mathrm{PdAr}_{2} \mathrm{Bu}\left(\mathrm{DE}^{\mathrm{I}}\right)\right]^{-}$resulted in the selective formation of the cross-coupling product. This is especially intriguing as the related palladate $\left[\mathrm{PdPh}_{2} \operatorname{Pr}\left(\mathrm{DE}^{\mathrm{I}}\right)\right]^{-}$showed a completely different fragmentation behavior when subjected to collision-induced dissociation, releasing only the homo-coupling product $\mathrm{Ph}_{2}$ as a minor fragmentation channel (see section 4.3.6). Apparently, the tendencies of the investigated palladate complexes to undergo reductive elimination reactions are governed by effects more complex than the mere electronic properties of the incorporated organic substituents, as is also 
indicated in the different fragmentation behaviors of the mixed palladates discussed in section 4.3.6.

\subsubsection{Transmetalation of Palladium(II) Precursors}

In synthetic applications, Kambe and coworkers used palladium(II) salts as precatalysts, which were supposedly reduced in situ by the organometallic reagent. Thus, it seemed an obvious step to generate the palladate complexes of interest from palladium(II) salts. However, when using palladium(II) salts, such as $\mathrm{PdCl}_{2}, \mathrm{PdI}_{2}$, or $\mathrm{Pd}(\mathrm{OAc})_{2}$, as precursors, no detectable organopalladates were formed. $\stackrel{87 .}{ }$ Instead, the ESI mass spectra were dominated by non-transmetalated $\mathrm{Pd}^{\mathrm{II}}$ species along with magnesates (figure 4.49).

The reduction of the palladium(II) precursor by the Grignard reagent doubtlessly took place, as can also be deduced from the presence of palladium species with the average oxidation state of $+\mathrm{I}$ (considering isoprene as a neutral ligand). The isoprene apparently does not bind to the palladium center strongly or fast enough after the reduction to stabilize organopalladate complexes in solution under the chosen conditions.

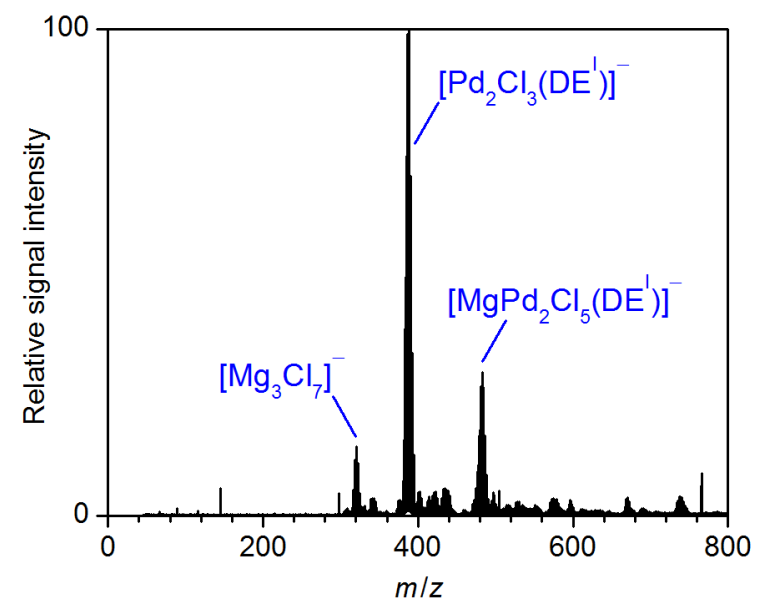

Figure 4.49: Negative-ion mode ESI mass spectrum (excerpt) of a solution of $\mathrm{Pd}(\mathrm{OAc})_{2}(3 \mathrm{mM})$, isoprene $\left(\mathrm{DE}^{\mathrm{I}}, 24 \mathrm{mM}\right)$, and $\mathrm{PhMgCl}(12 \mathrm{mM})$ in THF.

\subsubsection{Implications for the Catalytic Cycle}

The results discussed above confirm the assumption of Kambe and coworkers that organopalladate intermediates are a central element in the palladium-catalyzed cross-coupling of alkyl electrophiles with Grignard reagents.

The formation of a neutral bis-allylic palladium(II) species upon addition of the diene ligand to the palladium(0) precursor in the catalyst activation step could not be confirmed in the present studies. Upon transmetalation, the expected anionic intermediates $\left[\mathrm{PdR}(\mathrm{DE})_{2}\right]^{-}$were detected, 
although the proposed dimerization of the diene ligands is likely to be easily reversible, if taking place at all. The oxidative addition of alkyl electrophiles to the organopalladate intermediates following an $\mathrm{S}_{\mathrm{N}}$ 2-like mechanism could not be observed directly. However, the formation of the suggested neutral reaction product [PdRAlkyl(DE $\left.)_{2}\right]$ can be deduced from the presence of $\left[\mathrm{PdR}_{2} \mathrm{Alkyl}(\mathrm{DE})_{2}\right]^{-}$anions, which were presumably generated from the neutral oxidative addition products in a second transmetalation reaction. These complexes readily underwent reductive elimination reactions, thus closing the catalytic cycle. For the considered precursor anions, the elimination of the cross-coupling product competes with the elimination of the homo-coupling product, potentially hampering the selectivity of the reaction. However, under synthetic conditions, the formation of the homo-coupling product as a side reaction does not take place to a significant extent. It is therefore highly probable that the reductive elimination step takes place mainly at the neutral intermediate [PdRAlkyl(DE $\left.)_{2}\right]$, where only the formation of the cross-coupling product is possible. As a negative charge is known to decrease the tendency of a transition-metal complex to undergo reductive elimination reactions, $[37 \mathrm{s73]}$ this finding is in line with the expectations.

Apart from the mononuclear complexes, the formation of a plethora of dinuclear and oligonuclear organopalladates was observed, adding a new layer of complexity to the catalytic system. The heavier aggregates such as $\left[\mathrm{Pd}_{4} \mathrm{R}(\mathrm{DE})_{4}\right]^{-}$and $\left[\mathrm{Pd}_{6} \mathrm{R}(\mathrm{DE})_{6}\right]^{-}$were not found to participate in the catalytic cycle after the transmetalation step. Instead, given their easily achieved fragmentation into smaller subunits, it seems likely that they represent a catalyst reservoir for the reactive mononuclear species. Furthermore, it can be assumed that these oligomers aggregate over time to form even heavier nanoclusters and eventually lead to the observed precipitation of palladium black. In contrast, the dinuclear $\left[\mathrm{Pd}_{2} \mathrm{Bu}(\mathrm{DE})_{2}\right]^{-}$does indeed display catalytic activity, as could be seen from the formation of the anionized oxidative addition product $\left[\mathrm{Pd}_{2} \mathrm{Bu}_{2} \operatorname{Pr}(\mathrm{DE})_{2}\right]^{-}$and the subsequent reductive elimination of the coupling products $\operatorname{PrBu}$ and $\mathrm{Bu}_{2}$. This opens a second possible catalytic cycle, at least for the alkyl-alkyl cross-coupling, which involves a dinuclear palladate as the catalytically active species. Naturally, equilibria between the active species are imaginable.

Considering the results discussed above, a modified catalytic cycle can be proposed (scheme 4.4). 


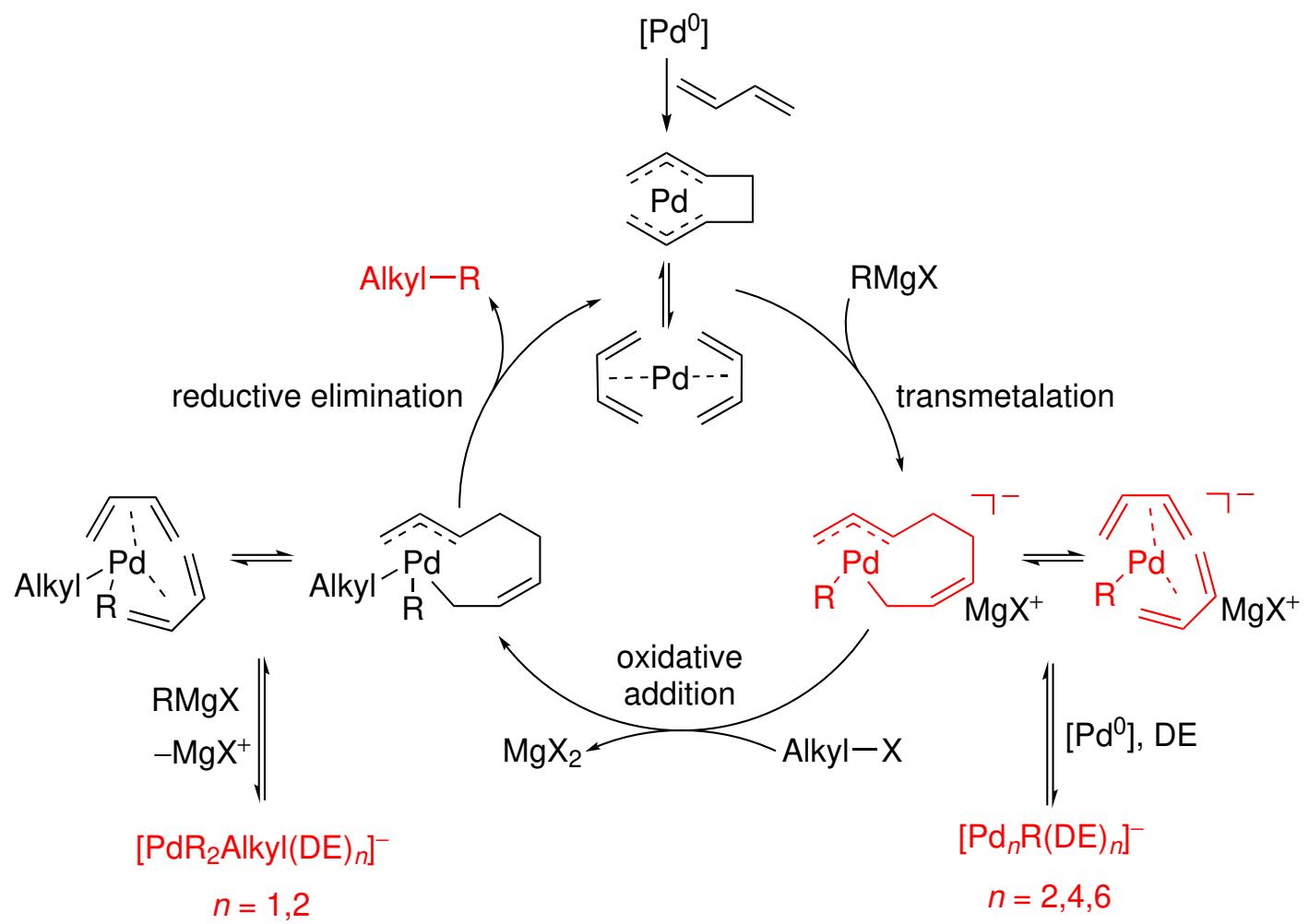

Scheme 4.4: Simplified catalytic cycle of a palladium-catalyzed cross-coupling reaction between an alkyl halide and a Grignard reagent in the presence of a 1,3-diene. Species observed by ESI mass spectrometry (as shown or as isoprene-containing analogues) are shown in red.

While many intermediates and elementary steps of the originally proposed catalytic cycle could be verified, a variety of further species were discovered that drastically increase the complexity of the catalytic cycle by introducing additional equilibria between potentially catalytically active and non-active palladium species. 


\subsection{Organopalladates Containing the Electron-Poor Phosphine Ligand $\operatorname{PAr}_{3}$}

The electron-poor phosphine ligand $\operatorname{PAr}_{3}^{\mathrm{F}}(\mathrm{L})$ has proven suitable for the stabilization of inorganic palladate $(0)$ complexes $\left[\mathrm{L}_{3} \mathrm{PdX}\right]^{-}$(section 4.2 ). Therefore, it is imaginable that it is also capable of stabilizing zero-valent organopalladate complexes. The generation of organopalladate complexes $\left[\mathrm{L}_{n} \mathrm{PdR}\right]^{-}$would open up new opportunities for cross-coupling reactions with alkyl halides following an alternative catalytic cycle as described in section 4.3 .

\subsubsection{Transmetalation of $\left[\operatorname{Pd}\left(\operatorname{PAr}_{3}^{\mathrm{F}}\right)_{3}\right]$ with Grignard Reagents}

To accomplish the generation of organopalladate $(0)$ complexes, solutions of $\left[\mathrm{L}_{3} \mathrm{Pd}\right]$ in $\mathrm{THF}$ were treated with Grignard reagents $\mathrm{RMgCl}$. ESI-mass spectrometric experiments of the resulting mixtures indeed revealed the presence of zero-valent organopalladates among other species.

When $n$ - $\mathrm{BuMgCl}$ was used as the transmetalating agent, $\left[\mathrm{L}_{2} \mathrm{PdBu}\right]^{-}$was detected as the dominant species in the ESI mass spectrum (figure 4.50). In addition, the dinuclear dianion $\left[\mathrm{L}_{2} \mathrm{Pd}_{2}\left(\mathrm{PAr}_{2}^{\mathrm{F}}\right) \mathrm{Bu}\right]^{2-}$ was detected, albeit with a very low signal intensity (figure 4.51).

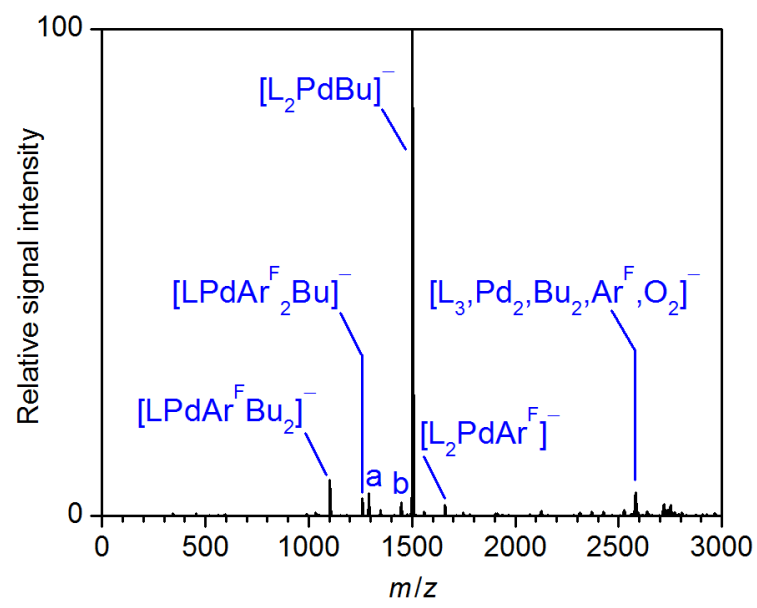

Figure 4.50: Negative-ion mode ESI mass spectrum of a solution of $\left[\mathrm{Pd}\left(\mathrm{PAr}_{3}^{\mathrm{F}}\right)_{3}\right]\left(\left[\mathrm{L}_{3} \mathrm{Pd}\right]\right.$, $3 \mathrm{mM})$ and $n$-BuMgCl $(12 \mathrm{mM})$ in $\mathrm{THF}$ $\left(\mathrm{a}=\left[\mathrm{LPd}\left(\mathrm{PAr}_{2}^{\mathrm{F}}\right) \mathrm{BuH}\right]^{-}, \mathrm{b}=\left[\mathrm{L}_{2} \mathrm{PdH}\right]^{-}\right)$.

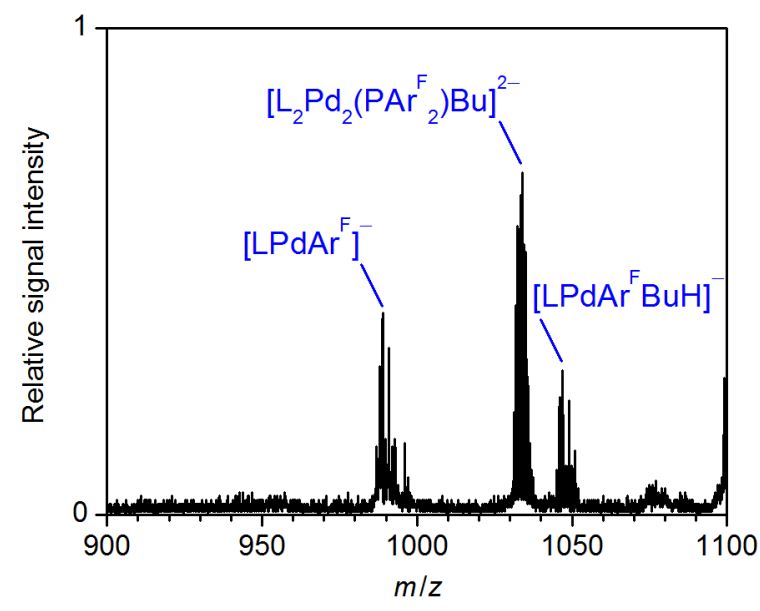

Figure 4.51: Negative-ion mode ESI mass spectrum (excerpt) of a solution of $\left[\mathrm{Pd}\left(\mathrm{PAr}_{3}^{\mathrm{F}}\right)_{3}\right]\left(\left[\mathrm{L}_{3} \mathrm{Pd}\right]\right.$, $3 \mathrm{mM})$ and $n-\mathrm{BuMgCl}(12 \mathrm{mM})$ in THF.

The presence of this dianionic organopalladate highlights the ability of the electron-poor phosphine ligand to stabilize palladium complexes with very high electron densities. Other species, which showed considerably lower signal intensities than the main species $\left[\mathrm{L}_{2} \mathrm{PdBu}\right]^{-}$, included $\left[\mathrm{L}_{2} \mathrm{PdAr}^{\mathrm{F}} \mathrm{Bu}_{2}\right]^{-},\left[\mathrm{L}_{2} \mathrm{PdAr}{ }_{2}^{\mathrm{F}} \mathrm{Bu}\right]^{-},\left[\mathrm{LPd}\left(\mathrm{PAr}_{2}^{\mathrm{F}}\right) \mathrm{BuH}\right]^{-},\left[\mathrm{L}_{2} \mathrm{PdH}\right]^{-},\left[\mathrm{L}_{2} \mathrm{PdAr}^{\mathrm{F}}\right]^{-}$, and a dinuclear complex of the overall composition of $\left[\mathrm{L}_{3}, \mathrm{Pd}_{2}, \mathrm{Bu}_{2}, \mathrm{Ar}^{\mathrm{F}}, \mathrm{O}_{2}\right]^{-}$. 
The $\operatorname{Ar}^{\mathrm{F}}$ and $\mathrm{PAr}_{2}^{\mathrm{F}}$ moieties incorporated in some of the less abundant ions presumably stem from decomposition reactions of the $\mathrm{PAr}_{3}^{\mathrm{F}}$ ligand, which are brought about by the Grignard reagent or can also take place in the palladate complexes themselves, as will be further discussed below. The triply substituted ions $\left[\mathrm{L}_{2} \mathrm{PdAr}^{\mathrm{F}} \mathrm{Bu}_{2}\right]^{-}, \quad\left[\mathrm{L}_{2} \mathrm{PdAr}_{2}^{\mathrm{F}} \mathrm{Bu}\right]^{-}$, and $\left[\mathrm{LPd}\left(\mathrm{PAr}_{2}^{\mathrm{F}}\right) \mathrm{BuH}\right]^{-}$display an oxidation state of the palladium center of $+\mathrm{II}$, which indicates the occurrence of oxidation processes. These oxidation processes might be caused by the reaction of the electron-rich palladium center with traces of oxygen in the sample solutions or inside the mass spectrometer. The tendency of organopalladate complexes to react with dioxygen has already been shown in section 4.3 . Another possibility is the reaction of the palladium(0) species with residual organyl chlorides $\mathrm{RCl}$ from the used Grignard reagents combined with a second transmetalation reaction (equation (4.67)). $\left[\mathrm{L}_{2} \mathrm{PdH}\right]^{-}$is presumably formed from $\left[\mathrm{L}_{2} \mathrm{PdBu}\right]^{-}$in a $\beta$-hydride elimination reaction (equation (4.68)).

$$
\begin{array}{r}
{\left[\mathrm{L}_{2} \mathrm{PdAr}^{\mathrm{F}}\right]^{-}+\mathrm{RCl} \underset{-\mathrm{MgCl}_{2}}{\stackrel{\mathrm{RMgCl}}{\longrightarrow}}\left[\mathrm{L}_{2} \mathrm{PdAr}^{\mathrm{F}} \mathrm{R}_{2}\right]^{-}} \\
{\left[\mathrm{L}_{2} \mathrm{PdBu}\right]^{-} \longrightarrow\left[\mathrm{L}_{2} \mathrm{PdH}\right]^{-}+\mathrm{C}_{4} \mathrm{H}_{8}}
\end{array}
$$

Dinuclear species incorporating multiple organic substitutents and/or oxygen, such as $\left[\mathrm{L}_{3}, \mathrm{Pd}_{2}, \mathrm{Bu}_{2}, \mathrm{Ar}^{\mathrm{F}}, \mathrm{O}_{2}\right]^{-}$, were observed frequently in other experiments some time after the preparation of the sample solutions. These usually grew in signal intensitiy over the course of the measurement, whereas the low-valent mononuclear organopalladates tended to decrease over time. This finding indicates that such complexes are the result of degradation reactions proceeding in the sample solution, which range from oxidation over the ongoing decomposition of the phosphine ligand to aggregation processes. Stable signal intensities could typically be achieved for time spans of approximately $0.5-2 \mathrm{~h}$.

Applying $\mathrm{PhMgCl}$ instead of $n-\mathrm{BuMgCl}$ resulted mainly in the formation of several palladates derived from ligand decomposition reactions (figure 4.52). The most prominent ion was $\left[\mathrm{L}_{2} \mathrm{Pd}\left(\mathrm{PAr}_{2}^{\mathrm{F}}\right)\right]^{-}$, followed by the dinuclear $\left[\mathrm{L}_{3} \mathrm{Pd}_{2}\left(\mathrm{PAr}_{2}^{\mathrm{F}}\right)\right]^{-}$and $\left[\mathrm{L}_{2} \mathrm{PdAr}^{\mathrm{F}}\right]^{-}$. $\left[\mathrm{L}_{2} \mathrm{PdPh}\right]^{-}$was also formed, yet in lower relative signal intensities. In contrast, no palladate( 0 ) complexes at all were detected with $\mathrm{BnMgCl}$ as the transmetalating reagent (figure 4.53). The ESI mass spectrum showed [LPdAr $\left.{ }^{\mathrm{F}} \mathrm{Bn}_{2}\right]^{-}$as the most abundant species, followed by $\left[\mathrm{LPdBn}_{3}\right]^{-}$. It seems apparent that ligand decomposition reactions tend to proceed mostly in the sample solutions with $\mathrm{PhMgCl}$, and that potential palladate(0) complexes formed in the presence of $\mathrm{BnMgCl}$ are very sensitive towards oxidation processes, as was already shown for the diene-ligated palladates in section 4.3 . However, it has to be kept in mind that the composition of the sample solution is not necessarily reflected correctly in the mass spectra, and other effects, for example the tendencies of the different organopalladate complexes to form ion pairs and thus become inaccessible to ESI mass spectrometry, have to be taken into account. 


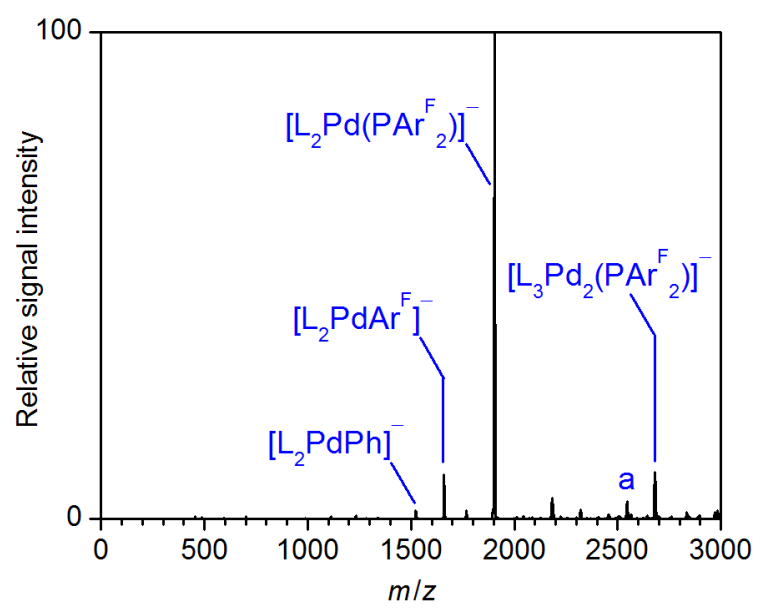

Figure 4.52: Negative-ion mode ESI mass spectrum of a solution of $\left[\mathrm{Pd}\left(\mathrm{PAr}_{3}^{\mathrm{F}}\right)_{3}\right]$ ([ $\left.\left.\mathrm{L}_{3} \mathrm{Pd}\right], 3 \mathrm{mM}\right)$ and $\mathrm{PhMgCl}(12 \mathrm{mM})$ in $\mathrm{THF}$ $\left(\mathrm{a}=\left[\mathrm{L}_{3} \mathrm{Pd}_{2}\left(\mathrm{PAr}{ }^{\mathrm{F}} \mathrm{Ph}\right) \mathrm{BuH}\right]^{-}\right)$.

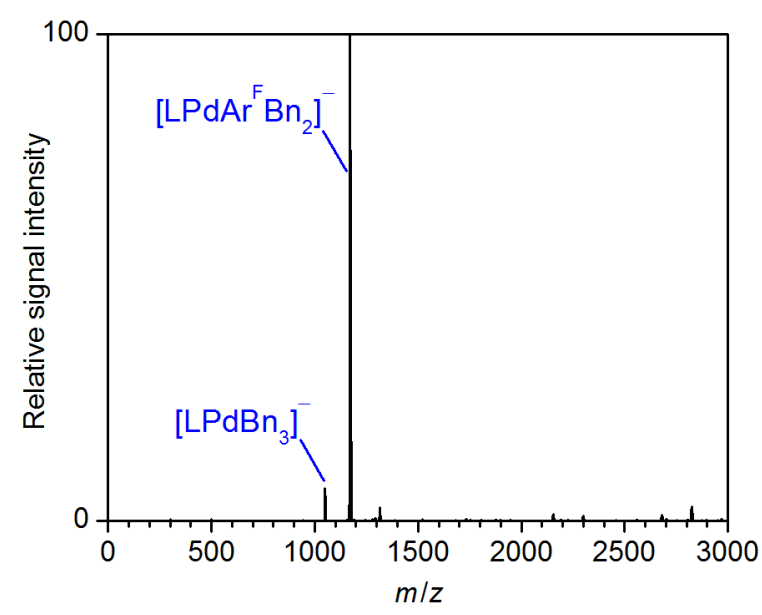

Figure 4.53: Negative-ion mode ESI mass spectrum of a solution of $\left[\mathrm{Pd}\left(\mathrm{PAr}_{3}^{\mathrm{F}}\right)_{3}\right]\left(\left[\mathrm{L}_{3} \mathrm{Pd}\right], 3 \mathrm{mM}\right)$ and $\mathrm{BnMgCl}(12 \mathrm{mM})$ in THF. 88.

\section{Unimolecular Reactivity of $\left[\mathrm{L}_{2} \mathrm{PdR}\right]^{-}$in the Gas Phase}

To compare the stability of the generated palladate $(0)$ complexes $\left[\mathrm{L}_{2} \mathrm{PdR}\right]^{-}$, with $\mathrm{R}=n$-Bu and $\mathrm{Ph}$, both anions were subjected to collision-induced dissociation experiments. In both cases, $\left[\mathrm{LPdAr}{ }^{\mathrm{F}}\right]^{-}$was the most abundant fragment ion, resulting from a dissociation of a $\left[\mathrm{P}, \mathrm{Ar}_{2}^{\mathrm{F}}, \mathrm{R}\right]$ unit (equation (4.69), figures 4.54 and 4.55).

$$
\left[\mathrm{L}_{2} \mathrm{PdR}\right]^{-} \longrightarrow\left[\mathrm{LPdAr}^{\mathrm{F}}\right]^{-}+\left[\mathrm{P}, \mathrm{Ar}_{2}^{\mathrm{F}}, \mathrm{R}\right]
$$

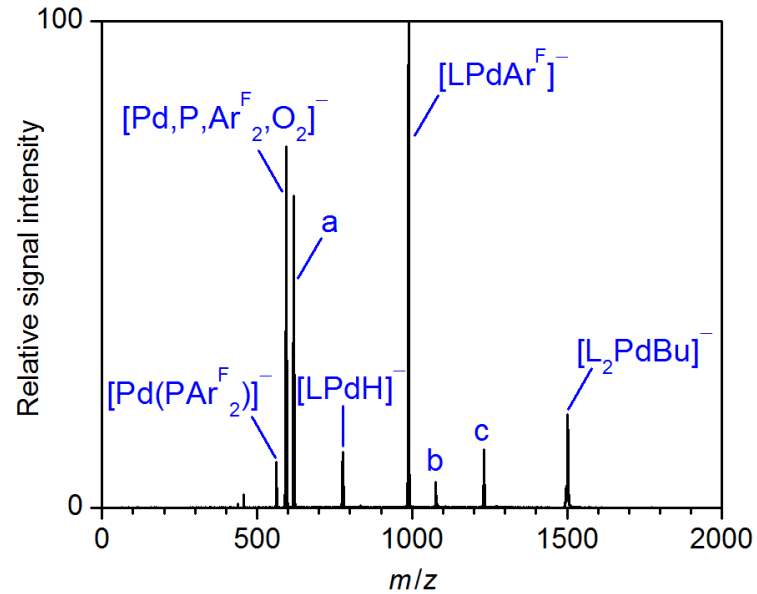

Figure 4.54: Mass spectrum of mass-selected $\left[\mathrm{L}_{2} \mathrm{PdBu}\right]^{-}$and its fragment ions produced upon collision-induced dissociation $\left(E_{\mathrm{LAB}}=20.0 \mathrm{eV}\right.$, $\mathrm{a}=\left[\mathrm{Pd}, \mathrm{P}, \mathrm{Ar}_{2}^{\mathrm{F}}, \mathrm{Bu}-\mathrm{H}\right]^{-}, \quad \mathrm{b}=\left[\mathrm{LPd}\left(\mathrm{PAr}{ }^{\mathrm{F}} \mathrm{Bu}\right)\right]^{-}$, $\left.\mathrm{c}=\left[\operatorname{LPd}\left(\operatorname{PAr}_{2}^{\mathrm{F}}\right)\right]^{-}\right)$.

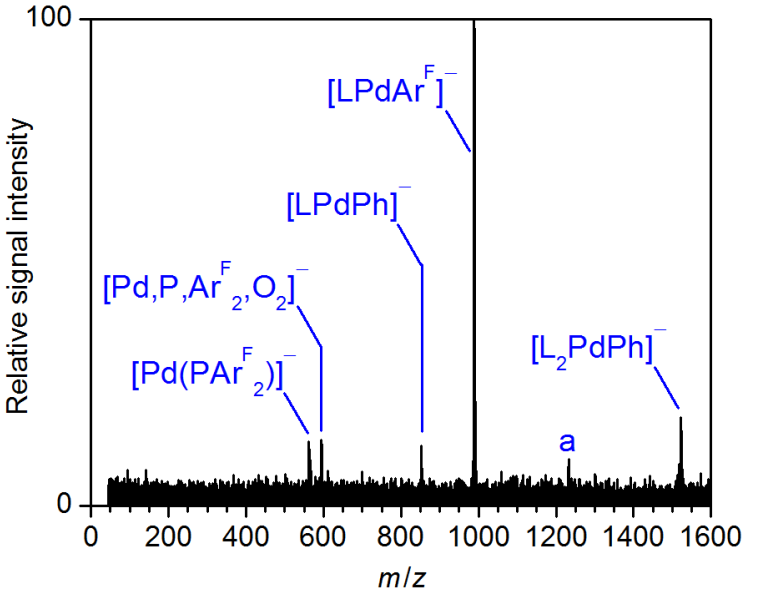

Figure 4.55: Mass spectrum of mass-selected $\left[\mathrm{L}_{2} \mathrm{PdPh}\right]^{-}$and its fragment ions produced upon collision-induced dissociation $\left(E_{\mathrm{LAB}}=20.0 \mathrm{eV}\right.$, $\mathrm{a}=\left[\operatorname{LPd}\left(\operatorname{PAr}_{2}^{\mathrm{F}}\right)\right]^{-}$. 
The dominance of this fragmentation reaction, compared to the more straightforward loss of a single ligand, is most likely due to the higher stability of the product ion bearing the electronwithdrawing $\mathrm{Ar}^{\mathrm{F}}$ substituent. From this experiment, it cannot be fully excluded that the transfer of an $\operatorname{Ar}^{\mathrm{F}}$ moiety onto the palladium center may take place already in solution, and that the ion in question bears the butyl or phenyl substituent as part of a $\operatorname{PAr}_{2}^{\mathrm{F}} \mathrm{R}$ ligand rather than at the palladium center. However, the dominance of an alleged $\left[\mathrm{L}\left(\mathrm{PAr}_{2}^{\mathrm{F}} \mathrm{Bu}\right) \mathrm{PdAr}^{\mathrm{F}}\right]^{-}$ion, in the case of $\mathrm{R}=n-\mathrm{Bu}$, seems highly unlikely, given the relatively low signal intensity of other ions that contain ligand fragments, including the presumably better stabilized $\left[\mathrm{L}_{2} \mathrm{PdAr}^{\mathrm{F}}\right]^{-}$. Furthermore, fragmentation of the phosphine ligand during collision-induced dissociation was also involved in other observed fragmentation reactions, for example in the formation of $\left[\operatorname{Pd}\left(\operatorname{PAr}_{2}^{\mathrm{F}}\right)\right]^{-}$ (equation (4.70) and in the dissociation of $\operatorname{Ar}_{2}^{\mathrm{F}}$ and $\operatorname{Ar}^{\mathrm{F}} \mathrm{R}$ (equations 4.71) and 4.72). The dissociation of the ligand $\mathrm{L}$ was also observed as a minor fragmentation pathway for $\mathrm{R}=\mathrm{Ph}$ (equation (4.73)). For $\mathrm{R}=n$ - $\mathrm{Bu}$, a ligand dissociation with subsequent $\beta$-hydride elimination gave the product ion $[\mathrm{LPdH}]^{-}$(equation (4.74)). Additionally, a fragmentation leading to the product ion $\left[\mathrm{Pd}, \mathrm{P}, \mathrm{Ar}_{2}^{\mathrm{F}}, \mathrm{Bu}-\mathrm{H}\right]^{-}$presumably involved the dissociation of $\mathrm{Ar}^{\mathrm{F}} \mathrm{H}$ along with one ligand L (equation 4.75).

$$
\begin{aligned}
{\left[\mathrm{L}_{2} \mathrm{PdR}\right]^{-} } & \longrightarrow\left[\mathrm{Pd}\left(\mathrm{PAr}_{2}^{\mathrm{F}}\right)\right]^{-}+\mathrm{Ar}^{\mathrm{F}} \mathrm{R}+\mathrm{L} \\
{\left[\mathrm{L}_{2} \mathrm{PdBu}\right]^{-} } & \longrightarrow\left[\mathrm{LPd}\left(\mathrm{PAr}^{\mathrm{F}} \mathrm{Bu}\right)\right]^{-}+\mathrm{Ar}_{2}^{\mathrm{F}} \\
{\left[\mathrm{L}_{2} \mathrm{PdR}\right]^{-} } & \longrightarrow\left[\mathrm{LPd}\left(\mathrm{PAr}_{2}^{\mathrm{F}}\right)\right]^{-}+\mathrm{Ar}^{\mathrm{F}} \mathrm{R} \\
{\left[\mathrm{L}_{2} \mathrm{PdPh}\right]^{-} } & \longrightarrow[\mathrm{LPdPh}]^{-}+\mathrm{L} \\
{\left[\mathrm{L}_{2} \mathrm{PdBu}\right]^{-} } & \longrightarrow[\mathrm{LPdH}]^{-}+\mathrm{C}_{4} \mathrm{H}_{8}+\mathrm{L} \\
{\left[\mathrm{L}_{2} \mathrm{PdBu}\right]^{-} } & \longrightarrow\left[\mathrm{Pd}, \mathrm{P}, \mathrm{Ar}_{2}^{\mathrm{F}}, \mathrm{Bu}-\mathrm{H}\right]^{-}+\mathrm{Ar}^{\mathrm{F}} \mathrm{H}+\mathrm{L}
\end{aligned}
$$

Again, as already seen in some cases in section 4.3, an ion-molecule reaction with $\mathrm{O}_{2}$ following the gas-phase fragmentation was observed for the fragment ion $\left[\operatorname{Pd}\left(\operatorname{PAr}_{2}^{\mathrm{F}}\right)\right]^{-}$, reflecting the high sensitivity of these low-valent and coordinatively unsaturated palladium species against dioxygen.

\subsubsection{Influences of the Transmetalating Agent and the Phosphine Ligand}

\section{Transmetalation of $\left[\operatorname{Pd}\left(\operatorname{PAr}_{3}^{\mathrm{F}}\right)_{3}\right]$ with Organolithium and Organozinc Reagents}

To test the influence of different transmetalation reagents on the resulting palladate complexes,

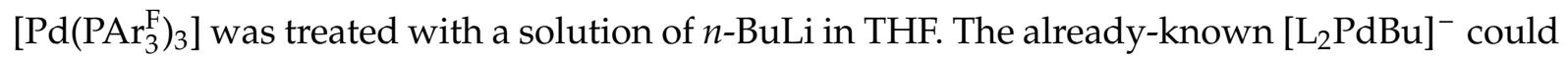
again be detected. However, the ESI mass spectrum was dominated by ligand decomposition products and triply substituted palladate(II) species and displayed a poor overall signal intensity. This indicates that the higher reactivity of the organolithium reagent compared to the Grignard reagent causes ligand decomposition reactions to a greater extent. In addition, as could also be derived from the low overall signal intensity, it is likely that the formation of 
contact-ion pairs with lithium counterions hampered the transfer of $\left[\mathrm{L}_{2} \mathrm{PdBu}\right]^{-}$ions into the gas phase.

Switching to $n$-BuZnCl$\cdot \mathrm{LiCl}$ produced heterobimetallic complexes, such as $\left[\mathrm{L}_{2} \mathrm{PdZnCl}_{2}\left(\mathrm{PAr}_{2}^{\mathrm{F}}\right)\right]^{-},\left[\mathrm{L}_{2} \mathrm{PdZnBuCl}\left(\mathrm{PAr}_{2}^{\mathrm{F}}\right)\right]^{-}$, and $\left[\mathrm{L}_{3} \mathrm{PdZnBuCl}_{2}\right]^{-}$, and even the heterotrinuclear species $\left.\left[\mathrm{L}_{2} \mathrm{LiPdZnCl} \mathrm{PAr}_{2}\right)\right]^{-}$, which may be described as a lithium chloride adduct of the first-mentioned complex. The main species were $\left[\mathrm{L}_{3} \mathrm{PdCl}\right]^{-}$and $\left[\mathrm{L}_{2} \mathrm{Pd}\left(\mathrm{PAr}_{2}^{\mathrm{F}}\right)\right]^{-}$(figure 4.56). As it cannot be told from the mass spectrum alone if the formation of the shown heterobimetallic species involves a transfer of the butyl substituent onto the palladium center, collision-induced dissociation experiments were conducted for $\left[\mathrm{L}_{3} \mathrm{PdZnBuCl}_{2}\right]^{-}$(figure 4.57) and $\left[\mathrm{L}_{2} \mathrm{PdZnBuCl}\left(\mathrm{PAr}_{2}^{\mathrm{F}}\right)\right]^{-}$.

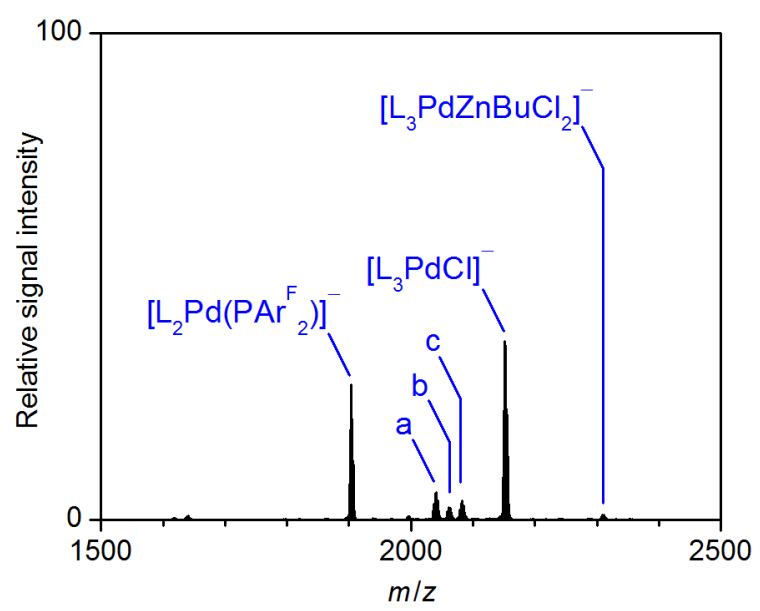

Figure 4.56: Negative-ion mode ESI mass spectrum of a solution of $\left[\mathrm{Pd}\left(\mathrm{PAr}_{3}^{\mathrm{F}}\right)_{3}\right]$ $\left(\left[\mathrm{L}_{3} \mathrm{Pd}\right], \quad 3 \mathrm{mM}\right)$ and $n$-BuZnCl$\cdot \mathrm{LiCl}$ $(12 \mathrm{mM})$ in THF $\left(\mathrm{a}=\left[\mathrm{L}_{2} \mathrm{PdZnCl}_{2}\left(\mathrm{PAr}_{2}^{\mathrm{F}}\right)\right]^{-}\right.$, $\mathrm{b}=\left[\mathrm{L}_{2} \mathrm{PdZnBuCl}\left(\mathrm{PAr}_{2}^{\mathrm{F}}\right)\right]^{-}$,

$\left.\mathrm{c}=\left[\mathrm{L}_{2} \mathrm{LiPdZnCl}_{3}\left(\mathrm{PAr}_{2}^{\mathrm{F}}\right)\right]^{-}\right)$.

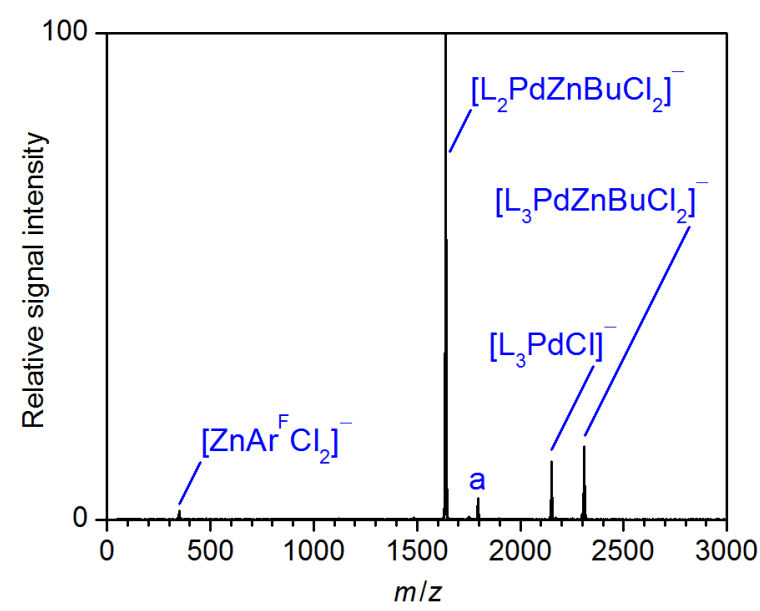

Figure 4.57: Mass spectrum of mass-selected $\left[\mathrm{L}_{3} \mathrm{PdZnBuCl}\right]^{-}$and its fragment ions produced upon collision-induced dissociation $\left(E_{\mathrm{LAB}}=8.0 \mathrm{eV}, \mathrm{a}=\left[\mathrm{L}_{2} \mathrm{PdZnAr} \mathrm{F}^{\mathrm{F}} \mathrm{Cl}_{2}\right]^{-}\right)$.

These experiments did not yield butyl-containing palladates as fragment ions, but rather showed the loss of one $\mathrm{BuZnCl}$ unit as a major fragmentation channel (equation (4.76)).

$$
\left[\mathrm{L}_{3} \mathrm{PdZnBuCl}\right]^{-} \longrightarrow\left[\mathrm{L}_{3} \mathrm{PdCl}\right]^{-}+\mathrm{BuZnCl}
$$

It is therefore assumed that no transmetalation took place when the organozinc reagent was applied, which is in line with the findings for the diene-ligated palladium complexes (section 4.3). The reactivity of the butylzinc reagent does apparently not suffice to bring about a transmetalation of the palladium(0) center.

\section{Influence of the Phosphine Ligand on the Stability of Organopalladate(0) Complexes}

To test if the electron-withdrawing phosphine ligand L was necessary to stabilize organopalladate complexes $\left[\mathrm{L}_{2} \mathrm{PdBu}\right]^{-},\left[\mathrm{Pd}\left(\mathrm{PPh}_{3}\right)_{4}\right]$ was treated with $n$-BuMgCl. ESI mass spectrometry 
of the resulting solution led to mass spectra of a low overall signal intensity, which did not show any palladium-containing anions under the chosen conditions. ESI mass spectrometry in the cationic mode showed the two-valent $\left[\left(\mathrm{PPh}_{3}\right) \mathrm{PdH}\right]^{+}$as the only palladium-containing species. This demonstrated that the $\mathrm{PPh}_{3}$ ligand was not sufficient to stabilize the palladate complexes in question. As a ligand that is less electron-withdrawing than $\mathrm{L}$, but more electronwithdrawing than $\mathrm{PPh}_{3}, \mathrm{~L}^{\mathrm{Ph} 1}$ (see section 4.2 ) was applied next. $\mathrm{L}^{\mathrm{Ph} 1}$ was added to $\left[\mathrm{Pd}_{2}(\mathrm{dba})_{3}\right]$ to form the corresponding palladium phosphine complex in situ, which was then treated with $n$-BuMgCl. The resulting ESI mass spectrum did not show $\left[\mathrm{L}_{2}^{\mathrm{Ph} 1} \mathrm{PdBu}\right]^{-}$or any other zerovalent palladate complexes, except for $\left[\mathrm{L}_{2}^{\mathrm{Ph} 1} \mathrm{PdAr}^{\mathrm{F}}\right]^{-}$and $\left[\mathrm{L}_{3}^{\mathrm{Ph} 1} \mathrm{PdAr}^{\mathrm{F}}\right]^{-}$in very low signal intensities, while the dominating species were triply substitued organopalladates such as $\left[\mathrm{L}^{\mathrm{Ph} 1} \mathrm{PdAr}_{2}^{\mathrm{F}} \mathrm{Bu}\right]^{-}$.

\subsubsection{Electronic Properties of $\left[\mathrm{L}_{n} \mathrm{PdR}\right]^{-}$in Comparison to $\left[\mathrm{L}_{n} \mathrm{PdX}\right]^{-}$}

Comparing the above results to those from the ligand exchange experiments with the inorganic palladates (section 4.2.2 made clear that palladate complexes $\left[\mathrm{L}_{3}^{\mathrm{Ph} 1} \mathrm{PdBr}\right]^{-}$were stable enough to be analyzed by ESI mass spectrometry, whereas the corresponding organopalladates bearing the $\mathrm{L}^{\mathrm{Ph} 1}$ ligand could not be detected. The electron-withdrawing properties of the used phosphine ligand directly correspond to its ability to stabilize complexes with high electron densities at the metal center. This allows the conclusion that the transfer of a butyl or phenyl anion results in palladate complexes with a higher electron density at the palladium center than the transfer of halide or acetate anions, which is not unexpected given the strong donor abilities of the involved organic substituents. However, the inorganic palladate complexes tended to incorporate three phosphine ligands, while only two phosphine ligands were present in most of the organopalladates, impeding a direct comparison between these complexes.

Further evidence regarding the different electron densities of the palladium center in the organic and the inorganic case can be gained from the gas-phase fragmentation behavior of the considered complexes. Organopalladate complexes $\left[\mathrm{L}_{2} \mathrm{PdR}\right]^{-}$tended to undergo ligand fragmentation reactions upon collision-induced dissociation. In contrast, $\left[\mathrm{L}_{3} \mathrm{PdX}\right]^{-}$, with $\mathrm{X}=\mathrm{Cl}$, $\mathrm{Br}, \mathrm{I},(\mathrm{OAc})$, was inclined to lose intact phosphine ligands $\mathrm{L}$ instead. The fragment ion containing only one phosphine ligand $\mathrm{L},[\mathrm{LPdX}]^{-}$, was frequently observed in CID experiments of $\left[\mathrm{L}_{3} \mathrm{PdX}\right]^{-}$and $\left[\mathrm{L}_{2} \mathrm{PdX}\right]^{-}$, yet its organopalladate counterpart, $[\mathrm{LPdR}]^{-}$, could not be produced from $\left[\mathrm{L}_{2} \mathrm{PdR}\right]^{-}$. One approach to explain these differences is the stability of the product anion, which is expected to be stabilized by the electron-withdrawing $\operatorname{Ar}^{\mathrm{F}}$ substituent rather than by a butyl or a phenyl substituent. In addition, the bonding interactions between the electron-rich metal center and the phosphine ligand in the precursor ion probably presumably play a role. Bonding interactions between transition metals and phosphine ligands involve $\pi$-bonding interactions to some degree, even for triorganylphosphines such as $\mathrm{PMe}_{3} \mathrm{Or} \mathrm{PPh}_{3}$,

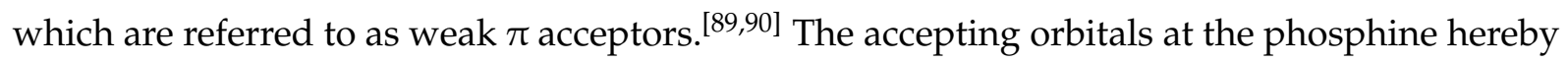
are mostly $\mathrm{P}-\mathrm{C} \sigma^{*}$ orbitals, which means that a strong $\pi$-backbonding interaction weakens the 
phosphorus-carbon bond, thus making fragmentation reactions of the phosphine ligand more likely. The strength of the $\pi$-backbonding interaction can be assumed to be relatively high compared to other palladium-triorganylphosphine complexes, as it tends to increase with the presence of electron-withdrawing substituents on the phosphorus atom, which lower the accepting orbitals in energy, and with an increasing electron densitiy at the metal center, which raises the energy of the donating orbitals.

These considerations suggest a higher electron densitiy at the palladium center in case of the organopalladates than for the inorganic palladates $\left[\mathrm{L}_{n} \mathrm{PdX}\right]^{-}$, which can also be stabilized under ESI conditions by the more electron-rich $\mathrm{L}^{\mathrm{Ph} 1}$ ligand and which show a significantly lower tendency to undergo ligand fragmentation reactions in both solution and gas-phase reactions.

\subsubsection{Reactivity of Organopalladates $\left[\mathrm{L}_{2} \mathrm{PdR}\right]^{-}$Towards Organyl Electrophiles}

\section{Reactivity of Organopalladates $\left[\mathrm{L}_{2} \mathrm{PdR}\right]^{-}$Towards Organyl Electrophiles in Solution}

The addition of alkyl iodides AlkylI, with Alkyl = Et and Pr, to solutions of $\left[\mathrm{L}_{3} \mathrm{Pd}\right]$ and $\mathrm{RMgCl}$, with $\mathrm{R}=n$-Bu and $\mathrm{Ph}$, gave the product ions [ $\left.\mathrm{LPdR}_{2} \mathrm{Alkyl}\right]^{-}$among other species (figure 4.58 for $\mathrm{R}=\mathrm{Ph}$ and $\mathrm{Alkyl}=\mathrm{Pr}$ ). These included triply substituted palladates bearing iodide substituents or $\operatorname{Ar}^{\mathrm{F}}$ and $\mathrm{PAr}_{2}^{\mathrm{F}}$ substituents, the latter two originating from ligand decomposition processes, as well as the zero-valent organopalladates $\left[\mathrm{L}_{2} \mathrm{PdR}\right]^{-}$and $\left[\mathrm{L}_{2} \mathrm{PdAr}^{\mathrm{F}}\right]^{-}$and the purely inorganic complexes $\left[\mathrm{L}_{n} \mathrm{PdI}\right]^{-}$, with $n=1-3$.

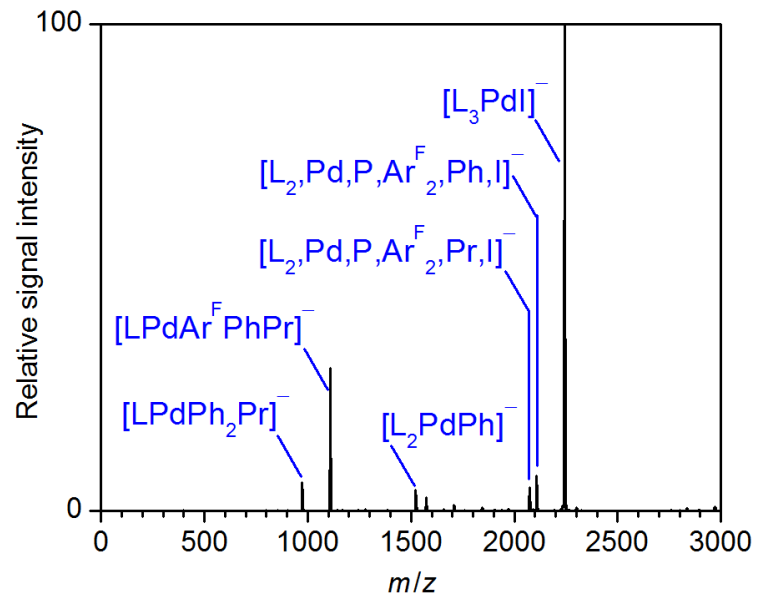

Figure 4.58: Negative-ion mode ESI mass spectrum of a solution of $\left[\mathrm{Pd}\left(\mathrm{PAr}_{3}^{\mathrm{F}}\right)_{3}\right]\left(\left[\mathrm{L}_{3} \mathrm{Pd}\right], 3 \mathrm{mM}\right), \mathrm{Ph}-$ $\mathrm{MgCl}(12 \mathrm{mM})$, and $\operatorname{PrI}(12 \mathrm{mM})$ in THF.

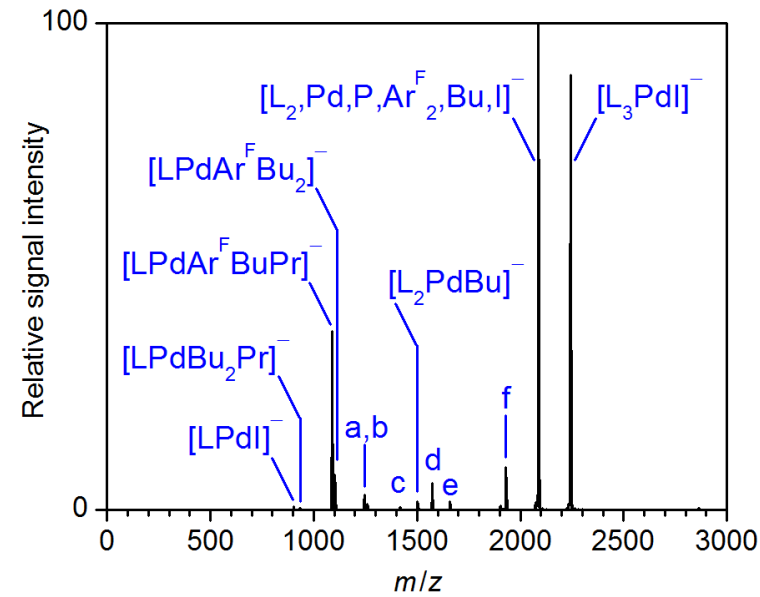

Figure 4.59: Negative-ion mode ESI mass spectrum of a solution of $\left[\mathrm{Pd}\left(\mathrm{PAr}_{3}^{\mathrm{F}}\right)_{3}\right]\left(\left[\mathrm{L}_{3} \mathrm{Pd}\right]\right.$, $3 \mathrm{mM}), n$-BuMgCl $(12 \mathrm{mM})$, and $\operatorname{PrI}(12 \mathrm{mM})$ in THF $\left(\mathrm{a}=\left[\mathrm{LPdAr}_{2}^{\mathrm{F} P r}\right]^{-}, \quad \mathrm{b}=\left[\mathrm{LPdAr}_{2}^{\mathrm{F}} \mathrm{Bu}\right]^{-}\right.$, $\mathrm{c}=\left[\mathrm{L}, \mathrm{Pd}, \mathrm{P}, \mathrm{Ar}_{2}^{\mathrm{F}}, \mathrm{Bu}, \mathrm{I}\right]^{-}, \quad \mathrm{d}=\left[\mathrm{L}_{2} \mathrm{PdI}\right]^{-}$, $\left.\mathrm{e}=\left[\mathrm{L}_{2} \mathrm{PdAr}^{\mathrm{F}}\right]^{-}, \mathrm{f}=\left[\mathrm{L}_{2}, \mathrm{Pd}, \mathrm{P}, \mathrm{Ar}^{\mathrm{F}}, \mathrm{Bu}_{2}, \mathrm{I}\right]^{-}\right)$. 
The product ions [LPdR $\mathrm{Alkyl}^{-}$can be interpreted as transmetalated, thus anionized, analoga of the neutral intermediates [LPdRAlkyl] ${ }^{-}$, which would form in an $\mathrm{S}_{\mathrm{N}} 2$-type reaction with the electrophile analogous to the reaction of diene-based palladates (section 4.3). The addition of the alkyl iodide to the palladium catalyst did not take place in the absence of the Grignard reagent, as was shown in a control experiment, which confirms the assumed order of elementary reaction steps. Furthermore, no reaction could be observed when $\mathrm{L}^{\mathrm{Ph} 1}$ was applied as a ligand, which is in line with the finding that $\mathrm{L}^{\mathrm{Ph} 1}$ is not able to stabilize palladate $(0)$ complexes $\left[\mathrm{L}_{2}^{\mathrm{Ph} 1} \mathrm{PdR}\right]^{-}$(section 4.4.3).

Even more interesting than the reactivity towards the relatively reactive alkyl iodides seemed the reactivity towards propyl bromide, which was tested for the combination of [ $\left.\mathrm{L}_{3} \mathrm{Pd}\right]$ with $n$-BuMgCl (figure 4.60).

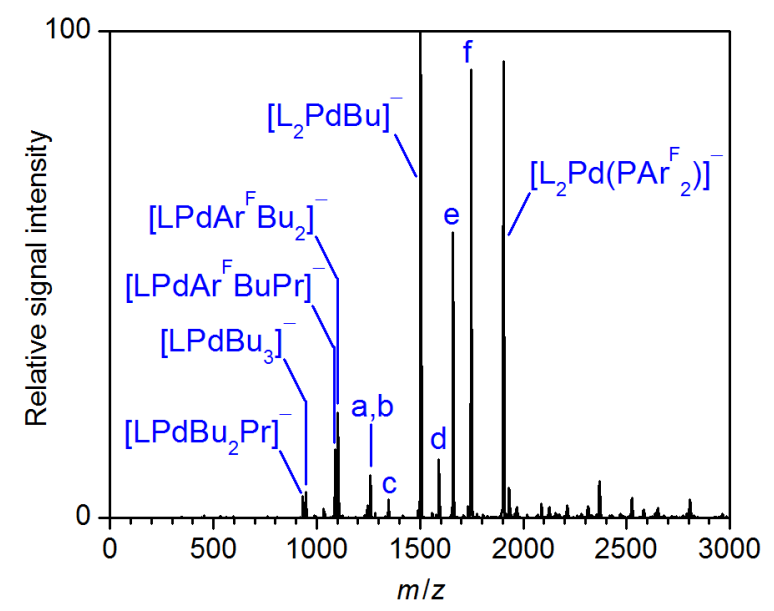

Figure 4.60: Negative-ion mode ESI mass spectrum of a solution of $\left[\mathrm{Pd}\left(\mathrm{PAr}_{3}^{\mathrm{F}}\right)_{3}\right]\left(\left[\mathrm{L}_{3} \mathrm{Pd}\right]\right.$, $3 \mathrm{mM}), n-\mathrm{BuMgCl}(12 \mathrm{mM})$, and $\operatorname{PrBr}(12 \mathrm{mM})$ in THF $\left(\mathrm{a}=\left[\operatorname{LPdAr}_{2}^{\mathrm{F}} \operatorname{Pr}\right]^{-}, \quad \mathrm{b}=\left[\operatorname{LPdAr}_{2}^{\mathrm{F} B u}\right]^{-}\right.$, $\left.\mathrm{c}=\left[\mathrm{L}, \mathrm{Pd}, \mathrm{P}, \mathrm{Ar}_{2}^{\mathrm{F}}, \mathrm{Bu}_{2}\right]^{-}, \mathrm{d}=\left[\mathrm{L}_{2} \mathrm{Pd}\left(\mathrm{PBu}_{2}\right)\right]^{-}, \mathrm{e}=\left[\mathrm{L}_{2} \mathrm{PdAr}^{\mathrm{F}}\right]^{-}, \mathrm{f}=\left[\mathrm{L}_{2} \mathrm{Pd}\left(\mathrm{PAr}^{\mathrm{F}} \mathrm{Bu}\right)\right]^{-}\right)$.

The tendency to undergo oxidative addition reactions with $\mathrm{PrBr}$ was considerably lower than with PrI, as could be deduced from the relatively small signal intensities of [ $\left.\mathrm{LPdBu}_{2} \mathrm{Pr}\right]^{-}$and $\left[\mathrm{LPdAr}{ }^{\mathrm{F}} \mathrm{BuPr}\right]^{-}$compared to that of $\left[\mathrm{L}_{2} \mathrm{PdBu}\right]^{-}$. Nevertheless, an oxidative addition reaction could also be observed in this case. In contrast, propyl chloride did not show any reactivity towards the low-valent palladate complexes. With the sterically more demanding isopropyl bromide, [ $\left.\mathrm{LPdAr}^{\mathrm{F}} \mathrm{Bu}^{i} \mathrm{Pr}\right]^{-}$could be observed, but only in very low signal intensities.

To extend the scope of the observed reactions to aryl and allyl electrophiles, allyl bromide (AllBr) and ethyl 4-bromobenzoate $(\mathrm{ArBr})$ were added to solutions of $\left[\mathrm{Pd}\left(\mathrm{PAr}_{3}^{\mathrm{F}}\right)_{3}\right]$ and $n$ - $\mathrm{BuMgCl}$, which were then analyzed by ESI mass spectrometry. In the case of allyl bromide, a fast reaction could be deduced from a rapid color change of the sample solution and the presence of allyl-containing palladate ions. However, the overall signal intensity in the ESI mass spectrum was quite low and the expected intermediates, such as [ $\mathrm{LPdBu}_{2} \mathrm{All}^{-}$or [LPdAr $\left.^{\mathrm{F}} \mathrm{BuAll}\right]^{-}$, were not detected, possibly due to fast consecutive reactions. For the aryl 
system, the expected species $\left[\mathrm{LPdBu}_{2} \mathrm{Ar}\right]^{-}$and $\left[\mathrm{LPdAr}{ }^{\mathrm{F}} \mathrm{BuAr}\right]^{-}$were both represented in the ESI mass spectrum, which was yet again dominated by ions stemming from ligand decomposition reactions.

\section{Reactivity of Organopalladates $\left[\mathrm{L}_{2} \mathrm{PdR}\right]^{-}$Towards Organyl Electrophiles in the Gas Phase}

Bimolecular reactivity experiments inside the collision cell of a mass spectrometer proved suitable to analyze reactivity trends of inorganic palladates $\left[\mathrm{L}_{n} \mathrm{PdX}\right]^{-}$(section 4.2.3). To determine if information on the rate or mechanism of the oxidative reaction could also be gained for the organopalladate complex $\left[\mathrm{L}_{2} \mathrm{PdBu}\right]^{-}$, this complex was mass-selected and exposed to different organyl electrophiles in a series of gas-phase experiments. Unlike $\left[\mathrm{L}_{n} \mathrm{PdX}\right]^{-}$, these organopalladates were supposed to react in an $\mathrm{S}_{\mathrm{N}}$ 2-like fashion yielding neutral products, which would be naturally unaccessible for mass spectrometric analysis. The second transmetalation step, which produced detectable anions in solution phase, could not take place in the gas phase as it required the presence of a transmetalating reagent. If $\mathrm{S}_{\mathrm{N}} 2$-type processes should occur in the gas phase, a residual halide ion would also be generated as a product ion. However, the measuring conditions did not allow the detection of these ions due to the low mass cutoff inherent in the CID experiment. Consequently, no reaction could be observed in the gas phase when mass-selected $\left[\mathrm{L}_{2} \mathrm{PdBu}\right]^{-}$was exposed to different electrophiles RX (MeI, EtI, AllBr, PhI, VinI). Instead, product ions of classical oxidative addition reactions of $R X$ onto the electron-rich fragment ion $\left[\operatorname{Pd}\left(\operatorname{PAr}_{2}^{\mathrm{F}}\right)\right]^{-},\left[\operatorname{Pd}\left(\operatorname{PAr}_{2}^{\mathrm{F}}\right) \mathrm{RX}\right]^{-}$, were present even in the MS ${ }^{1}$ spectra. As the electrophile was only present as part of the helium-mixture used as a background gas, the short time between the generation of gaseous ions and their detection obviously sufficed to produce detectable amounts of these species, highlighting again the sensitivity of $\left[\operatorname{Pd}\left(\operatorname{PAr}_{2}^{\mathrm{F}}\right)\right]^{-}$against oxidation reactions (figure 4.61 for the example of phenyl iodide).

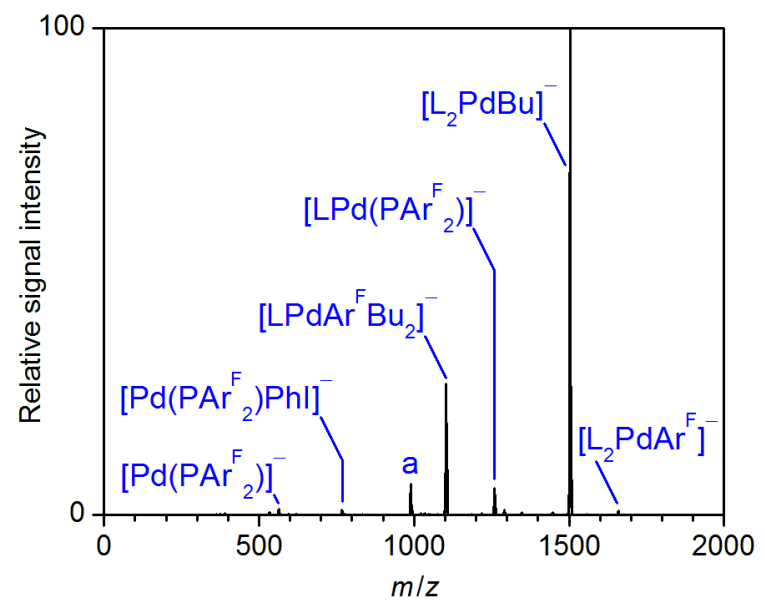

Figure 4.61: Negative-ion mode ESI mass spectrum of a solution of $\left[\mathrm{Pd}\left(\mathrm{PAr}_{3}^{\mathrm{F}}\right)_{3}\right]\left(\left[\mathrm{L}_{3} \mathrm{Pd}\right], 3 \mathrm{mM}\right)$ and $n$ $\mathrm{BuMgCl}(12 \mathrm{mM})$ in THF exposed to PhI in the gas phase $\left(\mathrm{a}=\left[\mathrm{LPdAr}^{\mathrm{F}}\right]^{-}\right)$. 
This was again emphasized by the fact that the product ions were already visible in significant signal intensities without any additional reaction time after the isolation of the precursor ions inside the ion trap (figure 4.62). To analyze these oxidative addition reactions quantitavely in the gas phase proved impractical, however, due to the low overall signal intensities and the competing reaction of $\left[\mathrm{Pd}\left(\mathrm{PAr}_{2}^{\mathrm{F}}\right)\right]^{-}$with background oxygen (figures 4.62 and 4.63 .

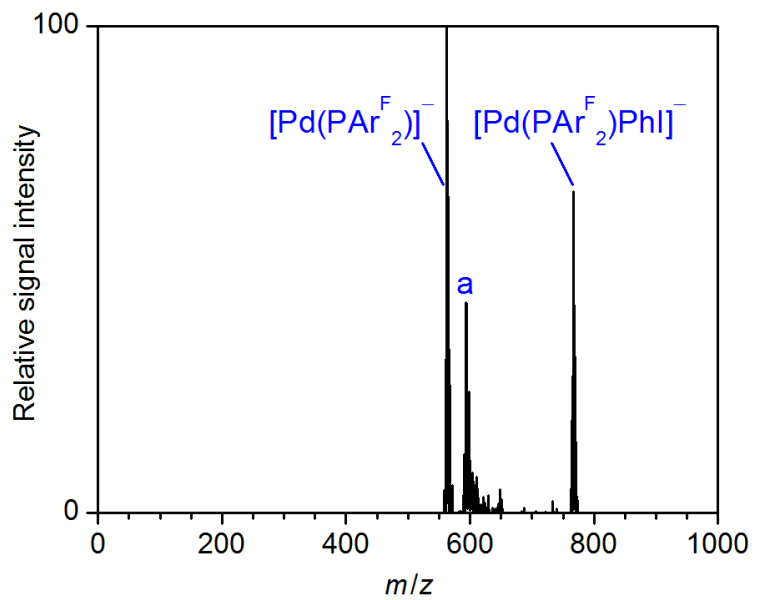

Figure 4.62: Mass spectrum of mass-selected $\left[\operatorname{Pd}\left(\operatorname{PAr}_{2}^{\mathrm{F}}\right)\right]^{-}$and its product ions produced upon exposure to $\mathrm{PhI}$ in a quadrupole ion trap with no additional reaction time after isolation $\left(\mathrm{a}=\left[\mathrm{Pd}, \mathrm{PAr}_{2}^{\mathrm{F}}, \mathrm{O}_{2}\right]^{-}\right)$.

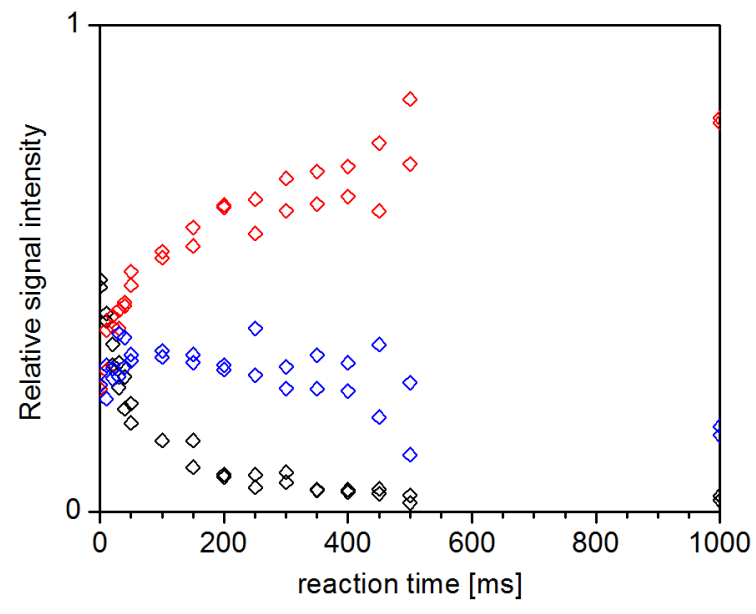

Figure 4.63: Relative signal intensities of $\left[\mathrm{Pd}\left(\mathrm{PAr}_{2}^{\mathrm{F}}\right)\right]^{-}$(black), $\left[\mathrm{Pd}\left(\mathrm{PAr}_{2}^{\mathrm{F}}\right) \mathrm{PhI}\right]^{-}$(red), and $\left[\mathrm{Pd}, \mathrm{PAr}_{2}^{\mathrm{F}}, \mathrm{O}_{2}\right]^{-}$(blue) plotted over the applied reaction time.

It would also have been interesting to analyze the reaction between mass-selected [LPdBu] ${ }^{-}$ and organyl electrophiles in the gas phase, for it was already found with the inorganic palladates that the tendency to undergo reactions with electrophiles increased with a decreasing number of electron-withdrawing ligands (section 4.2.3). This was, however, not possible, as the monoligated organopalladates of interest were not detectable in the source spectra and could also not be generated through collision-induced dissociation (see sections 4.4.1 and 4.4.3). As an alternative, the related anion $\left[\mathrm{LPdAr}^{\mathrm{F}}\right]^{-}$, which bore the electron-withdrawing $\mathrm{Ar}^{\mathrm{F}}$ substituent instead of a butyl group, was analyzed. When $\left[\mathrm{LPdAr}^{\mathrm{F}}\right]^{-}$was mass-selected and exposed to the electrophiles in the gas phase, the same product ions as for $\left[\operatorname{Pd}\left(\operatorname{PAr}_{2}^{\mathrm{F}}\right)\right]^{-},\left[\operatorname{Pd}\left(\operatorname{PAr}_{2}^{\mathrm{F}}\right) \mathrm{RX}\right]^{-}$, were formed, although at much lower reaction rates. It could not be established after which exact mechanism this reaction proceeded; yet it was noted that the reaction rates varied depending on the applied electrophile, suggesting RX to be directly involved in the rate-determining step and rendering a dissociative mechanism starting with the elimination of an $\mathrm{Ar}_{2}$ unit improbable.

The fact that no indications for an $\mathrm{S}_{\mathrm{N}} 2$-type reaction could be found under the present conditions does not necessarily mean that these reactions cannot take place in the gas phase, especially given the unstable signal intensities which in some cases hampered the reproducibility of the discussed results. Still, the findings point into the direction that one or several conditions necessary for such a reaction to occur are only met in solution. For example, the magnesium counterion, which might act as a Lewis acid to activate the electrophile for the substi- 
tution reaction, is unavailable in the gas-phase. Additionally, solvent effects might also play a role.

\subsubsection{Formation of C-C Coupling Products: Unimolecular Reactivity of Triply Substituted Heteroleptic Palladates}

The formation of the cross-coupling product, being the last step required to close the catalytic cycle, was monitored in gas-phase fragmentation reactions. [ $\left.\mathrm{LPdBu}_{2} \mathrm{Pr}\right]^{-}$as well as $\left[\mathrm{LPdAr}{ }^{\mathrm{F}} \mathrm{BuPr}\right]^{-}$showed the reductive elimination of the cross-coupling product PrBu upon collision-induced dissociation (equations (4.77) and (4.78)), although the main fragmentation channels in both cases involved ligand decomposition reactions combined with the loss of alkanes $\mathrm{PrH}$ or BuH (for examples see equations (4.79) to (4.81), figures 4.64 and 4.65 .

$$
\begin{aligned}
{\left[\mathrm{LPdBu}_{2} \mathrm{Pr}\right]^{-} } & \longrightarrow[\mathrm{LPdBu}]^{-}+\mathrm{PrBu} \\
{\left[\mathrm{LPdAr}{ }^{\mathrm{F}} \mathrm{BuPr}\right]^{-} } & \longrightarrow\left[\mathrm{LPdAr}^{\mathrm{F}}\right]^{-}+\mathrm{PrBu} \\
{\left[\mathrm{LPdBu}_{2} \mathrm{Pr}\right]^{-} } & \longrightarrow\left[\mathrm{PdAr}^{\mathrm{F}}\right]^{-}+\left[\mathrm{P}, \mathrm{Ar}_{2}^{\mathrm{F}}, \mathrm{Bu}_{2}, \mathrm{Pr}\right] \\
{\left[\mathrm{LPdBu}{ }_{2} \mathrm{Pr}\right]^{-} } & \longrightarrow\left[\mathrm{PdAr}^{\mathrm{F}} \mathrm{Bu}-\mathrm{H}\right]^{-}+\left[\mathrm{P}, \mathrm{Ar}_{2}^{\mathrm{F}}, \mathrm{Bu}, \mathrm{Pr}, \mathrm{H}\right] \\
{\left[\mathrm{LPdAr}{ }^{\mathrm{B}} \mathrm{BuPr}\right]^{-} } & \longrightarrow\left[\mathrm{PdAr}^{\mathrm{F}} \mathrm{Pr}-\mathrm{H}\right]^{-}+\left[\mathrm{P}, \mathrm{Ar}_{2}^{\mathrm{F}}, \mathrm{Bu}_{2}, \mathrm{H}\right]
\end{aligned}
$$

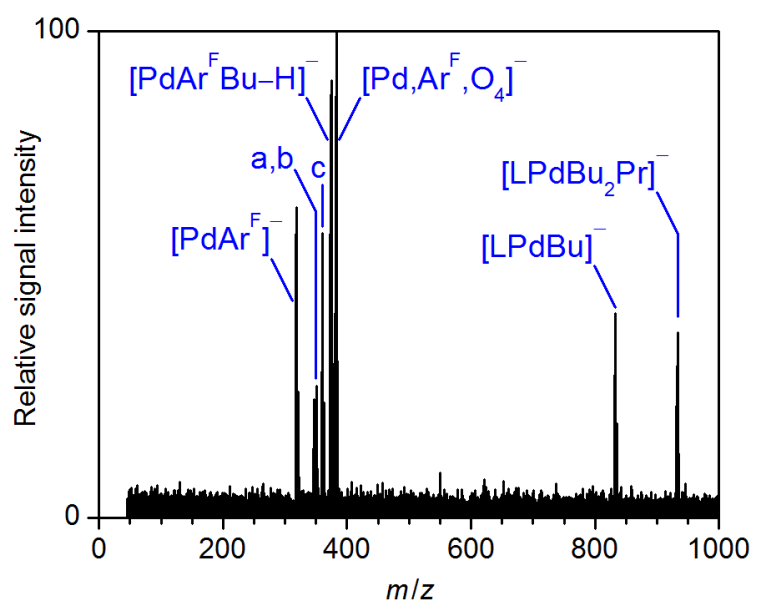

Figure 4.64: Mass spectrum of mass-selected $\left[\mathrm{LPdBu}_{2} \mathrm{Pr}\right]^{-}$and its fragment ions produced upon collision-induced dissociation $\left(E_{\mathrm{LAB}}=15.0 \mathrm{eV}, \mathrm{a}=\right.$ unknown, $\mathrm{b}=\left[\mathrm{Pd}, \mathrm{Ar}^{\mathrm{F}}, \mathrm{O}_{2}\right]^{-}$ $\left.\mathrm{c}=\left[\mathrm{PdAr}{ }^{\mathrm{F}} \mathrm{Pr}-\mathrm{H}\right]^{-}\right)$.

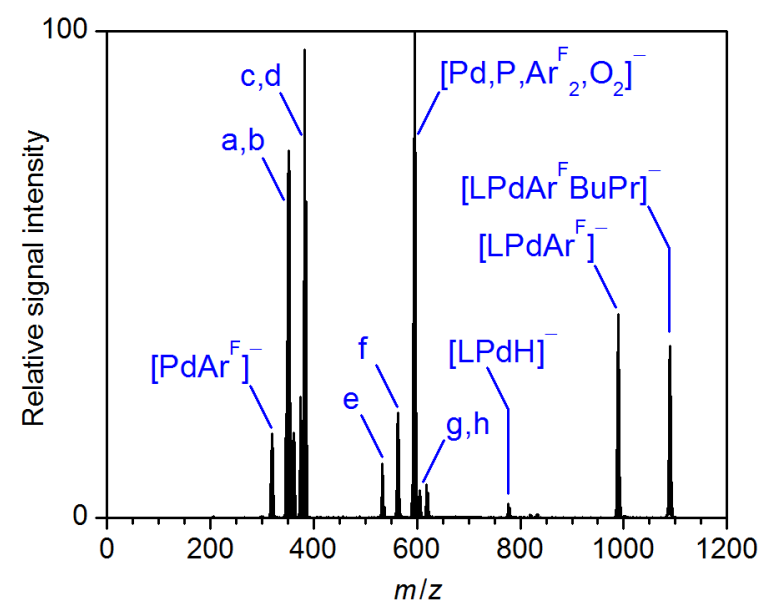

Figure 4.65: Mass spectrum of mass-selected $\left.{ }^{[\mathrm{LPdAr}}{ }^{\mathrm{F}} \mathrm{BuPr}\right]^{-}$and its fragment ions produced upon collision-induced dissociation $\quad\left(E_{\mathrm{LAB}}=18.0 \mathrm{eV}, \quad \mathrm{a}=\left[\mathrm{Pd}, \mathrm{Ar}^{\mathrm{F}}, \mathrm{O}_{2}\right]^{-}\right.$, $\mathrm{b}=\left[\mathrm{PdAr}{ }^{\mathrm{F}} \mathrm{Pr}-\mathrm{H}\right]^{-}, \quad \mathrm{c}=\left[\mathrm{PdAr}{ }^{\mathrm{F}} \mathrm{Bu}-\mathrm{H}\right]^{-}$, $\left.\mathrm{d}=\left[\mathrm{Pd}, \mathrm{Ar}^{\mathrm{F}}, \mathrm{O}_{4}\right]^{-}, \quad \mathrm{e}=\left[\mathrm{PdAr}_{2}^{\mathrm{F}} \mathrm{H}\right]^{-}\right)$, $\mathrm{f}=\left[\mathrm{Pd}\left(\mathrm{PAr}_{2}^{\mathrm{F}}\right)\right]^{-}, \quad \mathrm{g}=\left[\mathrm{Pd}\left(\mathrm{PAr}_{2}^{\mathrm{F}}\right) \operatorname{Pr}-\mathrm{H}\right]^{-}$, $\left.\mathrm{h}=\left[\mathrm{Pd}\left(\mathrm{PAr}_{2}^{\mathrm{F}}\right) \mathrm{Bu}-\mathrm{H}\right]^{-}\right)$. 
Analogous fragmentations were observed for $\left[\mathrm{LPdBu}_{2} \mathrm{Et}\right]^{-},\left[\mathrm{LPdAr}{ }^{\mathrm{F}} \mathrm{BuEt}\right]^{-},\left[\mathrm{LPdPh}_{2} \mathrm{Pr}\right]^{-}$, $\left.\left.\left.\left[\mathrm{LPdAr}{ }^{\mathrm{F}} \mathrm{PhPr}\right]^{-},{ }^{2} \mathrm{LPdPh}{ }_{2} \mathrm{Et}\right]^{-},{ }^{2} \mathrm{LPdAr}{ }^{\mathrm{F}} \mathrm{PhEt}\right]^{-},{ }^{2} \mathrm{LPdBu}_{2} \mathrm{Ar}\right]^{-}$, and $\left[\mathrm{LPdAr}^{\mathrm{F}} \mathrm{BuAr}\right]^{-}$. In all cases, reductive elimination reactions led only to the formation of the cross-coupling product, but never to the homo-coupling product $\mathrm{R}_{2}$. As mentioned before (section 4.3), it is likely that the reductive elimination of the product proceeds rather from a neutral than from an anionic species during the reaction in solution, minimizing the formation of homo-coupling products as side products. Nevertheless, preventing homo-coupling reactions as unwanted side reactions also from anionic intermediates might provide an additional advantage. However, the occurrence of other side reactions, especially the fast decomposition of the phosphine ligand, is likely to pose a major problem for potential synthetic applications.

\subsubsection{Preliminary Experiments for Synthetic Applications}

After all single elementary steps necessary for an alkyl-alkyl cross-coupling reaction between a Grignard reagent and an alkyl halide had been successfully observed in ESI-mass spectrometric experiments, the question remained if the used catalyst might already be a suitable alternative for such cross-coupling reactions on laboratory scale.

Preliminary experiments with phenylethyl iodide $\left(\mathrm{Ph}\left(\mathrm{C}_{2} \mathrm{H}_{4}\right) \mathrm{I}\right)$ and decyl iodide, respectively, as alkyl electrophiles and $n$-BuMgCl in the presence of $3 \mathrm{~mol} \%$ of $\left[\mathrm{Pd}\left(\mathrm{PAr}_{3}^{\mathrm{F}}\right)_{3}\right]$ indeed showed the formation of the cross-coupling product among the starting material and side products such as, for example, the dehalogenation product ethylbenzene (equation 4.82), figure 4.66).

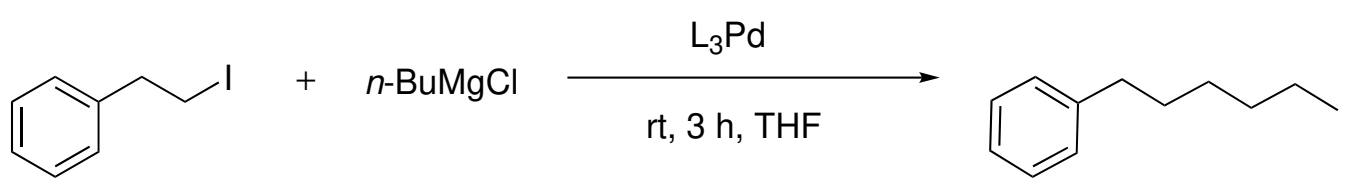

Longer reaction times $(24 \mathrm{~h})$ and higher temperatures both led to better product yields. It was, however, shown in control experiments that the coupling reaction with the alkyl iodide also took place in the absence of the catalyst, disqualifying this reaction mixture as a model system. Therefore, $n$ - $\mathrm{BuMgCl}$ was combined with the less reactive phenylethyl bromide and $3 \mathrm{~mol} \%$ of the catalyst at different reaction conditions. This reaction did not yield any cross-coupling product, even when the more reactive $n$ - $\mathrm{BuMgCl} \cdot \mathrm{LiCl}$ was used. As ethyl electrophiles had shown higher reactivites against $\left[\mathrm{L}_{2} \mathrm{PdBu}\right]^{-}$than other alkyl electrophiles in the ESI-mass spectrometric experiments, a reaction between ethyl bromide and hexylmagnesium chloride was conducted. In this case, very small amounts of the cross-coupling product were obtained, but again contol experiments showed that the same results were achieved without the chosen catalyst. Furthermore, ligand decomposition products such as $\operatorname{Ar}^{\mathrm{F}} \mathrm{H}$ could be identified by GC-MS, confirming the decomposition of the catalyst during the course of the reaction.

It can be summarized that the electron-poor palladium catalyst $\left[\operatorname{Pd}\left(\operatorname{PAr}_{3}^{\mathrm{F}}\right)_{3}\right]$ is not suitable for palladium-catalyzed cross-coupling reactions of alkyl bromides with Grignard reagents under 


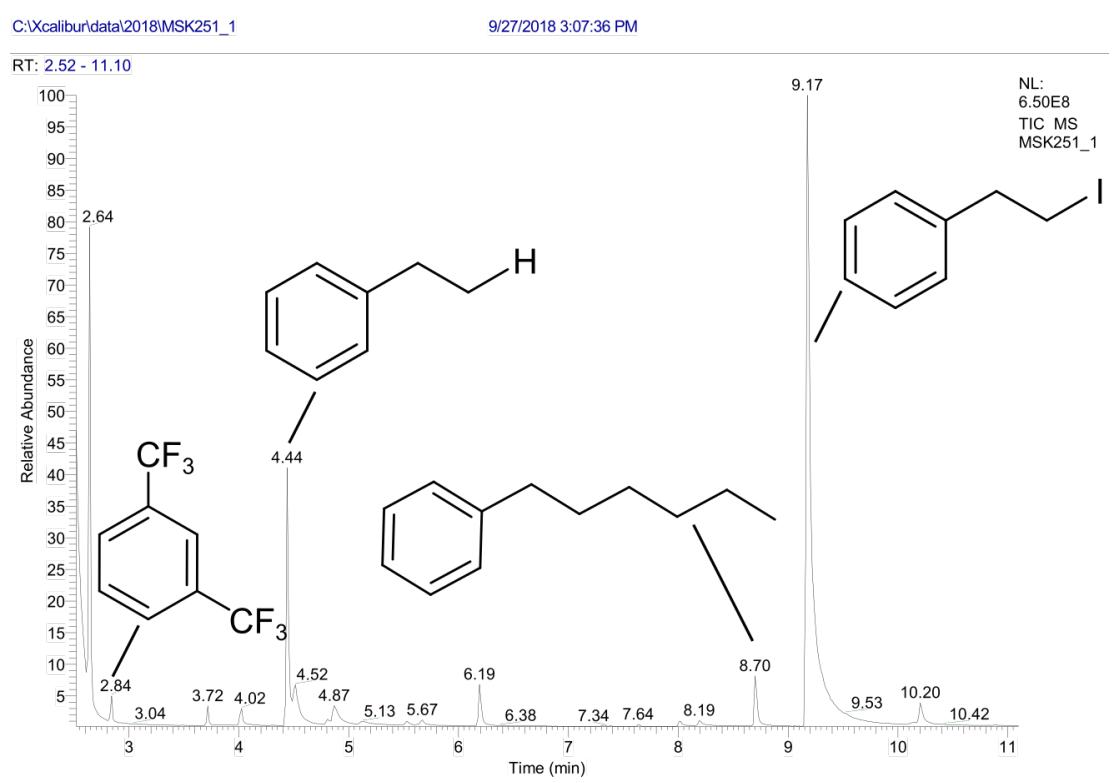

Figure 4.66: Gas chromatogram of a quenched sample solution containing $\left[\operatorname{Pd}\left(\operatorname{PAr}_{3}^{\mathrm{F}}\right)_{3}\right], n-\mathrm{BuMgCl}$, and $\mathrm{Ph}\left(\mathrm{C}_{2} \mathrm{H}_{4}\right) \mathrm{I}$ after a reaction time of $3 \mathrm{~h}$ at room temperature.

the chosen conditions, which is presumably mainly due to its sensitivity against decomposition reactions. While the use of an electron-poor phosphine ligand for an alkyl-alkyl cross-coupling reaction following a transmetalation-first mechanism showed promising results in the ESI-mass spectrometric experiments, only a less sensitive ligand might be applicable under synthetic conditions.

\subsubsection{Suggested Catalytic Cycle of a Cross-Coupling Reaction with Electron-Poor Palladium-Phosphine Catalysts}

Based on the results shown above, a catalytic cycle can be proposed for a palladium-catalyzed alkyl-alkyl cross-coupling reaction between an alkyl iodide or alkyl bromide AlkylX and a Grignard reagent $\mathrm{RMgCl}$ or an organolithium reagent $\mathrm{RLi}$ in the presence of an electronwithdrawing phosphine ligand $\mathrm{L}$ (scheme 4.5 for the reaction with $\mathrm{RMgCl}$ ). The electron-poor palladium(0) catalyst is transmetalated in the first step, forming an organopalladate intermediate, which could be successfully identified for several transmetalating reagents via ESI mass spectrometry. In the second step, the anionic intermediate reacts with the organyl electrophile, presumably in an $\mathrm{S}_{\mathrm{N}}$ 2-type reaction promoted by Lewis-acid activation of the organyl halide by the magnesium counterion. It is likely that neutral species [ $\mathrm{L}_{2} \mathrm{PdRAlkyl]}$ and/or [LPdRAlkyl] are formed, which were not accessible by mass spectrometric analysis. However, their formation can be deduced from the presence of the anion $\left[\mathrm{LPdR}_{2} \mathrm{Alkyl}\right]^{-}$, which is derived from the former by a second transmetalation step. The reductive elimination was followed by gasphase experiments, in which no formation of the the homo-coupling product, but only that of the cross-coupling product was observed. 
Thus, the presented mechanism is likely to be a viable alternative for palladium-catalyzed cross-coupling reactions with electrophiles that do not tend to react in the classical catalytic cycle. Still, the chosen phosphine ligand would have to be substituted for another electronpoor, but less sensitive ligand to avoid decomposition processes which impede a catalytic reaction.

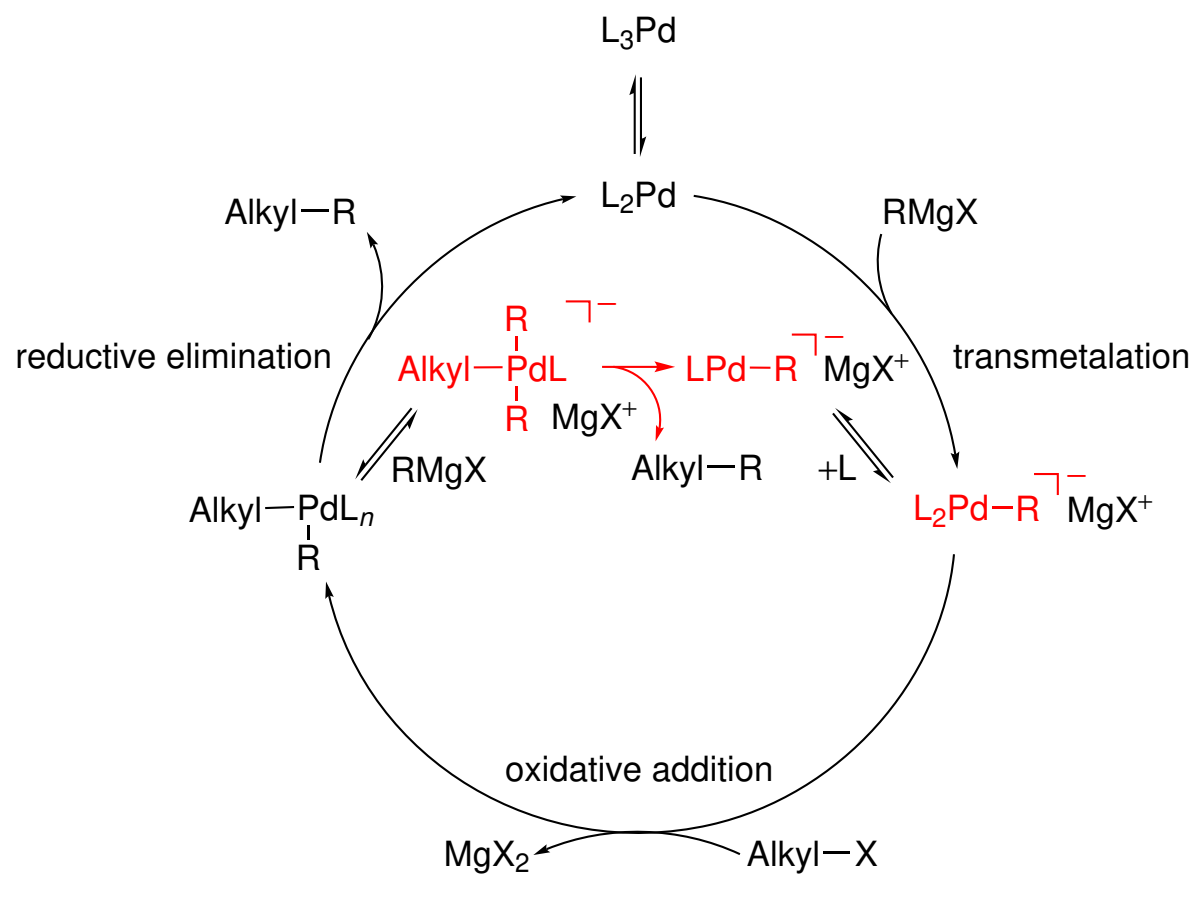

Scheme 4.5: Simplified catalytic cycle for a palladium-catalyzed cross-coupling reaction between a Grignard reagent $\mathrm{RMgCl}$ and an alkyl halide AlkylX in the presence of an electron-poor phosphine ligand L. Intermediates that were identified via ESI mass spectrometry are highlighted in red. 


\section{Conclusion and Outlook}

Anionic palladium complexes are already widely recognized as important intermediates in palladium-catalyzed transformations. Their significance in various cross-coupling reactions has been confirmed by the results presented in this work. Herein, different kinds of anionic palladium complexes were thoroughly characterized regarding their formation, structure, and reactivity, using ESI mass spectrometry and gas-phase reactions as the main analytical methods. These studies allow a deeper insight into the role of palladate intermediates in several variants of cross-coupling reactions at different stages of the catalytic cycle.

For palladium-catalyzed reactions using a palladium(0) catalyst formed from palladium acetate in the presence of a phosphine ligand, the catalyst activation by the transmetalating agent was investigated in detail by ESI-mass spectrometric analysis of organopalladate complexes $\left[(\mathrm{S}-\mathrm{PHOS}) \mathrm{PdR}_{3}\right]^{-}$(scheme 5.1). The transmetalation/reductive elimination reaction sequence presumably involved in the precatalyst reduction could be directly observed using these palladate complexes as model systems.

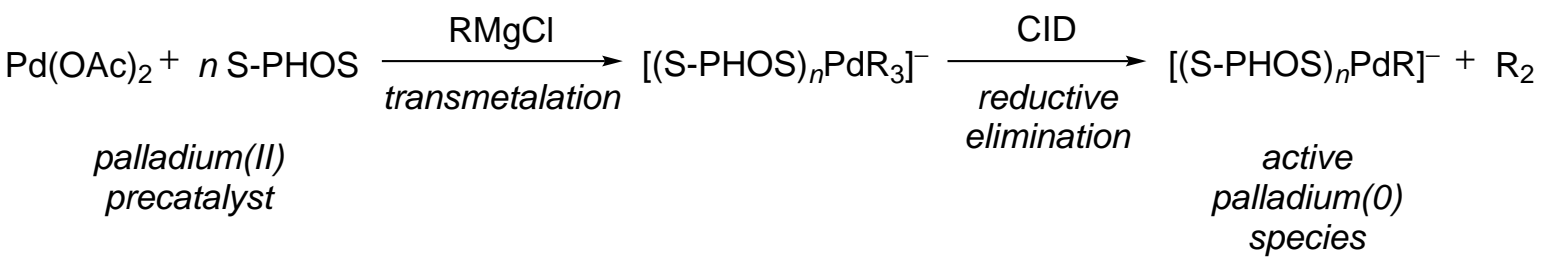

Scheme 5.1: Formation of organopalladate(II) complexes by transmetalation followed by reductive elimination of $R_{2}$ under formation of palladate $(0)$ species.

It was shown that the formation and stability of the organopalladate(II) complexes resulting from the transmetalation strongly depended on the phosphine ligand. From all used ligands, the electron-rich and sterically demanding S-PHOS ligand was best suited to stabilize palladate(II) complexes over a long time. The competing reduction of the palladium(II) precursor accomplished by the phosphine ligand reduced, but did not completely suppress the formation of transmetalation products, not even when longer reaction times of the precatalyst with the ligand prior to the addition of the transmetalation reagent were applied. The efficiency of the transmetalation depended on the nature of the transmetalating agent regarding its metal center as well as the organyl substituent $\mathrm{R}$. Palladate ions $\left[(\mathrm{S}-\mathrm{PHOS}) \mathrm{PdR}_{3}\right]^{-}$were preferably formed when Grignard reagents $\mathrm{PhMgCl}$ or $\mathrm{BnMgCl}$ were applied. 
The second step in the catalyst activation sequence, the reductive elimination of $R_{2}$, was also directly observed by gas-phase fragmentation experiments. While the generally low signal intensities indicated that the majority of species in the sample solutions was neutral, ESI-mass spectrometric analysis of their negatively charged derivatives as a model system provided valuable insights into the factors influencing the transmetalation of palladium(II) precursors and the subsequent reductive elimination. Apart from serving as a model system for their neutral counterparts and thus allowing for the mass-spectrometric analysis of the latter, however, the role of the examined palladate complexes themselves can be considered a less important one in this case.

A much more vital role is fulfilled by anionic palladium complexes in cross-coupling reactions in the presence of halide salts, as the results presented in this work point out once more. The halide-containing palladates $\left[\mathrm{L}_{n} \mathrm{PdX}\right]^{-}$, with $\mathrm{L}=\mathrm{PAr}_{3}^{\mathrm{F}}, \mathrm{X}=\mathrm{Cl}, \mathrm{Br}, \mathrm{I}$, and (OAc), and $n=1,2$, and 3 , could be generated and thoroughly examined with regard to their stability and unimolecular reactivity by ESI mass spectrometry and gas-phase experiments (scheme 5.2).

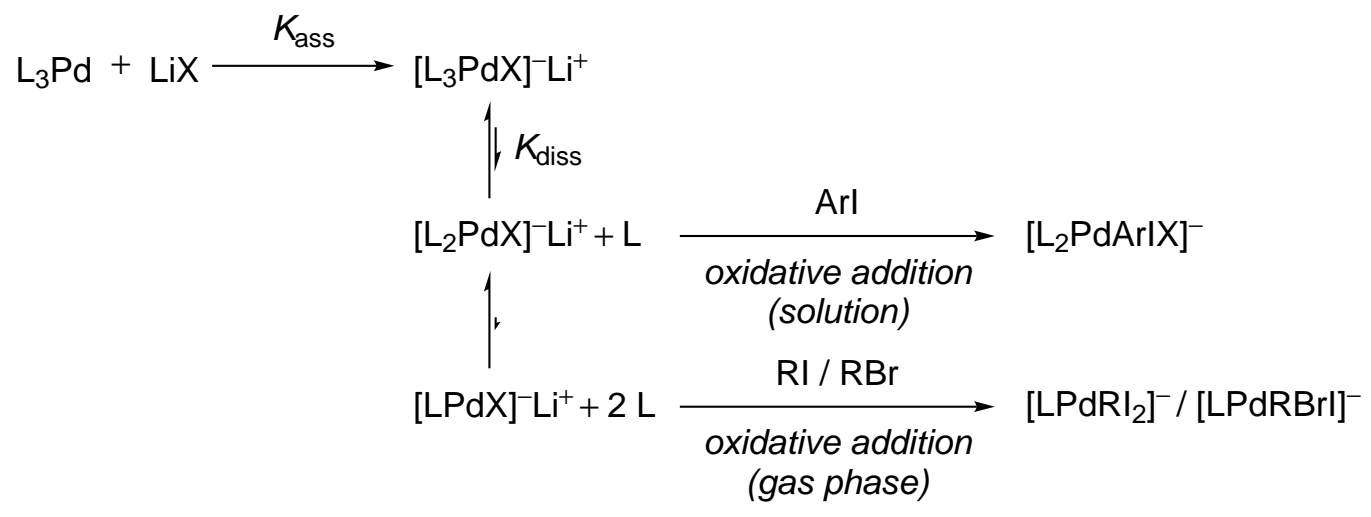

Scheme 5.2: Formation of palladate complexes in the presence of lithium salts and oxidative addition of organyl electrophiles.

ESI-mass spectrometric experiments showed that the dominant species in solutions of the palladium catalyst $\left[\mathrm{L}_{3} \mathrm{Pd}\right]$ and lithium salts $\mathrm{LiX}$ in THF was $\left[\mathrm{L}_{3} \mathrm{PdX}\right]^{-}$. Neither these results nor concentration-dependent conductivity studies revealed aggregation or ion-pairing processes at a large scale, suggesting that the considered palladates were present mainly as free, mononuclear anions in solution under the present conditions. It could be confirmed by quantitative NMR studies that the association equilibrium lay largely on the side of the anionic complex, and that the ligand dissociation necessary for the formation of the presumably catalytically active species $\left[\mathrm{L}_{2} \mathrm{PdX}\right]^{-}$was facilitated in the presence of the lithium halide. Furthermore, gasphase fragmentation experiments of $\left[\mathrm{L}_{3} \mathrm{PdX}\right]^{-}$showed that the dissociation of the phosphine ligands took place readily upon CID, especially for the more electron-rich phosphines $\mathrm{L}^{\mathrm{Ph} 1}$ and $\mathrm{L}^{\mathrm{Ph} 2}$. It is highly probable that this trend can be extrapolated to more electron-rich ligands such as the frequently-used $\mathrm{PPh}_{3}$, underlining the beneficial effect of halides in stabilizing coordinatively unsaturated reactive palladium complexes. 
ESI-mass spectrometric and gas-phase studies allowed a detailed investigation not only of the formation of palladate complexes $\left[\mathrm{L}_{n} \mathrm{PdX}\right]^{-}$, but also of their reactivity against organyl electrophiles. The addition of an aryl iodide to solutions of $\left[\mathrm{L}_{3} \mathrm{Pd}\right]$ and $\mathrm{LiX}$ yielded the expected intermediates $\left[\mathrm{L}_{2} \mathrm{PdArXI}\right]^{-}$, which were most likely formed by an oxidative addition of ArI to the coordinatively unsaturated $\left[\mathrm{L}_{2} \mathrm{PdX}\right]^{-}$. Further information on this intermediate was gained by gas-phase fragmentation experiments, which resulted in the sequential loss of the phosphine ligands, indicating a pentacoordinate structure of the palladate(II) complex.

Finally, bimolecular gas-phase reactions of palladate complexes $\left[\mathrm{L}_{2} \mathrm{PdX}\right]^{-}$and $[\mathrm{LPdX}]^{-}$with organyl halides gave an insight into the relative reactivities of these palladates in the gas phase. In contrast to its reactivity in solution, $\left[\mathrm{L}_{2} \mathrm{PdX}\right]^{-}$did only show oxidative addition of any organyl electrophiles in the gas phase after ligand dissociation. The halide-containing anions [LPdX] ${ }^{-}$ showed the highest reactivity for $\mathrm{X}=\mathrm{I}$ and the lowest for $\mathrm{X}=\mathrm{Cl}$, which stands in contrast to the results by Amatore and coworkers for the related anions $\left[\left(\mathrm{PPh}_{3}\right)_{2} \mathrm{PdCl}\right]^{-}$and $\left[\left(\mathrm{PPh}_{3}\right)_{2} \mathrm{PdBr}\right]^{-}$. Also, the acetate-containing complex $[\mathrm{LPd}(\mathrm{OAc})]^{-}$did not undergo any reaction in the gas phase, as opposed to the related $\left[\left(\mathrm{PPh}_{3}\right)_{2} \mathrm{Pd}(\mathrm{OAc})\right]^{-},[14 \mathrm{e}]$ probably because of a bidentate binding mode of the acetate ligand. Explanations for these discrepancies might be found in the differences between the considered species as well as in the different reaction environments in the gas phase and in solution.

For the palladium-catalyzed cross-coupling of alkyl electrophiles Alkyl-X with Grignard reagents $\mathrm{RMgCl}$ in the presence of 1,3-diene ligands DE, ESI-mass spectrometric studies demonstrated the presence of a variety of anionic palladium intermediates (scheme 5.3).

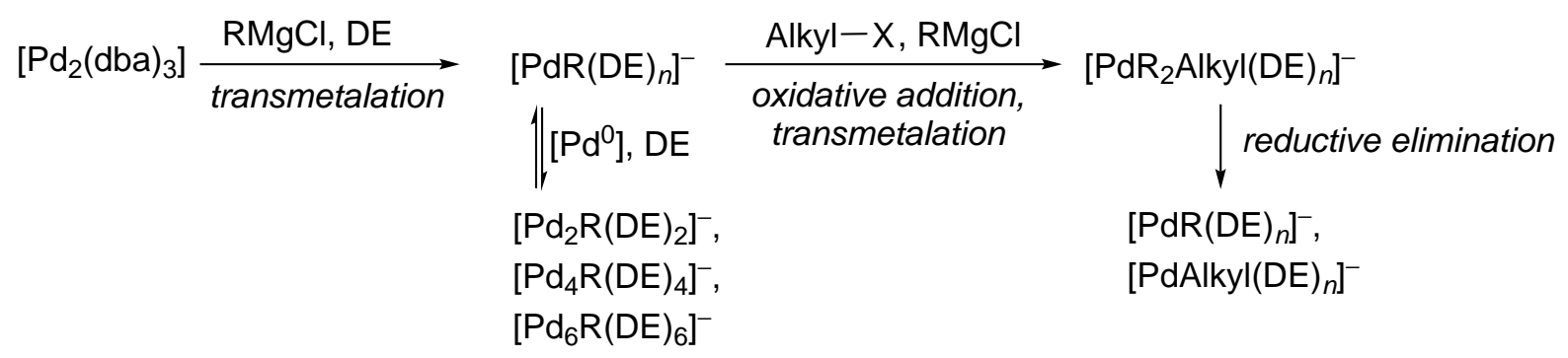

Scheme 5.3: Formation of mononuclear and oligonuclear organopalladate complexes by transmetalation of $\left[\mathrm{Pd}_{2}(\mathrm{dba})_{3}\right]$, oxidative addition of organyl electrophiles and subsequent transmetalation, and reductive elimination of the cross-coupling product.

The catalytic cycle reported by Kambe and coworkers could be largely validated in the presented results, although ESI mass spectrometry revealed a far more complex mixture of anionic palladium intermediates and potential catalyst resting states than originally proposed by the authors. $\stackrel{2931]}{2}$

In addition to the suggested mononuclear complex $\left[\mathrm{PdR}(\mathrm{DE})_{2}\right]^{-}$, dinuclear and oligonuclear palladates were detected when $\left[\mathrm{Pd}_{2}(\mathrm{dba})_{3}\right]$ was combined with a 1,3-diene ligand and a Grignard reagent. It could be demonstrated by time-dependent ESI mass spectrometry that these 
oligonuclear complexes formed over time, thus possibly representing the beginning of the formation of larger nanoclusters and eventually palladium black. This assumption was backed up by time-dependent UV/Vis-spectroscopic experiments. Furthermore, the favored formation of even-numbered palladates and the facile loss of $\left[\mathrm{Pd}_{2}(\mathrm{DE})_{2}\right]$ units upon CID indicated that these clusters consisted of dinuclear building blocks.

ESI mass spectrometry, along with supplementary UV/Vis and NMR studies for the isoprenecontaining system, also provided evidence regarding the binding mode of the diene ligand in the palladate complexes. While a dimerization of the diene ligands resulting in an $\left(\eta^{1}, \eta^{3}\right.$-allyl)palladium intermediate was proposed by Kambe and coworkers, the gas-phase fragmentation of $\left[\mathrm{PdR}(\mathrm{DE})_{2}\right]^{-}$and several other detected palladates led to the dissociation of single diene ligands, indicating at least an easy reversibility of the suggested dimerization.

The suggested $\mathrm{S}_{\mathrm{N}}$ 2-type mechanism for the oxidative addition of the alkyl electrophile to the palladate anion $\left[\mathrm{PdR}(\mathrm{DE})_{2}\right]^{-}$would have yielded the neutral intermediate $\left[\mathrm{PdAlkylR}(\mathrm{DE})_{2}\right]$. While the neutral species could not be detected directly, anions of the type $\left[\mathrm{PdAlkylR} 2(\mathrm{DE})_{2}\right]^{-}$, which were derived from the former by an additional transmetalation reaction, were observed by ESI mass spectrometry.

Finally, the product formation, being the last step of the catalytic cycle, was successfully followed by gas-phase fragmentation experiments from the anions $\left[\mathrm{PdAlkylR} 2(\mathrm{DE})_{2}\right]^{-}$. The use of a charge-tagged electrophile also allowed the direct detection of the cross-coupling product by ESI mass spectrometry.

In analogy to the transmetalation of diene-ligated palladium complexes, the transmetalation of $\left[\mathrm{L}_{3} \mathrm{Pd}\right]$, with $\mathrm{L}=\mathrm{PAr}_{3}^{\mathrm{F}}$, with Grignard reagents yielded palladate complexes $\left[\mathrm{L}_{2} \mathrm{PdR}\right]^{-}$ (scheme 5.4).

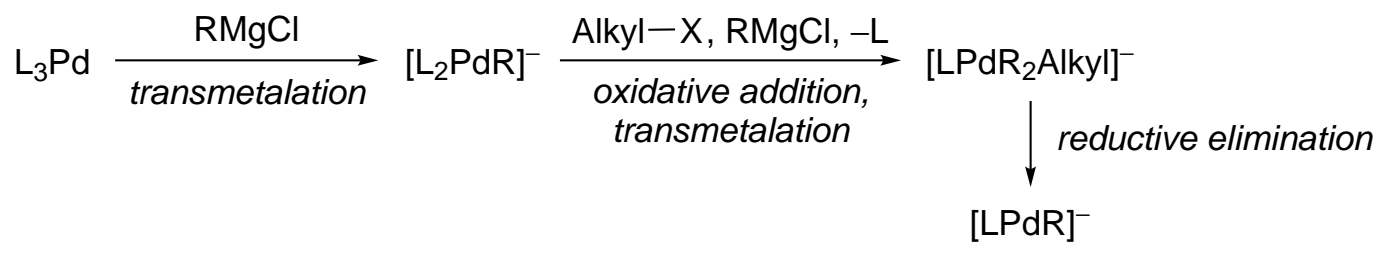

Scheme 5.4: Formation of organopalladate complexes by transmetalation of $\mathrm{L}_{3} \mathrm{Pd}$, oxidative addition of organyl electrophiles and subsequent transmetalation, and reductive elimination of the crosscoupling product.

ESI-mass spectrometric experiments showed that an oxidative addition reaction with alkyl halides yielded complexes of the type [LPdAlkylR $]^{-}$, suggesting an $\mathrm{S}_{\mathrm{N}}$ 2-like mechanism with subsequent transmetalation as in the case of $\left[\mathrm{PdR}(\mathrm{DE})_{2}\right]^{-}$. The analysis of bimolecular gasphase reactions did not lead to conclusive results in this case due to to the low stability of the organopalladate complexes. Gas-phase fragmentation of the heteroleptic complex [LPdAlkylR $]^{-}$resulted in the elimination of the cross-coupling product selectively. An alkylalkyl cross-coupling reaction under synthetic conditions could not be realized with the present 
catalyst, probably due to its sensitivity against decomposition reactions. Nevertheless, the present results suggest that alkyl-alkyl cross-coupling reactions following a transmetalationfirst mechanism could be realized with electron-poor palladium/phosphine catalysts.

To sum up, ESI mass spectrometry was used as a powerful tool to analyze palladium-catalyzed reactions involving anions in a direct and detailed manner and to identify and characterize individual species from complex mixtures of intermediates that would have been challenging to unravel by other analytical methods. This made it possible not only to identify previously suggested anionic intermediates unambiguously, but also to reveal other potentially reactive anionic species along with catalyst decomposition products and aggregates, as was most prominently shown for the palladium/diene-catalyzed cross-coupling reaction. Intrinsic reactivities of the anions of interest as well as important reaction steps of the investigated catalytic cycles were monitored directly in unimolecular and bimolecular gas-phase experiments. Complementing these experiments with UV/Vis spectroscopy, NMR spectroscopy, and electrical conductivity measurements provided additional information, for example regarding neutral species, and allowed for the quantification of reaction equilibria in solution as shown for the halide-containing palladate complexes $\left[\mathrm{L}_{n} \mathrm{PdX}\right]^{-}$.

For the future, an extension of the present results is imaginable in many directions. First and foremost, the selection of catalysts for cross-coupling reactions represented herein is but a small sampling of the reactions that potentially involve palladate complexes as intermediates. To gain a more complete picture of different kinds of anionic palladium intermediates and their reactivities, it would be desirable to extend the scope of analyzed palladium precursors, ligands, and additives. For example, the analysis of catalyst systems containing frequently used bidentate phosphine ligands or N-heterocyclic carbenes promises interesting insights. Apart from $\mathrm{C}-\mathrm{C}$ coupling reactions, palladium-mediated reactions under formation of carbon-heteroatom bonds would be another interesting extension of the present studies. Also, palladate anions in higher oxidation states represent another promising field of research, especially as the negative charge is presumably significantly better stabilized in these anions than in lower-valent palladates due to the lower electron density at the palladium center. Previous studies on organopalladate(IV) complexes have already shown the suitability of ESI mass spectrometry for the analysis of such complexes. $\frac{\text { [39] }}{}$

Additionally, the substitution of the added lithium salts by other additives, for example other metal halides, could broaden the understanding of cation effects on the formation of palladate intermediates. Furthermore, ion-mobility experiments on palladate ions, especially on the $\left.\left[\mathrm{L}_{2} \mathrm{PdArX}\right]_{2}\right]^{-}$anion discussed above, could offer valuable information on the geometry of said ions.

The first bimolecular gas-phase experiments with the palladate complexes [LPdX] ${ }^{-}$showed that reactivities of individual palladate anions can be determined in a qualitative and quantitative fashion under the present conditions. Thus, it could prove worthwhile to test other palladate complexes discussed in the present work with regard to their reactivity in oxidative 
addition or ligand exchange reactions in the gas phase. Furthermore, regarding the known anions $[\mathrm{LPdX}]^{-}$, an extension of the scope of organic electrophiles beyond unsubstituted allyl, vinyl, and phenyl halides could help to deduce reactivity trends for the anions in question. Concentration-dependent experiments as well as competition experiments featuring different gaseous substrates would open up lots of additional possibilities to analyze gas-phase reactivities quantitatively, eventually leading to a better mechanistic understanding of the considered reactions. In this context, quantum-chemical calculations could also help to rationalize observed reactivities of palladate anions. 


\section{Experimental Section}

\subsection{General}

To exclude oxygen and moisture, all experiments were carried out under standard Schlenk conditions unless otherwise stated. THF (HPLC grade) was dried over sodium/benzophenone and freshly distilled before use. All other applied chemicals, such as palladium precursors, ligands, and organic halides, were purchased and used as received. Organometallic reagents were purchased or synthesized according to literature procedures (section 6.3).

\subsection{Exact Concentrations of Organometallic Reagents}

Exact concentrations of the used organomagnesium reagents were determined by iodometric titration:

$$
\mathrm{RMgX}+\mathrm{I}_{2} \longrightarrow \mathrm{THF}, \mathrm{rt} \longrightarrow \mathrm{MgXI}
$$

Iodine was dissolved in a solution of $\mathrm{LiCl}$ in THF $(0.5 \mathrm{M})$ at room temperature and titrated with the $\mathrm{RMgCl}$ solution until a color change from brown to colorless could be observed. The amount of the Grignard reagent corresponded to one equivalent of $\mathrm{I}_{2}$. Exact concentrations of organozinc reagents were determined in an analogous manner.

Exact concentrations of the used organolithium reagents were determined by titration with 1,3-diphenylacetone $p$-tosylhydrazone:[92]<smiles>Cc1ccc(S(=O)(=O)NN=C(Cc2ccccc2)Cc2ccccc2)cc1</smiles><smiles>O=[N+](N=C(Cc1ccccc1)Cc1ccccc1)c1ccccc1</smiles>

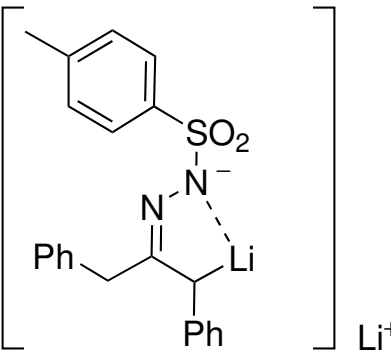


1,3-diphenylacetone $p$-tosylhydrazone was dissolved in dry THF and cooled to $273 \mathrm{~K}$. A solution of the organolithium reagent was added dropwise until the solution turned bright orange, indicating the presence of the above-shown dianion. The amount of the organolithium reagent corresponded to one equivalent of 1,3-diphenylacetone $p$-tosylhydrazone.

\subsection{Syntheses}

\subsubsection{Syntheses of Organometallic Reagents}

\section{Synthesis of Organomagnesium Reagents}

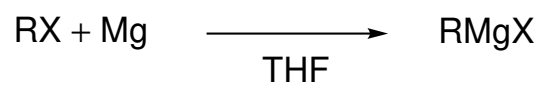

Magnesium turnings $(28 \mathrm{mmol})$ were repeatedly heated in vacuo $(3 \times 30 \mathrm{~min}, 570 \mathrm{~K})$ and suspended in dry THF (20 mL). $1 / 5$ of the organyl halide ( $5.0 \mathrm{mmol}$ out of a total of $25 \mathrm{mmol}$ ) was added to the magnesium suspension under vigorous stirring. After the start of the reaction, the remaining organyl halide was added slowly. The temperature of the solution was kept under the boiling temperature of THF $(340 \mathrm{~K})$ at all times. The reaction mixture was stirred at room temperature for $90 \mathrm{~min}$. The organomagnesium reagents were used directly after synthesis or stored at $273 \mathrm{~K}$.

\section{Synthesis of Organozinc Reagents}

$$
\mathrm{ZnCl}_{2}+\mathrm{RLi} \underset{\mathrm{THF}}{\longrightarrow} \mathrm{RZnCl} \cdot \mathrm{LiCl}
$$

Zinc chloride $(0.2 \mathrm{mmol})$ was repeatedly heated in vacuo $(3 \times 30 \mathrm{~min}, 570 \mathrm{~K})$ and dissolved in dry THF $(2 \mathrm{~mL})$. A solution of the organyllithium compound $(0.2 \mathrm{mmol})$ in THF was added dropwise and the reaction mixture was stirred at room temperature for $45 \mathrm{~min}$. Organozinc reagents were used directly after synthesis. 


\subsubsection{Ligand Syntheses}

The syntheses of the phosphine ligands $\mathrm{L}^{\mathrm{Ph} 1}$ and $\mathrm{L}^{\mathrm{Ph} 2}$ were carried out in analogy to the syn-

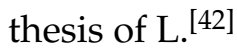

\section{Synthesis of Bis(3,5-bis(trifluoromethyl)phenyl)phenylphosphine $\left(\mathrm{L}^{\mathrm{Ph} 1}\right)$}<smiles>FC(F)(F)c1cc(Br)cc(C(F)(F)F)c1</smiles>

Magnesium turnings $(0.243 \mathrm{~g}, 10.0 \mathrm{mmol}, 2.00 \mathrm{eq}$. $)$ were heated in vacuo $(3 \times 30 \mathrm{~min}, 570 \mathrm{~K})$ and suspended in dry THF $(10.0 \mathrm{~mL})$. 1-Bromo-3,5-bis(trifluoromethyl)benzene $(1.72 \mathrm{~mL}, 2.93 \mathrm{~g}$, $10.0 \mathrm{mmol}, 2.00$ eq.) was added at room temperature under vigorous stirring, causing the reaction mixture to heat up to approx. $320 \mathrm{~K}$. The reaction mixture was allowed to cool down to room temperature and a solution of $\mathrm{LiCl}$ in THF $(20 \mathrm{~mL}, 0.50 \mathrm{M}, 10 \mathrm{mmol}, 2.0 \mathrm{eq}$.) was added. After stirring at room temperature for $2 \mathrm{~h}, \mathrm{P}, \mathrm{P}$-dichlorophenylphosphine $(0.83 \mathrm{~mL}, 1.1 \mathrm{~g}$, $5.0 \mathrm{mmol}, 1.0$ eq.) was added dropwise at $273 \mathrm{~K}$. The mixture was stirred at room temperature for another $36 \mathrm{~h}$ and treated with a saturated aqueous solution of $\mathrm{NH}_{4} \mathrm{Cl}(10 \mathrm{~mL})$. After extraction with EtOAc $(3 \times 20 \mathrm{~mL})$, the combined organic layers were dried over $\mathrm{Na}_{2} \mathrm{SO}_{4}$ before the solvent was removed under reduced pressure. Purification of the crude product by column chromatography $\left(\mathrm{SiO}_{2}, 100 \%\right.$ pentane, $\left.R_{\mathrm{f}}=0.36\right)$ yielded $\mathrm{L}^{\mathrm{Ph} 1}(2.49 \mathrm{~g}, 4.58 \mathrm{mmol}, 92 \%)$ as a colorless oil.

${ }^{1} \mathrm{H}-\mathrm{NMR}\left(400 \mathrm{MHz}, \mathrm{CDCl}_{3}: \delta(\mathrm{ppm})=7.90\left(\mathrm{~s}, 2 \mathrm{H}, \mathrm{C} 4-\mathrm{H}\left(\mathrm{Ar}^{\mathrm{F}}\right)\right), 7.71\left(\mathrm{~d}, 4 \mathrm{H}, \mathrm{C} 2-\mathrm{H}\left(\mathrm{Ar}^{\mathrm{F}}\right)\right.\right.$, $\left.{ }^{3} J_{\mathrm{HP}}=6.64 \mathrm{~Hz}\right), 7.43-7.55(\mathrm{~m}, 3 \mathrm{H}, \mathrm{Ph}-\mathrm{H}), 7.31-7.39$ (m, $\left.2 \mathrm{H}, \mathrm{Ph}-\mathrm{H}\right)$.

$\left.{ }^{13} \mathrm{C}^{1}{ }^{1} \mathrm{H}\right\}$-NMR (75.5 MHz, CDCl ${ }_{3}: \delta(\mathrm{ppm})=139.89\left(\mathrm{~d}, \mathrm{C} 1\left(\mathrm{Ar}^{\mathrm{F}}\right),{ }^{1} J_{\mathrm{CP}}=18.3 \mathrm{~Hz}\right), 134.16(\mathrm{~d}, \mathrm{C} 2$ $\left.(\mathrm{Ph}),{ }^{2} J_{\mathrm{CP}}=21.4 \mathrm{~Hz}\right), 133.23\left(\mathrm{br} \mathrm{d}, \mathrm{C} 2\left(\mathrm{Ar}^{\mathrm{F}}\right),{ }^{2} J_{\mathrm{CP}}=20.5 \mathrm{~Hz}\right), 132.77\left(\mathrm{~d}, \mathrm{C} 1(\mathrm{Ph}),{ }^{1} J_{\mathrm{CP}}=10.4 \mathrm{~Hz}\right)$, $132.41\left(\mathrm{qd}, \mathrm{C} 3\left(\mathrm{Ar}^{\mathrm{F}}\right),{ }^{2} J_{\mathrm{CF}}=33.5 \mathrm{~Hz},{ }^{3} J_{\mathrm{CP}}=6.34 \mathrm{~Hz}\right), 130.96(\mathrm{~s}, \mathrm{C} 4(\mathrm{Ph})), 129.77(\mathrm{~d}, \mathrm{C} 3(\mathrm{Ph})$, $\left.{ }^{3} J_{\mathrm{CP}}=7.99 \mathrm{~Hz}\right), 123.12\left(\mathrm{q}, \mathrm{CF}_{3},{ }^{1} J_{\mathrm{CF}}=273 \mathrm{~Hz}\right), 123.50\left(\mathrm{hept}, \mathrm{C} 4\left(\mathrm{Ar}^{\mathrm{F}}\right),{ }^{3} J_{\mathrm{CF}}=3.80 \mathrm{~Hz}\right)$.

${ }^{19} \mathbf{F}\left\{{ }^{1} \mathrm{H}\right\}-\mathrm{NMR}\left(282.4 \mathrm{MHz}, \mathrm{CDCl}_{3}: \delta(\mathrm{ppm})=-63.08(\mathrm{~s})\right.$.

${ }^{31} \mathbf{P}\left\{{ }^{1} \mathrm{H}\right\}-N M R\left(121.5 \mathrm{MHz}, \mathrm{CDCl}_{3}: \delta(\mathrm{ppm})=-4.07(\mathrm{~s})\right.$. 


\section{Synthesis of (3,5-Bis(trifluoromethyl)phenyl)diphenylphosphine $\left(\mathrm{L}^{\mathrm{Ph} 2}\right)$}<smiles>FC(F)(F)c1cc(Br)cc(C(F)(F)F)c1</smiles><smiles>FC(F)(F)c1cc(N(Br)c2ccccc2)cc(P(Cl)c2ccccc2)c1</smiles>

Magnesium turnings $(0.12 \mathrm{~g}, 5.0 \mathrm{mmol}, 1.0 \mathrm{eq}$. $)$ were heated in vacuo $(3 \times 30 \mathrm{~min}, 570 \mathrm{~K})$ and suspended in dry THF $(5.0 \mathrm{~mL})$. 1-Bromo-3,5-bis(trifluoromethyl)benzene $(0.86 \mathrm{~mL}, 1.5 \mathrm{~g}$, $5.0 \mathrm{mmol}, 1.0$ eq.) was added at room temperature under vigorous stirring, causing the reaction mixture to heat up to approx. $320 \mathrm{~K}$. The reaction mixture was allowed to cool down to room temperature and the concentration of the obtained Grignard reagent was determined by iodometric titration (see above). To the solution of (3,5-bis(trifluoromethyl)phenyl)magnesium bromide ( $4.3 \mathrm{~mL}, 0.69 \mathrm{M}, 3.0 \mathrm{mmol}, 1.0$ eq.), a solution of $\mathrm{LiCl}$ in THF $(6.0 \mathrm{~mL}, 0.50 \mathrm{M}, 3.0 \mathrm{mmol}$, 1.0 eq.) was added. After stirring at room temperature for $2 \mathrm{~h}, \mathrm{P}$-chlorodiphenylphosphine $(0.54 \mathrm{~mL}, 0.66 \mathrm{~g}, 3.0 \mathrm{mmol}, 1.0 \mathrm{eq}$.) was added dropwise at $273 \mathrm{~K}$. The mixture was stirred at room temperature for another $48 \mathrm{~h}$ and treated with a saturated aqueous solution of $\mathrm{NH}_{4} \mathrm{Cl}$ $(10 \mathrm{~mL})$. After extraction with EtOAc $(3 \times 20 \mathrm{~mL})$, the combined organic layers were dried over $\mathrm{Na}_{2} \mathrm{SO}_{4}$ before the solvent was removed under reduced pressure. Purification of the crude product by column chromatography $\left(\mathrm{SiO}_{2}, 100 \%\right.$ pentane, $\left.R_{\mathrm{f}}=0.41\right)$ yielded $\mathrm{L}^{\mathrm{Ph} 2}(0.51 \mathrm{~g}$, $1.3 \mathrm{mmol}, 43 \%$ ) as a colorless oil.

${ }^{1} \mathrm{H}-\mathrm{NMR}\left(400 \mathrm{MHz}, \mathrm{CDCl}_{3}: \delta(\mathrm{ppm})=7.81\left(\mathrm{~s}, 2 \mathrm{H}, \mathrm{C} 4-\mathrm{H}\left(\mathrm{Ar}^{\mathrm{F}}\right)\right), 7.68\left(\mathrm{~d}, 4 \mathrm{H}, \mathrm{C} 2-\mathrm{H}\left(\mathrm{Ar}^{\mathrm{F}}\right)\right.\right.$, $\left.{ }^{3} J_{\mathrm{HP}}=6.32 \mathrm{~Hz}\right), 7.36-7.45(\mathrm{~m}, 6 \mathrm{H}, \mathrm{Ph}-\mathrm{H}), 7.28-7.36(\mathrm{~m}, 4 \mathrm{H}, \mathrm{Ph}-\mathrm{H})$.

$\left.{ }^{13} \mathrm{C}^{1}{ }^{1} \mathrm{H}\right\}$-NMR $\left(75.5 \mathrm{MHz}, \mathrm{CDCl}_{3}: \delta(\mathrm{ppm})=142.11\left(\mathrm{~d}, \mathrm{C} 1\left(\mathrm{Ar}^{\mathrm{F}}\right),{ }^{1} J_{\mathrm{CP}}=18.7 \mathrm{~Hz}\right), 134.9(\mathrm{~d}, \mathrm{C} 1\right.$ $\left.(\mathrm{Ph}),{ }^{1} J_{\mathrm{CP}}=10.5 \mathrm{~Hz}\right), 133.84\left(\mathrm{~d}, \mathrm{C} 2(\mathrm{Ph}),{ }^{2} J_{\mathrm{CP}}=20.4 \mathrm{~Hz}\right), 132.98\left(\mathrm{br} \mathrm{d}, \mathrm{C} 2\left(\mathrm{Ar}^{\mathrm{F}}\right),{ }^{2} J_{\mathrm{CP}}=19.5 \mathrm{~Hz}\right)$, $131.59\left(\mathrm{qd}, \mathrm{C} 3\left(\mathrm{Ar}^{\mathrm{F}}\right),{ }^{2} J_{\mathrm{CF}}=33.2 \mathrm{~Hz},{ }^{3} J_{\mathrm{CP}}=5.80 \mathrm{~Hz}\right), 129.69(\mathrm{~s}, \mathrm{C} 4(\mathrm{Ph})), 129.00(\mathrm{~d}, \mathrm{C} 3(\mathrm{Ph})$, $\left.{ }^{3} J_{\mathrm{CP}}=7.42 \mathrm{~Hz}\right), 123.20\left(\mathrm{q}, \mathrm{CF}_{3},{ }^{1} J_{\mathrm{CF}}=273 \mathrm{~Hz}\right), 122.35\left(\right.$ hept $\left., \mathrm{C} 4\left(\mathrm{Ar}^{\mathrm{F}}\right),{ }^{3} J_{\mathrm{CF}}=3.82 \mathrm{~Hz}\right)$.

$\left.{ }^{19} \mathrm{~F}^{1} \mathrm{H}\right\}-\mathrm{NMR}\left(282.4 \mathrm{MHz}, \mathrm{CDCl}_{3}: \delta(\mathrm{ppm})=-62.9(\mathrm{~s})\right.$.

${ }^{31} \mathbf{P}\left\{{ }^{1} \mathrm{H}\right\}-\mathrm{NMR}\left(\mathbf{1 2 1 . 5} \mathrm{MHz}, \mathrm{CDCl}_{3}: \delta(\mathrm{ppm})=-4.53(\mathrm{~s})\right.$. 


\subsection{Analytical Methods}

\subsubsection{ESI Mass Spectrometry}

All mass spectrometric experiments were conducted at least twice to ascertain reproducibility of the obtained results. The recorded mass spectra were analyzed using Data Analysis and Isotope Pattern (Compass software package, Bruker Daltonik). Signals were assigned based on their exact mass-to-charge ratio and the comparison of measured isotope patterns with simulated patterns. Additionally, fragmentation patterns obtained from CID experiments were analyzed to support the signal assignments. Graphical representations were prepared using the OriginPro 8.5G software (OriginLab Corporation).

\section{Sample Preparation}

All samples were prepared with a palladium concentration of $3 \mathrm{mM}$, unless otherwise notified.

To investigate triply substitued organopalladate(II) complexes (see section 4.1), $\mathrm{Pd}(\mathrm{OAc})_{2}$ was heated in vacuo $(3 \times 30 \mathrm{~min}, 333 \mathrm{~K})$ and dissolved in dry THF. Two equivalents of the phosphine ligand of choice were put into a pre-dried $(3 \times 10 \mathrm{~min}, 570 \mathrm{~K})$ flask which was then evacuated and flushed with argon three times. The $\mathrm{Pd}(\mathrm{OAc})_{2}$ solution was added and the mixture was stirred at room temperature for $5-10 \mathrm{~min}$. The organometallic reagent (5 eq.) was cooled to $273 \mathrm{~K}$, before the precatalyst solution was added and the solution was left to stir for $5 \mathrm{~min}$.

To analyze palladate $(0)$ complexes of the type $\left[\mathrm{L}_{n} \mathrm{PdX}\right]^{-}$(see section 4.2), a pre-dried Schlenkflask was charged with $\left[\operatorname{Pd}\left(\operatorname{PAr}_{3}\right)_{3}\right]$, which was then dissolved in dry THF $(2 \mathrm{~mL})$. A solution of the lithium halide in THF $(0.5 \mathrm{M}, 5$ eq. $)$ was added at room temperature and the solution was left to stir for $5-10 \mathrm{~min}$. Organic halides ( $5 \mathrm{eq}$. relative to palladium), if desired, were added afterwards at room temperature and the solution was stirred for another 5-10 min. Time-dependent measurements were started immediately after the addition of the electrophile.

For the investigation of organopalladate complexes formed by the reaction of $\left[\mathrm{Pd}_{2}(\mathrm{dba})_{3}\right]$ with organometallic reagents in the presence of 1,3-dienes (see section 4.3$),\left[\mathrm{Pd}_{2}(\mathrm{dba})_{3}\right]$ was transferred into a Schlenk-flask under argon atmosphere. Dry THF and eight equivalents (relative to palladium) of 1,3-butadiene or isoprene, respectively, were added and the solution was left to stir for $45 \mathrm{~min}$. After the mixture was cooled to $196 \mathrm{~K}$ in a dry ice bath, four equivalents of the organometallic reagent were added dropwise and the resulting solution was stirred at this temperature for 1-2 min before the measurement was started.

For very sensititve sample solutions, such as the mixture of $\left[\mathrm{Pd}_{2}(\mathrm{dba})_{3}\right], n-\mathrm{BuMgCl}$, and propyl iodide in the presence of isoprene, the sample solution was added into the ion source directly after the addition of the electrophile using a pressurized sample infusion approach. .86 To this 
end, the Schlenk-flask containing a solution of $\left[\mathrm{Pd}_{2}(\mathrm{dba})_{3}\right]$ and isoprene in THF was cooled to $196 \mathrm{~K}$. Then, a PEEK tubing was immersed into the sample solution and connected to the ESI source of the mass spectrometer. A nitrogen pressure of approximately 0.5 psi was applied to the Schlenk flask to ensure a sufficient flow rate. The Grignard reagent and the propyl iodide were added subsequently to the stirred sample solution and the measurement was started immediately.

For the investigation of organopalladate complexes formed by the reaction of $\left[\operatorname{Pd}\left(\operatorname{PAr}_{3}\right)_{3}\right]$ with organometallic reagents (see section 4.4, a pre-dried Schlenk-flask was charged with $\left[\operatorname{Pd}\left(\operatorname{PAr}_{3}\right)_{3}\right]$, which was then dissolved in dry THF $(2 \mathrm{~mL})$. The resulting solution was cooled to $196 \mathrm{~K}$ in a dry ice bath. Four equivalents of the organometallic reagent were added dropwise and the reaction mixture was stirred for $1-2 \mathrm{~min}$ at $196 \mathrm{~K}$ before the measurement was started.

\section{Measuring Conditions}

Mass spectra were recorded with a micrOTOF QII instrument (Bruker Daltonik) equipped with an ESI source under mild conditions. Control experiments as well as studies regarding the bimolecular reactivity of ions in the gas phase were conducted using an HCT ion trap mass spectrometer (Bruker Daltonik) equipped with an ESI source under mild conditions. Sample solutions were transferred into the ion source using gas-tight Hamilton syringes $(1 \mathrm{~mL})$ at a flow rate of $0.5 \mathrm{~mL} / \mathrm{h}$, unless otherwise stated. Mass spectra were recorded with an accumulation time of at least $2 \mathrm{~min}$ for $\mathrm{MS}^{1}$ and at least $1 \mathrm{~min}$ for CID spectra. To avoid moisture and contaminations, the mass spectrometers were thoroughly purged with dry THF before each measurement and with dry THF and methanol afterwards. In experiments with the micrOTOF QII instrument, nitrogen was used as nebulizer gas, drying gas, and as collision gas for $\mathrm{MS}^{2}$ experiments. For the HCT ion trap spectrometer, nitrogen was used as nebulizer gas and drying gas, whereas helium was applied as the collision gas. The instrument parameters were chosen according to table 6.1 and table 6.2 unless otherwise stated. 
Table 6.1: Measuring parameters (Q-TOF)

\begin{tabular}{ll|ll}
\hline negative-ion mode & & positive-ion mode & \\
\hline Source: & & Source: & \\
End Plate Offset & $-500 \mathrm{~V}$ & End Plate Offset & $-500 \mathrm{~V}$ \\
Capillary & $+3500 \mathrm{~V}$ & Capillary & $-4500 \mathrm{~V}$ \\
Nebulizer & $10.2 \mathrm{psi}$ & Nebulizer & $10.2 \mathrm{psi}$ \\
Dry Gas & $5.0 \mathrm{~L} / \mathrm{min}$ & Dry Gas & $5.0 \mathrm{~L} / \mathrm{min}$ \\
Dry Temperature & $60^{\circ} \mathrm{C}$ & Dry Temperature & $60^{\circ} \mathrm{C}$ \\
\hline Transfer: & & Transfer: & \\
Funnel 1 RF & $300.0 \mathrm{Vpp}$ & Funnel 1 RF & $300.0 \mathrm{Vpp}$ \\
Funnel 2 RF & $400.0 \mathrm{Vpp}$ & Funnel 2 RF & $400.0 \mathrm{Vpp}$ \\
ISCID Energy & $0.0 \mathrm{eV}$ & ISCID Energy & $0.0 \mathrm{eV}$ \\
Hexapole RF & $400.0 \mathrm{Vpp}$ & Hexapole RF & $400.0 \mathrm{Vpp}$ \\
\hline Quadrupole: & & Quadrupole: \\
Ion Energy & $5.0 \mathrm{eV}$ & Ion Energy & $5.0 \mathrm{eV}$ \\
Low Mass & $55.00 \mathrm{~m} / \mathrm{z}$ & Low Mass & $55.00 \mathrm{~m} / \mathrm{z}$ \\
\hline Collision Cell: & & Collision Cell: \\
Collision Energy & $0.0 \mathrm{eV}$ & Collision Energy & $0.0 \mathrm{eV}$ \\
Transfer Time & $77.6 \mu \mathrm{s}$ & Transfer Time & $77.6 \mu \mathrm{s}$ \\
Collision RF & $650 \mathrm{Vpp}$ & Collision RF & $650 \mathrm{Vpp}$ \\
Pre Pulse Storage & $1.0 \mu \mathrm{s}$ & Pre Pulse Storage & $1.0 \mu \mathrm{s}$ \\
\hline Scan Mode: & & Scan Mode: & \\
Mass Range & $50-3000 \mathrm{~m} / z$ & Mass Range & $50-3000 \mathrm{~m} / z$ \\
\hline & & &
\end{tabular}

Table 6.2: Measuring parameters (HCT Ion Trap)

\begin{tabular}{ll|ll}
\hline negative-ion mode & & positive-ion mode & \\
\hline Source: & & Source: & \\
End Plate Offset & $-500 \mathrm{~V}$ & End Plate Offset & $-500 \mathrm{~V}$ \\
Capillary & $+3500 \mathrm{~V}$ & Capillary & $-4500 \mathrm{~V}$ \\
Nebulizer & $10.0 \mathrm{psi}$ & Nebulizer & $10.0 \mathrm{psi}$ \\
Dry Gas & $5.0 \mathrm{~L} / \mathrm{min}$ & Dry Gas & $5.0 \mathrm{~L} / \mathrm{min}$ \\
Dry Temperature & $60^{\circ} \mathrm{C}$ & Dry Temperature & $60^{\circ} \mathrm{C}$ \\
\hline Expert Parameter Setting: & & Expert Parameter Setting: & \\
Skimmer & $-20.0 \mathrm{~V}$ & Skimmer & $20.0 \mathrm{~V}$ \\
Cap Exit & $-20.0 \mathrm{~V}$ & Cap Exit & $20.0 \mathrm{~V}$ \\
OCT 1 DC & $-4.00 \mathrm{~V}$ & OCT 1 DC & $4.00 \mathrm{~V}$ \\
OCT 2 DC & $-1.70 \mathrm{~V}$ & OCT 2 DC & $1.70 \mathrm{~V}$ \\
Oct RF & $152.8 \mathrm{Vpp}$ & Oct RF & $152.8 \mathrm{Vpp}$ \\
Lens 1 & $-5.0 \mathrm{~V}$ & Lens 1 & $-5.0 \mathrm{~V}$ \\
Lens 2 & $-60.0 \mathrm{~V}$ & Lens 2 & $-60.0 \mathrm{~V}$ \\
Trap Drive & 40 & Trap Drive & 40 \\
\hline Trap: & & Trap: & \\
Max. Accu. Time & $100 \mathrm{~ms}$ & Max. Accu. Time & $100 \mathrm{~ms}$ \\
Mass Range & $50-3000 \mathrm{~m} / z$ & Mass Range & $50-3000 \mathrm{~m} / \mathrm{z}$ \\
\hline
\end{tabular}




\section{Ion-Molecule Reactions in the Gas Phase}

To analyze bimolecular reactions in the gas-phase, the neutral reactant of choice ( $1 \mu \mathrm{L}$ to $50 \mu \mathrm{L})$ was filled into the glas vial connected to the gas-mixing chamber (for the setup of the gasmixing apparatus, see reference [69]). After one freeze-pump-degassing cycle, the reactant was released into the evacuated apparatus, which was then filled with helium ( $V=2.5 \mathrm{~L}, p=6 \mathrm{bar})$. The collision cell of the mass spectrometer was flushed ten times with the gas mixture to ensure a constant reactant gas concentration. Ions of interest were isolated and stored inside the ion trap for a defined reaction time. Stable signal intensities could be achieved, depending on the investigated reaction, for reaction times of up to $8 \mathrm{~s}$ when a dry gas flow at the ESI source of $10 \mathrm{~L} / \mathrm{min}$ was applied. To avoid contaminations, the gas-mixing chamber as well as the helium line were thoroughly purged with helium after each experiment.

\subsubsection{NMR Spectroscopy}

${ }^{1} \mathrm{H}-\mathrm{NMR}$ spectra and ${ }^{13} \mathrm{C}-\mathrm{NMR}$ spectra were recorded with a Bruker Avance III 300 or a Bruker Avance III 400 instrument at $298 \mathrm{~K} .{ }^{19} \mathrm{~F}-\mathrm{NMR}$ spectra were recorded with a Bruker Avance III 300 instrument at $298 \mathrm{~K} .{ }^{31} \mathrm{P}-\mathrm{NMR}$ spectra were recorded with a Bruker Avance III 400 instrument at $298 \mathrm{~K}$, unless otherwise stated.

Sample solutions of the palladate complexes $\left[\mathrm{L}_{n} \mathrm{PdX}\right]^{-}$were prepared in a glove box under argon atmosphere. THF- $\mathrm{D}_{8}$ for these experiments was purchased from Eurisotop in high quality $(99.5 \% \mathrm{D},<0.05 \%$ water) in flame-sealed glass ampoules and handled and stored under argon atmosphere. In the concentration-dependent experiments described in section 4.2.1. only spectra that showed less than $3 \%$ oxidation of the phosphine ligand were taken into account.

Sample solutions of organopalladate complexes $\left[\mathrm{PdPh}\left(\mathrm{DE}^{\mathrm{I}}\right)_{2}\right]^{-}$were prepared under argon atmosphere. $\left[\mathrm{Pd}_{2}(\mathrm{dba})_{3}\right](25 \mathrm{mM})$ was dissolved in THF-D $\mathrm{D}_{8}$ and two equivalents (relative to $\mathrm{Pd}$ ) of freshly distilled isoprene were added. After a reaction time of $45 \mathrm{~min}$, one equivalent of $\mathrm{PhMgBr}$ in $\mathrm{THF}^{-\mathrm{D}_{8}}$ was added.

For the analysis and graphical representation of the recorded NMR spectra, MestReNova 10.0.2 (Mestrelab Research SL) was used.

\subsubsection{Electrical Conductometry}

Electrical conductivity measurements were conducted with a SevenMulti instrument (Mettler Toledo) equipped with an InLab741 stainless-steel electrode cell (Mettler Toledo) with a cell constant of $0.1 \mathrm{~cm}^{-1}$. The electrode was calibrated against an aqueous solution $(0.1 \mathrm{M})$ of $\mathrm{KCl}$. Sample solutions were prepared under argon atmosphere. To this end, the palladium catalyst of interest was added to a dried Schlenk flask, which was then evacuated and purged 
with argon. The electrode was inserted into the flask, THF $(25 \mathrm{~mL})$ was added and the mixture was stirred at $298 \mathrm{~K}$ until all solid constituents were dissolved, but at least for $10 \mathrm{~min}$ to assure a constant temperature. Lithium bromide solution was diluted from a stock solution with $c=0.5 \mathrm{M}$ to concentrations that corresponded to 500 times the palladium concentration of the sample solution and added in steps of 25 or $50 \mu \mathrm{L}$, respectively. After each addition, the sample was stirred for $2 \mathrm{~min}$ before at least three values for the electrical conductivity were determined to compensate for statistical scattering, which occured occasionally at low concentrations.

\subsubsection{UV/Vis Spectroscopy}

UV/Vis-spectroscopic experiments were carried out with a Cary60 instrument (Agilent Technologies) and an Excalibur Immersion Probe (Hellma Analytics) under argon atmosphere at $278 \mathrm{~K}$. To this end, a custom-designed Schlenk flask was equipped with the immersion probe, evacuated, repeatedly heated $(3 \times 10 \mathrm{~min}, 373 \mathrm{~K})$, flushed with argon, and cooled to $278 \mathrm{~K}$ in a cooling bath. Dry THF $(16 \mathrm{~mL})$ was used to record a baseline spectrum before a solution of $\left[\mathrm{Pd}_{2}(\mathrm{dba})_{3}\right]\left(2 \cdot 10^{-5} \mathrm{~mol}\right)$ in THF $(4 \mathrm{~mL})$ was added. After the addition of eight equivalents (relative to $\mathrm{Pd}$ ) of isoprene, the reaction mixture was stirred for $45 \mathrm{~min}$. The solution was treated with four equivalents of $n-\mathrm{BuMgCl}$ and the measurement was started immediately. Spectra were recorded in a wavelength range from 350 to $1100 \mathrm{~nm}$ with a resolution of $5 \mathrm{~nm}$ every $15 \mathrm{sec}$. 



\section{References and Notes}

[1] C. Elschenbroich, Organometallchemie, 4., überarb. und erw. Aufl., Teubner, Stuttgart, 2003, 756 pp.

[2] D. Steinborn, Grundlagen Der Metallorganischen Komplexkatalyse, 2nd ed., Vieweg + Teubner, GWH Fachverlage GmbH, Wiesbaden, 2010.

[3] A. de Meijere, S. Bräse, M. Oestreich, Metal-Catalyzed Cross-Coupling Reactions and More, Wiley-VCH, Weinheim, 2014.

[4] E.-i. Negishi, J. Organomet. Chem. 2002, 653, 34-40.

[5] S. Murahashi, M. Yamamura, K. Yanagisawa, N. Mita, K. Kondo, J. Org. Chem. 1979, 44, 2408-2417.

[6] (a) K. Tamao, K. Sumitani, M. Kumada, J. Am. Chem. Soc. 1972, 94, 4374-4376; (b) M. Yamamura, I. Moritani, S.-I. Murahashi, J. Organomet. Chem. 1975, 91, C39-C42.

[7] K. Sonogashira, Y. Tohda, N. Hagihara, Tetrahedron Lett. 1975, 4.

[8] A. O. King, N. Okukado, E.-i. Negishi, J. Chem. Soc. Chem. Commun. 1977, 0, 683-684.

[9] (a) N. Miyaura, A. Suzuki, J. Chem. Soc. Chem. Commun. 1979, 866-867; (b) N. Miyaura, K. Yamada, A. Suzuki, Tetrahedron Letters 1979, 20, 3437-3440.

[10] Y. Hatanaka, T. Hiyama, J. Org. Chem. 1988, 53, 918-920.

[11] (a) M. Kosugi, K. Sasazawa, Y. Shimizu, T. Migita, Chem. Lett. 1977, 6, 301-302; (b) D. Milstein, J. K. Stille, J. Am. Chem. Soc. 1979, 101, 4992-4998.

[12] (a) T. Jeffery, J. Chem. Soc. Chem. Commun. 1984, 0, 1287-1289; (b) T. Jeffery, Tetrahedron Lett. 1985, 26, 2667-2670; (c) W. Cabri, I. Candiani, S. DeBernardinis, F. Francalanci, S. Penco, R. Santo, J. Org. Chem. 1991, 56, 5796-5800; (d) T. Jeffery, Tetrahedron 1996, 52, 10113-10130; (e) R. J. Perry, B. D. Wilson, J. Org. Chem. 1996, 61, 7482-7485; (f) K. Fagnou, M. Lautens, Angew. Chem. Int. Ed. 2002, 41, 26-47; Angew. Chem. 2002, 114, 26-49; (g) S. T. Handy, M. Okello, Tetrahedron Letters 2003, 44, 8395-8397; (h) A. H. Roy, J. F. Hartwig, Organometallics 2004, 23, 194-202; (i) P. M. Maitlis, A. Haynes, B. R. James, M. Catellani, G. P. Chiusoli, Dalton Trans. 2004, 3409; (j) I. J. S. Fairlamb, R. J. K. Taylor, J. Luis Serrano, G. Sanchez, New J. Chem. 2006, 30, 1695-1704; (k) S. Shekhar, J. F. Hartwig, Organometallics 2007, 26, 340-351; (1) B. P. Carrow, J. F. Hartwig, J. Am. Chem. Soc. 2010, 132, 79-81; (m) F. Proutiere, F. Schoenebeck, Angew. Chem. Int. Ed. 2011, 50, 8192-8195; Angew. Chem. 2011, 123, 8342-8345.

[13] E.-i. Negishi, T. Takahashi, K. Akiyoshi, J. Chem. Soc. Chem. Commun. 1986, 1338-1339. 
[14] (a) C. Amatore, M. Azzabi, A. Jutand, J. Organomet. Chem. 1989, 363, C41-C45; (b) C. Amatore, M. Azzabi, A. Jutand, J. Am. Chem. Soc. 1991, 113, 8375-8384; (c) C. Amatore, A. Jutand, F. Khalil, M. F. Nielsen, J. Am. Chem. Soc. 1992, 114, 7076-7085; (d) C. Amatore, A. Jutand, A. Suarez, J. Am. Chem. Soc. 1993, 115, 9531-9541; (e) C. Amatore, E. Carre, A. Jutand, M. A. M’Barki, G. Meyer, Organometallics 1995, 14, 5605-5614; (f) C. Amatore, A. Jutand, J. Organomet. Chem. 1999, 576, 254-278; (g) C. Amatore, A. Jutand, Acc. Chem. Res. 2000, 33, 314-321; (h) C. Amatore, A. Jutand, F. Lemaître, J. Luc Ricard, S. Kozuch, S. Shaik, J. Organomet. Chem., Atom Efficient Organic Syntheses 2004, 689, 3728-3734; (i) S. Verbeeck, C. Meyers, P. Franck, A. Jutand, B. U. W. Maes, Chem. Eur. J. 2010, 16, 1283112837; (j) C. Amatore, A. Jutand, G. Le Duc, Angew. Chem. Int. Ed. 2012, 51, 1379-1382; Angew. Chem. 2012, 124, 1408-1411.

[15] (a) S. Kozuch, S. Shaik, A. Jutand, C. Amatore, Chem. Eur. J. 2004, 10, 3072-3080; (b) S. Kozuch, C. Amatore, A. Jutand, S. Shaik, Organometallics 2005, 24, 2319-2330.

[16] (a) L. J. Gooßen, D. Koley, H. Hermann, W. Thiel, Chem. Commun. 2004, 0, 2141-2143;

(b) L. J. Goossen, D. Koley, H. L. Hermann, W. Thiel, Organometallics 2005, 24, 2398-2410;

(c) L. J. Goossen, D. Koley, H. L. Hermann, W. Thiel, J. Am. Chem. Soc. 2005, 127, 1110211114.

[17] A. H. M. De Vries, F. J. Parlevliet, L. Schmieder-van de Vondervoort, J. H. M. Mommers, H. J. W. Henderickx, M. A. M. Walet, J. G. de Vries, Adv. Synth. Catal. 2002, 344, 996-1002.

[18] P. Espinet, A. M. Echavarren, Angew. Chem. Int. Ed. 2004, 43, 4704-4734; Angew. Chem. 2004, 116, 4808-4839.

[19] J. G. De Vries, Dalton Trans. 2006, 421-429.

[20] M. Kalek, J. Stawinski, Organometallics 2007, 26, 5840-5847.

[21] A. Seyboldt, B. Wucher, S. Hohnstein, K. Eichele, F. Rominger, K. W. Törnroos, D. Kunz, Organometallics 2015, 34, 2717-2725.

[22] (a) R. Usón, J. Forniés, P. Espinet, R. Navarro, F. Martinez, M. Tomas, J. Chem. Soc. Chem. Commun. 1977, 789-790; (b) R. Usón, J. Forniés, F. Martínez, M. Tomás, J. Chem. Soc. Dalton Trans. 1980, 888-894; (c) R. Usón, J. Fornies, F. Martinez, M. Tomas, I. Reoyo, Organometallics 1983, 2, 1386-1390.

[23] H. Nakazawa, F. Ozawa, A. Yamamoto, Organometallics 1983, 2, 241-250.

[24] (a) C. Amatore, A. Jutand, M. A. M'Barki, Organometallics 1992, 11, 3009-3013; (b) C. Amatore, E. Carre, A. Jutand, M. A. M’Barki, Organometallics 1995, 14, 1818-1826.

[25] P. W. N. M. van Leeuwen, Appl. Catal. A, Catalyst Deactivation 2001, 212, 61-81.

[26] K. Böck, J. E. Feil, K. Karaghiosoff, K. Koszinowski, Chem. Eur. J. 2015, 21, 5548-5560.

[27] (a) T.-Y. Luh, M.-k. Leung, K.-T. Wong, Chem. Rev. 2000, 100, 3187-3204; (b) A. C. Frisch, M. Beller, Angew. Chem. Int. Ed. 2005, 44, 674-688; (c) R. Jana, T. P. Pathak, M. S. Sigman, Chem. Rev. 2011, 111, 1417-1492.

[28] M. R. Netherton, G. C. Fu in Palladium in Organic Synthesis, Vol. 14, (Ed.: J. Tsuji), Springer Berlin Heidelberg, Berlin, Heidelberg, 2005, pp. 85-108. 
[29] N. Kambe, T. Iwasaki, J. Terao, Chem. Soc. Rev. 2011, 40, 4937-4947.

[30] J. Terao, H. Watanabe, A. Ikumi, H. Kuniyasu, N. Kambe, J. Am. Chem. Soc. 2002, 124, $4222-4223$.

[31] (a) J. Terao, Y. Naitoh, H. Kuniyasu, N. Kambe, Chem. Lett. 2003, 32, 890-891; (b) J. Terao, N. Kambe, Acc. Chem. Res. 2008, 41, 1545-1554.

[32] (a) T. Iwasaki, A. Tsumura, T. Omori, H. Kuniyasu, J. Terao, N. Kambe, Chem. Lett. 2011, 40, 1024-1026; (b) T. Iwasaki, A. Fukuoka, W. Yokoyama, X. Min, I. Hisaki, T. Yang, M. Ehara, H. Kuniyasu, N. Kambe, Chem. Sci. 2018, 9, 2195-2211.

[33] J. Terao, Y. Naitoh, H. Kuniyasu, N. Kambe, Chem. Commun. 2007, 0, 825-827.

[34] (a) B. H. Lipshutz, K. L. Stevens, B. James, J. G. Pavlovich, J. P. Snyder, J. Am. Chem. Soc. 1996, 118, 6796-6797; (b) B. H. Lipshutz, J. Keith, D. J. Buzard, Organometallics 1999, 18, 1571-1574.

[35] (a) D. A. Plattner, Int. J. Mass Spectrom. 2001, 207, 125-144; (b) P. Chen, Angew. Chem. Int. Ed. 2003, 42, 2832-2847; Angew. Chem. 2003, 115, 2938-2954; (c) K. L. Vikse, Z. Ahmadi, J. Scott McIndoe, Coord. Chem. Rev. 2014, 279, 96-114; (d) L. P. Yunker, R. L. Stoddard, J. S. McIndoe, J. Mass Spectrom. 2014, 49, 1-8; (e) J. Penafiel, A. V. Hesketh, O. Granot, J. S. McIndoe, Dalton Trans. 2016, 45, 15552-15556.

[36] (a) P. F. James, R. A. J. O'Hair, Org. Lett. 2004, 6, 2761-2764; (b) L. S. Santos, G. B. Rosso, R. A. Pilli, M. N. Eberlin, J. Org. Chem. 2007, 72, 5809-5812; (c) N. Rijs, G. N. Khairallah, T. Waters, R. A. J. O'Hair, J. Am. Chem. Soc. 2008, 130, 1069-1079; (d) N. J. Rijs, B. F. Yates, R. A. J. O'Hair, Chem. Eur. J. 2010, 16, 2674-2678; (e) N. J. Rijs, R. A. J. O'Hair, Organometallics 2010, 29, 2282-2291; (f) T. K. Trefz, M. A. Henderson, M. Y. Wang, S. Collins, J. S. McIndoe, Organometallics 2013, 32, 3149-3152; (g) A. Tsybizova, D. Schröder, J. Roithová, A. Henke, J. Šrogl, J. Phys. Org. Chem. 2014, 27, 198-203; (h) A. Škríba, J. Schulz, J. Roithová, Organometallics 2014, 33, 6868-6878; (i) N. V. Orlov, I. V. Chistyakov, L. L. Khemchyan, V. P. Ananikov, I. P. Beletskaya, Z. A. Starikova, J. Org. Chem. 2014, 79, 12111-12121; (j) T. K. Trefz, M. A. Henderson, M. Linnolahti, S. Collins, J. S. McIndoe, Chem. Eur. J. 2015, 21, 2980-2991; (k) A. Tsybizova, J. Roithová, Mass Spectrom. Rev. 2016, $35,85-110$.

[37] (a) K. Koszinowski, J. Am. Chem. Soc. 2010, 132, 6032-6040; (b) J. E. Fleckenstein, K. Koszinowski, Organometallics 2011, 30, 5018-5026; (c) A. Putau, H. Brand, K. Koszinowski, J. Am. Chem. Soc. 2012, 134, 613-622; (d) T. D. Blümke, T. Klatt, K. Koszinowski, P. Knochel, Angew. Chem. 2012, 124, 10064-10068; (e) C. Schnegelsberg, T. D. Blümke, K. Koszinowski, J. Mass Spectrom. 2015, 50, 1393-1395; (f) C. Schnegelsberg, S. Bachmann, M. Kolter, T. Auth, M. John, D. Stalke, K. Koszinowski, Chem. Eur. J. 2016, 22, 7752-7762; (g) S. Weske, R. Schoop, K. Koszinowski, Chem. Eur. J. 2016, 22, 11310-11316; (h) T. Parchomyk, K. Koszinowski, Chem. Eur. J. 2017, 23, 3213-3219; (i) T. Parchomyk, K. Koszinowski, Synthesis 2017, 49, 3269-3280; (j) S. Weske, R. A. Hardin, T. Auth, R. A. J. O'Hair, K. Koszinowski, C. A. Ogle, Chem. Commun. 2018, 54, 5086-5089; (k) T. Parchomyk, S. Demeshko, F. Meyer, K. Koszinowski, J. Am. Chem. Soc. 2018, 140, 9709-9720. 
[38] (a) K. L. Vikse, M. A. Henderson, A. G. Oliver, J. S. McIndoe, Chem. Commun. 2010, 46, 7412-7414; (b) M. A. Schade, J. E. Fleckenstein, P. Knochel, K. Koszinowski, J. Org. Chem. 2010, 75, 6848-6857; (c) D. Agrawal, D. Schröder, C. M. Frech, Organometallics 2011, 30, 3579-3587; (d) K. L. Vikse, Z. Ahmadi, C. C. Manning, D. A. Harrington, J. S. McIndoe, Angew. Chem. Int. Ed. 2011, 50, 8304-8306; Angew. Chem. 2011, 123, 8454-8456; (e) K. L. Vikse, G. N. Khairallah, R. A. J. O'Hair, Organometallics 2012, 31, 7467-7475; (f) J. Hývl, J. Roithová, Org. Lett. 2014, 16, 200-203; (g) Z. Ahmadi, L. P. E. Yunker, A. G. Oliver, J. S. McIndoe, Dalton Trans. 2015, 44, 20367-20375; (h) E. Janusson, H. S. Zijlstra, P. P. T. Nguyen, L. MacGillivray, J. Martelino, J. S. McIndoe, 2017, 53, 854-856; (i) L. P. E. Yunker, Z. Ahmadi, J. R. Logan, W. Wu, T. Li, A. Martindale, A. G. Oliver, J. S. McIndoe, Organometallics 2018, 37.

[39] M. Kolter, K. Koszinowski, Chem. Eur. J. 2016, 22, 15744-15750.

[40] M. Kolter, K. Böck, K. Karaghiosoff, K. Koszinowski, Angew. Chem. Int. Ed. 2017, 56, 13244-13248; Angew. Chem. 2017, 129, 13427-13431.

[41] A. Faulkner, J. F. Bower, Angew. Chem. Int. Ed. 2012, 51, 1675-1679; Angew. Chem. 2012, $124,1707-1711$.

[42] A. Jakab, Z. Dalicsek, T. Holczbauer, A. Hamza, I. Pápai, Z. Finta, G. Timári, T. Soós, Eur. J. Org. Chem. 2015, 60-66.

[43] Organoaluminates $\left[\mathrm{AlR}_{4}\right]^{-}$originated from aluminum impurities in the used Grignard reagents, as control experiments showed.

[44] (a) A. Krasovskiy, P. Knochel, Angew. Chem. Int. Ed. 2004, 43, 3333-3336; Angew. Chem. 2004, 116, 3396-3399; (b) F. Kopp, A. Krasovskiy, P. Knochel, Chem. Commun. 2004, 22882289.

[45] J. H. Gross, Mass Spectrometry, Springer Berlin Heidelberg, Berlin, Heidelberg, 2011.

[46] (a) M. Dole, L. L. Mack, R. L. Hines, R. C. Mobley, L. D. Ferguson, M. B. Alice, J. Chem. Phys. 1968, 49, 2240-2249; (b) L. L. Mack, P. Kralik, A. Rheude, M. Dole, J. Chem. Phys. 1970, 52, 4977-4986.

[47] (a) M. Yamashita, J. B. Fenn, J. Phys. Chem. 1984, 88, 4451-4459; (b) M. Yamashita, J. B. Fenn, J. Phys. Chem. 1984, 88, 4671-4675; (c) J. B. Fenn, Angew. Chem. Int. Ed. 2003, 42, 3871-3894; Angew. Chem. 2003, 115, 3999-4024.

[48] N. B. Cech, C. G. Enke, Mass Spectrom. Rev. 2001, 20, 362-387.

[49] R. Colton, A. D'Agostino, J. C. Traeger, Mass Spectrom. Rev. 1995, 14, 79-106.

[50] A. J. Canty, P. R. Traill, R. Colton, I. M. Thomas, Inorg. Chim. Acta 1993, 210, 91-97.

[51] P. Kebarle, L. Tang, Anal. Chem. 1993, 65, 972A-986A.

[52] P. Kebarle, M. Peschke, Anal. Chim. Acta 2000, 406, 11-35.

[53] T. C. Rohner, N. Lion, H. H. Girault, Phys. Chem. Chem. Phys. 2004, 6, 3056.

[54] P. Kebarle, U. H. Verkerk, Mass Spectrom. Rev. 2009, 28, 898-917.

[55] J. V. Iribarne, B. A. Thomson, J. Chem. Phys. 1976, 64, 2287-2294. 
[56] L. Konermann, E. Ahadi, A. D. Rodriguez, S. Vahidi, Anal. Chem. 2013, 85, 2-9.

[57] C. Weickhardt, F. Moritz, J. Grotemeyer, Mass Spectrom. Rev. 1996, 15, 139-162.

[58] B. A. Mamyrin, Int. J. Mass Spectrom. 2001, 206, 251-266.

[59] U. Boesl, Mass Spec. Rev. 2017, 36, 86-109.

[60] (a) W. Paul, Z. Naturforsch. A 1953, 8, 448-450; (b) W. Paul, H. P. Reinhard, U. von Zahn, Z. Physik 1958, 152, 143-182.

[61] The Mathieu equations, originally applied by the french mathematician Émile Léonard Mathieu for the description of vibrations of elliptical drumheads, are nowadays applied to various physical problems. É. Mathieu, J. Math. Pures Appl. 1868, 13, 137-203.

[62] W. Paul, Angew. Chem. Int. Ed. Engl. 1990, 29, 739-748; Angew. Chem. 1990, 102, 780-789.

[63] (a) R. E. March, J. Mass Spectrom. 1997, 32, 351-369; (b) R. E. March, Int. J. Mass Spectrom. 2000, 200, 285-312; (c) R. E. March, Mass Spectrom. Rev. 2009, 28, 961-989.

[64] G. L. Glish, R. W. Vachet, Nat. Rev. Drug Discov. 2003, 2, 140.

[65] R. G. Cooks, J. S. Patrick, T. Kotiaho, S. A. McLuckey, Mass Spectrom. Rev. 1994, 13, 287339.

[66] M. T. Rodgers, P. B. Armentrout, Mass Spectrom. Rev. 2000, 19, 215-247.

[67] (a) S. Gronert, Chem. Rev. 2001, 101, 329-360; (b) R. A. J. O'Hair, Chem. Commun. 2006, 0, 1469-1481; (c) K. L. Vikse, J. S. McIndoe, Pure Appl. Chem. 2015, 87, 361-377.

[68] S. Gronert, Mass Spectrom. Rev. 2005, 24, 100-120.

[69] T. Parchomyk, K. Koszinowski, J. Mass Spectrom. 2019, 54, 81-87.

[70] As the results for all different alkyl Grignard reagents were analogous, the single experiments were not reproduced in this case.

[71] V. P. Ananikov, D. G. Musaev, K. Morokuma, Organometallics 2005, 24, 715-723.

[72] M. Pérez-Rodríguez, A. A. C. Braga, M. Garcia-Melchor, M. H. Pérez-Temprano, J. A. Casares, G. Ujaque, A. R. de Lera, R. Álvarez, F. Maseras, P. Espinet, J. Am. Chem. Soc. 2009, 131, 3650-3657.

[73] P. W. Atkins, J. De Paula, Atkins' Physical Chemistry, 8th ed., Oxford University Press, Oxford ; New York, 2006.

[74] The results of these NMR-studies, conducted by Prof. Dr. K. Karaghiosoff, were published together with the results presented herein in [40].

[75] The addition of the square-root term instead of its subtraction would also have provided a correct solution of equation 4.20, however, no physically reasonable values were obtained in this case.

[76] The subtraction of the square-root term instead of its addition would also have provided a correct solution of equation (4.32), however, no physically reasonable values were obtained in this case. 
[77] As the ion-mobility spectrometric experiments were conducted on a travelling-wave instrument, a calibration is necessary to obtain absolute values for the collision-crosssection. However, it became evident that the usually applied calibrant does not give reliable results for analytes with a fluorinated or partly fluorinated exterior, resulting in errors much larger than the actual difference in the collision cross-sections of the species in question. Further research regarding alternative calibrant systems is currently under way.

[78] These experiments were conducted by Marcel Jipp in the course of the research for his Bachelor thesis.

[79] T. Waters, R. A. J. O'Hair, A. G. Wedd, J. Am. Chem. Soc. 2003, 125, 3384-3396.

[80] K. Fagnou, M. Lautens, Angew. Chem. 2002, 114, 26-49.

[81] T. Gärtner, W. Henze, R. M. Gschwind, J. Am. Chem. Soc. 2007, 129, 11362-11363.

[82] F. Kreyenschmidt, K. Koszinowski, Chem. Eur. J. 2018, 24, 1168-1177.

[83] M. T. Reetz, M. Maase, Adv. Mater. 1999, 11, 773-777.

[84] J. Wang, H. F. M. Boelens, M. B. Thathagar, G. Rothenberg, ChemPhysChem 2004, 5, 93-98.

[85] A. V. Gaikwad, G. Rothenberg, Phys. Chem. Chem. Phys. 2006, 8, 3669-3675.

[86] K. L. Vikse, M. P. Woods, J. S. McIndoe, Organometallics 2010, 29, 6615-6618.

[87] Experiments with all three palladium(II) precursors led to similar results and were thus not individually reproduced.

[88] The ESI mass spectrum shown was recorded by Marius Deuker during a supervised practical laboratory course.

[89] (a) A. G. Orpen, N. G. Connelly, J. Chem. Soc. Chem. Commun. 1985, 0, 1310-1311; (b) A. G. Orpen, N. G. Connelly, Organometallics 1990, 9, 1206-1210.

[90] T. Leyssens, D. Peeters, A. G. Orpen, J. N. Harvey, New J. Chem. 2005, 29, 1424-1430.

[91] A. Krasovskiy, P. Knochel, Synthesis 2006, 890-891.

[92] M. F. Lipton, C. M. Sorensen, A. C. Sadler, R. H. Shapiro, J. Organomet. Chem. 1980, 186, 155-158. 